\title{
Identifizierung infektionsrelevanter Antigene des Schimmelpilzes Aspergillus fumigatus sowie deren rekombinante Herstellung mit dem Ziel der Entwicklung eines Impfstoffes gegen die invasive Aspergillose
}

\author{
Dissertation \\ zur Erlangung des Doktorgrades \\ der Mathematisch-Naturwissenschaftlichen Fakultäten \\ der Georg-August-Universität zu Göttingen
}

vorgelegt von

Martin Rosenow

aus Hannover

Göttingen 2010 
D7

Referent: Prof. Dr. Groß

Koreferent: Prof. Dr. Braus

Tag der mündlichen Prüfung: 08.07.2010 


\section{Inhaltsverzeichnis}

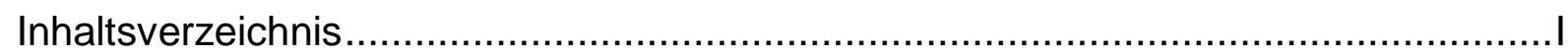

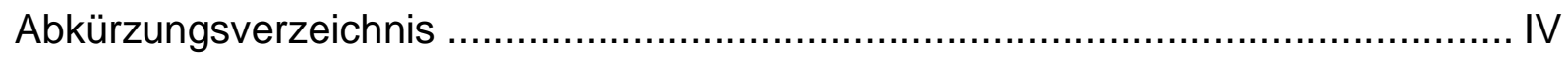

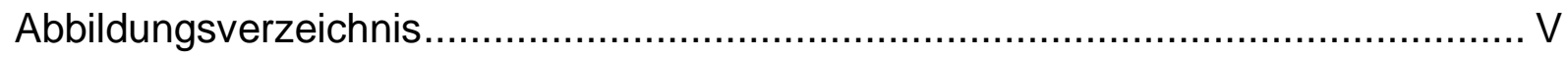

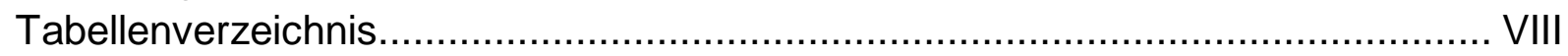

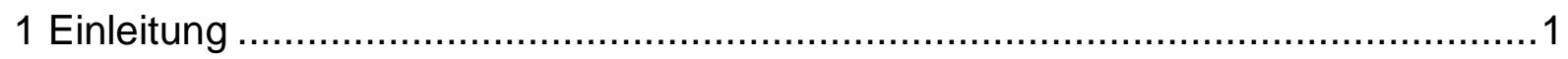

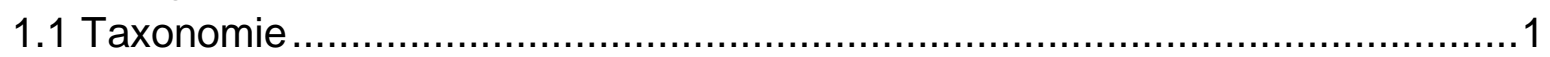

1.1.1 Aspergillus fumigatus und seine ökologische Bedeutung ........................1

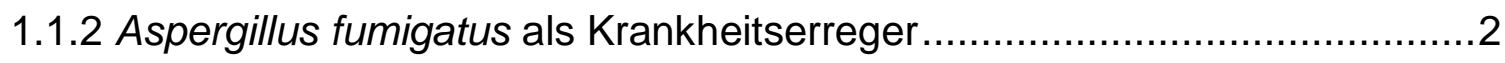

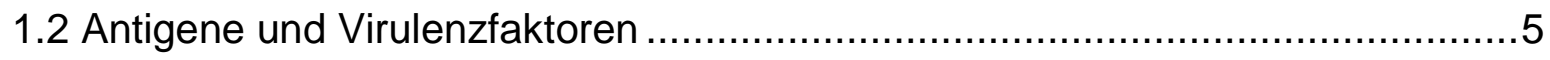

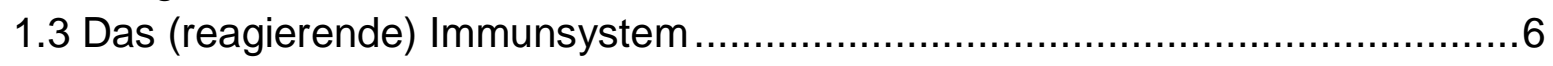

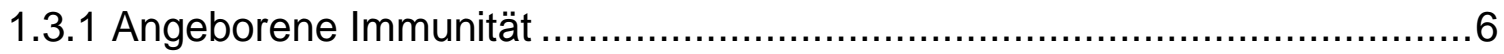

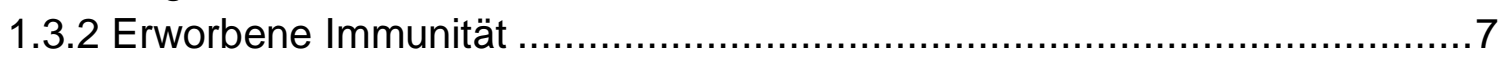

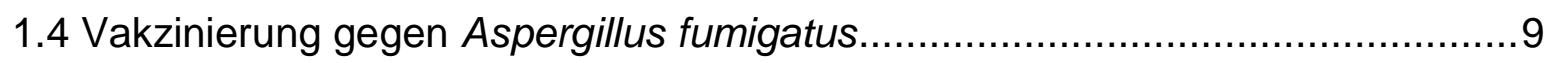

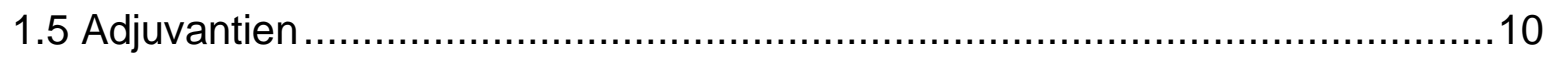

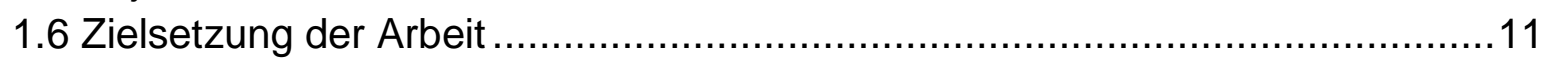

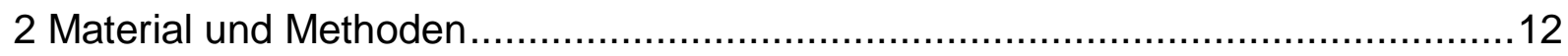

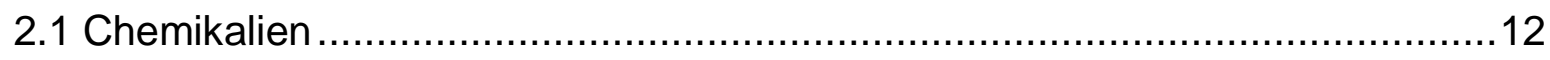

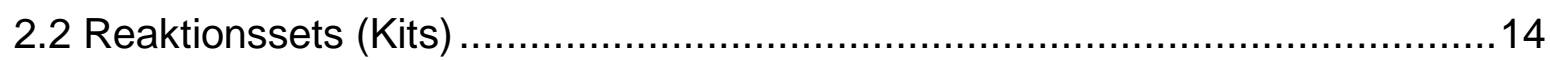

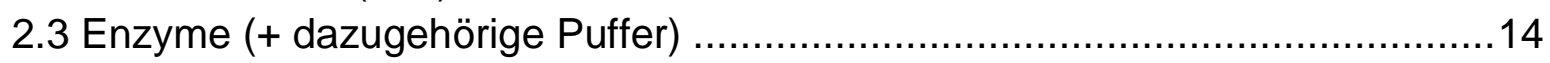

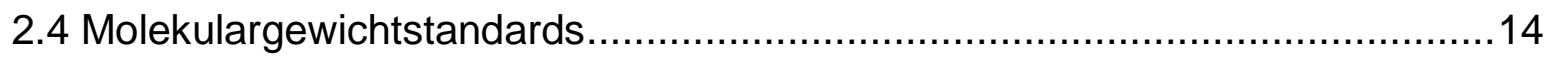

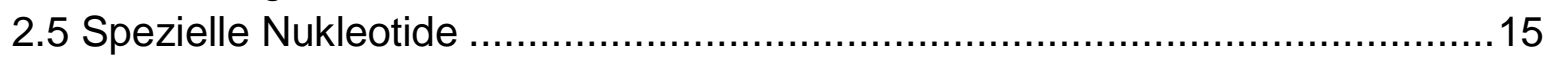

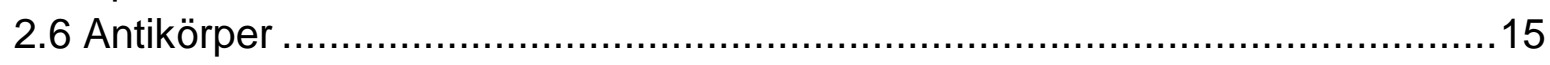

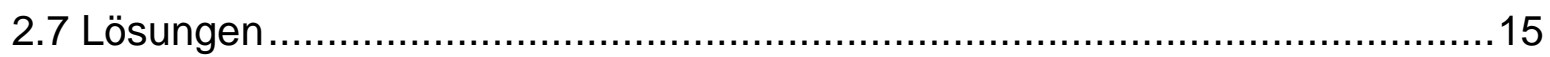

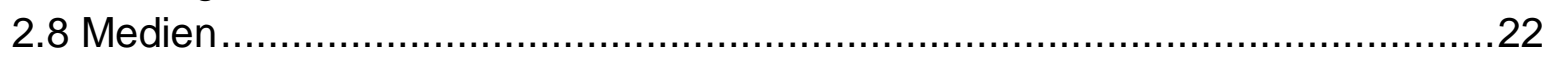

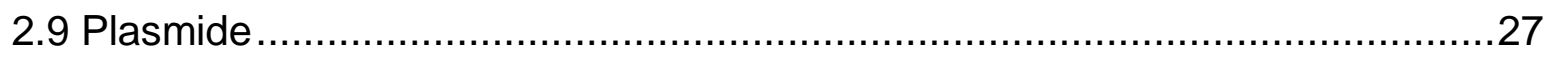

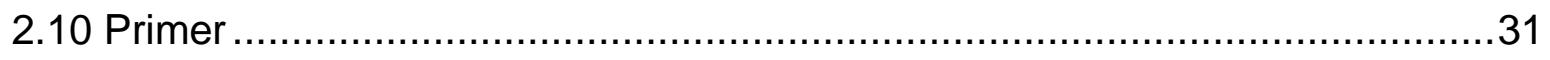

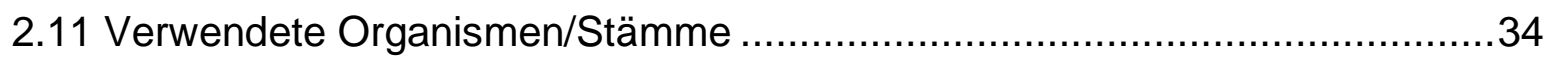

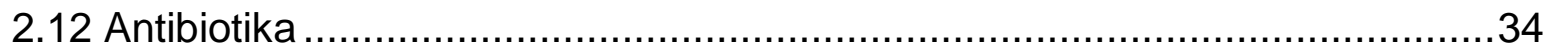

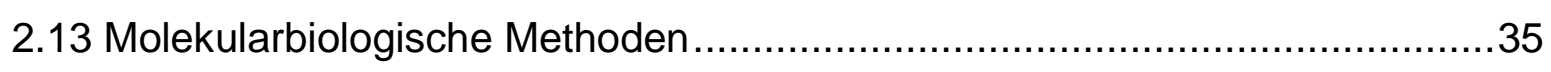

2.13.1 Isolierung von Plasmiden aus E. coli (alkalische Lyse) .........................35

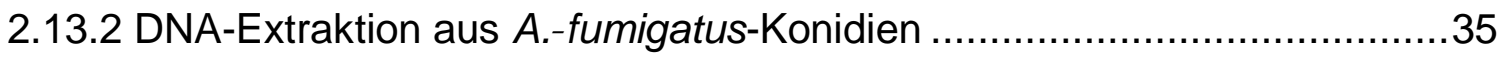

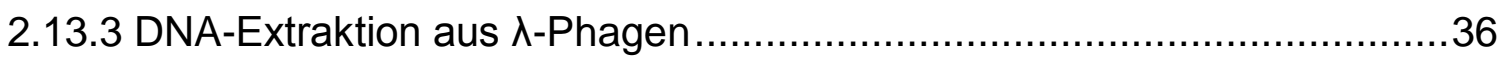

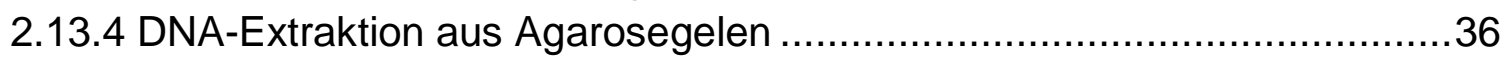

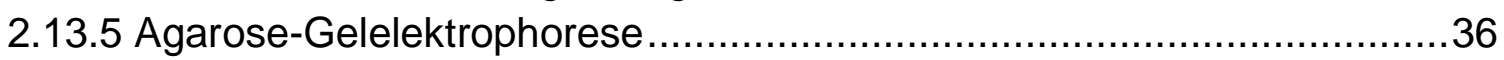

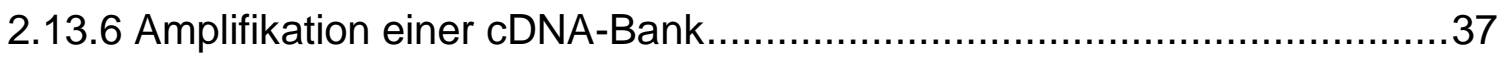

2.13.7 DNA-Aufreinigung (PCR Purification Kit (Qiagen)) ...............................37

2.13.8 DNA-Konzentrationsbestimmung über photometrische Messung ............38

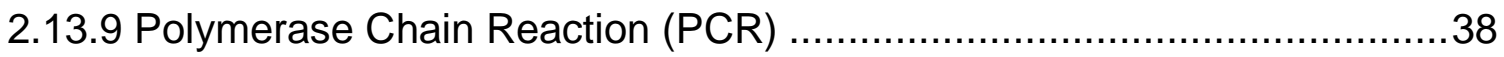

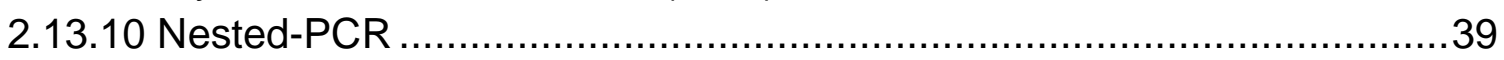

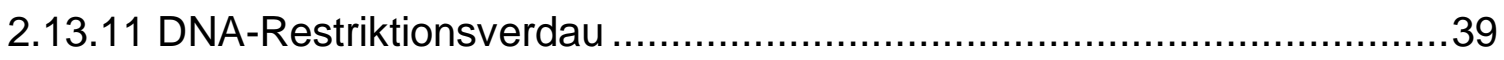

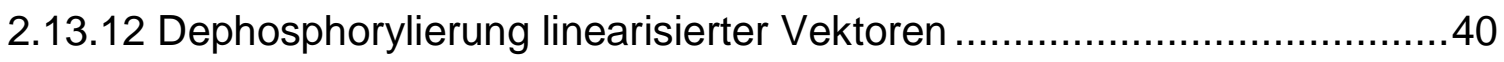

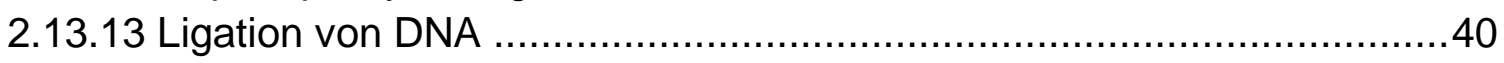


2.13.14 Transformation von E. coli durch Elektroporation...............................40

2.13.15 Transformation von A. fumigatus .................................................... 41

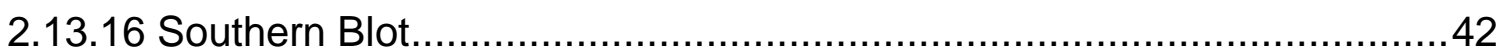

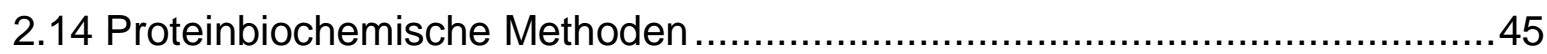

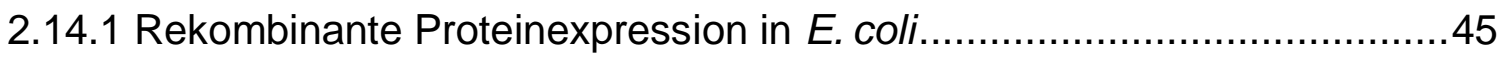

2.14.2 Rekombinante Proteinexpression in P. pastoris..................................46

2.14.3 Denaturierende Polyacrylamid-Gel-Elektrophorese (SDS-PAGE) ..........46

2.14.4 Aufarbeitung von A.-fumigatus-Gesamtzellprotein ..............................47

2.14.5 Aufarbeitung von Membran-assoziierten Proteinen aus A. fumigatus .....47

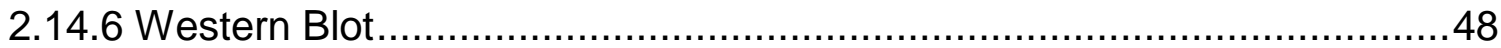

2.14.7 Detektion Peroxidase (POD)-gekoppelter Antikörper............................48

2.15 Biochemische Charakterisierung der A.-fumigatus-Gen-Deletionsmutanten . 49

2.15.1 Wachstumskontrollen der ADAM-Gen-Deletionsmutanten ....................49

2.15.2 Wachstumskontrolle der Aspf3-Gen-Deletionsmutanten........................49

2.16 Immunisierung mit rekombinanten A.-fumigatus-Proteinen im Mausmodell ..50

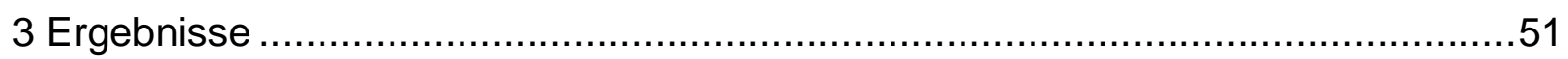

3.1 Herstellung rekombinanter Proteine aus Aspergillus fumigatus.....................51

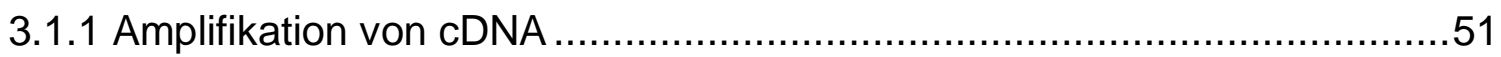

3.1.2 Klonierung von amplifizierter cDNA in Expressionsplasmide ..................52

3.1.3 Kontrolle der Proteinexpression in E. coli.........................................52

3.1.4 Produktion und Aufreinigung rekombinanter Proteine .............................53

3.2 Immunisierung durch rekombinante A.-fumigatus-Proteine im Mausmodell ....58

3.3 Herstellung von Gen-Deletionsmutanten in Aspergillus fumigatus .................63

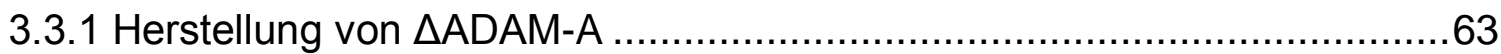

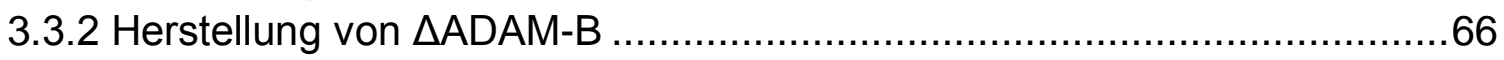

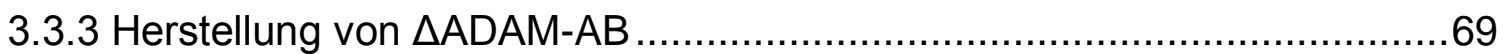

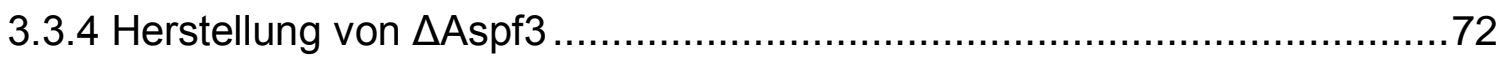

3.4 Charakterisierungen der Gen-Deletionsmutanten .................................... 74

3.4.1 Western-Blot der ADAM-Deletionsmutanten......................................74

3.4.2 Biochemische Charakterisierungen der ADAM-Gen-Deletionsmutanten ..76

3.4.3 Biochemische Charakterisierungen der Aspf3-Gen-Deletionsmutante .....76

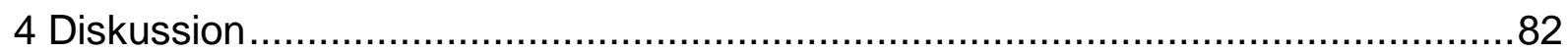

4.1 Immunisierung mit rekombinant hergestellten A.-fumigatus-Antigenen ...........83

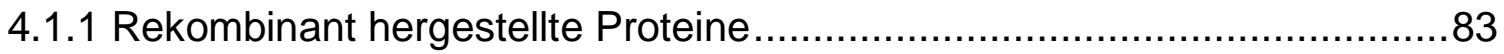

4.1.2 Immunisierung von Mäusen mit rekombinant hergestellten Proteinen .......84

4.2 Deletionsmutanten ausgewählter Gene in Aspergillus fumigatus ...................86

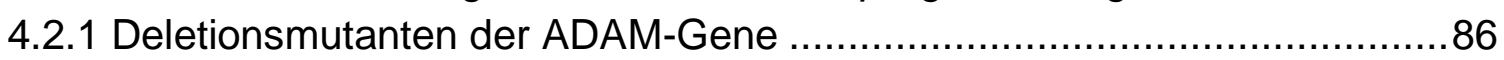

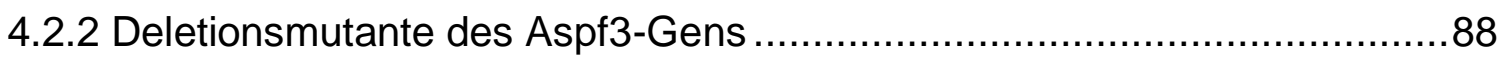

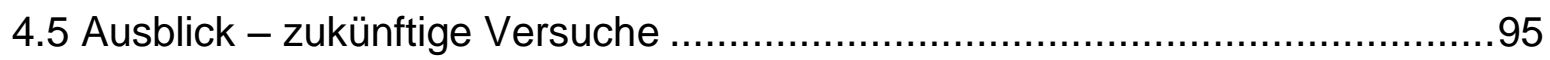

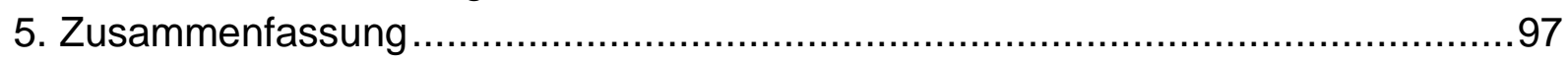

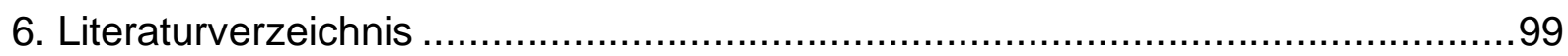

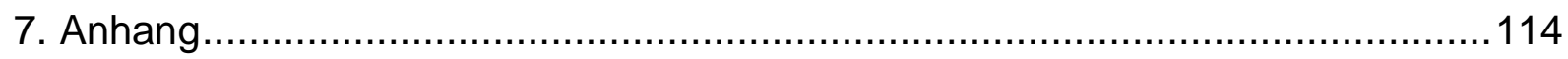


7.1 Gerätenachweis

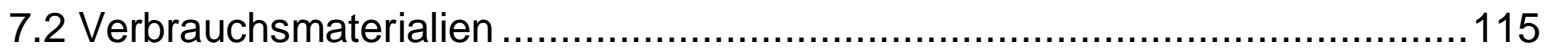

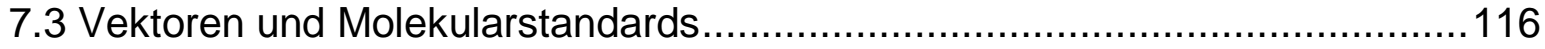

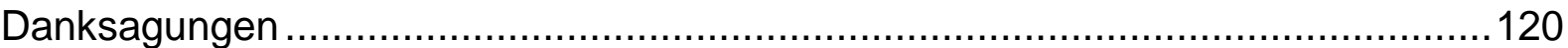

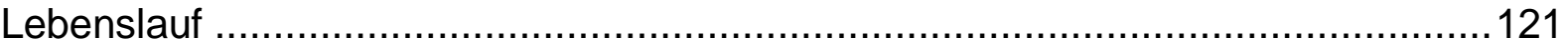




\section{Abkürzungsverzeichnis}

Tabelle: Abkürzungsverzeichnis

\begin{tabular}{|l|l|}
\hline$A$. & Aspergillus \\
\hline A & Adenin \\
\hline A. bidest. & Aqua bidestillata \\
\hline Abb. & Abbildung \\
\hline AS & Aminosäure(n) \\
\hline cDNA & copy deoxyribonucleic acid \\
\hline C & Cytosin \\
\hline$E$. & Escherichia \\
\hline et al. & et alii (und andere) \\
\hline d & Tag \\
\hline$g$ & Erdbeschleunigungskonstante \\
\hline G & Guanin \\
\hline h & hora (Stunde) \\
\hline IA & Invasive Aspergillose \\
\hline Ig & Immunglobuline \\
\hline IL & Interleukin \\
\hline IFN & Interferon \\
\hline i.v. & intravenös \\
\hline kDA & Kilodalton \\
\hline$\lambda$ & Lambda \\
\hline LB & Luria-Bertani \\
\hline M & Molarität (mol/l) \\
\hline MCS & multiple cloning site \\
\hline MHC & major histocompatibility complex \\
\hline MM & Minimal Medium \\
\hline mRNA & messenger Ribonucleic acid \\
\hline no. & number (Nummer) \\
\hline OD $x$ & optische Dichte der Wellenlänge x (nm) \\
\hline OM & osmotisches Medium \\
\hline$P$. & Pichia \\
\hline pH & per hydrogenum \\
\hline p.i. & post infectionem \\
\hline ROI & reactive oxygen intermediates (reaktive Sauerstoffspezies) \\
\hline RT & Raumtemperatur \\
\hline SDS-PAGE & Natrium(Sodium)dodecylsulfat-Polyacrylamid-Gelelektrophorese \\
\hline T & Thymin \\
\hline TH & T-Helferzelle \\
\hline$U$ & unit \\
\hline U/min & Umdrehungen pro Minuten \\
\hline ÜN & über Nacht \\
\hline$U V$ & Ultraviolett \\
\hline V/v & volume per volume \\
\hline w/v & weight per volume \\
\hline WT & Wildtyp \\
\hline & \\
\hline
\end{tabular}




\section{Abbildungsverzeichnis}

Abbildung 1: Schematische Darstellung der Morphologie von Aspergillus fumigatus .2 Abbildung 2: Häufigkeit von invasiven Aspergillus- und Candida-Infektionen (mit freundlicher Genehmigung von Prof. Rüchel (1999)) ............................................. 3 Abbildung 3: Amplifikation von cDNA aus Plasmiden ........................................51 Abbildung 4: Amplifikation von genomischer DNA ............................................51 Abbildung 5: Amplifikation von cDNA aus einer cDNA-Expressionsbank ................52 Abbildung 6: kontrollierte Expressionsplasmide................................................52 Abbildung 7: Kontroll-SDS-PAGE der Proteinproduktion ....................................53 Abbildung 8: SDS-PAGE gereinigter Proteine aus E.coli......................................53 Abbildung 9: SDS-PAGE eines gereinigten Proteins aus P. pastoris (Elastinolytic metalloproteinase Mep) .57 Abbildung 10: Prozentualer Anteil an überlebenden Mäusen je Versuchsgruppe und Tag. 62

Abbildung 11: Prozentualer Anteil überlebender Mäuse gegenüber gestellt .............62 Abbildung 12: Kontrolle des Deletionsplasmids pADAM-A-del (EcoRI-verdaut) .......63 Abbildung 13: Kontrolle des Deletionsplasmids pADAM-A-del (Notl- und Paclverdaut).

Abbildung 14: schematischer Aufbau des Austausches des ADAM-A-Gens ............64

Abbildung 15: Southern-Blot auf $\triangle$ ADAM-A ....................................................64

Abbildung 16: Schema der Lage der Kontrollprimer nach Deletion von ADAM-A .....65

Abbildung 17: Mutanten nach Deletion von ADAM-A; Primerpaar Adel1/2 ...............65

Abbildung 18: Mutanten nach Gen-Deletion von ADAM-A; Primerpaar Adel3/4 .......65

Abbildung 19: PCR Kontrolle nach Gen-Deletion (ADAM-A) ..................................66

Abbildung 20: Kontrolle von Deletionsplasmiden (pADAM-B-del EcoRI-verdaut) .....66 Abbildung 21: Kontrolle von Deletionsplasmiden (pADAM-B-del Notl- und Pacl-

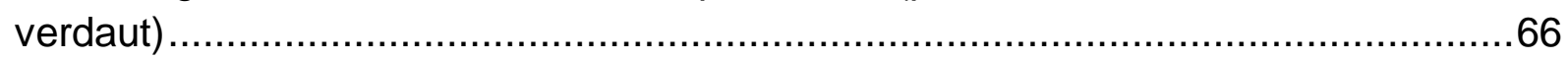

Abbildung 22: schematischer Aufbau des Austausches des ADAM-B-Gens ...........67

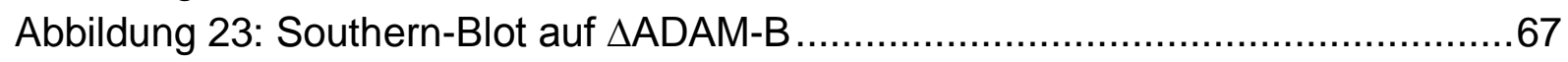

Abbildung 24: Schema der Lage der Kontrollprimer nach Deletion von ADAM-B .....68

Abbildung 25: Mutanten nach Gen-Deletion von ADAM-B; Primerpaar Bdel1/2 .......68

Abbildung 26: Mutanten nach Gen-Deletion von ADAM-B; Primerpaar Bdel1/2 .......68

Abbildung 27: Mutanten nach Gen-Deletion von ADAM-B; Primerpaar Bdel3/4 .......69

Abbildung 28: PCR Kontrolle nach Gen-Deletion (ADAM-B) ................................69

Abbildung 29: schematische Darstellung des genomischen Bereiches nach

Entfernung des Resistenz-liefernden Inserts mit angegebener Lage der zur Kontrolle

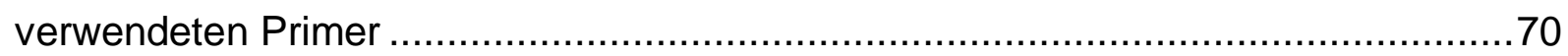

Abbildung 30: PCR-Kontrolle nach marker-rescue; Primerpaar ADAMA-Lox1/2 …..70

Abbildung 31: Southern-Blot auf $\triangle A D A M-A B$............................................... 71

Abbildung 32: Mutanten nach Gen-Deletion zu $\triangle A D A M-A B$; Primerpaar Bdel1/2.....71 Abbildung 33: Mutanten nach Gen-Deletion zu $\triangle A D A M-A B$; Primerpaar Bdel3/4 .....71 Abbildung 34: Kontrolle von Deletionsplasmiden (pAspf3-del Pvull-verdaut)............72 
Abbildung 35: Kontrolle eines Deletionsplasmids (pAspf3-del Notl und Pacl-verdaut)

Abbildung 36: schematischer Aufbau des Austausches des Aspf3-Gens ................73

Abbildung 37: Southern-Blot auf $\Delta$ Aspf3 ......................................................73

Abbildung 38: Schema der Lage der Kontrollprimer nach Deletion von Aspf3 ...........73

Abbildung 39: Mutanten nach Gen-Deletion zu $\triangle$ Aspf3; Primerpaar Af3-screen1/2

(1316 bp)

Abbildung 40: Mutanten nach Gen-Deletion zu $\triangle$ Aspf3; Primerpaar Af3-screen3/4 (1169 bp)

Abbildung 41: PCR Kontrolle nach Gen-Deletion (Aspf3) ...................................74

Abbildung 42: Western-Blot auf zytosolische Proteine von D141, $\triangle$ ADAM-A, -B und -

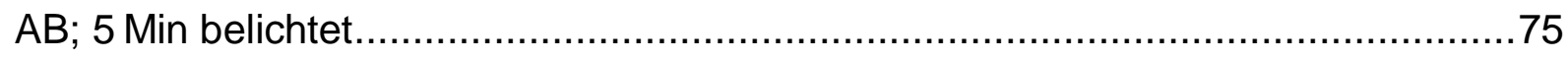

Abbildung 43: Western-Blot mit Anti-ADAM-A-Antikörper auf Membran- Proteine von

D141, $\triangle$ ADAM-A, -B und -AB; 5 Min belichtet.....................................................75

Abbildung 44: Western-Blot mit Anti-ADAM-B-Antikörper auf Membran- Proteine von

D141, $\triangle$ ADAM-A, -B und -AB; 5 Min belichtet..................................................... 75

Abbildung 45: Wachstumsgraph der ADAM-Deletionsmutanten im Vergleich zu dem

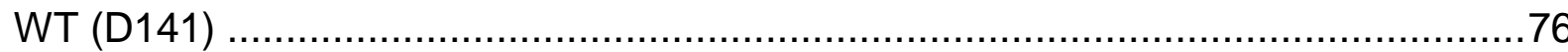

Abbildung 46: Wachstumsgraph der Aspf3-Deletionsmutante im Vergleich zu dem

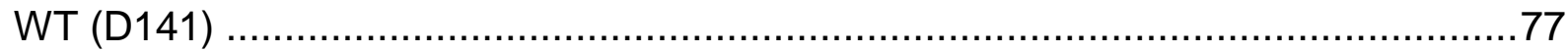

Abbildung 47: Agardiffusionstest mit $20 \mu$ einer $0,75 \% \mathrm{H}_{2} \mathrm{O}_{2}$-Lösung von $\triangle$ Aspf3 und

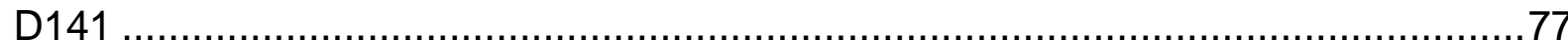

Abbildung 48: Agardiffusionstest mit $20 \mu \mathrm{l}$ einer $1 \%$ Wasserstoffperoxid-Lösung von D141, $\Delta$ Aspf3 und Aspf3komplementiert

Abbildung 49: Wachstumsgraph des Agardiffusionstests gegen ungefähr

logarithmische Konzentrationen an Wasserstoffperoxid

Abbildung 50: Wachstumsgraph des Agardiffusionstests gegen etwa logarithmische Konzentrationen an Wasserstoffperoxid nicht logarithmisch aufgetragen

Abbildung 51: Wachstumsgraph des Agardiffusionstests gegen ungefähr logarithmische Konzentrationen an Wasserstoffperoxid bei $24 \mathrm{~h}$ zuvor inkubierten Kulturen

Abbildung 52: Wachstumsgraph des Agardiffusionstests gegen etwa logarithmische Konzentrationen an Wasserstoffperoxid nicht logarithmisch aufgetragen Abbildung 53: vorinkubierte Kulturen von $\Delta$ Aspf3, D141, und Aspf3komplementiert im Agardiffusionstest mit $20 \mu \mathrm{l}$ einer $30 \%$ Wasserstoffperoxid-Lösung . Abbildung 54: Sequenzvergleich von Aspf3 gegenüber menschlichem Peroxiredoxin V (Synonym: peroxisomal membrane protein 20); das katalytische Cystein ist mit orangefarbenem Rahmen gekennzeichnet, die konservierte Region um das katalytische Cystein mit einem schwarzen Rahmen ..........................................94 Abbildung 55: Expressionsplasmid pQE30.

Abbildung 56: Plasmid pSK397; Resistenz-lieferndes Insert der Deletionsplasmide 
Abbildung 57: Plasmid pBlueskript II SK +

Abbildung 58: peqGOLD protein marker IV

Abbildung 59: MassRuler High Range DNA Ladder

Abbildung 60: GeneRuler 100bp ladder 118

Abbildung 61: MassRuler Low Range DNA ladder 


\section{Tabellenverzeichnis}

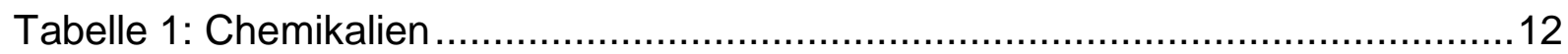

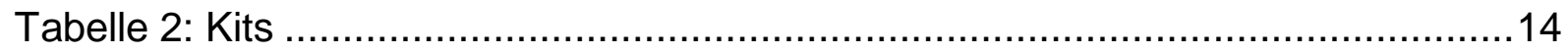

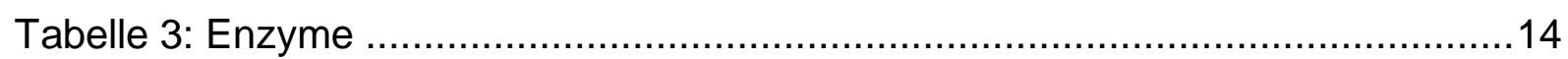

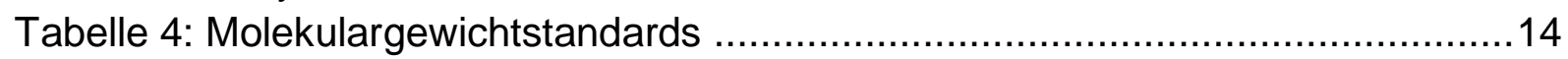

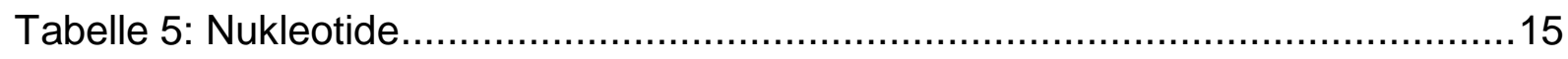

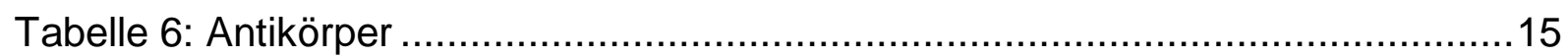

Tabelle 7: Deletions- und kommerziell erworbene Plasmide..................................27

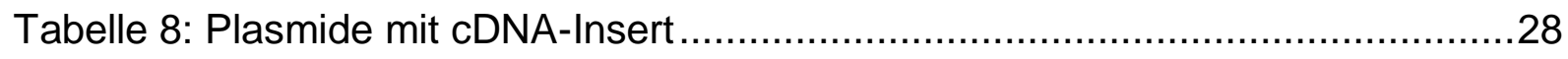

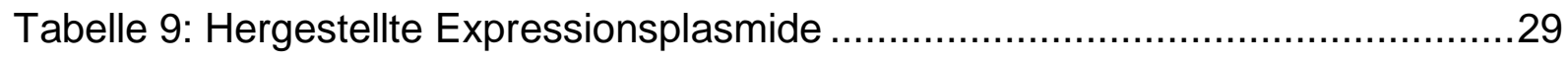

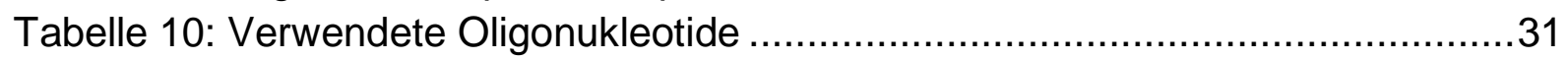

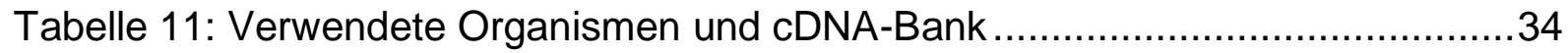

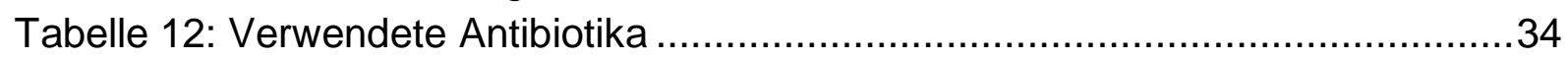

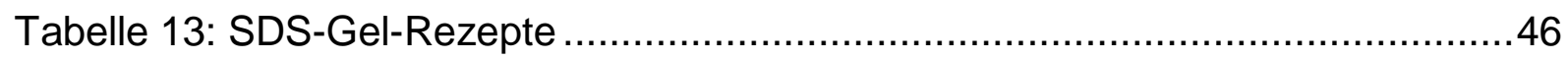

Tabelle 14: rekombinante Proteine aus E. coli, zwei Abbildungen pro Tabellenfeld bedeuten, dass das Protein in zwei Fragmenten exprimiert wurde .........................54

Tabelle 15: rekombinante Proteine aus $P$. pastoris............................................57

Tabelle 16: Gewichtstabelle der täglichen Wiegungen der Versuchstiere (beginnend mit Tag 1 p.i.; Angaben in Gramm (g)) ............................................................59

Tabelle 17: Beobachtungen an den Versuchstieren und Ergebnisse der

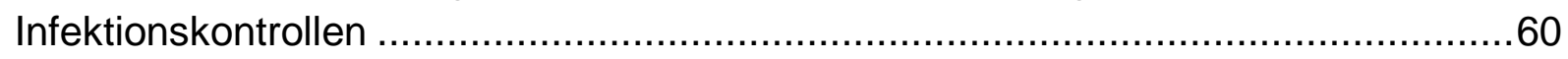

Tabelle 18: bei $\triangle$ ADAM-A zur Kontrolle verwendete Restriktionsenzyme ................64

Tabelle 19: bei $\triangle A D A M-B$ zur Kontrolle verwendete Restriktionsenzyme .................67

Tabelle 20: bei $\triangle A D A M-A B$ zur Kontrolle verwendete Restriktionsenzyme................71

Tabelle 21: bei $\triangle A D A M-A B$ zur Kontrolle verwendete Restriktionsenzyme...............73

Tabelle 22: Verwendete Geräte....................................................................114

Tabelle 23: Verwendete Verbrauchsmaterialien .............................................115 


\section{Einleitung}

\subsection{Taxonomie}

Die Gattung Aspergillus wurde zuerst im Jahre 1729 beschrieben (Micheli 1729). Sie wird wegen ihrer morphologischen Ähnlichkeiten der Sporenträger (Konidiophore) zu dem Brausekopf von Gießkannen auch als Gießkannenschimmel bezeichnet. Sind ausschließlich asexuelle - also anamorphe - Stadien bekannt, werden diese in das nicht systematische Form-Taxon Deuteromycetes eingeordnet; als Synonym wird dieses Taxon auch Fungi imperfecti genannt. Dieser Begriff bezeichnet asexuell wachsende höhere Pilze, deren Teleomorphe unbekannt sind; er ist also ein Sammelbegriff (Rolle und Mayr 1993).

Nach molekularen Untersuchungen wird die Gattung Aspergillus zu der Ordnung Eurotiales sowie der Familie Trichocomaceae gezählt (Sugiyama 1998).

Ein Großteil der Deuteromycetes ist vermutlich den Ascomycota zugehörig, weswegen der Begriff mittlerweile als Synonym für Anamorphe dieser Gruppe verwendet wird. Heutzutage sind in etwa 250 Aspergillus-Arten beschrieben worden (Geiser 2007).

\subsubsection{Asperqillus fumigatus und seine ökologische Bedeutung}

Der Organismus befindet sich im Erdboden und z. B. auch in Kompost. Er kommt ubiquitär auf sich zersetzendem organisch-pflanzlichem Material vor (Tekaia 2005). Er übernimmt eine wichtige Rolle im Recycling von Stickstoff und Kohlenstoff (Wilson 2002). Asexuell pflanzt sich der Organismus durch eine Vielzahl an Konidiosporen fort. Diese überdecken fast vollständig die gewachsene Kultur. Dank der graugrünen Farbe der Sporen wird inm den Artnamen „fumigatus" - „der rauchgraue“ - zu Teil. Diese Konidiosporen sind mit 2 - 5 Sporen pro $\mathrm{m}^{3}$ Luft überall so stark verbreitet, dass jeder Mensch weltweit täglich mehrere hundert dieser Sporen einatmet (Hospenthal 1998), welche auf Grund ihrer geringen Größe von 2 - $3 \mu \mathrm{m}$ im Durchmesser bis in die Alveolen der Lunge gelangen können.

A. fumigatus wächst trichal als stark verzweigtes und vielseptiertes Myzel (s. Abb. 1). Ein wichtiges Kriterium zur Abgrenzung von A. fumigatus gegenüber anderen Arten dieser Gattung ist seine Thermotoleranz. Er wächst sowohl bei niedrigen Temperaturen von ungefähr $10^{\circ} \mathrm{C}$ bis zu Temperaturen von weit über $50^{\circ} \mathrm{C}$ (Reiss 1997), wobei sein Temperaturoptimum bei $37-42^{\circ} \mathrm{C}$ - also deutlich höher als bei verwandten Arten - liegt, was inm optimal ermöglicht, in dem Habitat Mensch zu wachsen. Aspergillus fumigatus wurde lange Zeit zu der zuvor erwähnten Gruppe der Deuteromycetes gezählt. Es war also nur das asexuelle Anamorph bekannt. Dies wurde jedoch vor kurzem durch die Beschreibung des zugehörigen Teleomorphs Neosartorya fumigata (O'Gorman 2009) geändert. 


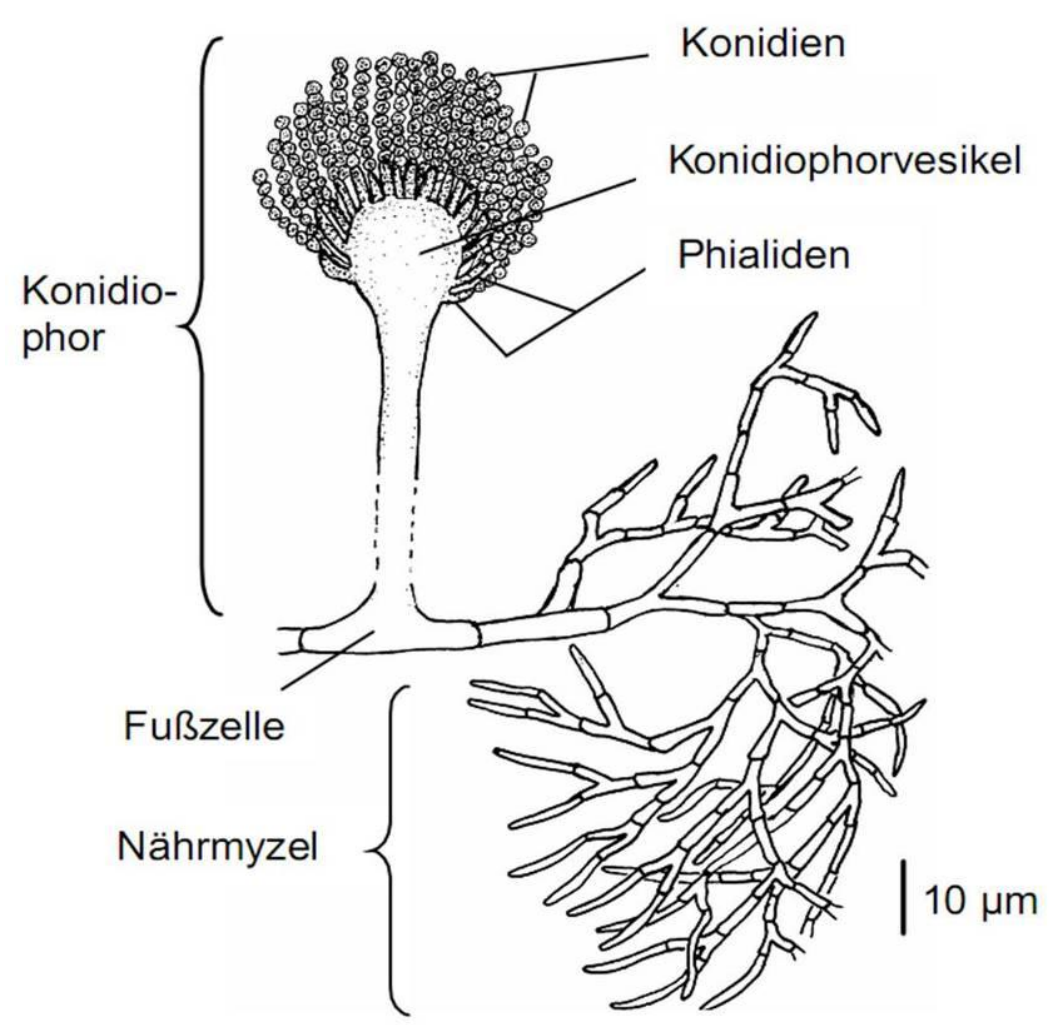

Abbildung 1: Schematische Darstellung der Morphologie von Aspergillus fumigatus

\subsubsection{Aspergillus fumigatus als Krankheitserreger}

Der Pilz Aspergillus fumigatus ist ein opportunistischer Krankheitserreger. Die effiziente Verbreitung über Konidien führt dazu, dass Mensch und Tier ihm fast ständig ausgesetzt sind (Latgé 1999). Er befindet sich großteils in den Lungen von befallenen Individuen, wobei er nicht ausschließlich auf diesen Ort beschränkt ist. Er kann auch die Haut befallen oder disseminiert in anderen Organen wachsen.

Zusätzlich zu seinem Dasein als opportunem Erreger wird A. fumigatus dadurch wichtig, dass er als Allergen fungiert (Greenberger 2002). Er ruft in dafür anfälligen Menschen Allergien hervor und führt zu asthmatischen Erkrankungen. Auch in gesunden Individuen finden sich durch die Allgegenwärtigkeit dieses Pilzes geringe anti-Aspergillus-fumigatus-Antikörpertiter (Igea 1993). Normalerweise werden die Hundertschaften an Konidiosporen des Pilzes, die jeder Mensch täglich inhaliert, von den diversen Stufen des Immunsystems des Menschen sehr effizient eliminiert. Versagt dieser Schutz jedoch, kommt es zur Besiedlung durch diesen Erreger. Bei Leukämiepatienten kommt es in 5 - 25\% aller Fälle zur Entwicklung einer Invasiven Aspergillose (Denning 1998). Die Letalität dieser Erkrankung ist mit über $50 \%$ (Lin 2001) trotz antimykotischer Behandlung sehr hoch; die Standardbehandlung ist aktuell die Gabe von Voriconazol. Alternativ wird liposomales Amphotericin B oder normales Amphotericin B gegeben (Böhme 2009). Die heutzutage immer stärkere Verwendung findende immunsuppressive Therapie, sei es in Verbindung mit der Therapie von Krebserkrankungen oder bei der Immunsuppression von Menschen nach einer Organ- oder Knochenmarktransplantation, führt beinahe zwangsläufig zu gesteigerten Infektionszahlen mit $A$. fumigatus. So wurde in den USA ein deutlicher 
Anstieg um das Vierfache an Aspergillose-bedingten Todesfällen (durch Autopsien bestätigt) in den Jahren 1980 bis 1999 verzeichnet (Segal 2009). Auch in Deutschland findet sich solch ein Trend. So wurden im Universitätsklinikum Göttingen in den Jahren 1988 bis 1997 vermehrt invasive Infektionen mit Aspergillus (und Candida) dokumentiert (s. Abb. 2). Hierbei stellt A. fumigatus mit 90-prozentiger Wahrscheinlichkeit den verantwortlichen Erreger dar (Latgé 1999).

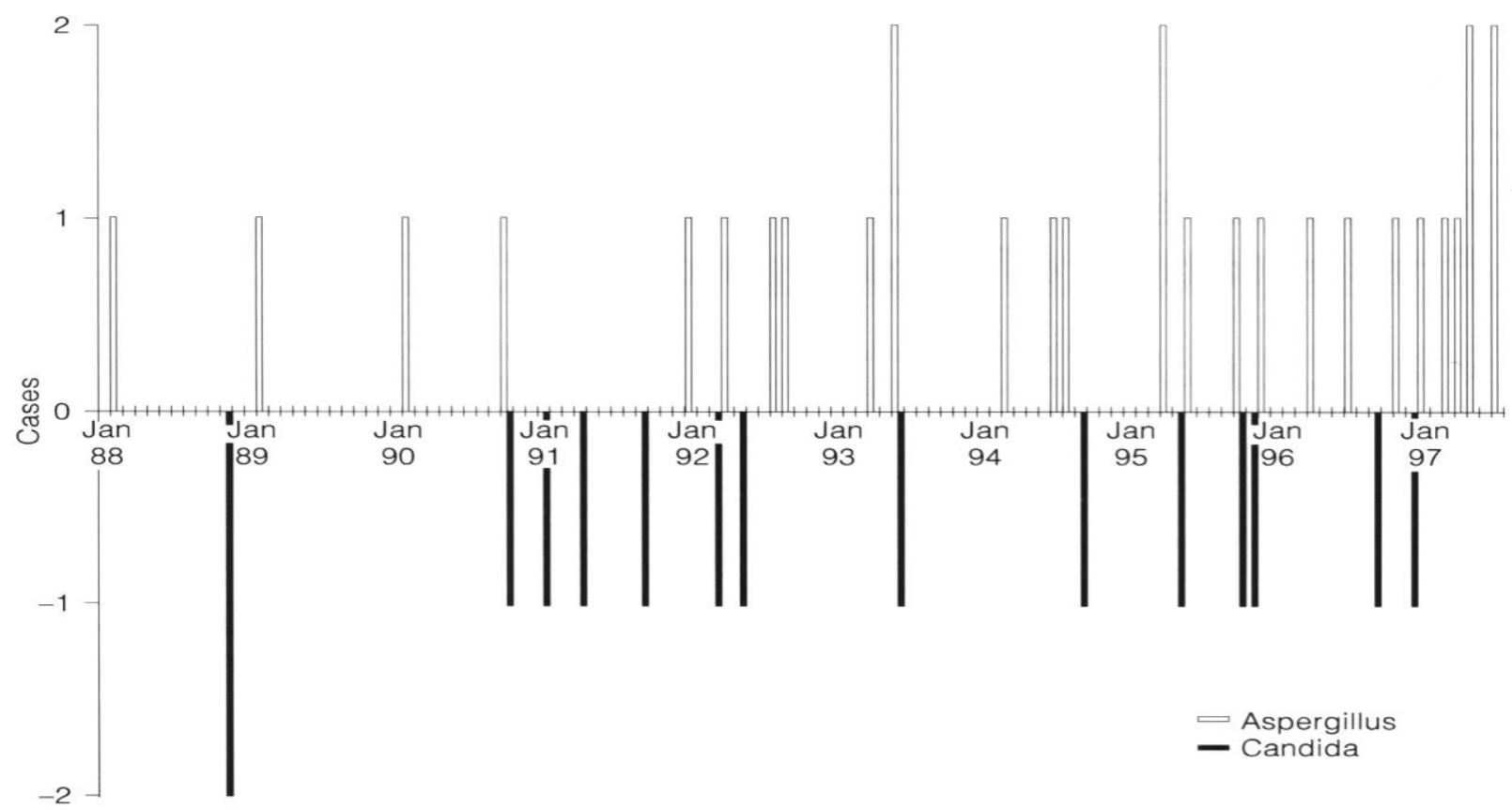

Abbildung 2: Häufigkeit von invasiven Aspergillus- und Candida-Infektionen (mit freundlicher Genehmigung von Prof. Rüchel (1999))

Die Art und Weise, durch die der Pilz seine Pathogenität erzielt, ist viel diskutiert worden; jedoch noch nicht mit hinreichend entschlüsselndem Ergebnis. So wurden zum einen die Hitzetoleranz, die Fähigkeit schnell zu wachsen, die Konidiengröße, aber auch die Fähigkeit Proteasen zu sekretieren in Überlegungen einbezogen (Latgé 1999).

\subsubsection{Alveoläres bronchopulmonales Asthma (ABPA)}

Eine der Erkrankungen, die von A. fumigatus ausgelöst werden können, ist ABPA. Es ist eine Form der Allergie der Typen I, III und IV (Latgé 1999), die an klassisches Asthma erinnert. Obwohl die Lunge von Patienten mit ABPA ständig von Aspergillus fumigatus kolonisiert ist, findet kein invasives Wachstum des Pilzes statt.

Hauptsächlich wird diese Form der Aspergillose bei Menschen gefunden, die bereits zuvor unter Lungenerkrankungen litten (z. B. Asthma oder zystische Fibrose; Salez 2000). Die übermäßige Immunreaktion hierbei beruht auf einer verstärkten Immunantwort von $\mathrm{T}_{\mathrm{H}} 2$-Helferzellen und der damit verbundenen vermehrten Sezernierung von IL-5. Laut Gibson (2006) prädispositioniert ein genetischer Polymorphismus des Surfactantprotein-A für die Entwicklung einer ABPA. Als Problem tritt die gesicherte Diagnose hervor, weil sich die Symptome nur 
schwierig von denen eines normalen Asthmas unterscheiden lassen. Dies führt unter schlimmsten Umständen zum Versagen des gesamten Atemapparates (Latgé 1999).

\subsubsection{Aspergillom}

Eine Form der Aspergillose, bei der ebenfalls kein invasives Wachstum des Pilzes zu finden ist, ist das Aspergillom. Hierbei wächst der Pilz in den Nasennebenhöhlen oder in anderen bereits existierenden Körperaushöhlungen, wie sie zum Beispiel in den Lungen bei Patienten mit Tuberkulose oder zystischer Fibrose zu finden sind. Diese - auch als Pilzball bezeichneten - Wuchsformen können bei nachträglich geminderter Immunabwehr zu invasivem Wachstum übergehen (Shibuya 2006), was wiederum durch angegriffene Pulmonalarterien zu Lungenblutungen mit letalem Ausgang führen kann.

\subsubsection{Invasive Aspergillose (IA)}

Die dritte und schwerwiegendste Form der Aspergillose stellt die invasive Aspergillose dar. Die Sterblichkeitsrate liegt trotz Behandlung mit Antimykotika bei etwa $50 \%$ (Lin 2001). Die Diagnose dieser Erkrankung wird durch sehr unspezifische Symptome erschwert. A. fumigatus ist hierbei unter allen Aspergillen mit über $90 \%$ der herausragende Krankheitsverursacher (Denning 1998). Im Gegensatz zu den beiden anderen Formen der Aspergillose wachsen die Pilzhyphen invasiv in das besiedelte Gewebe ein. Diese Wuchsform tritt jedoch nur bei immungeschwächten oder -supprimierten Menschen auf. Als besonders gefährdete Gruppe treten Patienten mit Leukämie hervor, bei denen es in 5 - $25 \%$ aller Fälle zu einer IA kommt (Denning 1998). Nach allogener Knochenmarktransplantation liegt die Mortalität bei über $50 \%$, wobei die Inzidenz der IA mit 5 - 11\% deutlich niedriger ist (Latgé 1999; Wald 1997). Mittlerweile ist jedoch ein Zusammenhang bekannt geworden, nach dem Patienten lange Zeit nach erfolgter Transplantation (und auch nach Neutropenie) eine IA entwickeln. Dies wird auf die Gabe von Calcineurin-Inhibitoren zurückgeführt, welche eine $T_{H} 1$-Immunatwort unterbinden (Armstrong-James 2009). Als weitere Risikogruppen sind Patienten zu nennen, deren Immunsystem nach einer Organtransplantation solider Organe therapeutisch induzierte Immunsuppression erfordert, um eine Abstoßung des transplantierten Organs zu vermeiden, und generell Patienten mit erniedrigter Immunabwehr (z.B. AIDS-Kranke oder Menschen unter Corticosteroid-Therapie; Henderson 1996; Rogers 1995).

Der Hauptmanifestationsort der IA ist die Lunge. Hier tritt sie in etwa $90 \%$ aller Fälle auf (Denning 2000). Bei gestörtem Immunsystem werden die inhalierten Konidiosporen nicht phagozytiert bzw. im Endolysosom der residenten Alveolarmakrophagen nicht getötet. Daraufhin kommt es zur Auskeimung zu Hyphen und, darauf folgend, deren invasiver Wuchs in das Lungengewebe hinein. Kennzeichnend ist eine diffuse, fortschreitende Pneumonie (Denning 1998 und 2000; Latgé 1999; Rüchel 1999). Zudem kommt es oft zur Einwanderung der Hyphen in das vaskuläre System der Lunge, was zu Obliteration und folgender Ischämie des betroffenen Bereiches führt. Sollten die Gefäße durch dieses Wachstum zerstört werden, kann es zu blutigem Husten kommen (Bodey 1989; Pagano 1995). 
Die hohe Mortalität bei dieser Erkrankung wirft die Frage auf, inwiefern infektionsrelevante Antigene identifiziert werden können und daraus resultierend, ob die Möglichkeit besteht, Vakzine für die Risikogruppen zu entwickeln (Stevens 2004). Es besteht weiterhin dringender Bedarf an besseren Therapien oder besser an der Prävention der Krankheit an sich.

\subsection{Antigene und Virulenzfaktoren}

A. fumigatus muss spezielle Fähigkeiten haben, die es inm erlauben, dem (restlichen) Immunsystem zu entkommen (Latgé 1994). Sofern die inhalierten Sporen von residenten Lungenmakrophagen phagozytiert wurden, muss der Pilz in einer relativ nährstoffarmen Umgebung - dem Phagolysosom - existieren können, wofür er spezielle metabolische Fähigkeiten benötigt (McKinney 2000; Lorenz 2002). Es wird sogar angenommen, dass die Lunge selbst als Stickstoff-armer Lebensraum anzusehen ist (Krappmann 2004). Ein weiterer wichtiger Punkt ist die Ausbildung von Adhäsinen, mit deren Hilfe er sich an das respiratorische Epithel anlagern kann. In diese Gruppe gehören Komplementrezeptoren, ein Lamininrezeptor und Hydrophobine (Sturtevant 1992; Tronchin 1997; Thau 1994). Mit diesen Strukturen kann es zu spezifischen oder unspezifischen Interaktionen mit den Oberflächen der Wirtszellen oder mit deren assoziierten Proteinen kommen. Typische, gebundene Moleküle sind Fibrinogen, Laminin, Fibronectin und Collagen Typ IV (Gil 1996). Eine weitere Teilgruppe der Adhäsine stellen die Hydrophobine dar. Diese befinden sich in den oberen Konidienwandschichten und dienen der Bindung der Konidien an hydrophobe Wirtsproteine. Sie sind auch aus Sporen anderer Pilze bekannt. Auch wenn die Gruppe der Adhäsine einen wichtigen Punkt bei der Anlagerung an den Wirt darstellt, so ist ihr Beitrag als Pathogenitätsfaktor ungewiss (Latgé 1999, Thau 1994).

Die zweite große Gruppe, deren mögliche Virulenz diskutiert wird, ist die der Pigmente. Diese sorgen bei den Konidien neben dem Schutz vor Schäden an der DNA durch UV-Strahlen auch für das typische grau-grüne Erscheinungsbild. Mutanten, deren Pigment-Bildung gestört ist, und die weißliche Sporen bilden, sind deutlich stärker empfänglich für antimykotische Wirkungen von Pharmaka, was wahrscheinlich auf eine durchlässigere Zellwand zurückzuführen ist. Ein wichtiger Bestandteil der Pigmentbildung ist Melanin, welches es dem Pilz ermöglicht, eine höhere Resistenz der Sporen zu erzielen (Latgé 1999, Tsai 1997; Verweij 1998). Im Gegensatz hierzu gibt es Studien, die ebenfalls involvierte Proteine der Pigmentbildung untersuchten, jedoch keinen Einfluss auf die Virulenz zeigen konnten (Sugareva 2006). In einem Projekt, in dem mehrere Mutanten der Melaninsynthese untersucht wurden, konnte ein deutlicher Einfluss auf die Pathogenität entdeckt werden. Ein genereller Mechanismus, der dafür verantwortlich sein könnte, wurde jedoch nicht gefunden (Jackson 2009).

A. fumigatus bildet weiterhin toxische Moleküle mit diversen Eigenschaften. Als wichtigster Vertreter tritt das Gliotoxin hervor, welches eine immunsuppressive Wirkung durch Zytotoxizität gegenüber Makrophagen und T-Lymphozyten hat und 
die Produktion von IFN-y behindert (Armstrong-James 2009). Eine Verminderung der Virulenz konnte mit einer Gliotoxin-Gen-Deletionsmutante in einem murinen Tiermodell jedoch nicht nachgewiesen werden (Kupfahl 2006). Zu den toxischen Molekülen zählt auch das gebildete Hämolysin. Dieses ist in der Lage, Blutzellen zu zerstören, wobei diese Eigenschaft allerdings ebenfalls keinen direkten Einfluss auf die Virulenz hat. Vielmehr wird davon ausgegangen, dass es während einer Infektion eine unterstützende Funktion gegenüber anderen toxischen Faktoren einnimmt, die ihrerseits Einfluss auf die Pathogenität nehmen (Fukuchi 1996; Malicev 2007).

Enzyme bilden eine ebenfalls sehr große Gruppe an Molekülen mit unterschiedlichen Funktionen, die möglicherweise an der Virulenz beteiligt sind. In dem Habitat „Lunge“ benötigt $A$. fumigatus z. B. Proteasen um aus dem umgebenden Gewebe Collagen und Elastin zu degradieren und daraus Nährstoffe zu beziehen (Monod 1995). Unterstützt wird dieser Punkt durch vergleichende Untersuchungen zwischen klinischen Aspergillus-fumigatus-Isolaten und solchen, die aus der Umwelt isoliert wurden. In den klinischen Isolaten wurde eine höhere Produktion an Proteasen gefunden. Eine dieser Hauptproteasen ist Alp - eine alkalische Serin-Protease - mit der Fähigkeit, Elastin zu lysieren. Nichtsdestotrotz verursachten Klone ohne diese Protease in einem Tiermodell die gleiche Mortalität, wie sie der Wildtyp verursacht (Tang 1993; Smith 1994). Eine weitere der Hauptproteasen von Interesse ist Pep1. Es ist eine Pepsin-ähnliche Protease. Für dieses Enzym konnte zwar keine verminderte Virulenz unter Verwendung einer Deletionsmutante nachgewiesen werden (Reichard 1997), Bozza (2009) zeigte allerdings eine induzierbare Immunität im Tierversuch unter Verwendung dieses Proteins als Vakzin. Außerdem zeigte eine Mutante, der ein übergeordneter Transkriptionsfaktor für mehrere Hauptproteasen fehlte, ebenso keine veränderte Virulenz (Bergmann 2009).

Als nicht-proteolytische Enzyme sind solche anzumerken, die gegen reaktive Sauerstoffspezies gerichtet sind und diese entgiften können. Hierbei sind Katalasen und Peroxidasen zu nennen; wobei mehrere Katalasen von Paris (2003) untersucht wurden, deren Deletionsmutanten nur eine gering erhöhte Empfindlichkeit gegenüber Wasserstoffperoxid im Vergleich zum Wildtyp zeigten, jedoch eine verzögerte Infektion im Tiermodell verursachten. Die wirkliche Rolle hinsichtlich der Pathogenität muss für Katalasen und Peroxidasen noch gezeigt werden.

Insgesamt lässt sich erkennen, dass die Virulenz von A. fumigatus nicht auf nur einen Faktor zurückzuführen ist, sondern dass sie multifaktoriell veranlagt ist (Latgé 1999;

Tekaia 2005).

\subsection{Das (reagierende) Immunsystem}

\subsubsection{Angeborene Immunität}

Im immunkompetenten Menschen treffen die Konidiosporen von Aspergillus fumigatus zunächst auf verschiedene Komponenten des angeborenen Immunsystems. Die daran beteiligten Faktoren sind zum einen anatomischphysikalische Barrieren, zum anderen Komplementfaktoren und phagozytierende Zellen (Latgé 1999). 
Gelangen Konidien in die Lunge, so werden sie als erstes mit einem Flimmerepithel konfrontiert, welches bereits etliche Konidien über die Bewegungen der Zilien aus der Lunge heraus befördert.

Im Bronchialsekret der Lunge trifft der Pilz auf mehrere Moleküle des angeborenen Immunsystems. Unter innen befinden sich z. B. Defensine und die Komponenten des Komplementsystems. Bei diesen sind es besonders die $\beta$-Defensine, die im Lungensekret als endogene Breitspektrum-Antibiotika wirken. Zum einen wird diese Gruppe von Epithelzellen in Haut und Schleimhäuten freigesetzt, zum anderen sind sie zu einem großen Teil in neutrophilen Granulozyten enthalten. In ihrem Aufbau sind mehrere hydrophobe Regionen enthalten, wegen derer sie in die Membranen von Pathogenen eindringen und diese durchlässiger machen können. Die verschiedenen Anteile des Komplementsystems, welche ebenfalls im Bronchialsekret zu finden sind (van de Graaf 1992), können eingedrungene Konidien und Hyphen entweder direkt schädigen, oder sie opsonisieren das Pathogen für die folgende zelluläre Abwehr (Sturtevant 1992). Außerdem sorgen sie für eine akute Entzündungsreaktion.

Im immunkompetenten Menschen werden die eingeatmeten Konidien, so sie denn bis hierher gelangen, von den residenten Alveolarmakrophagen über eine der Lectinbindung ähnliche Interaktion mit einem speziellen Rezeptor erkannt und phagozytiert (Serrano-Gómez 2004). Die folgende Abtötung der Konidien geschieht jedoch ausschließlich bei metabolisch aktiven Konidien; also bei Konidien, die sich kurz vor oder in der Keimung befinden. Somit müssen zunächst ein paar Stunden vergehen, bis die Elimination vollständig ist. Die recht wirkungsvolle Arbeit der Makrophagen benötigt in etwa 36 Stunden, bis alle Konidien verdaut sind (Schaffner 1994). Sollten die Konidien außerhalb von Makrophagen bereits ausgekeimt und dadurch zu groß für Makrophagen geworden sein, so heften sich neutrophile Granulozyten an die Hyphen. Sie setzen Defensine und Sauerstoffradikale frei und bekämpfen dadurch den Pilz; wobei die Granulozyten die gleichen Strukturen erkennen wie die Makrophagen zuvor (Serrano-Gómez 2004). Zusätzlich können auch diese Zellen Konidien phagozytieren und eliminieren. A. fumigatus besitzt jedoch offenbar die Möglichkeit, die von den erwähnten Zelltypen über NADPH-Oxidase und anderen Enzymen gebildeten reaktiven Sauerstoffspezies (z. B. $\mathrm{H}_{2} \mathrm{O}_{2}$ oder $\mathrm{O}_{2}{ }^{-}$) zu detoxifizieren (Hamilton 1999).

In immunsupprimierten Individuen fehlen diese Abwehrzellen oder sind in ihrer Funktion gestört. Dadurch können die Konidien und die folgenden auskeimenden Hyphen ohne Einschränkung durch den Wirt wachsen (Hohl 2007). Dies beinhaltet auch die Möglichkeit, invasiv in praktisch alle Gewebe zu wachsen.

\subsubsection{Erworbene Immunität}

Die Abwehrmechanismen der erworbenen Immunität sind bei einer erstmaligen Konfrontation mit Aspergillus fumigatus von untergeordneter Rolle. Hingegen kommt bei chronischen Krankheitsverläufen dieser Zweig des Immunsystems stärker zum Ausdruck (Denning 1998 und 2000; Latgé 1999). Dendritische Zellen dienen als Vermittler zwischen dem angeborenen und dem erworbenen Immunsystem. Nach 
ihrer Reifung über Nuklearfaktor kB (NF-kB) sowie Zyto- und Chemokine aktivieren sie verschiedene $\mathrm{T}$-Zellen der adaptiven Immunität. Sie erkennen eingedrungene Zellen während der Phagozytose über „pattern-recognition“-Rezeptoren wie z.B. Dectin-1 (erkennt $\beta$-Glucane) oder Toll-like-Rezeptoren (TLR; Segal 2009). Außerdem sind sie in der Lage, Antigen-Peptide auf dem MHC II (major histocompatibility complex) zu präsentieren. Die 18 bis 25 AS großen, präsentierten Peptide entstammen den im Phagolysosom verdauten Pathogenen; bzw. den denaturierten Proteinen aus diesen Organismen. Erkannt wird der MHC-II-AntigenKomplex von CD4-positiven T-Lymphozyten, die dafür spezielle Rezeptoren an ihrer Zelloberfläche besitzen (TCR). Außer an den dendritischen Zellen finden sich MHCII-Moleküle an Makrophagen und B-Zellen. Allerdings kann nach Einwirken des inflammatorischen Zytokins IFN-y beinahe jeder andere Zelltyp auch MHC II exprimieren. Sobald die naiven $\mathrm{CD}^{+}{ }^{+} \mathrm{T}-$-Lymphozyten mit einem Antigenpräsentierenden MHC II in Kontakt gekommen sind, wandeln sie sich zu $T_{H} 1$ - oder $\mathrm{T}_{\mathrm{H}}$ 2-Lymphozyten um. Die Art des Antigens sowie der Ort der Aktivierung spielen bei der Entscheidung, welcher T-Zelltyp entsteht eine Rolle. So wirkt die $T_{H} 1$-Population mit ihren Zytokinen als Auslöser und verstärkend auf die zelluläre Immunität. Auch können sie B-Zellen veranlassen, stark opsonisierende Antikörper zu bilden, auf dass das Komplement-System und die Fresszellen effektivere Arbeit leisten können. Diese Steigerung der zellulären Immunität senkt auch die Belastung des Organismus durch pilzliche Erreger (Latgé 1999). Die $\mathrm{T}_{\mathrm{H}} 2$-T-Zellen hingegen veranlassen die Produktion der humoralen Immunantwort durch B-Zell-Aktivierung. Beiden T-ZellPopulationen gemein ist, dass ihre gebildeten Zytokine auf die jeweils andere Gruppe inhibierend wirken. Armstrong-James (2009) zeigte, dass in immunsupprimierten Mäusen ein deutlicher Anstieg an IFN-y und Interleukin-17 (IL17) als Antwort auf eine Konfrontation mit $A$. fumigatus entstand. In immunkompetenten Mäusen war kein Unterschied in der IFN- $y$-Produktion erkennbar. Gleichzeitig konnte er zeigen, dass es zu einer verstärkten Ablesung der für Gliotoxin-Produktion verantwortlichen Gene während einer sich etablierenden Aspergillus-fumigatus-Infektion kommt. Für eine Rolle der T-Zellen spricht auch, dass es nach überlebter IA oder nach Konfrontation in immunkompetenten Menschen mit A. fumigatus zu einer verstärkten Produktion von IFN- $\mathrm{y}$-produzierenden $\mathrm{T}_{\mathrm{H}}$ 1-Zellen kommt (Bellocchio 2005).

Die adaptive Immunantwort gegenüber $A$.-fumigatus-Infektionen kommt großteils bei den subakuten Formen der IA zur Bedeutung. Hierbei ist die $T_{H} 1$-Zell-Antwort für eine entzündungsfördernde Antwort verantwortlich, während eine $T_{H} 2$-Zell-Antwort zu einer Unterdrückung der antimykotischen Zellaktivität führt. Stattdessen führt eine $\mathrm{T}_{\mathrm{H}} 2$-Antwort zu humoral(IgE)-unterstützender Interleukin-Produktion (Interleukin-4 und -10; Bellocchio 2005). Es wurde außerdem noch kein definitiver Nachweis einer humoralen Protektion gegen IA erbracht. Lediglich Teilimmunität gegen A. fumigatus konnte mit einem glykokonjugierten Antikörper-Vakzin erzeugt werden (Torosantucci 2005). Die Pathogenität von A. fumigatus legt jedoch den Gedanken nahe, dass es eventuell durch Antikörper-vermittelte Neutralisierung von Proteasen und/oder 
Toxinen zu einer Unterstützung der Immunabwehr kommen kann; doch ist hierfür grundlegend eine intakte Funktion der T-Zellen notwendig (Casadevall 2002).

Diese Zellen teilen sich in mehrere Gruppen auf, die zusammengenommen eine hohe Plastizität an Effektoren besitzen. Eben diese Eigenschaft zeigt die Möglichkeit auf, auch in immundefizienten Individuen eine Vakzin-basierte Protektion zu erzielen (Romani 2004).

\subsection{Vakzinierung gegen Aspergillus fumigatus}

Eine große Hoffnung in Bezug auf die Prävention einer Aspergillus-Infektion bei Individuen mit geschwächtem oder gestörtem Immunsystem liegt darin, eine protektive Immunantwort durch Vakzinierung hervorzurufen, bevor es zu einem Kontakt mit dem Erreger kommt. Bislang ist die Forschung auf diesem Gebiet nur von kleineren Erfolgen gekrönt. Die erzielten Wirkungen liegen dabei wahrscheinlich an einer T-Zell-vermittelten Steigerung der Abwehr durch Makrophagen (Asif 2006), und nicht an einer Antikörper-Produktion. Auch ist nicht geklärt, ob sich eine schützende, erworbene Immunität während der Erkrankung im immunsupprimierten Menschen etablieren kann.

Bereits in der 1970ern konnten erste Tierversuche zeigen, dass sich eine protektive Immunität gegen Infektionen mit Aspergillus fumigatus ausbilden kann. In Mäusen, denen zunächst Konidiosporen i.v. gegeben wurden, wurde nach einer späteren zweiten Infektion unter Cortisongabe lediglich Aspergillus-fumigatus-Wachstum in den Nieren beobachtet; während in Mäusen ohne vorherige Disposition Pilzwachstum in Nieren, Leber und Herz zu finden war (Lehmann 1976). Ebenfalls in diesem Jahrzehnt wurde gezeigt, dass ältere adulte Mäuse eine deutlich höhere Resistenz gegenüber $A$. fumigatus haben, als es bei juvenilen Mäusen der Fall war (Corbel 1977). Eine protektive Immunität, die sich nach subletaler Infektion mit A. fumigatus in Mäusen entwickelte, ließ sich auf naive Mäuse durch den Transfer von Makrophagen übertragen (de Repentigny 1993). Eine Immunität ließ sich in Mäusen auch dadurch erzeugen, dass der Kulturüberstand einer Aspergillusfumigatus-Kultur dreimalig i.n. appliziert wurde. Eine folgende Infektion mit dem Erreger wurde überlebt. Die aus diesen Mäusen gewonnenen CD4+-T-Lymphozyten wurden auf naive Mäuse übertragen, in denen es dadurch ebenfalls zu einer protektiven Immunreaktion kam (Cenci 2000). Auch konnte der Nutzen von dendritischen Zellen aufgezeigt werden, die mit lebensfähigen Aspergillus-Konidien oder mit konidialer RNA aktiviert wurden. Diese unterstützten ebenfalls nach Übertragung auf naive Mäuse eine Immunität (Bozza 2003). Es gab sogar erste Ansätze, Antikörper-vermittelte Immunität in Mäusen zu erzeugen. Dabei erzeugte ein glykokonjugiertes Vakzin ( $\beta$-Glucan) inhibitorische Wirkung auf das Hyphenwachstum von Candida albicans und schützte vor einer letalen Infektion mit Aspergillus fumigatus (Torosantucci 2005).

Ito (2002) konnte zeigen, dass eine immunprotektive Wirkung in durch Cortison immunsupprimierten Mäusen erzeugbar ist, wenn ihnen zuvor gründlichst zerstörte und steril filtrierte Hyphenmasse s.c. gespritzt wurde. 
Von dem ungefähr 10000 Gene umfassenden Genom von Aspergillus fumigatus (Niermann 2005) konnte eine protektive Immunreaktion bislang mit nur vier verschiedenen Einzel-Antigenen induziert werden. Vor einigen Jahren gelang eine Vakzinierung mit rekombinant hergestelltem Aspf3 (Ito 2006). Dieses wurde zusammen mit dem Adjuvans TiterMax (TiterMax ${ }^{\circledR}$ ist eingetragenes Markenzeichen der Firma TiterMax Inc.) s.c. verimpft.

In einer anderen Studie konnte eine immunprotektive Antwort auf das Antigen Aspf16 erzielt werden, welches zusammen mit CpG-Oligodenukleotiden als Adjuvans i.n. appliziert wurde. In dieser Studie konnte jedoch mit Aspf3 keinerlei Wirkung erzielt werden (Bozza 2002).

Als weitere potenzielle Vakzine wurden Pep1 (aspartic protease) und Gel1 (1,3- $\beta$ glucanosyltransferase) gefunden. Diese wurden ebenfalls mit dem zuvor beschriebenen CpG-Adjuvans i.n. verabreicht (Bozza 2009).

Auf diesen bekannten Erfolgen aufbauend liegt der Gedanke nahe, dass es noch weitere A.-fumigatus-Antigene gibt, die protektiv auf die Immunität gegen eine Infektion mit diesem Erreger wirken.

\subsection{Adjuvantien}

Im Rahmen von Vakzinierungen werden häufig Zusatzstoffe zu den eigentlich wirkenden Impfstoffen gegeben, die entweder die Wirkung überhaupt erst ermöglichen oder sie so unterstützen, dass eine geringere Menge an Vakzin verabreicht werden muss. Generell werden in der Pharmakologie als solcher Adjuvantien zu diversen Wirkgruppen zugegeben (z. B. Protonenpumpenhemmer bei Rheumamedikamenten). Die Wirkung beruht dabei auf verschiedenen Funktionen. Eine Funktion davon ist die eines Lösungsvermittlers oder Emulgators. So wird Dimethylsulfoxid (DMSO) zusammen mit Wirkstoffen verabreicht, die über die Haut aufgenommen werden sollen (Schmidt 2007). Eine andere Wirkung kann die verzögerte Freisetzung des Wirkstoffes und dadurch eine Wirkverlängerung sein. Dies geschieht z. B. bei dem Adjuvans Aluminiumhydroxid. Dieses adsorbiert das Antigen und setzt es nur langsam frei. Unter anderem wird der Stoff in den Humanimpfstoffen gegen Tetanus und Hepatitis-A verwendet (Moos 2005). Vor kurzem wurde ein weiteres Adjuvans im Rahmen der Bekämpfung der InfluenzaA/H1N1 („Schweinegrippe“) zur Verwendung beim Menschen zugelassen: AS03. Dies ist eine Öl-in-Wasser-Emulsion bestehend aus Squalen, DL- $\alpha$-Tocopherol (Vitamin E) und Polysorbat 80 (Roman 2010).

In der Immunologie werden seit langem Adjuvantien verwendet. Und auch in den bekannten Vakzinierungsversuchen gegen $A$. fumigatus wurden Adjuvantien eingesetzt; hierbei ist allerdings zu beobachten, dass nicht jedes Antigen mit jedem Adjuvans zu erwünschten Erfolgen führt. Ito (2006) verimpfte das Antigen Aspf3 zusammen mit dem Adjuvans TiterMax, welches die $T_{H} 1$-Zellantwort stimuliert, und erzeugte dadurch eine protektive Immunität. Dies schaffte Bozza (2002) mit CpGOligodenukleotiden nicht, sie erreichte jedoch eine Wirkung mit dem CpG-Adjuvans und verschiedenen anderen Antigenen (Bozza 2009). Die CpG-Oligodenukleotide 
wirken dabei direkt immunstimulierend. Dies schaffen sie durch die direkte Stimulierung von Toll-like-9-Rezeptoren, welche besonders effizient das unmethylierte CpG-Motiv - das Dinukleotid Cytosin-Guanin - erkennen (Krieg 2006). Dieses Motiv ist in menschlicher DNA im Gegensatz zu z. B. bakterieller DNA unterrepräsentiert. Das Motiv löst die Aktivierung von u. a. dendritischen Zellen aus; aber auch B-Zellen und Natürliche Killerzellen werden dadurch aktiviert (Krieg 2000). TiterMax wirkt als Wasser-in-Öl-Emulsion mit einem Copolymer CBL-8941, Squalen auf einer metabolisierbaren Ölbasis plus eines mikropartikulären Stabilisierers. Als klassisches Adjuvans gilt wegen der langen Verwendung das inkomplette Freund-Adjuvans, welches ebenfalls als Wasser-in-Öl-Emulsion mit einem Emulgator und Mineralöl als Basis seine Wirkung erzielt. Teilweise enthalten die Adjuvantien Bestandteile mikrobiellen Ursprungs, die ihrerseits eine unspezifische Aktivierung von Makrophagen bewirken sollen (komplettes Freund-Adjuvans). Als neueres Adjuvans beschrieb Zaharoff (2007) ein biokompatibles, nicht giftiges, biologisch abbaubares, natürliches Polysaccharid, welches sowohl eine humorale als auch Zell-vermittelte Immunreaktion bei subcutaner Verabreichung stärkte (Chitosan). Die Wirkung scheint auf einer Depot-Bildung zu beruhen; es löst Zellvermehrung in den umgebenden Lymphknoten aus.

\subsection{Zielsetzung der Arbeit}

In den letzten Jahrzehnten ist Aspergillus fumigatus einer der schädlichsten pathogenen Pilze für immunsupprimierte Individuen - besonders für Menschen mit Leukämie - geworden. Dies liegt unter anderem an immer häufiger Verwendung findender immunsuppressiver Therapie (Segal 2009). Es steht hierbei fest, dass die hohe Pathogenität multifaktoriell veranlagt ist (Latgé 1999). Welche Charakteristika explizit dafür verantwortlich sind, dass $A$. fumigatus von einem saprophytischen zu einem Lebensstil als Pathogen wechseln kann, sind immer noch unklar. Im Rahmen dieser Arbeit sollten mögliche Antigene evaluiert werden, welche bei einer Infektion mit $A$. fumigatus potenziell beteiligt sein könnten. Diese Proteine sollten rekombinant in E. coli oder P. pastoris exprimiert werden. Es ist aus wenigen Arbeiten bekannt, dass eine protektive Immunreaktion durch Vakzinierung einzelner Antigene im Tiermodell erzeugt werden kann (Bozza 2002 und 2009; Ito 2006). Daher sollten im Anschluss die so hergestellten Antigene auf ihr Potenzial, sie als Vakzin zu verwenden, im Tierversuch getestet werden.

Weiterhin sollten zu potenziellen Virulenzfaktoren Gen-Deletionsmutanten erstellt werden. Diese sollten biochemisch charakterisiert werden. 


\section{Material und Methoden}

\subsection{Chemikalien}

Tabelle 1: Chemikalien

\begin{tabular}{|c|c|}
\hline Agarose peqGold & peqLab, Erlangen \\
\hline Ammoniumtartrat & Sigma-Aldrich, Seelze \\
\hline Ampicillin & Sigma-Aldrich, Seelze \\
\hline Bacto-Agar & Becton Dickinson GmbH, Heidelberg \\
\hline Bacto-Tryptone & Becton Dickinson GmbH, Heidelberg \\
\hline Bacto-Yeast extract & Becton Dickinson GmbH, Heidelberg \\
\hline$\beta$-Mercaptoethanol & Serva, Heidelberg \\
\hline Bisacrylamid & Roth, Karlsruhe \\
\hline Bioquant Protein Reagenzlösung (Bradford) & Merck KGaA, Darmstadt \\
\hline Blankophor & Serva, Heidelberg \\
\hline Bromphenolblau & Serva, Heidelberg \\
\hline Bovines Serum Albumin (BSA) & Sigma-Aldrich, Seelze \\
\hline Iso-Butanol & J.T. Baker B.V., Deventer, Holland \\
\hline Calciumchlorid-dihydrat & Merck KGaA, Darmstadt \\
\hline Casein & Sigma-Aldrich, Seelze \\
\hline Chitosan & Novamatrix, Drammen, Norwegen \\
\hline Chloramphenicol & Sigma-Aldrich, Seelze \\
\hline Chloroform & Merck KGaA, Darmstadt \\
\hline $\begin{array}{l}\text { Complete Mini EDTA-free (Proteaseinhibitor- } \\
\text { Mix) }\end{array}$ & Roche, Mannheim \\
\hline Coomassie Brillant Blau R250 & Merck KGaA, Darmstadt \\
\hline Cortisonacetat & Sigma-Aldrich, Seelze \\
\hline Diethylether & Merck KGaA, Darmstadt \\
\hline Diethylformamat (Diethyl pyrocarbonate) & Sigma-Aldrich, Seelze \\
\hline ECL-System (Lösung 1\&2) & Amersham, Buckingshire, UK \\
\hline Eisenphosphat-Dihydrat & Sigma-Aldrich, Seelze \\
\hline EDTA (Ethylendiamintetraacetat) & Merck KGaA, Darmstadt \\
\hline Entwickler (für (Röntgen-)filme) & Sigma-Aldrich, Seelze \\
\hline Essigsäure & Merck KGaA, Darmstadt \\
\hline Ethanol & Merck KGaA, Darmstadt \\
\hline Ethidiumbromid & Sigma-Aldrich, Seelze \\
\hline Ficoll Typ 400 & Pharmacia, Uppsala, Schweden \\
\hline Fixierer Kodak processing chemicals & Sigma-Aldrich, Seelze \\
\hline Fleischextrakt (trocken) & Merck KGaA, Darmstadt \\
\hline Formamid & Merck KGaA, Darmstadt \\
\hline Gelatine & Merck KGaA, Darmstadt \\
\hline Guanidine-hydrochlorid & Roth, Karlsruhe \\
\hline D-(+)-Glucose-Monohydrat & Merck KGaA, Darmstadt \\
\hline
\end{tabular}




\begin{tabular}{|c|c|}
\hline Glycerin & Merck KGaA, Darmstadt \\
\hline Glycin & Roth, Karlsruhe \\
\hline Guanidin-Hydrochlorid & Roth, Karlsruhe \\
\hline Harnstoff & Roth, Karlsruhe \\
\hline Heringssperma-DNA & Invitrogen $\mathrm{GmbH}$, Karlsruhe \\
\hline 8-Hydroxychinolin & Sigma-Aldrich, Seelze \\
\hline Hygromycin B & Sigma-Aldrich, Seelze \\
\hline IPTG (Isopropyl- $\beta$-D-thiogalactosid) & peqLab, Erlangen \\
\hline Isoamylalkohol & Merck KGaA, Darmstadt \\
\hline Kaliumchlorid & Merck KGaA, Darmstadt \\
\hline Kaliumdihydrogenphosphat & Merck KGaA, Darmstadt \\
\hline Kanamycin & Sigma-Aldrich, Seelze \\
\hline Kongo Rot & Merck KGaA, Darmstadt \\
\hline Kupfersulfat-Pentahydrat & Merck KGaA, Darmstadt \\
\hline Magermilchpulver (Sucofin) & TSI, Zeven \\
\hline Magnesiumchlorid-Hexahydrat & Merck KGaA, Darmstadt \\
\hline Magnesiumsulfat-Heptahydrat & Merck KGaA, Darmstadt \\
\hline Mangansulfat-Dihydrat & Sigma-Aldrich, Seelze \\
\hline Methanol & Roth, Karlsruhe \\
\hline $\begin{array}{l}\text { MOPS (3-[N-Morpholino]propane- } \\
\text { sulfonicacid) }\end{array}$ & Sigma-Aldrich, Seelze \\
\hline Natriumborat-Decahydrat & Sigma-Aldrich, Seelze \\
\hline Natriumchlorid & Roth, Karlsruhe \\
\hline tri-Natriumcitrat-Dihydrat & Merck KGaA, Darmstadt \\
\hline Natriumdihydrogenphosphat-Monohydrat & Merck KGaA, Darmstadt \\
\hline Natriumhydroxid Plätzchen & Merck KGaA, Darmstadt \\
\hline Natriumhypochlorid & Sigma-Aldrich, Seelze \\
\hline Natriummolybdat-dihydrat & Roth, Karlsruhe \\
\hline tetra-Natriumdiphosphat-decahydrat & Merck KGaA, Darmstadt \\
\hline Ni-NTA-Agarose & Qiagen GmbH, Hilden \\
\hline Pepstatin A & Sigma-Aldrich, Seelze \\
\hline Pepton aus Casein & Roth, Karlsruhe \\
\hline Pepton aus Fleisch & Merck KGaA, Darmstadt \\
\hline Phenol & Roche, Mannheim \\
\hline PMSF (Phenylmethylsulfonylfluorid) & Sigma-Aldrich, Seelze \\
\hline Polyethylenglykol PEG3350 & Sigma-Aldrich, Seelze \\
\hline Polyvinylpyrrolidon & Sigma-Aldrich, Seelze \\
\hline Pyrithiamine hydrobromide & Sigma-Aldrich, Seelze \\
\hline Saccharose & Roth, Karlsruhe \\
\hline Salzsäure & Merck KGaA, Darmstadt \\
\hline SDS (Dodecylschwefelsäure) & Sigma-Aldrich, Seelze \\
\hline Sorbitol & Merck KGaA, Darmstadt \\
\hline Stickstoff, flüssig & Messer Griesheim, Krefeld \\
\hline
\end{tabular}




\begin{tabular}{|l|r|}
\hline TEMED (N,N,N',N'- & Merck KGaA, Darmstadt \\
Tetramethylenethylendiamin) & Roth, Karlsruhe \\
\hline Tris & Merck KGaA, Darmstadt \\
\hline TCA (Trichloressigsäure) & Sigma-Aldrich, Seelze \\
\hline Triton X 114 & Merck KGaA, Darmstadt \\
\hline $\begin{array}{l}\text { Tween } 20 \\
\text { (Polyoxyethylensorbitanmonolaurat) }\end{array}$ & Sigma-Aldrich, Seelze \\
\hline $\begin{array}{l}\text { Tween } 80 \\
\text { (Polyoxyethylensorbitanmonooleat) }\end{array}$ & Roth, Karlsruhe \\
\hline Wasserstoffperoxid & Becton Dickinson GmbH, Heidelberg \\
\hline Yeast carbon base (YCB) & Becton Dickinson GmbH, Heidelberg \\
\hline Yeast nitrogen base (YNB) & Merck KGaA, Darmstadt \\
\hline Zinksulfat-Heptahydrat & \\
\hline
\end{tabular}

\subsection{Reaktionssets (Kits)}

Tabelle 2: Kits

\begin{tabular}{|l|l|}
\hline QIAEX II & Qiagen $\mathrm{GmbH}$, Hilden \\
\hline QIAGEN $^{\Theta}$ Lambdaction Kini Kit & Qiagen $\mathrm{GmbH}$, Hilden \\
\hline QIAprep $^{\circledast}$ Spin Miniprep Kit & Qiagen $\mathrm{GmbH}$, Hilden \\
\hline QIAquick $^{\circledR}$ PCR Purification Kit & Qiagen $\mathrm{GmbH}$, Hilden \\
\hline
\end{tabular}

\subsection{Enzyme (+ dazugehörige Puffer)}

Tabelle 3: Enzyme

Restriktionsendonukleasen

Taq-DNA-Polymerase (+dNTP-Mix)

New England Biolabs, Schwalbach

Taq-Verdünnung (s. 2.7 Lösungen)

T4 DNA Ligase

Antarctic Phosphatase

Roche, Mannheim

Alkaline Shrimp Phosphatase

Glucanex

Pfu-Ultra-DNA-Polymerase (+dNTP-Mix)

RNAse Type XII

New England Biolabs, Schwalbach

New England Biolabs, Schwalbach

Roche, Mannheim

Sigma-Aldrich, Seelze

Roche, Mannheim

Sigma-Aldrich, Seelze

\subsection{Molekulargewichtstandards}

Tabelle 4: Molekulargewichtstandards

\begin{tabular}{|l|l|}
\hline $\begin{array}{l}\text { DNA molecular-weight marker III } \\
\text { digoxigenin-labeled }\end{array}$ & Boehringer Mannheim GmbH, Mannheim \\
\hline GeneRuler ${ }^{\mathrm{TM}}$ 100bp DNA Ladder Plus & MBI Fermentas, St.Leon-Rot \\
\hline MassRuler ${ }^{\mathrm{TM}}$ DNA Ladder Low Range & MBI Fermentas, St.Leon-Rot \\
\hline MassRuler ${ }^{\mathrm{TM}}$ DNA Ladder Mix & MBI Fermentas, St.Leon-Rot \\
\hline MassRuler ${ }^{\mathrm{TM}}$ High Range DNA Ladder & MBI Fermentas, St.Leon-Rot \\
\hline peqGold Prestained Protein-Marker IV & PEQLAB Biotechnologie GMBH, \\
\hline
\end{tabular}




\begin{tabular}{|c|c|}
\hline & Erlangen \\
\hline (DNA-)Elektrophorese-Probenpuffer & \\
\hline 6x MassRuler ${ }^{\mathrm{TM}}$ Loading Dye Solution & MBI Fermentas, St.Leon-Rot \\
\hline
\end{tabular}

\subsection{Spezielle Nukleotide}

Tabelle 5: Nukleotide

\begin{tabular}{|l|l|}
\hline Digoxigenin-11-UTP & Boehringer, Ingelheim \\
\hline dGTP & Boehringer, Ingelheim \\
\hline dATP & Boehringer, Ingelheim \\
\hline dTTP & Boehringer, Ingelheim \\
\hline dCTP & Boehringer, Ingelheim \\
\hline
\end{tabular}

\subsection{Antikörper}

Tabelle 6: Antikörper

\begin{tabular}{|l|l|}
\hline Anti-Digoxigenin-POD, Fab fragment & Roche, Mannheim \\
\hline $\begin{array}{l}\text { Monoclonal Anti-Rabbit Immunoglobulins } \\
\text { Clone RG-16 }\end{array}$ & Sigma-Aldrich, Seelze \\
\hline $\begin{array}{l}\text { Rabbit-Anti-A.-fumigatus-ADAM-A } \\
\text { ZCHO8038 }\end{array}$ & Prof. Michel Monod, Schweiz \\
\hline $\begin{array}{l}\text { Rabbit-Anti-A.-fumigatus-ADAM-B } \\
\text { ZCHO8039 }\end{array}$ & Prof. Michel Monod, Schweiz \\
\hline
\end{tabular}

\subsection{Lösungen}

Sofern nicht anders angegeben wurden die Lösungen in A. bidest angesetzt/gelöst und der $\mathrm{pH}$-Wert mit $\mathrm{HCl}$ bzw. $\mathrm{NaOH}$ eingestellt.

\section{Biotin 500x}

Biotin $0,02 \%$

lösen und steril filtrieren

\section{BSA-Lösung}

Bovines Serum Albumin

lösen in OM, steril filtrieren

BSA (10x)
BSA (acetyliert)
$0,1 \%$

\section{Cortisonacetat-Suspension}

\section{Cortisonacetat}

mit PBS + 0,1\% Tween 80 versetzen, 1:1 mit sterilen glass beads versetzen und gründlichst vortexen. Kurz vor Gebrauch Suspension von glass beads trennen. 
Denhardts Reagenz (50x)

Ficoll Typ $400 \quad 1 \%$

Polyvinylpyrrolidon $\quad 1 \%$

BSA $1 \%$

steril filtrieren

Elutions-Puffer (EB)

Tris $\quad 10 \mathrm{mM}$

$\mathrm{pH}$ auf 8,5 einstellen

Glucanex-Lösung

Glucanex $\quad 5 \%$

lösen in OM, filtrieren und auf Eis auffangen, steril filtrieren

Glycerol 10x

Glycerol $\quad 10 \%$

verdünnen und steril filtrieren

Harnstoff-Lösung

Harnstoff $8 \mathrm{M}$

angesetzt in $1 \times$ PBS

HCl-Lösung

Salzsäure $\quad 0,25 \mathrm{M}$

Hybridisierungslösung

Digoxigenin markierte DNA-Sonde $\quad 1 \%$

5 Min bei $100^{\circ} \mathrm{C}$ denaturieren und mit Formamid $1: 1$ mischen, 5 Min auf Eis

inkubieren

IPTG-Stammlösung

IPTG (Isopropyl- $\beta$-D-thiogalactosid) $\quad 500 \mathrm{mM}$

Kaliumphosphat-Puffer (pH 6)

$\mathrm{K}_{2} \mathrm{HPO}_{4}(1 \mathrm{M}) \quad 13,2 \%$

$\mathrm{KH}_{2} \mathrm{PO}_{4}(1 \mathrm{M}) \quad 86,8 \%$

Methanol 10x

Methanol

$5 \%$

verdünnen und steril filtrieren 
MS

MOPS

$10 \mathrm{mM}$

Sorbitol

$1 \mathrm{M}$

$\mathrm{pH}$ auf 6,5 einstellen, steril filtrieren

\section{MSC}

MOPS

$10 \mathrm{mM}$

Sorbitol

$1 \mathrm{M}$

$\mathrm{CaCl}_{2}$

$20 \mathrm{mM}$

$\mathrm{pH}$ auf 6,5 einstellen, steril filtrieren

Na-Acetat-Lösung (3 M)

Na-Acetat

$3 \mathrm{M}$

auf $\mathrm{pH}$ 5,2 einstellen

Na-Acetat-Lösung (8 M)

(Eis-)Essig

$17,4 \mathrm{M}$

mit $10 \mathrm{M} \mathrm{NaOH}$ auf $\mathrm{pH}$ 4,2 einstellen

Na-Citrat-Puffer

tri-Natriumcitrat-Dihydrat

$20 \mathrm{mM}$

auf $\mathrm{pH}$ 5,5 einstellen

(alkalische) $\mathrm{NaCl}$-Lösung $(1,5 \mathrm{M})$

$\mathrm{NaCl}$

$1,5 \mathrm{M}$

$\mathrm{NaOH}$

$0,5 \mathrm{M}$

NaCl-Lösung (2 M)

$\mathrm{NaCl}$

$2 \mathrm{M}$

NaCl-Tris-Lösung

$\mathrm{NaCl}$

$1,5 \mathrm{M}$

TrisCl (pH 8)

$0,5 \mathrm{M}$

$\mathrm{NaCl}-T w e e n-L o ̈ s u n g$

$\mathrm{NaCl}$

$0,9 \%$

Tween 80

$0,1 \%$

$\mathrm{Na}_{2}$ EDTA-SDS-Lösung

$\mathrm{Na}_{2}$ EDTA

$50 \mathrm{mM}$ 
SDS

$\mathrm{pH}$ auf 8,5 einstellen

$\mathrm{Na}_{2}$ EDTA-TrisCl-SDS-Lösung (Lysispuffer)

$\mathrm{Na}_{2}$ EDTA

$0,1 \mathrm{M}$

TrisCl $(\mathrm{pH} 8,5)$

$0,2 \mathrm{M}$

SDS

$1 \%$

$\mathrm{pH}$ auf 8,5 einstellen

Narkoselösung

Diethylether

3 Vol.

Chloroform

$2 \mathrm{Vol}$.

Ethanol

1 Vol.

Osmotisches Medium (OM)

$\mathrm{Na}_{3} \mathrm{PO}_{4}$

$10 \mathrm{mM}$

$\mathrm{MgSO}_{4} \times 7 \mathrm{H}_{2} \mathrm{O}$

$1,2 \mathrm{M}$

$\mathrm{pH}$ auf 5,8 einstellen, steril filtrieren

PBS 10x

$\mathrm{NaCl}$

$8 \%$

$\mathrm{KCl}$

$0,2 \%$

$\mathrm{Na}_{2} \mathrm{HPO}_{4}$

$1,44 \%$

$\mathrm{KH}_{2} \mathrm{PO}_{4}$

$0,24 \%$

$\mathrm{pH}$ auf 7,4 einstellen

\section{PEG-Lösung}

Polyethylenglykol PEG3350

$60 \%$

in MSC Iösen und steril filtrieren

\section{Phenol-Chloroform-Isoamylalkohol}

Phenol-Lösung

1 Vol.

Chloroform-Isoamylalkohol (24:1)

1 Vol.

gut mischen und Phasentrennung abwarten

\section{Phenol-Lösung}

Phenol (fest) $500 \mathrm{~g}$

8-Hydroxychinolin $0,5 \mathrm{~g}$

im $65^{\circ} \mathrm{C}$ Wasserbad erwärmen

$+1 \mathrm{M}$ TrisCl $(\mathrm{pH} 8)$

1 Vol.

schütteln und Phasentrennung abwarten, obere Phase verwerfen 
$+0,1 \mathrm{M} \mathrm{TrisCl}(\mathrm{pH} 8)$

1 Vol.

schütteln und Phasentrennung abwarten, obere Phase verwerfen;

wie folgt aliquotieren und bei $-20^{\circ} \mathrm{C}$ lagern:

Phenol (s. o.)

$40 \mathrm{ml}$

$0,1 \mathrm{M}$ TrisCl $(\mathrm{pH} 8)$

$8 \mathrm{ml}$

$\beta$-Mercaptoethanol

$8 \mu \mathrm{l}$

\section{Prähybridisierungslösung}

Formamid

$50 \%$

SSC (20x)

$30 \%$

Denhardts Reagenz (50x)

$10 \%$

SDS (10\%)

$5 \%$

Heringssperma-DNA (10 mg/ml)

$1 \%$

\section{Protein-Extraktionspuffer}

Tris $(\mathrm{pH} 7,0)$

$20 \mathrm{mM}$

Saccharose

$0,25 \mathrm{M}$

PMSF

$1 \mathrm{mM}$

Pepstatin

$1 \mathrm{mM}$

Protein-Produktion-Puffer A

Guanidine-hydrochlorid

$6 \mathrm{M}$

$\mathrm{NaH}_{2} \mathrm{PO}_{4}$

$0,1 \mathrm{M}$

Tris

$10 \mathrm{mM}$

$\mathrm{pH}$ auf 8,0 einstellen

Protein-Produktion-Puffer B

Harnstoff

$8 \mathrm{M}$

$\mathrm{NaH}_{2} \mathrm{PO}_{4}$

$0,1 \mathrm{M}$

Tris

$10 \mathrm{mM}$

$\mathrm{pH}$ auf 8,0 einstellen

Protein-Produktion-Puffer C

Harnstoff

$8 \mathrm{M}$

$\mathrm{NaH}_{2} \mathrm{PO}_{4}$

$0,1 \mathrm{M}$

Tris

$10 \mathrm{mM}$

$\mathrm{pH}$ auf 6,3 einstellen

Protein-Produktion-Puffer E Harnstoff 
$\mathrm{NaH}_{2} \mathrm{PO}_{4}$

$0,1 \mathrm{M}$

Tris

$10 \mathrm{mM}$

$\mathrm{pH}$ auf 4,5 einstellen

Protein-Produktion-Puffer F

Guanidine-hydrochlorid

$6 \mathrm{M}$

Essigsäure

SDS-Lösung (10\%)

Dodecylschwefelsäure (SDS)

$10 \%$

SDS-PAGE-Probenpuffer (2x)

Glycerin (87\%) 20\%

SDS (10\%) $\quad 50 \%$

SDS-Sammelgelpuffer $\quad 30 \%$

Bromphenolblau $\quad 0,01 \%$

$\beta$-Mercaptoethanol $\quad 1: 10$

SDS-PAGE-Laufpuffer

Tris

$0,3 \%$

Glycin

$1,44 \%$

SDS (10\%)

$1 \%$

SDS-PAGE-Färbelösung \& -Entfärber

Färbung:

Coomassie R250 0,16\%

Essigsäure $\quad 6,6 \%$

Methanol 33,3\%

Entfärbung:

Essigsäure

$7,5 \%$

Methanol

$33,3 \%$

SDS-Sammelgelpuffer

Tris

$1 \mathrm{M}$

$\mathrm{pH}$ auf 8,8 einstellen

SDS-Trenngelpuffer

Tris

$1 \mathrm{M}$

$\mathrm{pH}$ auf 6,8 einstellen 


$\begin{array}{ll}\text { SM-Puffer } & \\ \mathrm{NaCl} & 0,58 \% \\ \mathrm{MgSO} 4 \times 7 \mathrm{H} 2 \mathrm{O} & 0,2 \% \\ 1 \mathrm{M} \text { TrisHCl-Lsg } & 5 \% \\ \text { Gelatine } & 0,01 \% \\ \text { autoklavieren } & \end{array}$

SSC 20x

$\mathrm{NaCl} \quad 3 \mathrm{M}$

tri-Natriumcitrat-dihydrat $\quad 0,3 \mathrm{M}$

$\mathrm{pH}$ auf 7,0 einstellen

Southern-Blot-Block-Puffer

Milchpulver $5 \%$

Tween $20 \quad 0,1 \%$

in 1x PBS, pH auf 7,4 einstellen

Southern-Blot-Denaturierungslösung

$\mathrm{NaCl} \quad 1,5 \mathrm{M}$

$\mathrm{NaOH} \quad 0,5 \mathrm{M}$

Southern-Blot-Depurinierungslösung

$\mathrm{HCl} \quad 0,25 \mathrm{M}$

Southern-Blot-Neutralisierungslösung

$\mathrm{NaCl}$

$1,5 \mathrm{M}$

TrisCl (pH 8)

$0,5 \mathrm{M}$

Southern-Blot-Waschpuffer I

SDS

$0,5 \%$

in $2 x$ SSC

Southern-Blot-Waschpuffer II

SDS

$0,5 \%$

in $0,1 \times S S C$

Spurenelementlösung

$\begin{array}{ll}\mathrm{Na}_{2} \mathrm{~B}_{4} \mathrm{O}_{7} \times 10 \mathrm{H}_{2} \mathrm{O} & 0,004 \% \\ \mathrm{CuSO}_{4} \times 5 \mathrm{H}_{2} \mathrm{O} & 0,04 \% \\ \mathrm{FePO}_{4} \times 2 \mathrm{H}_{2} \mathrm{O} & 0,08 \% \\ \mathrm{MnSO}_{4} \times 2 \mathrm{H}_{2} \mathrm{O} & 0,08 \%\end{array}$


$\mathrm{Na}_{2} \mathrm{MoO}_{4} \times 2 \mathrm{H}_{2} \mathrm{O}$

$0,08 \%$

$\mathrm{ZnSO}_{4} \times 7 \mathrm{H}_{2} \mathrm{O}$

$0,8 \%$

Taq-DNA-Polymerase-Verdünnung

Taq-DNA-Polymerase

$5 \%(v / v)$

in 0,1 x Taq-Puffer

\section{TBE-Puffer $5 x$}

Tris

$5,4 \%$

Borsäure

$2,75 \%$

0,5 M EDTA-Lsg. (pH 8)

$2 \%$

\section{TE-Puffer}

TrisCl (pH 8)

$10 \mathrm{mM}$

EDTA

$1 \mathrm{mM}$

$\mathrm{pH}$ auf 8,0 einstellen

(Western-Blot-) Transfer-Puffer

Tris

$0,3 \%$

Glycin

$1,44 \%$

Methanol

$15 \%(\mathrm{v} / \mathrm{v})$

Trapping buffer

MOPS

$0,1 \mathrm{M}$

\section{Tris-EDTA-Puffer}

EDTA

$0,1 \mathrm{M}$

mit festem Tris auf $\mathrm{pH} 7,4$ titrieren $(\sim 1,25 \%)$

\subsection{Medien}

Die angegebenen Prozentzahlen entsprechen w/v-Angaben

Buffered Glycerol/Methanol-complex Medium (BMGY/BMMY)

Yeast extract

$1 \%$

Peptone

$2 \%$

Iösen und autoklavieren, danach zufügen von folgenden gelösten Substanzen:

Kaliumphosphatpuffer ( $\mathrm{pH} 6)$

$100 \mathrm{mM}$

YNB 10x

$1 / 10 \mathrm{Vol}$

Biotin 500x

$1 / 500$ Vol.

+entweder Glycerol 10x

1/10 Vol. 
+oder Methanol 10x

1/10 Vol.

\section{(E. coli-) Expressionsmedium}

Yeast extract

$0,8 \%$

Trypton

$1,8 \%$

$\mathrm{NaCl}$

$0,5 \%$

Glucose

$2 \%$

in A. bidest lösen und autoklavieren

\section{Glucosebouillion}

$\mathrm{NaCl}$

$0,7 \%$

Glucose

$4 \%$

Pepton (aus Fleisch)

$1 \%$

Fleischextrakt (trocken)

$0,35 \%$

In A. bidest lösen und autoklavieren

\section{GYE-Agar}

Glucose

$1 \%$

Yeast extract

$0,5 \%$

in A. bidest lösen

Agar

$2 \%$

hinzufügen und autoklavieren

\section{LB-Agar}

Agar

$2 \%$

in LB-Medium ansetzen, autoklavieren

\section{LB-Maltose-MgSO ${ }_{4}$}

Maltose

$0,2 \%$

$\mathrm{MgSO}_{4} \times 7 \mathrm{H}_{2} \mathrm{O}$

$0,25 \%$

in LB-Medium Iösen, steril filtrieren

\section{Luria-Bertani-Medium (LB)}

Tryptone

$1 \%$

Yeast extract

$0,5 \%$

$\mathrm{NaCl}$

$1 \%$

in $\mathrm{A}$. bidest ansetzen, $\mathrm{pH}$ auf 7 einstellen und autoklavieren

(Resistenz-)Marker-Rescue Minimal Medium (MM*) 


$\begin{array}{ll}\mathrm{NaNO}_{3} & 0,085 \% \\ \mathrm{KCl} & 0,052 \% \\ \mathrm{MgSO}_{4} \times 7 \mathrm{H}_{2} \mathrm{O} & 0,052 \% \\ \mathrm{KH}_{2} \mathrm{PO}_{4} & 0,152 \% \\ \text { Spurenelement-Lösung } & 0,1 \%\end{array}$

in A. bidest ansetzen, $\mathrm{pH}$ auf 6,8 einstellen, steril filtrieren und bei $4^{\circ} \mathrm{C}$ aufbewahren

(Aspergillus-) Minimal Medium (MM)

Glucose

Ammoniumtartrat

$\mathrm{KCl}$

$\mathrm{MgSO}_{4} \times 7 \mathrm{H}_{2} \mathrm{O}$

$\mathrm{KH}_{2} \mathrm{PO}_{4}$

Spurenelement-Lösung
$1 \%$

$0,092 \%$

$0,052 \%$

$0,052 \%$

$0,152 \%$

$0,1 \%$

in A. bidest ansetzen, $\mathrm{pH}$ auf 6,8 einstellen, steril filtrieren und bei $4^{\circ} \mathrm{C}$ aufbewahren

\section{MM-Agar}

Agar

$2 \%$

in $\mathrm{MM}$ ansetzen und autoklavieren $\left(20 \mathrm{Min}\right.$ bei $\left.105^{\circ} \mathrm{C}\right)$

\section{MM+Zusatz-Agar}

Zusatz (nur einer pro Medium):

Kongo Rot

$0,1 \%$

Calcofluor White

$0,02 \%$

Koffein

$5 \mathrm{mM}$

SDS

$0,02 \%$

$\mathrm{NaCl}$

$1 \mathrm{M} / 2 \mathrm{M}$

$\mathrm{KCl}$

$1 \mathrm{M} / 2 \mathrm{M}$

Sorbitol

$1 \mathrm{M} / 2 \mathrm{M}$

$\mathrm{H}_{2} \mathrm{O}_{2}$

$0,012 \%$

Chloramphenicol

$0,5 \% / 2 \%$

$\mathrm{NaOCl}$

$0,01 \% / 0,1 \%$

in 2x MM gelöst

+Wasseragar (4\%)

\section{MM-BSA-Agar}

BSA

in MM ohne Glucose und Ammoniumtartrat ansetzen

+ Wasseragar (4\%) 


\section{MM-Casein-Agar}

Casein

in MM ohne Glucose und Ammoniumtartrat ansetzen, steril filtrieren

+ Wasseragar (4\%)

1:1

\section{MM-Gelatine-Agar}

Gelatine

in MM ohne Glucose und Ammoniumtartrat ansetzen

+Wasseragar (4\%)

\section{MMS-Agar}

Saccharose

$1 \mathrm{M}$

Agar

$2 \%$

in $\mathrm{MM}$ ansetzen und autoklavieren (20 Min bei $\left.105^{\circ} \mathrm{C}\right)$

\section{MMS*-Agar}

Saccharose

$1 \mathrm{M}$

Agar

$2 \%$

in $\mathrm{MM}^{*}$ ansetzen und autoklavieren $\left(20\right.$ Min bei $105^{\circ} \mathrm{C}$ )

\section{MMS-Topagar}

Saccharose

$1 \mathrm{M}$

Agar

$0,7 \%$

in $\mathrm{MM}$ ansetzen und autoklavieren (20 Min bei $105^{\circ} \mathrm{C}$ )

\section{MMS*-Topagar}

Saccharose

$1 \mathrm{M}$

Agar

$0,7 \%$

in $\mathrm{MM}^{*}$ ansetzen und autoklavieren (20 Min bei $105^{\circ} \mathrm{C}$ ).

\section{NZY-Agarose}

Agarose

in NZY-Medium ansetzen; autoklavieren

\section{NZY-Medium}

$\begin{array}{ll}\mathrm{NaCl} & 0,5 \% \\ \mathrm{MgSO}_{4} \times 7 \mathrm{H} 2 \mathrm{O} & 0,2 \% \\ \text { Yeast extract } & 0,5 \% \\ \text { NZ Amine (Casein Hydrolysat) } & 1 \%\end{array}$


in A. bidest lösen, $\mathrm{pH}$ 7,0 einstellen und autoklavieren

$+1 \mathrm{M} \mathrm{MgCl}_{2}$-Lsg. (steril)

$1,25 \%$

$+1 \mathrm{M} \mathrm{MgSO}_{4}$-Lsg. (steril)

$1,25 \%$

+2 M Glucose-Lsg. (steril)

$1 \%$

\section{NZY-Topagarose}

Agarose $\quad 0,7 \%$

in NZY-Medium ansetzen; autoklavieren

SOC-Medium

Bacto-Tryptone

$2 \%$

Yeast (Hefe) Extract

$0,5 \%$

$\mathrm{NaCl}$

$0,05 \%$

$1 \mathrm{M} \mathrm{KCL-Lsg.}$

$0,25 \%$

in A. bidest lösen, $\mathrm{pH}$ auf 7,0 einstellen, autoklavieren

$+1 \mathrm{M} \mathrm{MgCl}_{2}$-Lsg. (steril)

$1 \%$

+1 M Glucose-Lsg. (steril)

$2 \%$

Sabouraud-Agar

Pepton

$2 \%$

Glucose

$4 \%$

in A. bidest lösen, $\mathrm{pH}$ auf 5,6 einstellen

Agar

$2 \%$

autoklavieren, nach abkühlen auf $50^{\circ} \mathrm{C}$

+Gentamicin

$0,00016 \%$

+Chloramphenicol

$0,00016 \%$

Wasseragar (4\%)

Agar

$4 \%$

in A. bidest ansetzen, autoklavieren

\section{YCB-BSA-Agar}

$B S A$

in YCB 2x ansetzen, steril filtrieren

+Wasseragar (4\%)

YCB-Casein-Agar

Casein

in YCB 2x ansetzen, steril filtrieren

+Wasseragar (4\%) 


\section{YCB-Gelatine-Agar}

Gelatine

in YCB 2x ansetzen, steril filtrieren

+Wasseragar (4\%)

\section{YCB-Medium (2x)}

Yeast carbon base (Difco)

in A. bidest ansetzen, steril filtrieren

\section{YNB-BSA-Agar}

BSA

in YNB $2 x$ ansetzen, steril filtrieren

+Wasseragar (4\%)

YNB-Casein-Agar

Casein

in YNB 2x ansetzen, steril filtrieren

+Wasseragar (4\%)

\section{YNB-Gelatine-Agar}

Gelatine

in YNB 2x ansetzen, steril filtrieren

+Wasseragar (4\%)

YNB-Medium (2x)

Yeast nitrogen base (Difco)

in $A$. bidest ansetzen, steril filtrieren

\subsection{Plasmide}

Tabelle 7: Deletions- und kommerziell erworbene Plasmide

\begin{tabular}{|c|c|c|}
\hline Name & Beschreibung/relevante Merkmale & Hersteller \\
\hline pADAM-Adel & $\begin{array}{l}\text { Deletionsplasmid für ADAM-A/ C-\&N- } \\
\text { terminus flankierende Bereiche des Gens, } \\
\text { loxP, Sfil, } \mathrm{hph}^{\mathrm{r}},{ }^{\mathrm{P}} \mathrm{gpdA}, \mathrm{HSV} 1 \mathrm{tk}, \mathrm{trp} C^{\mathrm{t}}, \mathrm{amp}^{\mathrm{r}}\end{array}$ & $\begin{array}{l}\text { eigene } \\
\text { Herstellung }\end{array}$ \\
\hline pADAM-Bdel & $\begin{array}{l}\text { Deletionsplasmid für ADAM-B/ C-\&N- } \\
\text { terminus flankierende Bereiche des Gens, } \\
\text { loxP, Sfil, hph }{ }^{r},{ }^{\mathrm{p}} g p d A, H S V 1 t k, t r p C{ }^{\mathrm{t}}, \mathrm{amp}^{\mathrm{r}}\end{array}$ & $\begin{array}{l}\text { eigene } \\
\text { Herstellung }\end{array}$ \\
\hline pAN7-1 & A.-nidulans-Promotor ${ }^{\mathrm{p}} g p d A$ & Punt (1987) \\
\hline pAspf3-del & $\begin{array}{l}\text { Deletionsplasmid für Aspf3/ C-\&N-terminus } \\
\text { flankierende Bereiche des Gens, loxP, Sfil, }\end{array}$ & $\begin{array}{l}\text { eigene } \\
\text { Herstellung }\end{array}$ \\
\hline
\end{tabular}




\begin{tabular}{|c|c|c|}
\hline & $\mathrm{hph}^{\mathrm{r}},{ }^{\mathrm{p}} \mathrm{gpdA}, \mathrm{HSV} 1 \mathrm{tk}, \mathrm{trpC} C^{\mathrm{t}}, \mathrm{amp}{ }^{\mathrm{r}}$ & \\
\hline $\begin{array}{l}\text { pBlueskript II } \\
\text { SK+ }\end{array}$ & $a m p^{r}$ & Stratagene \\
\hline $\begin{array}{l}\text { pBlueskript II } \\
\text { SK+ Pacl }\end{array}$ & $\begin{array}{l}\text { pBluescript SK+ mit addierter Pacl- } \\
\text { Schnittstelle zu Beginn der MCS }\end{array}$ & Utz Reichard \\
\hline pCR2.1 & Blunt-end-Kit für T- oder A-Überhänge & Invitrogen \\
\hline pQE30 & $\begin{array}{l}\text { Proteinproduktion/ T5-Promotor, ampr }{ }^{r}, \mathrm{His}_{6^{-}} \\
\text {tag }\end{array}$ & Qiagen \\
\hline pSK215 & $\begin{array}{l}\text { cre-Rekombinase beinhaltendes Plasmid - } \\
\text { Markerrescue Deletionsplasmid (=pME2892)/ } \\
\text { ptrA } A^{r},{ }^{\text {niaD }}, \text { cre, niaD }\end{array}$ & Sven Krappmann \\
\hline pSK397 & $\begin{array}{l}\text { Insert für Deletionsplasmide (=pME3002)/ } \\
\text { ampr }^{r} \text {, loxP, Sfil, } h p h^{r},{ }^{\circ} g p d A, H S V 1 t k, \operatorname{trp}^{\mathrm{t}}\end{array}$ & Sven Krappmann \\
\hline
\end{tabular}

Tabelle 8: Plasmide mit cDNA-Insert

\begin{tabular}{|c|c|c|}
\hline $\begin{array}{l}\text { Kaninchen- } \\
\text { Plasmide }\end{array}$ & $\begin{array}{l}\text { cDNA enthaltende Plasmide nach Umklonierung } \\
\text { aus } \lambda \text {-Phagen }\end{array}$ & Hersteller \\
\hline $\mathrm{p} 2 \mathrm{a} / 8$ & cDNA zu M protein repeat protein & $\begin{array}{l}\text { Nicole } \\
\text { Denikus }\end{array}$ \\
\hline $\mathrm{p} 2 \mathrm{a} / 55$ & $\begin{array}{l}\text { cDNA zu cytoskeleton assembly control protein Sla2, } \\
\text { putative }\end{array}$ & $\begin{array}{l}\text { Nicole } \\
\text { Denikus }\end{array}$ \\
\hline $\mathrm{p} 2 \mathrm{~b} / 15$ & cDNA zu Acyl CoA binding protein family & $\begin{array}{l}\text { Nicole } \\
\text { Denikus }\end{array}$ \\
\hline $\mathrm{p} 2 \mathrm{~b} / 43$ & cDNA zu pyruvate decarboxylase PdcA, putative & $\begin{array}{l}\text { Nicole } \\
\text { Denikus }\end{array}$ \\
\hline $\mathrm{p} 3 \mathrm{a} / 17$ & $\begin{array}{l}\text { cDNA zu conserved hypothetical protein } \\
\text { AFUA_6G07410 }\end{array}$ & $\begin{array}{l}\text { Nicole } \\
\text { Denikus }\end{array}$ \\
\hline $\mathrm{p} 3 \mathrm{a} / 8$ & $\begin{array}{l}\text { cDNA zu conserved hypothetical protein } \\
\text { AFUA_1G02290 }\end{array}$ & $\begin{array}{l}\text { Nicole } \\
\text { Denikus }\end{array}$ \\
\hline $\mathrm{p} 3 \mathrm{a} / 6$ & cDNA zu class II aldolase/adducin domain protein & $\begin{array}{l}\text { Nicole } \\
\text { Denikus }\end{array}$ \\
\hline $\mathrm{p} 3 \mathrm{~b} / 3$ & cDNA zu Coatomer subunit delta, putative & $\begin{array}{l}\text { Nicole } \\
\text { Denikus }\end{array}$ \\
\hline $\mathrm{p} 4 \mathrm{a} / 6$ & cDNA zu involucrin repeat protein & $\begin{array}{l}\text { Nicole } \\
\text { Denikus }\end{array}$ \\
\hline $\mathrm{p} 4 \mathrm{a} / 9$ & cDNA zu Hsp70 chaperone Hsp88 & $\begin{array}{l}\text { Nicole } \\
\text { Denikus }\end{array}$ \\
\hline $\mathrm{p} 4 \mathrm{a} / 13$ & cDNA zu heat shock protein Hsp30/Hsp42, putative & $\begin{array}{l}\text { Nicole } \\
\text { Denikus }\end{array}$ \\
\hline $\mathrm{p} 5 / 1$ & cDNA zu aryl-alcohol dehydrogenase, putative & $\begin{array}{l}\text { Nicole } \\
\text { Denikus }\end{array}$ \\
\hline $\mathrm{p} 5 / 17$ & cDNA zu spherulin 4-like cell surface protein, putative & $\begin{array}{l}\text { Nicole } \\
\text { Denikus }\end{array}$ \\
\hline
\end{tabular}




\begin{tabular}{|l|l|l|}
\hline$p 6 / 11$ & cDNA zu phosphoglucomutase PgmA & $\begin{array}{l}\text { Nicole } \\
\text { Denikus }\end{array}$ \\
\hline$p 6 / 14$ & cDNA zu transketolase TktA & $\begin{array}{l}\text { Nicole } \\
\text { Denikus }\end{array}$ \\
\hline$p 6 / 20$ & cDNA zu Aminopeptidase & $\begin{array}{l}\text { Nicole } \\
\text { Denikus }\end{array}$ \\
\hline
\end{tabular}

Tabelle 9: Hergestellte Expressionsplasmide

\begin{tabular}{|c|c|c|}
\hline $\begin{array}{l}\text { Expressions } \\
\text {-plasmide }\end{array}$ & $\begin{array}{l}\text { Proteinexpressionsplasmide für (aus pQE30 } \\
\text { erstellt): }\end{array}$ & Hersteller \\
\hline pAAD & aryl-alcohol dehydrogenase (AS 211-510) & $\begin{array}{l}\text { eigene } \\
\text { Herstellung }\end{array}$ \\
\hline pAAT & aspartate aminotransferase (AS 69-261) & $\begin{array}{l}\text { eigene } \\
\text { Herstellung }\end{array}$ \\
\hline $\mathrm{pADH}$ & alcohol dehydrogenase (AS 29-200) & $\begin{array}{l}\text { eigene } \\
\text { Herstellung }\end{array}$ \\
\hline pADMA & $\begin{array}{l}\text { ADAM family of metalloprotease ADM-A } \\
\text { (AS 116-435) }\end{array}$ & $\begin{array}{l}\text { eigene } \\
\text { Herstellung }\end{array}$ \\
\hline pADMB & $\begin{array}{l}\text { ADAM family of metalloprotease ADM-B (AS 26- } \\
217 \text { ) }\end{array}$ & $\begin{array}{l}\text { eigene } \\
\text { Herstellung }\end{array}$ \\
\hline $\mathrm{pADMB3/4}$ & $\begin{array}{l}\text { ADAM family of metalloprotease ADM-B } \\
\text { (AS 236-455) }\end{array}$ & $\begin{array}{l}\text { eigene } \\
\text { Herstellung }\end{array}$ \\
\hline pAIAd & $\begin{array}{l}\text { classll Aldolase/Adducin domain protein (AS 8- } \\
294 \text { ) }\end{array}$ & $\begin{array}{l}\text { eigene } \\
\text { Herstellung }\end{array}$ \\
\hline pAP & Aminopeptidase (AS 285-609) & $\begin{array}{l}\text { eigene } \\
\text { Herstellung }\end{array}$ \\
\hline $\mathrm{pAP} 5 / 6$ & Aminopeptidase (AS 661-849) & $\begin{array}{l}\text { eigene } \\
\text { Herstellung }\end{array}$ \\
\hline pBGT & 1,3-beta glucanosyltransferase Gel1 (AS 25-188) & $\begin{array}{l}\text { eigene } \\
\text { Herstellung }\end{array}$ \\
\hline pBGT3/4 & $\begin{array}{l}\text { 1,3-beta glucanosyltransferase Gel1 (AS 219- } \\
\text { 398) }\end{array}$ & $\begin{array}{l}\text { eigene } \\
\text { Herstellung }\end{array}$ \\
\hline $\mathrm{pCOA}$ & Coatomer subunit delta (AS 86-406) & $\begin{array}{l}\text { eigene } \\
\text { Herstellung }\end{array}$ \\
\hline $\mathrm{pDI}$ & protein disulfid isomerase Pdi1 (AS 26-220) & $\begin{array}{l}\text { eigene } \\
\text { Herstellung }\end{array}$ \\
\hline $\mathrm{pDI} / 4$ & protein disulfid isomerase Pdi1 (AS 255-424) & $\begin{array}{l}\text { eigene } \\
\text { Herstellung }\end{array}$ \\
\hline pFBA & $\begin{array}{l}\text { fructose bisphosphate aldolase, classIl (AS 251- } \\
420)\end{array}$ & $\begin{array}{l}\text { eigene } \\
\text { Herstellung }\end{array}$ \\
\hline pGAPD & $\begin{array}{l}\text { Glyceraldehyd 3-phosphat dehydrogenase (AS } \\
63-240)\end{array}$ & $\begin{array}{l}\text { eigene } \\
\text { Herstellung }\end{array}$ \\
\hline pHP10 & conserved hypothetical protein AFUA_6G07410 & eigene \\
\hline
\end{tabular}




\begin{tabular}{|l|l|l|}
\hline & (AS 578-742) & Herstellung \\
\hline pHP70 & $\begin{array}{l}\text { conserved hypothetical protein AFUA_1G13670 } \\
\text { (AS 61-244) }\end{array}$ & $\begin{array}{l}\text { eigene } \\
\text { Herstellung }\end{array}$ \\
\hline pHP90 & $\begin{array}{l}\text { conserved hypothetical protein AFUA_1g02290 } \\
\text { (AS 2-95) }\end{array}$ & $\begin{array}{l}\text { eigene } \\
\text { Herstellung }\end{array}$ \\
\hline pHsp30 & heat shock protein Hsp30/Hsp42 (AS 4-519) & $\begin{array}{l}\text { eigene } \\
\text { Herstellung }\end{array}$ \\
\hline pHsp70 & Hsp70 chaperone Hsp88 (AS 212-533) & $\begin{array}{l}\text { eigene } \\
\text { Herstellung }\end{array}$ \\
\hline plnv03/4 & involucrin repeat protein (AS 650-887) & $\begin{array}{l}\text { eigene } \\
\text { Herstellung }\end{array}$ \\
\hline pMIPS & myo-inositol-phosphate synthase (AS 4-210) & $\begin{array}{l}\text { eigene } \\
\text { Herstellung }\end{array}$ \\
\hline pMpro5/6 & M protein repeat protein (AS 818-1137) & $\begin{array}{l}\text { eigene } \\
\text { Herstellung }\end{array}$ \\
\hline pNDGD & $\begin{array}{l}\text { NAD+ dependent glutamate dehydrogenase } \\
\text { (AS 413-699) }\end{array}$ & $\begin{array}{l}\text { eigene } \\
\text { Herstellung }\end{array}$ \\
\hline pPD & pyruvate decarboxylase PdcA (AS 99-378) & $\begin{array}{l}\text { eigene } \\
\text { Herstellung }\end{array}$ \\
\hline pPG & phosphoglucomutase PgmA (AS 49-369) & $\begin{array}{l}\text { eigene } \\
\text { Herstellung }\end{array}$ \\
\hline pPG3/4 & phosphoglucomutase PgmA (AS 385-548) & $\begin{array}{l}\text { eigene } \\
\text { Herstellung }\end{array}$ \\
\hline pPGM & $\begin{array}{l}\text { phosphoglycerate mutase, 2,3- } \\
\text { bisphosphoglycerate-independent (AS 22-248) }\end{array}$ & $\begin{array}{l}\text { eigene } \\
\text { Herstellung }\end{array}$ \\
\hline pPK & $\begin{array}{l}\text { 6-phosphofructokinase alpha subunit (AS 254- } \\
\text { 399) }\end{array}$ & $\begin{array}{l}\text { eigene } \\
\text { Herstellung }\end{array}$ \\
\hline pPK3/4 & 6-phosphofructokinase alpha subunit (AS 8-185) & $\begin{array}{l}\text { eigene } \\
\text { Herstellung }\end{array}$ \\
\hline pSHMT & serine hydroxymethyltransferase (AS 248-439) & $\begin{array}{l}\text { eigene } \\
\text { Herstellung }\end{array}$ \\
\hline pSla & $\begin{array}{l}\text { cytoskeleton assembly control protein Sla2 } \\
\text { (AS 427-742) }\end{array}$ & $\begin{array}{l}\text { eigene } \\
\text { Herstellung }\end{array}$ \\
\hline pTKK & spherulin 4-like cell surface protein (AS 148-280) & $\begin{array}{l}\text { eigene } \\
\text { Herstellung }\end{array}$ \\
\hline
\end{tabular}




\subsection{Primer}

Tabelle 10: Verwendete Oligonukleotide

\begin{tabular}{|c|c|}
\hline Name & Sequenz (5’-3') \\
\hline \multicolumn{2}{|c|}{ im Rahmen rekombinanter Proteinexpression } \\
\hline AAD_1 & AAATTTGAGCTCGGGTATGCAGCGGCCTACTAC \\
\hline AAD_2 & TATTATGGTACCCTAGCCGTTCCTTGAGAAGAGAC \\
\hline AAT_1 & AAATTTGGATCCGACAAGGGCAAGCCATATGTTC \\
\hline AAT_2 & TATTATAAGCTTCTATCTAGGGGCAAAAGCATCAC \\
\hline ADH_1 & AAATTTGGATCCCCCGGTCCTGATGACATTCTTG \\
\hline ADH_2 & TATTATAAGCTTCTACGCTACGACTCGCAATCCCATC \\
\hline ADMA_1 & AAATTTGCATGCCATGGTGTTGACGCCTACTCAC \\
\hline ADMA_2 & TATTATGGTACCCTAAAGATCTCCTGCCGAGCAGTC \\
\hline ADMB_1 & AAATTTGGTACCTCGCAAGAACCTAGTGCCATCC \\
\hline ADMB_2 & TATTATAAGCTTCTACTGCGGGTCACTGTTGAAG \\
\hline ADMB_3 & AAATTTGGTACCGGTTCCATGTCGCTGAACTCC \\
\hline ADMB_4 & TATTATAAGCTTCTATTGAGAGGACGCCTCCAAATTC \\
\hline AlAd_1 & AAATTTGGATCCGAATCTGCGAAGCAGACACTTG \\
\hline AlAd_2 & TATTATAAGCTTCTAATTGGTCTCCTCCACAATCAAC \\
\hline AP_3 & AAATTTGCATGCTTCATCGTCGGTCATCTGAAG \\
\hline AP_4 & TATTATCCCGGGCTAGTAAAAGTCAAGGTCGGGAACC \\
\hline AP_5 & AAATTTGCATGCCAGAGCACTTCTGGTCTGCTGTC \\
\hline AP_6 & TATTATCCCGGGCTAGAGTCCTCCGAGAGGCATGTAG \\
\hline BGT_1 & AAATTTGGATCCGCTCGTGACGACGTTACTCC \\
\hline BGT_2 & TATTATAAGCTTCTAGCGGCTACGGATGTACTGAC \\
\hline BGT_3 & AAATTTGGATCCGACGAGCGCAGTGACTTCTTC \\
\hline BGT_4 & TATTATAAGCTTCTACTCAGCAGTGGCAGTGGAC \\
\hline COA_1 & AAATTTGGATCCGGCAAAGCAGTGCTCTCACGTC \\
\hline COA_2 & TATTATGTCGACCTAGAATTGTGCGCCATGTGTAG \\
\hline DI_1 & AAATTTGGTACCACCACTTCCGATGTCGTCTC \\
\hline DI_2 & TATTATAAGCTTCTAGATCGCTCCATCGTAGACAGC \\
\hline DI_3 & AAATTTGGTACCCTGGCATACATCTTCGCTGAG \\
\hline Dl_4 & TATTATAAGCTTCTAAGCATCAATCTTGGCAATGGTG \\
\hline FBA_1 & AAATTTGGATCCGTCAACAACGAGGACGTTGAC \\
\hline FBA_2 & TATTATAAGCTTCTAGTTGAAGTCCTCCAGAGCAACC \\
\hline GAPD_1 & AAATTTGCATGCTACGACCAGGGTCTGATTGTC \\
\hline GAPD_2 & TATTATAAGCTTCTAGACGTTGGAGGTAGGAACACG \\
\hline HP10_1 & AAATTTGGATCCGGGGCAGTGGAGACAAATCAG \\
\hline HP10_2 & TATTATGGTACCCTAAAGCCGCCTTCTATTCTTACCC \\
\hline HP70_1 & AAATTTGGTACCGACGTTTGTCCCAAAAAGGTG \\
\hline HP70_2 & TATTATGTCGACCTAAGGGTTTGAGGCCTTTTTCTC \\
\hline HP90_1 & AAATTTGGATCCAGCTTCCACCTCACCGCTGA \\
\hline HP90_2 & TATTATAAGCTTCTAACGCTCAGACAGATTCACGTC \\
\hline
\end{tabular}




\begin{tabular}{|l|l|}
\hline Hsp30_1 & AAATTTGGATCCTTCCACACCTTCCACACTCC \\
\hline Hsp30_2 & TATTATAAGCTTCTACCCAGTGTTGACGACCTTC \\
\hline Hsp70_3 & AAATTTGGATCCGTCGAGTTCAGAAAGGGTGAGC \\
\hline Hsp70_4 & TATTATCTGCAGCTAGACCTGCTTCTTGACCTTGC \\
\hline inv_3 & AAATTTGGATCCCTGCAAGACGCTATGGAAAAGC \\
\hline invo_4 & TATTATGGTACCCTATGCGCCTTCGTTCTTCTTGTTC \\
\hline MIPS_1 & AAATTTGGATCCCATGCTACCTCGGATGCTG \\
\hline MIPS_2 & TATTATAAGCTTCTACTGATTGGCAGCAATGAAGTC \\
\hline Mpro_5 & AAATTTGGATCCGCAAAGCTAGAGGCGGAACTG \\
\hline Mpro_6 & TATTATGGTACCCTAGGCTGTCGGACCACTCTCTTC \\
\hline NDGD_1 & AAATTTGCATGCCAGCAGTTCTTGAACCGTCTCG \\
\hline NDGD_2 & TATTATCTGCAGCTAGACCAACTCAGCCGTGTTCTC \\
\hline PD_1 & AAATTTGCATGCTCCGAGTTCGTACCCATTGTCC \\
\hline PD_2 & TATTATGGTACCCTAGAACCATCTGTGCGTGATTG \\
\hline PG_1 & AAATTTGGATCCGCTGAGGGAGCTTTCCTTGTC \\
\hline PG_2 & TATTATGGTACCCTAGAAACTCTCCTCACCGCAGATG \\
\hline PG_3 & AAATTTGGATCCATTGTCGCCTGGCTGAAC \\
\hline PG_4 & TATTATGGTACCCTACCGGCCGATGTACTCCTTGAAC \\
\hline PGM_1 & AAATTTGGATCCGACTCTCCCAAAGACGGAGATG \\
\hline PGM_2 & TATTATAAGCTTCTAAACAATGATGGGCTTGAGGAAC \\
\hline PGM_3 & AAATTTGGATCCACCCTCTTCTTCTTCAACTACCG \\
\hline PGM_4 & TATTATAAGCTTCTAGATTTCACCAATGGCCTTGTC \\
\hline PK_1 & AAATTTGGATCCAAGCGTCGCACTATTGTTATCG \\
\hline PK_2 & TATTATAAGCTTCTATTGAGGGAGGATCATCTTGG \\
\hline PK_3 & AAATTTGGATCCGTCGAGCCACCCAAGAGAC \\
\hline PK_4 & TATTATAAGCTTCTAATCGCAAATTCGTGTCAGAGAG \\
\hline SHMT_1 & AAATTTGGATCCCACAAGTCTCTCCGTGGTCCTC \\
\hline SHMT_2 & TATTATAAGCTTCTACTTGAGCTTATTGGCCTCCTTG \\
\hline Sla_3 & AAATTTGGATCCTTGCAGGAGCAAGTCAACAC \\
\hline Sla_4 & TATTATGAGCTCCTACGCATTGAGCAACTGATCTGC \\
\hline SP_3 & AAATTTGGATCCGGGATCTTTTTCGACGAGGTG \\
\hline SP_4 & TATTATAAGCTTCTAGGGCAACTGTGGGTCGAAACTC \\
\hline TBP_1 & AAATTTGGATCCATGACTGCCGACGACTACACTG \\
\hline TBP_2 & TATTATAAGCTTCTAAGCAGAAGCAGACACGTGAAGG \\
\hline TK_1 & AAATTTGAGCTCGGTGATGGCTGTGCTATGGAG \\
\hline TK_2 & TATTATCTGCAGCTAATTCTTCCAGCGAGTGTTGTTG \\
\hline Kontrollprimer der Deletionsmutanten \\
\hline Adel1 & ACGGTGGAATTTACCGATGA \\
\hline Adel2 & TTCATACACCGGGCAAAGAT \\
\hline Adel3 & TCGTTTACCCAGAATGCACA \\
\hline Adel4 & GTGGCGTTTAGGAGATCCAG \\
\hline Af3- & ATGGAAGCCAGCCCTCATAC \\
screen1 & \\
\hline & \\
\hline
\end{tabular}




\begin{tabular}{|l|l|}
\hline $\begin{array}{l}\text { Af3- } \\
\text { screen2 }\end{array}$ & AGGTGATATCGGCCTGAGTG \\
\hline $\begin{array}{l}\text { Af3- } \\
\text { screen3 }\end{array}$ & CTCCGTAACACCCAATACGC \\
\hline $\begin{array}{l}\text { Af3- } \\
\text { screen4 }\end{array}$ & GGAGGTGAGAAACGAGTTGG \\
\hline Bdel1 & CCGAGGTGGTATATGCTTCG \\
\hline Bdel2 & TTCATACACCGGGCAAAGAT \\
\hline Bdel3 & TGCACAGGTACACTTGTTTAGAGG \\
\hline Bdel4 & TAACCGGATCCAACAAGGTC \\
\hline pADAMA1 & AGACGCAACTTGGAATCAGG \\
\hline pADAMA2 & ATGCATTGTCATCGTTGAGG \\
\hline pADAMB1 & CCAACGACATGAACACAAGG \\
\hline pADAMB2 & CTGTTTGGTCTTGGGACACC \\
\hline pAspf3-1 & CCGATTTATCGGGTTCTGAC \\
\hline pAspf3-2 & CAAGATTACCTACGCCGCTC \\
\hline Primer zur Erstellung von Deletionsplasmiden \\
\hline AA1 & ATAGCACGCACCAAAAATCC \\
\hline AA2 & ATATCATGGTTCGGCTCCAG \\
\hline AA3 & TATATGCGGCCGCAAACTGACGGCTTAACCACACT \\
\hline AA4 & ATATTACCCGGGGGCCTGAGTGGCCATTCTCGAGTCGGGTTTCACTA \\
\hline AA5 & AGGAGATGTGTACCGGCAAT \\
\hline AA6 & AACTACACCTTGGCCCAGAA \\
\hline AA7 & TATATTAGGCATCTAGGCCCATCGATCACTCATTATTGGTCTC \\
\hline AA8 & ATCGTTAATTAAATGAAGCTCTTGGATTTGATTAGG \\
\hline AB1 & TCCAGCGTGAACCATACAAA \\
\hline AB2 & CCTTGTGTTCATGTCGTTGG \\
\hline AB3 & TATATGCGGCCGCCATCGGTTCTAACTCAATGTGG \\
\hline AB4 & TATTATCTAGAGGCCTGAGTGGCCACGTCGAAATCTGTAAGGTGGT \\
\hline AB5 & TGGGTCGAACAACACAAGAA \\
\hline AB6 & TACCAGATACAGCCCGGTTC \\
\hline AB7 & TATTAGAATTCGGCCATCTAGGCCGGCTTACTTGTGCTCTCCATTC \\
\hline AB8 & TATCGTTAATTAAGCCACTGTAATGTAATGCCTCA \\
\hline Aspf3-1 & CAGCCCTCATACCCCATAAC \\
\hline Aspf3-2 & AGAAGATGAGGCGGGTGAG \\
\hline Aspf3-3 & TATATGCGGCCGCCGGGCCTCTAGCAAATAAACTT \\
\hline Aspf3-4 & ATATTACCCGGGGGCCTGAGTGGCCGCGGTCAATATATACACCATCTG \\
\hline Aspf3-5 & CATCAACTACAACGCCTCCA \\
\hline Aspf3-6 & GGAGGTGAGAAACGAGTTGG \\
\hline Aspf3-7 & ATATTAAAGCTTGGCCATCTAGGCCCCTTCACTCCCGTCTGCTCT \\
\hline Aspf3-8 & TATCGTTAATTAATGCCGAACAGACGGATTATT \\
\hline Kontrollprimer der ADAM-A-Mutante nach Marker Rescue (loxP-Rekombination) \\
\hline ADAMA- & TATGGGGATGAGGTTTATCG \\
\hline & \\
\hline
\end{tabular}




\begin{tabular}{|l|l|}
\hline Lox1 & \\
\hline $\begin{array}{l}\text { ADAMA- } \\
\text { Lox2 }\end{array}$ & TAGCTGTGCTCGTTGATTGC \\
\hline Primer zum Bau einer Digoxigenin-markierten DNA-Sonde \\
\hline Phle1 & TGCTTTGCCCGGTGTATGAAACC \\
\hline Phle2 & AAGGGATGGGAAGGATGGAGTATGG \\
\hline Phle3 & TCTGTAGGGCGTCCAAATATCGTGC \\
\hline Phle4 & CATGGTGATGTCTGCTCAAGCGG \\
\hline
\end{tabular}

\subsection{Verwendete Organismen/Stämme}

Tabelle 11: Verwendete Organismen und cDNA-Bank

\begin{tabular}{|l|r|}
\hline Aspergillus fumigatus \\
\hline D141 & Wildstamm/klinisches Isolat \\
\hline Pichia pastoris & Michel Monod \\
\hline Kultur-Nr. 49 & Michel Monod \\
\hline Kultur-Nr. 113 & Michel Monod \\
\hline Kultur-Nr. 122 & Michel Monod \\
\hline Kultur-Nr. (28 bzw.) 128 & Michel Monod \\
\hline Kultur-Nr. 326 & Michel Monod \\
\hline Kultur-Nr. 443 & Michel Monod \\
\hline Kultur-Nr. 445 & \\
\hline Kultur-Nr. 461 & Merck KGaA, Darmstadt \\
\hline E. coli & Qiagen GmbH, Hilden \\
\hline Top10 & Stratagene, La Jolla, USA \\
\hline Rosetta TM 2(DE3) & Stratagene, La Jolla, USA \\
\hline M15 pREP4 & Eigene Herstellung \\
\hline BL21-CodonPlus RIL & \\
\hline XL1 Blue MRF' & Invitrogen GmbH, Karlsruhe \\
\hline DH5a & \\
\hline E. coli mit Expressionsplasmiden & \\
\hline A.-fumigatus-cDNA-Expressionsbank & \\
\hline Premade Aspergillus Uni Zap XR & Stratagene, La Jolla, USA \\
Express Bank & \\
\hline Versuchstiere & Harlan Laboratories GmbH, \\
\hline HsdWin:NMRI (Auszucht Mäuse) & Eystrup \\
\hline
\end{tabular}

\subsection{Antibiotika}

Tabelle 12: Verwendete Antibiotika

\begin{tabular}{|l|l|l|}
\hline Name & Stammlösung & Endkonzentration \\
\hline Ampicillin & $100 \mathrm{mg} / \mathrm{ml}$ & $80 \mu \mathrm{g} / \mathrm{ml}$ \\
\hline
\end{tabular}




\begin{tabular}{|l|l|l|}
\hline Chloramphenicol & $10 \mathrm{mg} / \mathrm{ml}$ & $20 \mu \mathrm{g} / \mathrm{ml}$ \\
\hline Ciprofloxacin & - & $250 \mathrm{ng} / \mathrm{ml}$ \\
\hline Gentamicin & - & $16 \mathrm{ng} / \mathrm{ml}$ \\
\hline Hygromycin B & $50 \mathrm{mg} / \mathrm{ml}$ & $200 \mu \mathrm{g} / \mathrm{ml}$ \\
\hline Kanamycin & $10 \mathrm{mg} / \mathrm{ml}$ & $50 \mu \mathrm{gl} /$ \\
\hline Pyrithiamin & $100 \mu \mathrm{ml} / \mathrm{ml}$ & $100 \mathrm{ng} / \mathrm{ml}$ \\
\hline
\end{tabular}

Die verwendeten Antibiotika wurden gelöst und steril filtriert; anschließend bei $-20^{\circ} \mathrm{C}$ gelagert. Die Antibiotika wurden erst nach Autoklavieren und Abkühlen der Medien auf $55^{\circ} \mathrm{C}$ zugegeben.

\subsection{Molekularbiologische Methoden}

\subsubsection{Isolierung von Plasmiden aus E. coli (alkalische Lyse)}

Es wurde das Kit Qiaprep Spin Miniprep (Qiagen) verwendet; Durchführung laut Anweisungen des Herstellers. In Kürze:

- 4 bis $10 \mathrm{ml}$ E.-coli-ÜN-Kultur ( $10 \mathrm{ml}$ wenn es sich um low-copy Plasmide handelte) zentrifugieren ( 3500 x $g$ für $5 \mathrm{Min}$ )

- Pellet in Puffer P1 (inkl. RNAse A) aufnehmen

- Zufügen von Puffer P2, mischen durch invertieren, Inkubation bei RT für max. 5 Min (alkalische Lyse)

- Neutralisation durch Zufügen von Puffer N3, mischen durch invertieren, Zentrifugation für $10 \mathrm{Min}$ bei RT und $\sim 16000 \times g$ in Tischzentrifuge (Eppendorf)

- Überstand auf Säulchen geben und 30 - 60 s zentrifugieren wie oben

- Waschung mit $500 \mu \mathrm{l}$ PB-Puffer, dann Waschung mit $750 \mu \mathrm{l}$ PE-Puffer und anschließendes trocken zentrifugieren wie oben

- Elution mit 40 - $50 \mu$ l EB-Puffer und Zentrifugation wie oben

Die Konzentration der Plasmidlösung wurde photometrisch bestimmt.

\subsubsection{DNA-Extraktion aus A.-fumigatus-Konidien}

Es wurden mit kleiner Impföse einige Konidien eines gewachsenen Klons in $100 \mu \mathrm{l}$ $0,9 \% \mathrm{NaCl}+0,1 \%$ Tween80 überführt. Nach gründlichem Vortexen wurde $5 \mathrm{Min}$ bei $16000 \times g$ und RT zentrifugiert. Der Überstand wurde verworfen. Die geschlossenen Tubes wurden 2x mit je $250 \mathrm{ml}$ Wasser (in Schottflasche ohne Deckel) in einer Mikrowelle bei $750 \mathrm{~W}$ für 2,5 Min inkubiert. Die Tubes wurden danach gründlich gevortext, mit $30 \mu$ l EB-Puffer versetzt und erneut gevortext. Nach erneutem Zentrifugieren (s.o.) wurden etwa $20 \mu \mathrm{l} \mathrm{Überstand} \mathrm{abgenommen} \mathrm{und} 2 \mu \mathrm{l}$ in einer PCR kontrolliert. 


\subsubsection{DNA-Extraktion aus $\lambda$-Phagen}

Um an die in $\lambda$-Phagen verpackte cDNA zu gelangen wurde das Lambda Mini Kit (Qiagen) nach Anweisungen des Herstellers verwendet. Das Vorgehen war in Kürze:

- $30 \mu \mathrm{l}$ Puffer L1 mit $10 \mathrm{ml}$ Phagensuspension mischen und bei $37^{\circ} \mathrm{C} 30 \mathrm{Min}$ inkubieren

- 2 ml eisgekühlten Puffer L2 zufügen, vorsichtig mischen und 60 Min auf Eis inkubieren

- 10 Min bei $15000 \times g$ zentrifugieren und Überstand verwerfen

- Pellet in $1 \mathrm{ml}$ Puffer L3 resuspendieren und mit $1 \mathrm{ml}$ Puffer L4 mischen und bei $70^{\circ} \mathrm{C} 10$ Min inkubieren

- $1 \mathrm{ml}$ Puffer L5 zufügen und sofort vorsichtig durch invertieren mischen

- bei $4^{\circ} \mathrm{C}$ für $30 \mathrm{Min}$ bei min. $15000 \times g$ zentrifugieren

- Überstand in neues Tube überführen und den letzten Zentrifugationsschritt wiederholen

- Säule mit $1 \mathrm{ml}$ Puffer QBT äquilibrieren und den Überstand durchlaufen lassen

- Waschung mit $2 \mathrm{ml}$ Puffer QC

- Elution der DNA mit 1,5 ml Puffer QF

- Waschung mit Isopropanol gefolgt von Zentrifugation für 30 Min bei $4^{\circ} \mathrm{C}$ und min. $15000 \times$ g. Zweite Waschung mit eiskaltem $70 \%$ Ethanol mit anschließender Zentrifugation für $10 \mathrm{Min}$ bei RT und $15000 \times g$

- Pellet lufttrocknen (5 - $10 \mathrm{Min}$ ) und in $30 \mu \mathrm{l} \mathrm{TE-Puffer} \mathrm{resuspendieren}$

\subsubsection{DNA-Extraktion aus Agarosegelen}

Die Exzision und Extraktion von DNA-Fragmenten aus Agarosegelen erfolgte unter Verwendung des Gel Extraction Kits "QIAEX II“ (Qiagen) nach den Angaben des Herstellers. Dies war in Kürze:

- Gelfragment ausschneiden und wiegen und mit 3 Vol. (w/v) Puffer QX1 versetzen

- 10 - $30 \mu \mathrm{l}$ Qiaex II-Suspension zufügen und $10 \mathrm{Min}$ bei $50^{\circ} \mathrm{C}$ unter regelmäßigem Mischen inkubieren

- zentrifugieren und Überstand verwerfen

- Pellet mehrfach waschen mit Puffern: QX1, PE, PE

- luftgetrocknetes Pellet mit $15 \mu$ EB-Puffer resuspendieren und 5 - 10 Min bei $\mathrm{RT}$ oder $50^{\circ} \mathrm{C}$ (abhängig von der extrahierten Fragment-Größe) inkubieren

- zentrifugieren und Überstand in neues Tube überführen

Die angegebenen Zentrifugationsschritte wurden in einer Eppendorf-Tischzentrifuge bei max. Umdrehung $(\sim 16000 \times$ g) für $30-60$ s durchgeführt. Die Puffer stammten aus dem angegebenen Kit.

\subsubsection{Agarose-Gelelektrophorese}

Die in der Elektrophorese verwendeten Puffer sind im Abschnitt Lösungen aufgeführt. Es wurden $1 \%$ Agarosegele (in 0,5 $\times$ TBE $+5 \times 10^{-5} \%$ Ethidiumbromid)) verwendet. In einer horizontalen Elektrophorese wurden DNA-Fragmente ihrer molekularen Größe nach aufgetrennt und gegen einen definierten Standard (ladder) der zu erwartenden 
Fragmentgröße entsprechend kontrolliert.

Für präparative Gele und/oder Southern Blots wurden 0,7\% Gele verwendet.

Die Proben wurden mit 1/6 Vol. 6 x Ladepuffer (Fermentas) und ggf. A. bidest gemischt zu einem Gesamtvolumen von $6 \mu$ l. Die Auftrennung der Fragmente erfolgte in einer Puffer (0,5 x TBE) gefluteten Elektrophoresekammer der Firma Biometra (Horizon 58) bei durchschnittlich 5-6 V/cm Elektrodenabstand. Der Nachweis erfolgte unter UV-Durchlicht in einem Transilluminator der Firma Biometra (BioDocll).

\subsubsection{Amplifikation einer cDNA-Bank}

Zur unspezifischen Vervielfältigung der vorhandenen cDNA-Expressionsbank (Premade Aspergillus Uni Zap XR Express Bank) wurde der E. coli-Stamm XL1-Blue MRF' auf LB-Agar angezogen. Eine Kolonie dieses Stamms wurde in LB-Maltose$\mathrm{MgSO}_{4}$-Medium für $4-6 \mathrm{~h}$ bei $37^{\circ} \mathrm{C}$ angezogen, wobei die $\mathrm{OD}_{600}$ unter 1,0 gehalten werden musste. Die cDNA enthaltende Phagensuspension wurde auf eine geeignete Konzentration $\left(5 \times 10^{6} \mathrm{cfu} / \mathrm{ml}\right)$ verdünnt. Zusammen mit den zentrifugierten $(500 \times \mathrm{g}$, RT für $10 \mathrm{Min}$ ) und mit $10 \mathrm{mM} \mathrm{MgSO}_{4}$ entsprechend verdünnten Bakterienzellen, um eine $\mathrm{OD}_{600}$ von $0,5 \mathrm{zu}$ erreichen, wurden diese mit der Phagensuspension gemischt (10 $\mu$ l Suspension $+600 \mu \mathrm{l}$ Bakterien) und unter leichtem Schütteln bei $37^{\circ} \mathrm{C}$ für $15 \mathrm{Min}$ inkubiert. Nach hinzufügen und mischen von 6,5 ml vorgewärmter NZY-TopAgarose wurde die Mixtur auf eine große vorgewärmte NZY-Agarose-Platte aufgetragen und verteilt. Nach Erstarren der Top-Agarose-Schicht wurde $6-8 \mathrm{~h}$ bei $37^{\circ} \mathrm{C}$ inkubiert bis deutliche Plaques erkennbar waren. Diese wurden mit $8-10 \mathrm{ml}$ SM-Puffer überschichtet und ÜN bei $4^{\circ} \mathrm{C}$ unter leichtem Schwenken inkubiert. Der Puffer wurde entfernt, aliquotiert ( $\sim 35 \mathrm{ml})$ und mit $5 \%(\mathrm{v} / \mathrm{v})$ Chloroform versetzt. Nach mischen und 15 Min Inkubation bei RT wurde 10 Min bei $500 \times g$ und RT zentrifugiert. Die Überstande wurden abgenommen und erneut mit 0,3\% (v/v) Chloroform sowie $7 \%$ DMSO versetzt und bei $-80^{\circ} \mathrm{C}$ als 50 oder $500 \mu \mathrm{l}$ Aliquot gelagert.

\subsubsection{DNA-Aufreinigung (PCR Purification Kit (Qiagen))}

Die Aufreinigung mittels Purification Kit wurde entsprechend der Anleitung des Herstellers durchgeführt. In Kürze:

- DNA + 5 Vol. PB-Puffer

- Probe in Säulchen überführen und zentrifugieren

- Säulchen mit Puffer PE spülen, zentrifugieren

- erneut (trocken) zentrifugieren

- Säulchen in neues Tube einsetzen und mit $40 \mu \mathrm{l}$ EB-Puffer eluieren durch Zentrifugation

Die angegebenen Zentrifugationsschritte wurden in einer Eppendorf-Tischzentrifuge bei max. Umdrehung $(\sim 16000 \times$ g) für $30-60$ s durchgeführt. Die Puffer stammten aus dem angegebenen Kit. 
Neben der Entfernung diverser Puffer und Salze wurden mit diesem Kit auch (Oligo-) Nukleotide von bis zu 40 bp Länge und Enzyme entfernt.

\subsubsection{DNA-Konzentrationsbestimmung über photometrische Messung}

Die Konzentrationsbestimmung von sehr reiner DNA erfolgte unter Verwendung einer geeigneten Probenverdünnung in einer Quarzküvette bei einer Wellenlänge von 260nm (während RNA Absorption bei $280 \mathrm{~nm}$ Wellenlänge aufweist) in einem Photometer der Firma Pharmacia Biotech (Ultrospec 1000).

Die Berechnung der Konzentration doppelsträngiger DNA erfolgte nach der Formel

$$
\mathrm{c}(\mu \mathrm{g} / \mathrm{ml})=\mathrm{OD} 260 \times \mathrm{F} \times 50
$$

$\mathrm{F}=$ Verdünnungsfaktor

Reine DNA zeigte einen $\mathrm{OD}_{260 / 280}$-Quotienten von 1,8.

Reine RNA zeigte einen $\mathrm{OD}_{260 / 280}$-Quotienten von 2,0.

\subsubsection{Polymerase Chain Reaction (PCR)}

Die PCR wurde mit DNA-Polymerasen der Firma Roche in einem PCR-cycler der Firma Biometra durchgeführt. Es wurde Taq-DNA-Polymerase verwendet. Die verwendete DNA wurde aus unterschiedlichen Quellen erlangt. Zum einen diente Plasmid-DNA als template. Zum anderen wurde genomische A.-fumigatus-DNA verwendet. Außerdem wurde aus $\lambda$-Phagen isolierte $A$-fumigatus-cDNA benutzt. Ein PCR-Ansatz setzte sich wie folgt zusammen:

PCR-Ansatz $(25 \mu \mathrm{l}): 2,5 \mu \mathrm{l}$ 10x Puffer (optional additiv 2,5 $\mu \mathrm{IgCl}_{2} 15 \mathrm{mM}$ )

$$
\begin{aligned}
& \text { 2,5 } \mu \text { l Nukleotid-Mix 2mM } \\
& \text { 12,5 pmol Sense-Primer } \\
& \text { 12,5 pmol Antisense-Primer } \\
& \sim 10 \text { ng DNA } \\
& 1 \text { U Polymerase }
\end{aligned}
$$

A. bidest ad $25 \mu \mathrm{l}$

Sämtliche PCR-Reaktionen wurden in PCR-Cyclern mit Deckelheizung $\left(105^{\circ} \mathrm{C}\right)$ durchgeführt. Die gefahrenen Programme wurden je nach Amplifikatlänge und Primerschmelztemperaturen angepasst.

$\begin{aligned} \text { Beispiel-PCR-Programm: } & 95^{\circ} \mathrm{C} 2 \mathrm{Min} \\ & 95^{\circ} \mathrm{C} 30 \mathrm{~s} \\ & \mathrm{X}^{\circ} \mathrm{C} 30 \mathrm{~s} \\ & 72^{\circ} \mathrm{C} \mathrm{Y} \mathrm{s} \\ & 72^{\circ} \mathrm{C} 10 \mathrm{Min} \\ & 4^{\circ} \mathrm{C} \quad \infty\end{aligned}$

Die Gesamtreaktion gliederte sich in sechs Schritte, von denen die Schritte $2=$ Denaturierung, 3 = Anlagerung der Primer (Annealing) und 4 = Elongation mit 18 - 35 Zyklen gefahren wurden. Die PCR wurde durch Abkühlen auf $4^{\circ} \mathrm{C}$ gestoppt. Die Temperatur zur Anlagerung der Primer wurde ausgehend von der Schmelztemperatur der Primer $\left(\mathrm{t}_{\mathrm{m}}\right)$ errechnet: 
$t_{m}=81,5+16,6\left(\log _{10}\left[J^{+}\right]\right)+0,41(\% G+C)-(600 / L)$

$\left[\mathrm{J}^{+}\right]=$Konzentration monovalenter Kationen

$\mathrm{L}=$ Länge der Oligonukleotide

Die verwendete Anlagerungstemperatur lag etwa $5^{\circ} \mathrm{C}$ unter der errechneten Durchschnitts $-\mathrm{t}_{m}$ beider verwendeter Primer.

Für größere Folge-Versuche wie Restriktionsverdaus etc. wurde ein $100 \mu \mathrm{l}$-Ansatz gefahren.

Die verwendeten Primer sind in Tabelle 10 aufgeführt. Die angegebenen Nummern am Ende der Primernamen dienten der Zuordnung. Nummer 1 wurde stets mit 2 gepaart, 3 mit 4,5 mit 6 und 7 mit 8 .

\subsubsection{Nested-PCR}

In der nested PCR wurde Pfu-Ultra-DNA-Polymerase mit dazu gehörigem Puffer (Roche) verwendet. Im Weiteren entsprachen Pipettierschema und Programm dem der normalen PCR (s. 2.13.9). Um die Korrekturfunktion (proof reading) der PfuPolymerase (3'-5'-Exoneclease-Aktivität) zu unterbinden wurde der gesamte PCRAnsatz auf Eis zusammenpipettiert und gemischt. Außerdem wurde eine Hot-StartPCR durchgeführt, was bedeutet, dass zunächst Deckelheizung und Block auf Betriebstemperatur gebracht wurden bevor die Proben in das PCR-Gerät gestellt wurden.

\subsubsection{DNA-Restriktionsverdau}

Unter Verwendung von Restriktionsendonukleasen der Firma New England Biolabs mit den entsprechenden Puffern wurden verschiedene DNA-Fragmente (PCR-

Produkte, Plasmide u. ä.) geschnitten.

$1,5 \mu \mathrm{g}$ DNA

$1 / 10$ Vol. Restriktionspuffer

$1 / 10$ Vol. BSA $10 x$

10 - 15 U Restriktionsendonuklease

optional 10 - $15 \mathrm{U}$ einer zweiten Restriktionsendonuklease

Inkubation für $4 \mathrm{~h}$ bei $37^{\circ} \mathrm{C}$ (oder jeweiligem Temperaturoptimum)

Aufreinigung über PCR-Purification-Kit (Qiagen)

Doppelverdau mit Enzymen, die nicht zum Doppelverdau geeignet waren, wurden einzeln nacheinander verdaut mit einem eingeschobenen Inaktivierungsschritt des ersten Enzyms ( $15 \mathrm{Min} 70^{\circ} \mathrm{C}$ ).

Sollte ein Doppelverdau durchgeführt worden sein, dessen beiden

Restriktionsenzyme inkompatible Puffer benötigten, so wurde ein Verdau mit nur einem Enzym gestartet. Nach dem erstem Verdau wurde ein Reinigungsschritt (PCRPurification-Kit (Qiagen)) eingefügt. Der zweite Verdau wurde ebenfalls mit 1/10 Vol. Puffer, 1/10 Vol. BSA 10x und 10-15 U des zweiten Enzyms versetzt und entsprechend dem ersten verdaut. Im Anschluss erfolgte wie zuvor ein Reinigungsschritt. 


\subsubsection{Dephosphorylierung linearisierter Vektoren}

Die Abspaltung endständiger Phosphatreste linearisierter Vektoren wurde durchgeführt, indem ein $10 \mu l$-Ansatz wie folgt gemischt und $1 \mathrm{~h}$ bei $37^{\circ} \mathrm{C}$ inkubiert wurde:

- $8 \mu$ linearisierter Vektor

- $1 \mu \mathrm{l}$ Phosphatase $(1 \mathrm{U} / \mu \mathrm{l})$

- $1 \mu$ l Phosphatase-Puffer

Im Anschluss wurde der Ansatz bei $70^{\circ} \mathrm{C}$ für 10 - 15 Min. inaktiviert.

\subsubsection{Ligation von DNA}

Unter Verwendung von T4-DNA-Ligase der Firma NEB wurden DNA Fragmente wie folgt berechnet und zusammen gefügt:

$$
\text { Masse Insert }(\mathrm{ng})=\frac{\text { Masse Vektor }(\mathrm{ng}) * \text { Insertgröße }(\mathrm{kbp})}{\text { Vektorgröße }(\mathrm{kbp})} * \text { molare Ratio } \frac{\text { Insert }}{\text { Vektor }}
$$

hierbei wurde eine molare Ratio von Insert zu Vektor von 3/1 verwendet. In der Regel wurden $100 \mathrm{ng}$ Vektor verwendet und eine der Formel entsprechende Menge an Insert.

$100 \mathrm{ng}$ geschnittener Vektor

$x$ ng geschnittenes Insert

A. bidest ad $8 \mu \mathrm{l}$

Inkubation für 5 Min bei $45^{\circ} \mathrm{C}$

$+1 \mu$ L Ligase-Puffer (inkl. ATP)

$+1 \mu \mathrm{l}$ T4-DNA-Ligase

Inkubation für $1 \mathrm{~h}$ bei RT

Inaktivierung der Ligase für $10 \mathrm{Min}$ bei $70^{\circ} \mathrm{C}$

Als Negativkontrolle wurde der gleiche Ansatz ohne Insert verwendet und entsprechend des eigentlichen Ligationsansatzes behandelt.

\subsubsection{Transformation von E. coli durch Elektroporation}

\subsubsection{Herstellung elektrokompetenter Zellen}

1 - $2 \mathrm{ml}$ einer Übernachtkultur des gewünschten E. coli-Stamms wurde verwendet um $500 \mathrm{ml}$ vorgewärmtes LB-Medium (ggf. inkl. Antibiotikum) zu inokulieren. Diese Kultur wurde bei $37^{\circ} \mathrm{C}$ unter konstantem Schütteln (ungefähr 150 Umdrehungen/Min) bis zu einer $\mathrm{OD}_{600}$ von etwa 0,4 angezogen. Direkt danach wurde die Kultur im Eisbad unter ständigem Schwanken für 20 bis 30 Min gekühlt. Es folgten mehrere Zentrifugationsschritte bei $4^{\circ} \mathrm{C}$ für je 15 Min bei $4000 \times g$ und jeweiligem resuspendieren in gekühltem, sterilem A. bidest (erst $500 \mathrm{ml}$, dann $2 \times 250 \mathrm{ml}$ und $1 \times 10 \mathrm{ml}$ ). Nach der letzten Waschung wurde das Pellet in eiskaltem $10 \%$ Glycerin aufgenommen. Diese so resuspendierten Zellen wurden als $50 \mu \mathrm{l}$-Aliquots auf Trockeneis oder in flüssigem Stickstoff schnellst möglich gefroren und bei $-70^{\circ} \mathrm{C}$ gelagert. 


\subsubsection{Elektroporation}

Die wie oben beschrieben hergestellten Zellen wurden mit der zu transformierenden DNA (z.B. $1 \mu$ L Ligationsansatz) unter folgenden Einstellungen in einer vorgekühlten $1 \mathrm{~mm}$ Elektroporationsküvette (peqlab) transformiert:

2,5 kV, $50 \mu \mathrm{F}, 129 \Omega, 1,3-1,5 \mathrm{kV}$.

Um einen Kurzschluss zu vermeiden, wurde die Küvette vor der Elektroporation abgetrocknet und darauf geachtet, dass wenig lonen/Salze im

Transformationsansatz waren. Binnen weniger Sekunden nach der Elektroporation wurden $500 \mu$ SOC-Medium (RT) zu den kompetenten Zellen pipettiert und vorsichtig gemischt. Es folgte eine Inkubation bei $37^{\circ} \mathrm{C}$ für $1 \mathrm{~h}$ nach der verschiedene Volumina auf LB-Agar-Platten (inkl. entsprechender Antibiotika) ausplattiert wurden inkl. folgender Inkubation ÜN bei $37^{\circ} \mathrm{C}$.

\subsubsection{Transformation von A. fumigatus}

\subsubsection{Protoplastierung von A. fumigatus}

Die Konidien einer dicht bewachsenen Sabouraud-Platte des A-fumigatus-Stamms D141 wurden mit $15 \mathrm{ml} \mathrm{MM} \mathrm{+} \mathrm{0,1 \%} \mathrm{Tween80} \mathrm{abgeschwemmt.} \mathrm{Mit} \mathrm{dieser}$ Suspension wurden $250 \mathrm{ml} \mathrm{MM}$ beimpft und ÜN bei $37^{\circ} \mathrm{C}$ und $90 \mathrm{U} / \mathrm{Min}$ (in Erlenmeyerkolben mit Schikane) inkubiert, bis sich die Konidien aufblähten. Es durften auch Ansätze von Keimschläuchen vorhanden sein. Die Konidien wurden mit einem Bottle-Top-Filter $(0,45 \mu \mathrm{m})$ geerntet. 1 bis $2 \mathrm{~g}$ dieser Konidienmasse wurde in $20 \mathrm{ml}$ eiskaltem OM resuspendiert und für 5 Min bei $4000 \times g$ bei $4{ }^{\circ} \mathrm{C}$ zentrifugiert. Es folgten zwei Waschungen mit je $5 \mathrm{ml}$ eiskaltem OM bei gleichen Bedingungen. Anschließend wurde in $7 \mathrm{ml} \mathrm{OM}$ resuspendiert. Inkubation für $5 \mathrm{Min}$ auf Eis nach Zugabe von $2 \mathrm{ml}$ Glucanex-Lösung ( $50 \mathrm{mg} / \mathrm{ml}) .1 \mathrm{ml}$ BSA-Lösung wurde zu einem Gesamtvolumen von $10 \mathrm{ml}$ zugefügt und $3 \mathrm{~h}$ bei 30 bis $33^{\circ} \mathrm{C}$ im Schüttelwasserbad inkubiert. Die Lösung wurde mit $10 \mathrm{ml}$ trapping buffer überschichtet, wobei darauf zu achten war, dass sich zwei Phasen bildeten. Dieses Konstrukt wurde 15 Min bei $4{ }^{\circ} \mathrm{C}$ und $4000 \times g$ zentrifugiert. Die Protoplasten, die sich nun in der unscharf abgegrenzten Interphase befanden, wurden vorsichtig abpipettiert ( $\sim \mathrm{ml})$. Es wurde mit weiteren 9 Vol. MS-Puffer durch Schwenken gemischt und erneut zentrifugiert (15 Min bei $1000 \times g$ und $4^{\circ} \mathrm{C}$ ). Das Pellet wurde zweimal mit je $20 \mathrm{ml}$ MSC-Puffer gewaschen ( 7 Min bei $1000 \times g$ und $4^{\circ} \mathrm{C}$ ); es wurde in $110 \mu \mathrm{l} \mathrm{MSC-Puffer}$ resuspendiert.

\subsubsection{Transformation von A. fumigatus-Protoplasten mit PEG}

$100 \mu \mathrm{l}$ der zuvor hergestellten Protoplasten wurden mit $10 \mu \mathrm{g}$ vorbereiteter DNA (z. B.: linearisierte Plasmid-DNA) und $30 \mu \mathrm{IPEG}$ gemischt. $10 \mu \mathrm{l}$ Protoplasten wurden als Negativkontrolle mit $90 \mu \mathrm{l} \mathrm{MSC}$ gemischt. Beides wurde für $30 \mathrm{Min}$ auf Eis 
inkubiert. Es wurden jeweils $900 \mu$ PEG zugefügt, gemischt und wiederum 30 Min bei RT inkubiert und im Anschluss 15 Min bei $5000 \times g$ bei RT zentrifugiert. Das PEG wurde entfernt. Nach einer weiteren Zentrifugation (1 Min bei $5000 \times \mathrm{g}$ und RT) wurde auch das restliche PEG abgenommen. Das Pellet wurde in $500 \mu \mathrm{l}$ MSC sacht resuspendiert; das Pellet der Negativkontrolle wurde nur in $50 \mu \mathrm{l}$ MSC aufgenommen. Der resuspendierte Transformationsansatz wurde in $30 \mu$-Aliquots aufgeteilt und mit je 1,6 ml MM-Topagar gemischt. Diese Mischung wurde auf vorbereitete, vorgewärmte $\left(37^{\circ} \mathrm{C}\right) \mathrm{MM}$-Agar-Platten $(8 \mathrm{ml})$ gegeben und durch Schwenken verteilt. Nach Erstarren des Topagars wurde für $20 \mathrm{~h}$ bei $20^{\circ} \mathrm{C}$ in Feuchtekammer vorinkubiert. Am nächsten Tag wurden die Platten mit MM-Topagar überschichtet in dem $20 \mu \mathrm{l}$ Hygromycin B $(50 \mathrm{mg} / \mathrm{ml})$ je $\mathrm{ml}$ Lösung gemischt wurden; dies führte nach Diffusion des Hygromycins zu einer Endkonzentration von $200 \mu \mathrm{g} / \mathrm{ml}$. Nach Erstarren dieser zweiten Topagar-Schicht wurde $5 \mathrm{~d}$ bei $20-25^{\circ} \mathrm{C}$ und im Anschluss $1 \mathrm{~d}$ bei $42{ }^{\circ} \mathrm{C}$ inkubiert.

\subsubsection{Marker-Rescue}

Im Rahmen einer normalen Transformation wurde das Plasmid pSK215 (Sven Krappmann) in den erfolgreich erstellten Deletionsklon $\triangle$ ADAM-A6 eingebracht. Dieses codierte für eine Pyrithiamin-Resistenz und eine cre-Rekombinase, welche den Resistenzmarker für Hygromycin-B-Resistenz entfernte (s. Abb. 29). Nach der Protoplastenherstellung (s. o.) wurden mit diesen $2 \mu \mathrm{g}$ Plasmid-DNA inklusive PEG gemischt. Die transformierten Protoplasten wurden in MMS*-Topagar aufgenommen und auf MMS*-Platten gebracht. Nach $20 \mathrm{~h}$ Inkubation bei $20^{\circ} \mathrm{C}$ wurde eine zweite MMS*-Topagarschicht mit Pyrithiamin (Endkonzentration nach Diffusion 0,1 $\mu \mathrm{g} / \mathrm{ml}$ ) auf die Platten gegossen. Nach Inkubation wie zuvor (s. o.) wurden gewachsene Klone erneut auf $\mathrm{MM}^{*}$-Agar+Pyrithiamin ausgestrichen. Von den hier wachsenden Einzelsporklonen aus wurde die Resistenz gegenüber Hygromycin B auf $\mathrm{MM}^{\star}$ Agarplatten mit Hygromycin B getestet. Es erfolgten Validierungen über PCR mit verschiedenen Primerpaaren. Die positiv getesteten Klone wurden auf MM-Agar ohne Nitrat und ohne Pyrithiamin ausgestrichen, was zum Verlust des transformierten Plasmids führte. Dies wurde über erneute Wachstumskontrolle gegen Pyrithiamin-haltigen $\mathrm{MM}^{*}$-Agar getestet.

\subsubsection{Southern Blot}

\subsubsection{Aufarbeitung genomischer A. fumigatus DNA}

Von einer dicht bewachsenen Sabouraud-Platte wurden mit 2 bis $3 \mathrm{ml} 0,9 \% \mathrm{NaCl}+$ 0,1\% Tween80 Konidien abgeschwemmt. Hiermit wurden $200 \mathrm{ml}$ Glucosebouillion beimpft, welche 1 bis $2 \mathrm{~d}$ bei $37^{\circ} \mathrm{C}$ unter Schütteln (etwa $90 \mathrm{U} / \mathrm{Min}$ ) inkubiert wurde. Das gewachsene Myzel wurde mit Filterpapier gefiltert und mit Tris-EDTA-Puffer gewaschen. $5 \mathrm{~g}$ des ausgewrungenen Myzels wurden in flüssigem Stickstoff mit 
Mörser und Pistill zerrieben. Das Pulver wurde mit $70 \mu \mathrm{l}$ Diethylformamat und $20 \mathrm{ml}$ vorgewärmter $\left(68^{\circ} \mathrm{C}\right) \mathrm{Na}_{2}$ EDTA-SDS-Lösung gemischt und bei $68^{\circ} \mathrm{C}$ für $30 \mathrm{Min}$ im Schüttelwasserbad inkubiert. Im Anschluss wurden Proteine mit $2 \mathrm{ml} 8 \mathrm{M}$ Natriumacetat $(\mathrm{pH} 4,2)$ aus der Lösung gefällt (10 Min auf Eis inkubieren und Zentrifugation für $10 \mathrm{Min}$ bei $4{ }^{\circ} \mathrm{C}$ und $4000 \times \mathrm{g}$ ). Der Überstand wurde in ein neues Tube überführt, 1:1 mit Isopropanol überschichtet und vorsichtig durch Über-Kopfdrehen gemischt. Die gefälte DNA wurde durch kurzes Zentrifugieren (max. 1 Min bei RT und max. $250 \times$ g) pelletiert. Der Überstand wurde entfernt und Reste dampften über einige Minuten bei Raumtemperatur ab. Das Pellet wurde in $10 \mathrm{ml}$ Lysispuffer resuspendiert und bei $56^{\circ} \mathrm{C}$ ÜN im Schüttelwasserbad inkubiert. Dann wurde die Lösung mit Phenol-Chloroform-Isoamylalkohol 1:1 überschichtet, durch Über-Kopf-drehen gemischt und bei $4{ }^{\circ} \mathrm{C}$ und $4000 \times g$ für $1 \mathrm{~h}$ zentrifugiert. Obere, wässrige Phase wurde abgenommen und mit $0,1 \mathrm{Vol} .2 \mathrm{M} \mathrm{NaCl}+2 \mathrm{Vol}$. Ethanol gemischt. Nach kurzem Zentrifugieren (1 Min bei RT und $150 \times$ g) wurde das Pellet komplett von Ethanol befreit. Das Pellet wurde in $4 \mathrm{ml}$ TE-Puffer + RNAse (zu $50 \mu \mathrm{g} / \mathrm{ml}$ Endkonzentration) gelöst und $2 \mathrm{~h}$ bei $37^{\circ} \mathrm{C}$ im Schüttelwasserbad inkubiert. Es folgten mehrere Phenol-Chloroform-Isoamylalkohol-Waschungen und EthanolFällungen (s.o.) zunächst eine weitere in $4 \mathrm{ml}$ Volumen und danach zwei weitere in $0,5 \mathrm{ml}$ Volumen. Im Anschluss wurde das DNA Pellet in $250 \mu \mathrm{l} \mathrm{TE}$-Puffer gelöst. Die Reinheit und Konzentration wurde über photometrische Messung bestimmt (s. 2.13.8).

\subsubsection{Herstellung einer Digoxigenin-markierten Sonde}

Ausgehend von dem Plasmid pAN7.1 wurden mit den Primern Phle3 und Phle4 eine erste PCR gefahren: $\quad$ PCR-Ansatz $(25 \mu \mathrm{l}): 2,5 \mu \mathrm{l} 10 \mathrm{x}$ PCR-Puffer

$$
\begin{aligned}
& 2,5 \mu \mathrm{l} \text { Nukleotid-Mix } 2 \mathrm{mM} \\
& 12,5 \text { pmol Sense-Primer } \\
& \text { 12,5 pmol Antisense-Primer } \\
& 5 \mathrm{ng} \text { pAN7-1 } \\
& 1 \mathrm{U} \text { Taq-DNA-Polymerase }
\end{aligned}
$$
A. bidest ad $25 \mu \mathrm{l}$

Mit folgendem Programm

$$
\begin{aligned}
& 95^{\circ} \mathrm{C} 2 \mathrm{Min} \\
& 95^{\circ} \mathrm{C} 30 \mathrm{~s} \\
& 59^{\circ} \mathrm{C} 20 \mathrm{~s} \\
& 72^{\circ} \mathrm{C} 30 \mathrm{~s} \\
& 72^{\circ} \mathrm{C} 7 \mathrm{Min} \\
& 4^{\circ} \mathrm{C} \quad \infty
\end{aligned}
$$

Schritte 2 bis 4 wurden insgesamt $35 \times$ gefahren. 
Im Anschluss wurde eine nested PCR mit den Primern phle1 und phle2 wie folgt gefahren:

$5 \mu \mathrm{l}$ DNA aus erster PCR (s.o.) 1:1 000 verdünnt
12,5 pmol Sense-Primer
12,5 pmol Antisense-Primer
$2,5 \mu \mathrm{l}$ PCR-Puffer (10 x)
2,5 $\mu$ l Digoxigenin-markierte dNTP/Nukleotide
2,5 $\mu$ l Taq-DNA-Verdünnung (1:20 in 1x PCR-Puffer)
A. bidest ad $25 \mu$ l

Das Programm entsprach den vorherigen Bedingungen (s.o.).

\subsubsection{Southern Blot}

Das Agarosegel nach dem vollführten Restriktionsverdau (s. 2.13.11) wurde zunächst mit der Southern-Blot-Depurinierungslösung für 10 Min, dann 2x für je 20 Min mit Southern-Blot-Denaturierungslösung und schließlich 2 mal mit SouthernBlot-Neutralisierungslösung ebenfalls für je 20 Min gewaschen. Unter Ausnutzung von Kapillarkräften und 20x SSC wurde die DNA binnen 16 - 24 h aus dem Gel auf eine Nitrozellulosemembran übertragen (Optitran BA-S85 0,45 $\mu \mathrm{m}$ ). Die Membran wurde daraufhin $5 \mathrm{Min}$ in $6 \mathrm{x}$ SSC gewaschen und $30 \mathrm{Min}$ an der Luft getrocknet. Zwischen zwei Lagen Whatman Gel Blotting Papier wurde die Membran 1-2 $\mathrm{h}$ bei $80^{\circ} \mathrm{C}$ im Vakuumofen fixiert.

\subsubsection{Hybridisierung}

Die zuvor geblottete Membran (s. oben) wurde in $10 \mathrm{ml}$ Prähybridisierungslösung bei $42^{\circ} \mathrm{C}$ (ungefähr $25^{\circ} \mathrm{C}$ unter der $\mathrm{t}_{\mathrm{m}}$ der Sonde) für $2 \mathrm{~h}$ inkubiert (Hybridisierungsofen, Biometra).

$$
\begin{aligned}
& \mathrm{t}_{\mathrm{m}}=81,5^{\circ} \mathrm{C}+16,6\left(\log _{10}\left[\mathrm{~J}^{+}\right]\right)+0,41(\% \mathrm{G}+\mathrm{C})-0,63(\% \text { Formamid })-(600 / \mathrm{L}) \\
& {\left[\mathrm{J}^{+}\right]=\text {Konzentration monovalenter Kationen }} \\
& \mathrm{L}=\text { Länge der Oligonukleotide }
\end{aligned}
$$

Danach wurde $1 \mu$ l Digoxigenin-markierte Sonde in $100 \mu$ A. bidest aufgenommen und 5 Min bei $95^{\circ} \mathrm{C}$ denaturiert. Nach sofortiger Zugabe von $100 \mu \mathrm{l}$ Formamid wurde 5 Min auf Eis inkubiert. Dieses Gemisch wurde auf die Membran und die Prähybridisierungslösung gegeben und für weitere 18 bis $24 \mathrm{~h}$ bei $42^{\circ} \mathrm{C}$ inkubiert. Am nächsten Tag wurde die Membran zweimal mit $37^{\circ} \mathrm{C}$ warmem Southern-BlotWaschpuffer I für je $15 \mathrm{Min}$ und zweimal mit $68^{\circ} \mathrm{C}$ warmem Southern-BlotWaschpufferll gewaschen. Die Membran wurde danach 1 Min bei RT in PBS äquilibriert und im Anschluss in Southern-Blot-Block-Puffer für $1 \mathrm{~h}$ bei RT geblockt. Es wurden 5 bis $10 \mu \mathrm{l}$ des Anti-Digoxigenin-POD-Antikörpers zugefügt und 1,5 bis $2 \mathrm{~h}$ bei RT weiter inkubiert. Die Membran wurde daraufhin dreimal mit PBS + 0,1\% 
Tween20 für je 7 Min bei RT gewaschen. Detektion erfolgte wie in 2.14.7 beschrieben.

\subsection{Proteinbiochemische Methoden}

\subsubsection{Rekombinante Proteinexpression in E. coli}

\subsubsection{Anzucht und Induktion von E. coli}

Nach erfolgreicher Transformation der Expressionsplasmide (auf Basis von pQE30 (Qiagen)) in E. coli wurde der Stamm zur rekombinanten Produktion des jeweiligen Proteins verwendet. Hierfür wurde eine ÜN-Kultur des Stammes angesetzt (1-2 ml), mit der $50 \mathrm{ml}$ Expressionsmedium inokuliert wurden. Diese Kultur wurde bis zu einer $\mathrm{OD}_{600}$ von etwa 0,45 angezogen. Ein $1 \mathrm{ml}$-Aliquot wurde von der Kultur abgenommen und bei RT für 5 Min und $6000 \times g$ zentrifugiert (Überstand wurde verworfen). Zu der Kultur wurden $100 \mu \mathrm{l} 0,5 \mathrm{M} \mathrm{IPTG}$ gegeben und für weitere $4 \mathrm{~h}$ bei $37^{\circ} \mathrm{C}$ inkubiert.

Dann wurde wiederum $1 \mathrm{ml}$ abgenommen und zentrifugiert (s.o.). Der Rest der Kultur wurde ebenfalls komplett zentrifugiert (RT, $10 \mathrm{Min}, 4500 \times \mathrm{g}$ ).

\subsubsection{Expressionskontrolle}

Die jeweiligen $1 \mathrm{ml}$-Aliquots vor und nach IPTG-Zugabe wurden jeweils mit $100 \mu \mathrm{l}$ SDS-PAGE-Probenpuffer (1x) versetzt und für $5 \mathrm{Min}$ im $95^{\circ} \mathrm{C}$ heißen Heizblock gekocht. Kurzes Zentrifugieren sorgte dafür, dass Zelltrümmer pelletierten. $30 \mu \mathrm{l}$ des Überstandes wurden mittels SDS-PAGE kontrolliert. War durch IPTG induzierte Proteinexpression ersichtlich, wurde das Protein aus der Kultur aufgereinigt.

\subsubsection{Proteinaufreinigung aus (positiver) E.-coli-Kultur}

Aus dem Pellet einer knapp $50 \mathrm{ml}$ E.-coli-Kultur wurde das induzierte Protein aufgereinigt. Hierfür wurden folgende Schritte vollzogen (die Puffer wurden möglichst frisch angesetzt):

- Pellet in $20 \mathrm{ml}$ Protein-Produktions-Puffer A (folgend nur noch Puffer A-F) lösen und 2 Tabletten Complete Mini EDTA-free (Protease-Inhibitor-Mix) zufügen und gut vortexen. Inkubation bei $37^{\circ} \mathrm{C}$ im Überkopfschüttler (Snijders Scientific) für $2 \mathrm{~h}$

- Zentrifugation bei RT und 10000 x g für 20 Min

- PD10-Säule mit Ni-NTA-Agarose füllen ( 1 - $2 \mathrm{ml})$ und vorbereiten:

○ Säule mit $25 \mathrm{ml} 30 \%$ Ethanol spülen

- Säule mit $25 \mathrm{ml} \mathrm{A}$. bidest waschen

- Säule mit $25 \mathrm{ml}$ Puffer A äquilibrieren

- Überstand aus vorheriger Zentrifugation mit vorbereiteter Ni-NTA-Agarose ÜN bei $4^{\circ} \mathrm{C}$ im Überkopfschüttler (s.o.) anlagern lassen

- Suspension bei max. 700 x g und RT für 5 Min zentrifugieren 
- pelletierte Ni-NTA-Agarose wieder in PD10-Säule füllen und Sukzessive mit folgenden Puffern waschen: $15 \mathrm{ml}$ Puffer A, $25 \mathrm{ml}$ Puffer B, $25 \mathrm{ml}$ Puffer C

- Elution mit $20 \mathrm{ml}$ Puffer E

Entsalzung gegen A. bidest und Volumeneinengung wurde durch Zentrifugation in Vivaspin 20 Säulen (Sartorius) bei $5400 \times g$ und $17^{\circ} \mathrm{C}$ vollzogen (Dauer variierte). Die Aufreinigung wurde mittels SDS-PAGE kontrolliert.

\subsubsection{Rekombinante Proteinexpression in P. pastoris}

$25 \mathrm{ml}$ BMGY-Medium wurden mit der gewünschten $P$.-pastoris-Dauerkultur beimpft und bei $30^{\circ} \mathrm{C}$ für $16-20 \mathrm{~h}$ bei 250 - $300 \mathrm{U} /$ Min bis zu einer $O_{600}$ von 2 - 6 inkubiert. Die Kultur wurde bei $3000 \times g$ und RT für 5 Min zentrifugiert. Das Pellet wurde in einem solchen Volumen BMMY resuspendiert, dass eine $\mathrm{OD}_{600}$ von 1 erreicht wurde. Die Kultur wurde für mehrere Tage bei $28^{\circ} \mathrm{C}$ und 250 - $300 \mathrm{U} /$ Min inkubiert, wobei täglich Methanol zu einer Endkonzentration von 0,5\% zugefügt wurde. Die Zellen wurden durch Zentrifugation bei RT und $10000 \times$ g für 20 Min pelletiert. Die im Überstand befindlichen Proteine wurden über Vivaspin 20 Säulen (Sartorius) gewaschen (A. bidest) und konzentriert (Zentrifugation bei $5400 \times g$ und $17^{\circ} \mathrm{C}$ (Dauer variierte)).

\subsubsection{Denaturierende Polyacrylamid-Gel-Elektrophorese (SDS-PAGE)}

Verwendet wurden 12,5\% SDS-Gele. Die in der folgenden Tabelle (s. Tab. 13) angegebenen Komponenten des Trenngels wurden gemischt in die vorbereitete Höfer-Kammer pipettiert und mit $300 \mu$ I Isobutanol überschichtet. Nach Erstarren des Trenngels wurde das überschüssige Isobutanol mit A. bidest abgespült. Im Anschluss wurde das Sammelgel gegossen.

\subsubsection{Aufpolymerisieren des Sammelgels}

Die Polyacrylamidkonzentration in den verwendeten SDS-Sammelgelen betrug $5 \%$. Ebenfalls in der folgenden Tabelle sind die verwendeten Volumina zu entnehmen. Nach Erstarren des Trenngels und Entfernung des Isobutanols wurde das gemischte Sammelgel darauf pipettiert und mit Gel-Kämmen versehen. Nachdem diese Schicht auspolymerisierte, wurden die Gele aus der Höfer-Kammer entfernt und feucht bei 4 $8^{\circ} \mathrm{C}$ bis zur Verwendung jedoch nicht länger als 1 bis 2 Wochen gelagert.

Tabelle 13: SDS-Gel-Rezepte

\begin{tabular}{|l|l|l|}
\hline & SDS-Trenngel $12,5 \%$ & SDS-Sammelgel $5 \%$ \\
\hline $40 \%$ Bisacrylamid & $4,7 \mathrm{ml}$ & $500 \mu \mathrm{l}$ \\
\hline SDS-Trenngelpuffer & $5,65 \mathrm{ml}$ & - \\
\hline SDS-Sammelgelpuffer & - & $500 \mu \mathrm{l}$ \\
\hline A. bidest & $4,4 \mathrm{ml}$ & $2,9 \mathrm{ml}$ \\
\hline $10 \%$ SDS & $150 \mu \mathrm{l}$ & $40 \mu \mathrm{l}$ \\
\hline $1 \%$ Bromphenolblau & $37,5 \mu \mathrm{l}$ & $40 \mu \mathrm{l}$ \\
\hline
\end{tabular}




\begin{tabular}{|l|l|l|}
\hline $10 \%$ APS & $127,5 \mu \mathrm{l}$ & $10 \mu \mathrm{l}$ \\
\hline Temed & $15 \mu \mathrm{l}$ & $2,5 \mu \mathrm{l}$ \\
\hline
\end{tabular}

\subsubsection{SDS-PAGE}

Die zu analysierenden Proben wurden direkt vor der Elektrophorese 1:1 mit SDSPAGE-Probenpuffer gemischt und für $5 \mathrm{Min}$ bei $95^{\circ} \mathrm{C}$ erhitzt. Die Elektrophorese fand in einer mit SDS-PAGE-Laufpuffer gefluteten Kammer bei $120 \mathrm{~V}$ (etwa $25 \mathrm{~mA}$ ) für 45 Min statt. Im Anschluss wurde das Gel in SDS-PAGE-Färbelösung für 30 bis 60 Min gefärbt und danach bis zur gewünschten Intensität wieder entfärbt (s. Lösungen 2.7).

\subsubsection{Aufarbeitung von A.-fumigatus-Gesamtzellprotein}

Die Konidien einer mit Aspergillus fumigatus dicht bewachsenen Sabouraud-Platte wurden mit $10 \mathrm{ml} \mathrm{MM}$ abgeschwemmt und in $250 \mathrm{ml}$ MM überführt. Dieses wurde ÜN bei $30^{\circ} \mathrm{C}$ und $80-100 \mathrm{U} / \mathrm{Min}$ inkubiert. Die gewachsene Kultur wurde filtriert und mit $\mathrm{Na}$-Citrat-Puffer gewaschen. Die gewaschene Kultur wurde in $3 \mathrm{ml}$ ProteinExtraktionspuffer suspendiert. 1:1 mit sterilen glass beads (500 $\mu \mathrm{m}$ Durchmesser) gemischt wurde diese Mischung in je etwa $1 \mathrm{ml}$ Volumen im fast prep (Thermo Scientific) in 10 Intervallen der Stärke 6,5 für je 20 s zermahlen; zwischen den Intervallen wurden die Proben auf Eis gekühlt. Es folgte ein Zentrifugationsschritt für $15 \mathrm{Min}$ bei $4^{\circ} \mathrm{C}$ und $10000 \times \mathrm{g}$. Der Überstand wurde danach erneut bei $4^{\circ} \mathrm{C}$ und $100000 \times g$ für $1 \mathrm{~h}$ zentrifugiert. Der Überstand wurde abgenommen und aliquotiert bei $-20^{\circ} \mathrm{C}$ gelagert.

\subsubsection{Aufarbeitung von Membran-assoziierten Proteinen aus A. fumigatus} Die Konidien einer mit Aspergillus fumigatus dicht bewachsenen Sabouraud-Platte wurden mit $10 \mathrm{ml}$ MM abgeschwemmt und in $250 \mathrm{ml}$ MM überführt. Dieses wurde ÜN bei $30^{\circ} \mathrm{C}$ und $80-100 \mathrm{U} /$ Min inkubiert. Die gewachsene Kultur wurde abfiltriert und mit $\mathrm{Na}$-Citrat-Puffer gewaschen. Die gewaschene Kultur wurde in $3 \mathrm{ml}$ ProteinExtraktionspuffer suspendiert. 1:1 mit sterilen glass beads (500 $\mu \mathrm{m}$ Durchmesser) gemischt wurde diese Mischung in je etwa $1 \mathrm{ml}$ Volumen im fast prep (Thermo Scientific) in 10 Intervallen der Stärke 6,5 für je $20 \mathrm{~s}$ zermahlen; zwischen den Intervallen wurden die Proben auf Eis gekühlt. Es folgte ein Zentrifugationsschritt für 10 Min bei $4^{\circ} \mathrm{C}$ und $4000 \times \mathrm{g}$. Die Überstände wurden erneut bei $4^{\circ} \mathrm{C}$ und $36000 \times \mathrm{g}$ für $1 \mathrm{~h}$ zentrifugiert. Die pelletierten Membranen wurden je behandeltem Klon in $300 \mu \mathrm{l}$ Extraktionspuffer aufgenommen.

20 bis $40 \mu$ lieses Extraktes wurden mit $1 \mathrm{ml}$ Extraktionspuffer $+0,2 \%$ Triton X114 gemischt und $1 \mathrm{~h}$ bei $4^{\circ} \mathrm{C}$ inkubiert. Im Anschluss erfolgte ein 1 minütiges Wasserbad bei $37^{\circ} \mathrm{C}$. Dann wurde $5 \mathrm{Min}$ bei RT und $7500 \times g$ zentrifugiert. Der Überstand wurde weitere 2 bis 3 Mal mit $0,2 \%$ Triton X114 versetzt, bei $37^{\circ} \mathrm{C}$ inkubiert und 
zentrifugiert. Das Pellet wurde weitere 2 bis 3 mal mit je 2 - $300 \mu$ l Extraktionspuffer versetzt, ebenfalls bei $37^{\circ} \mathrm{C}$ inkubiert und zentrifugiert. Die Überstände und Pellets wurden jeweils gepoolt und mit 5\%TCA versetzt, 10 Min auf Eis inkubiert und $10 \mathrm{Min}$ bei RT und $16000 \times g$ zentrifugiert. Die Überstände wurden verworfen. Auf die Pellets wurden 2 - $300 \mu \mathrm{l}$ eiskaltes Aceton pipettiert und nicht gemischt. Es folgte eine Zentrifugation wie direkt zuvor (s.o.), nach der das Aceton abpipettiert wurde und Reste abdampften (5 - $10 \mathrm{Min}$ bei RT). Die Pellets wurden in $20 \mu \mathrm{l}$ 1x SDS-PAGEProbenpuffer aufgenommen.

\subsubsection{Western Blot}

Die zu analysierende Probe musste zunächst auf einer SDS-PAGE aufgetrennt werden (s. 2.14.3.2). Geblottet wurde auf Nitrozellulosemembranen der Firma Schleicher\&Schüll (Protran 0,2 $\mu \mathrm{m}$ ). Diese Membran wurde zunächst $5 \mathrm{Min}$ in A. bidest und anschließend $5 \mathrm{Min}$ in Transfer-Puffer äquilibriert. Das SDS-PAGE-Gel wurde ebenfalls in Transferpuffer äquilibriert (5 Min). In einer Blotkammer der Firma Höfer wurde für $2-4 \mathrm{~h}$ bei 100-150 V unter ständiger Kühlung des Transfer-Puffers die Übertragung durchgeführt. Die Membran wurde danach getrocknet und mit Blockpuffer für $2 \mathrm{~h}$ bei RT oder ÜN bei $4^{\circ} \mathrm{C}$ gewaschen. Es folgte zweimaliges Waschen in PBS + 0,1\%Tween20 für jeweils 5 Min bei RT. Der erste Antikörper (z. B. Rabbit-Anti-A.-fumigatus-ADAM-A) wurde in Blockpuffer verdünnt (1:2 000) mit der Membran für 1 bis $18 \mathrm{~h}$ bei RT inkubiert. Im Anschluss wurde viermalig in PBS $+0,1 \%$ Tween20 für jeweils 5 Min bei RT gewaschen. Der zweite Antikörper (z. B. Monoclonal Anti-Rabbit Immunoglobulins Clone RG-16) wurde in Blockpuffer verdünnt (1:10 000) für $1 \mathrm{~h}$ bei RT inkubiert, dreimalig mit PBS + 0,1\%Tween20 für jeweils $5 \mathrm{Min}$ bei RT und einmal ohne Tween20 gewaschen.

\subsubsection{Detektion Peroxidase (POD)-gekoppelter Antikörper}

Die zu behandelnde und mit PBS gewaschene Membran (aus Southern- oder Western-Blot) wurde mit $0,125 \mathrm{ml} \mathrm{je} \mathrm{cm}^{2}$ mit einer 1:1-Mischung aus den ECLReagenzien (Amersham) 1 und 2 für $1 \mathrm{Min}$ bei RT inkubiert. Es folgte Exposition/Belichtung des Röntgenfilms in lichtdichter Kassette für 1 bis 30 Min. Der Film wurde 2 Min entwickelt (Kodak), was durch ein Bad in Essigsäure (5\%) gestoppt wurde. Danach wurde der Film für 2 - 5 Min in Fixierer (Kodak) geschwenkt. Im Anschluss erfolgte Wässern des Films in Leitungswasser und die Trocknung des Films bei RT. 


\subsection{Biochemische Charakterisierung der A.-fumigatus-Gen- Deletionsmutanten}

Sämtliche Wachstumskontrollen der Deletionsmutanten wurden im Vergleich zum Wachstum des Wildstammes (D141) unter den jeweils gleichen Bedingungen untersucht.

\subsubsection{Wachstumskontrollen der ADAM-Gen-Deletionsmutanten}

Die drei erzeugten Gen-Deletionsmutanten $\triangle$ ADAM-A, $\triangle A D A M-B$ und die DoppelDen-Deletionsmutante $\triangle A D A M-A B$ wurden auf verschiedenen Medien, Temperaturen und/oder Stressfaktoren inkubiert.

So wurde GYE-als komplexes Medium verwendet. Im Gegensatz dazu wurde MM als definiertes Medium benutzt. Letzteres wurde auch so verändert eingesetzt, dass nur speziell zugefügte Substanzen als Kohlenstoff- und Stickstoffquelle enthalten waren (MM-BSA-, MM-Casein und MM-Gelatine-Agar).

Weiterhin wurden die oben erwähnten Deletionsmutanten daraufhin getestet, ob die Substanzen BSA, Casein und Gelatine zusammen mit YNB-Medium als Kohlenstoffquelle oder zusammen mit YCB-Medium als Stickstoffquelle verwendet werden konnten.

Außerdem wurde der Einfluss des $\mathrm{pH}$-Wertes des Mediums ( $\mathrm{pH} 4$ bis 8 ) und der der Temperatur $\left(37^{\circ} \mathrm{C}\right.$ und $\left.42^{\circ} \mathrm{C}\right)$ untersucht.

Zusätzlich wurden in MM+Zusatz-Agar folgende verschiedene Stoffe getestet: zur Erzeugung von osmotischem Stress: Natriumchlorid, Kaliumchlorid, Sorbitol; zur Destabilisierung von Zellwandkomponenten: SDS, Koffein, Kongo-Rot, Calcofluor White; und Chloramphenicol um eine evtl. erhöhte Durchlässigkeit der Zellwand zu testen.

Die Medien wurden als $2 x$ konzentriert angesetzt, ggf. mit doppelt konzentriertem (zuvor gelöstem und steril filtriertem) Zusatz versetzt und mit $4 \%$ Wasseragar 1:1 gemischt. Auf die verschiedenen Nährmedienplatten wurden jeweils zentral 2,5 $\mu \mathrm{l}$ Sporensuspension ( $=2500$ Konidien) pipettiert und das Wachstum in Form des Durchmessers der gewachsenen Kolonie wurde vier Tage lang täglich kontrolliert.

\subsubsection{Wachstumskontrolle der Aspf3-Gen-Deletionsmutanten}

Die hergestellte Gen-Deletionsmutante $\Delta$ Aspf3 wurde speziell daraufhin getestet, wie gut oder schlecht sie bei oxidativem Stress wachsen kann. Zu diesem Zweck wurde $\mathrm{MM}+$ Zusatz-Agar entweder mit Natriumhypochlorid oder mit Wasserstoffperoxid verwendet.

Die Medien wurden wie oben (s. 2.15.1) beschrieben hergestellt, und die wachsende Kultur wurde nach zentraler Inokulation mit 2500 Konidiosporen von A. fumigatus über mehrere Tage überwacht und der Koloniedurchmesser notiert.

\subsubsection{Agardiffusionstest der Gen-Deletionsmutanten}

Auf einer MM-Agarplatte wurden $1 \times 10^{5}$ Konidien ausplattiert (100 $\mu \mathrm{l}$ einer Sporensuspension mit der Konzentration $1 \times 10^{6}$ Sporen $/ \mathrm{ml}$ ). Im Anschluss wurde ein 
Loch in die Plattenmitte gestanzt ( $\sim-4 \mathrm{~mm}$ Durchmesser). In diese so hergestellten Löcher mehrerer Platten wurden verschiedene Konzentrationen der zu testenden Lösungen pipettiert (Fassungsvermögen ungefähr $20 \mu \mathrm{l}$ ). Die Platten wurden für $24 \mathrm{~h}$ bei $37^{\circ} \mathrm{C}$ inkubiert und der Hemmhofdurchmesser gemessen. Hierbei wurde der Einfluss der zu testenden Substanzen auf $A$.-fumigatus-Kulturen von Beginn der Keimung an untersucht.

Als Alternative wurden die ausplattierten Konidien zunächst $24 \mathrm{~h}$ bei $37^{\circ} \mathrm{C}$ inkubiert, bevor das Loch gestanzt und die Lösung hinein pipettiert wurde. Es wurde dann für weitere $24 \mathrm{~h}$ bei $37^{\circ} \mathrm{C}$ inkubiert und im Anschluss der beobachtete Hemmhof gemessen. Bei diesem Ansatz wurde der Einfluss der zu testenden Substanzen auf bereits gekeimte $A$.-fumigatus-Kulturen untersucht.

\subsection{Immunisierung mit rekombinanten A.-fumigatus-Proteinen im Mausmodell}

Mehrere Proteine aus A. fumigatus, die in E. coli rekombinant exprimiert wurden, wurden als Kohorte zu einem Vakzin aufbereitet. Hierfür wurden die Proteine: Spherulin, ADM-A, ADM-B, ADM-B3/4, Extrazelluläre Lipase, Protein Disulfid Isomerase, Protein Disulfid Isomerase3/4, Catalase A zu je $10 \mu \mathrm{g}$ mit 1/10 Vol. 10x PBS gemischt und mit 1x PBS auf ein gewünschtes Volumen aufgefüllt. Diese Mischung wurde 1:1 mit dem Adjuvans (AS03/Pandemrix) und etwa $300 \mu \mathrm{l} \mathrm{sterilen}$ glass beads ( $500 \mu \mathrm{m}$ Durchmesser) versetzt und mehrere Minuten gründlich gevortext. Das Vakzin wurde abgenommen und in einem Volumen von $100 \mu \mathrm{l} \mathrm{je}$ Maus s.c. gespritzt. Als Positivkontrolle wurden die Proteine: Aspf3, Aspf16, 1,3- $\beta$ Glucanosyltransferase (inkl. BGT3/4) entsprechend des Vakzins behandelt und injiziert. Einer Negativkontrollgruppe wurde Adjuvans 1:1 mit 1x PBS gemischt gegeben. Die Immunisierung wurde nach 14 Tagen einmal wiederholt. Weitere 12 , 14 und 16 Tage später wurde den Mäusen jeweils $0,25 \mathrm{mg}$ CortisonacetatSuspension pro g Körpergewicht s.c. gespritzt. Einen Tag später erfolgte die Infektion unter leichter Narkose mit Narkoselösung. Den betäubten, auf dem Rücken liegenden Mäusen wurden $35 \mu$ Konidiensuspension $\left(5 \times 10^{8}\right.$ Konidien pro $\left.\mathrm{ml}\right)$ auf die Nasenlöcher pipettiert, so dass die Mäuse die Suspension inhalierten. Um eine zusätzliche bakterielle Infektion zu vermeiden, wurde dem Trinkwasser Ciprofloxacin zu einer Endkonzentration von $0,25 \mathrm{mg} / \mathrm{ml}$ zugesetzt. Tägliche Kontrollen von Verhalten, Atmung, Fell und Körpergewicht erfolgten für 10 Tage. Geschwächte, abgemagerte (mehr als $20 \%$ Körpergewichtsverlust) und/oder sich sichtbar quälende Mäuse wurden in $\mathrm{CO}_{2}$-Atmosphäre getötet. Die Lungen der Mäuse wurden entnommen und in einem Gesamtvolumen von 2,5 $\mathrm{ml} \mathrm{0,9 \%} \mathrm{NaCl-Lösung} \mathrm{in} \mathrm{einem}$ Handhomogenisator zerkleinert. Die zerkleinerten Lungen wurden jeweils in drei dekadischen Verdünnungsschritten (1:10, 1:100, 1:1000) auf Sabouraud-Platten ausgestrichen. Zusätzlich wurde eine $5 \mu$ Probe der homogenisierten Lunge mit Blankophor gefärbt unter einem Fluoreszenzmikroskop begutachtet. 


\section{Ergebnisse}

\subsection{Herstellung rekombinanter Proteine aus Aspergillus fumigatus}

Bei der Herstellung rekombinanter Proteine wurde stets zunächst cDNA amplifiziert, diese in Expressionsplasmide kloniert, welche ihrerseits in E. coli transformiert wurden. In diesen E.-coli-Kulturen wurde die Proteinproduktion induziert, und aus diesen wurden die Proteine aufgereinigt.

Alternativ wurden Proteine in Pichia pastoris exprimiert.

\subsubsection{Amplifikation von cDNA}

\subsubsection{Amplifikation von cDNA aus Plasmiden}

Es lagen einige Plasmide vor, die cDNA zu korrelierenden Proteinen einer früheren Arbeit (Denikus 2005) enthielten. Von diesen Plasmiden ausgehend (s. Tabelle 8) wurde die jeweilig enthaltene cDNA mittels PCR und spezifischen Primern amplifiziert. Kontrolliert wurden die Amplifikate auf Agarosegelen gegen Standards definierter Größe; beispielsweise:

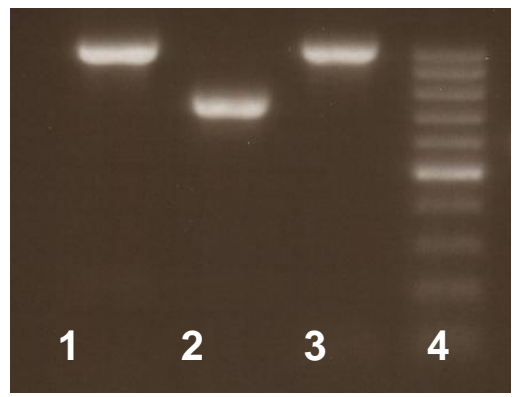

PCR-Produkte zu der korrelierenden cDNA der
folgenden Proteine (erwartete Größen in Klammern):
1.) AP ( $999 \mathrm{bp})$
2.) TK (735 bp)
3.) PG ( $987 \mathrm{bp})$
4.) ladder $100 \mathrm{bp}$ (s. Anhang)

Abbildung 3: Amplifikation von cDNA aus Plasmiden

\subsubsection{Amplifikation von genomischer DNA}

Die Vervielfältigung von DNA über PCR mit genomischer DNA als template war die zweite verwendete Methode. Hierbei war darauf zu achten, dass die verwendeten Primer so gewählt wurden, dass nur Exon-Bereiche amplifiziert wurden. Wie zuvor wurden die Ergebnisse auf Agarosegelen kontrolliert; beispielhaft:

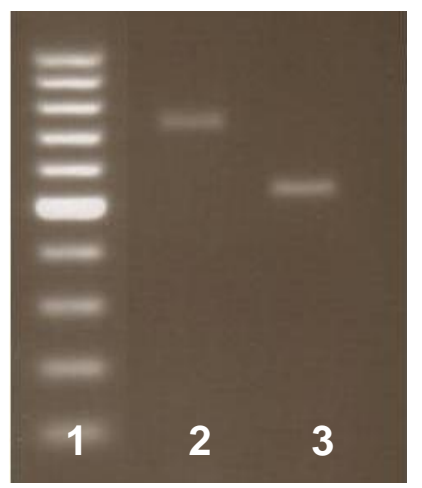

PCR-Produkte zu der korrelierenden cDNA der folgenden Proteine (erwartete Größen in Klammern):

1.) ladder $100 \mathrm{bp}$ (s. Anhang)

2.) $P G M(681 \mathrm{bp})$

3.) $B G T(520 \mathrm{bp})$

Abbildung 4: Amplifikation von genomischer DNA 


\subsubsection{Amplifikation von cDNA aus einer A.-fumigatus-cDNA-Expressionsbank}

Als weitere Basis, von der aus CDNA über PCR amplifiziert wurde, existierte ein Gemisch an verschiedenen cDNAs, das aus der „Premade Aspergillus Uni Zap XR Express Bank" isoliert wurde. Von diesem aus wurden mit spezifischen Primern einzelne enthaltene cDNAs vervielfältigt und auf Agarosegelen kontrolliert, so zum Beispiel:

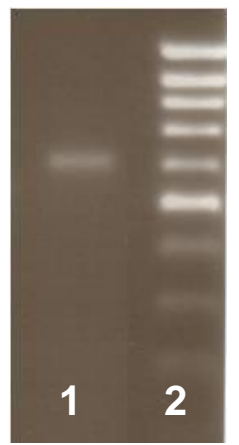

PCR-Produkt zu der korrelierenden cDNA des folgenden Proteins (erwartete Größen in Klammern):

1.) AAT (600 bp)

2.) Ladder $100 \mathrm{bp}$ (s. Anhang)

Abbildung 5: Amplifikation von cDNA aus einer cDNA-Expressionsbank

\subsubsection{Klonierung von amplifizierter cDNA in Expressionsplasmide}

Nachdem die jeweiligen cDNA-Fragmente amplifiziert wurden, wurden sie in linearisierte und dephosphorylierte Vektoren ligiert. Diese Konstrukte wurden danach über Elektroporation in E. coli transformiert. Aus diesen transformierten Zellen wurden die Plasmide extrahiert und in einem Restriktionsverdau mit anschließender Auftrennung in einer Agarosegelelektrophorese kontrolliert. Es wurde jeweils ein linearisierter Vektor ohne Insert als Negativkontrolle neben einem definierten Molekulargewichtsstandard mit aufgetragen.

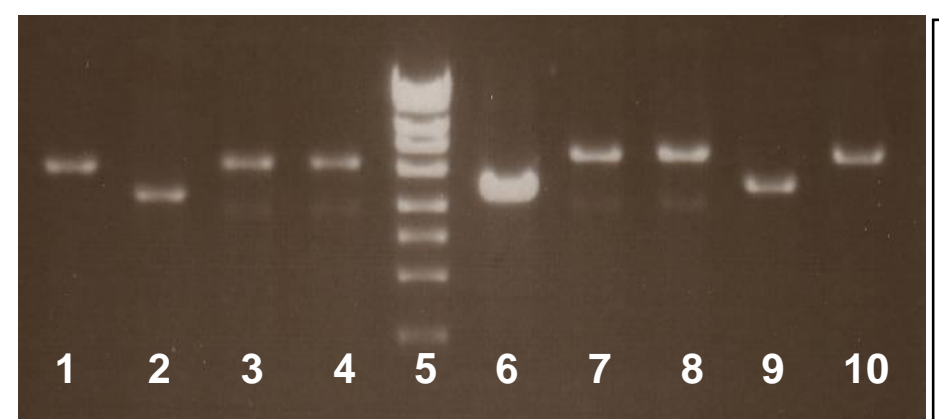

Verdaute Plasmide:

1 - 4) Plasmide aus 4 verschiedenen

E. coli-Kulturen zu AlAd

5) Molekulargewichtstandard ladder high

(s. Anhang)

6) linearisiertes Plasmid $p Q E 30$

7-10) Plasmide aus 4 verschiedenen

E.coli-Kulturen zu Sla

Abbildung 6: kontrollierte Expressionsplasmide

Die Proben 1, 3, 4, 7, 8 und 10 ließen deutlich erkennen, dass ein Insert enthalten ist. Proben 2 und 9 liefen auf gleicher Höhe wie die Negativkontrolle, weil diese kein Insert enthielten wurden diese Kulturen verworfen. Die erwarteten Größen waren bei fehlendem Insert 3,4 kbp, Plasmide mit Insert für AlAd sollten ungefähr 4,2 kbp groß sein, die Plasmide mit Insert für Sla 4,3 kbp.

\subsubsection{Kontrolle der Proteinexpression in E. coli}

Die zuvor positiv kontrollierten Expressionsplasmide - und somit auch die Plasmide beinhaltenden E.-coli-Kulturen - wurden in geringem Volumen $(50 \mathrm{ml})$ auf die 
Expression der gewünschten Proteine hin getestet. Dies wurde auf jeweils einer SDS-PAGE kontrolliert. Hierzu wurden Proben vor und nach Induktion der Proteinexpression nebeneinander verglichen.

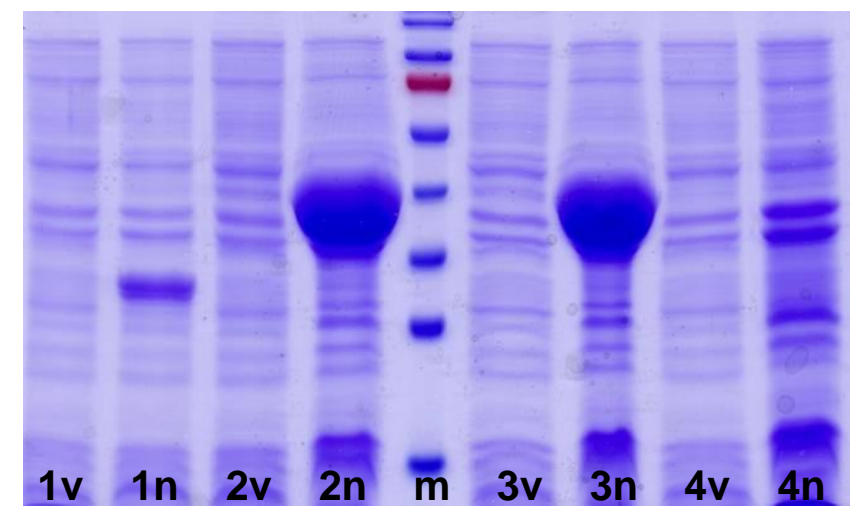

Proteinexpressionskontrolle vor $(v)$ und nach $(\mathrm{n})$ Induktion:
1.) Invo3/4
2.) Mpro5/6 Klon 1
3.) $\mathrm{Mpro5} / 6$ Klon 2
4.) $P C 5 / 6$
m) peqGOLD protein marker IV

Abbildung 7: Kontroll-SDS-PAGE der Proteinproduktion

Es war deutliche Expression bei $2 n$ und bei $3 n$ ersichtlich. $1 n$ zeigte ebenfalls Expression, wenn auch nur schwach. 4 hingegen brachte kein positives Ergebnis. Es wurde verstärkte Expression in folgenden Größen bei positiver Protein-Induktion erwartet: Invo3/4 etwa 26 kDa, Mpro5/6 etwa 35 kDa und PC5/6 etwa 26 kDa.

\subsubsection{Produktion und Aufreinigung rekombinanter Proteine}

Die hergestellten Proteine wurden auf zwei verschiedene Arten gewonnen. Dies geschah zum einen durch Expression in und Aufreinigung aus E. coli zum anderen durch Produktion mittels Pichia pastoris und die Reinigung der Proteine aus dem Kulturüberstand.

\subsubsection{Produktion und Aufreinigung rekombinanter Proteine aus $E$. coli}

Nachdem ausgetestet wurde, ob die hergestellten E.-coli-Kulturen das gewünschte Protein exprimieren, wurde eben dieses Protein über den durch pQE30 angefügten $6 \times$ His-tag durch Bindung an Ni-NTA-Agarose aufgereinigt. Nach Entsalzung und Konzentrierung wurde das Produkt auf einer SDS-PAGE kontrolliert.

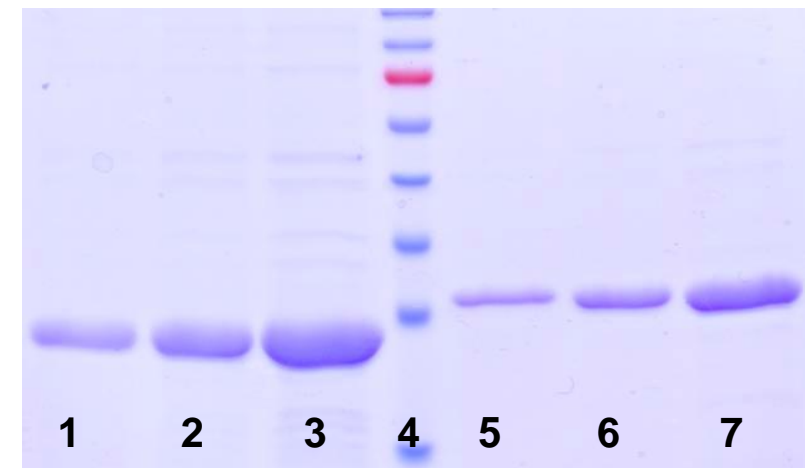

\begin{tabular}{|l|}
\hline aufgereinigte Proteine: \\
1.) $1 \mu \mathrm{AAT}$ \\
2.) $2 \mu \mathrm{AAT}$ \\
3.) $5 \mu \mathrm{AAT}$ \\
4.) peqGOLD protein marker IV \\
5.) $1 \mu \mathrm{MIPS}$ \\
6.) $2 \mu \mathrm{MIPS}$ \\
7.) $5 \mu \mathrm{MI}$ MIPS
\end{tabular}

Abbildung 8: SDS-PAGE gereinigter Proteine aus E.coli

Die erwarteten Proteingrößen waren für AAT etwa $22 \mathrm{kDa}$ und für MIPS ungefähr $23 \mathrm{kDa}$. 
Insgesamt wurden folgende Proteine in E. coli hergestellt und daraus aufgereinigt:

Tabelle 14: rekombinante Proteine aus E. coli, zwei Abbildungen pro Tabellenfeld bedeuten, dass das Protein in zwei Fragmenten exprimiert wurde

\begin{tabular}{|c|c|c|}
\hline Name & Abkürzung & accession-no. \\
\hline $\begin{array}{l}\text { aryl-alcohol dehydrogenase (AS 211-510) } \\
\text { Aminosäuretransport und -metabolismus }\end{array}$ & AAD & AFUA_4G00610 \\
\hline $\begin{array}{l}\text { aspartate aminotransferase (AS 69-261) } \\
\text { Transaminierungen, Verteilung von Enantiomeren }\end{array}$ & AAT & AFUA_4G10410 \\
\hline $\begin{array}{l}\text { alcohol dehydrogenase (AS 29-200) } \\
\text { abhängig von } \mathrm{Zn}^{2+}\end{array}$ & $\mathrm{ADH}$ & AFUA_5G06240 \\
\hline $\begin{array}{l}\text { ADAM family of metalloprotease ADM-A } \\
\text { (AS 116-435) } \\
\text { Protease, Adhäsion, Signalgebung und Fusion }\end{array}$ & ADMA & AFUA_6G14420 \\
\hline $\begin{array}{l}\text { ADAM family of metalloprotease ADM-B } \\
\text { (AS 26-217) } \\
\text { Protease, Adhäsion, Signalgebung und Fusion }\end{array}$ & ADMB & AFUA_4G11150 \\
\hline $\begin{array}{l}\text { ADAM family of metalloprotease ADM-B } \\
\text { (AS 236-455) } \\
\text { Protease, Adhäsion, Signalgebung und Fusion }\end{array}$ & ADMB3/4 & AFUA_4G11150 \\
\hline $\begin{array}{l}\text { classll Aldolase/Adducin domain protein } \\
\text { (AS 8-294) } \\
\text { Kohlenhydratstoffwechsel, Enolat-Stabilisierung }\end{array}$ & AlAd & AFUA_3G09800 \\
\hline $\begin{array}{l}\text { Aminopeptidase (AS 285-609) } \\
\text { Aminosäuretransport und -metabolismus }\end{array}$ & AP & AFUA_4G09030 \\
\hline $\begin{array}{l}\text { Aminopeptidase (AS 661-849) } \\
\text { Aminosäuretransport und -metabolismus }\end{array}$ & AP5/6 & AFUA_4G09030 \\
\hline $\begin{array}{l}\text { 1,3-beta glucanosyltransferase Gel1 (AS 25-188) } \\
\text { immunprotektiv im Tiermodell (Bozza 2009) }\end{array}$ & BGT & AFUA_2G01170 \\
\hline $\begin{array}{l}\text { 1,3-beta glucanosyltransferase Gel1 (AS 219-398) } \\
\text { immunprotektiv im Tiermodell (Bozza 2009) }\end{array}$ & BGT3/4 & AFUA_2G01170 \\
\hline $\begin{array}{l}\text { Coatomer subunit delta (AS 86-406) } \\
\text { Protein-Bindung und -Transport }\end{array}$ & $\mathrm{COA}$ & AFUA_1G15860 \\
\hline $\begin{array}{l}\text { protein disulfid isomerase Pdi1 (AS 26-220) } \\
\text { Bildung von Disulfidbrücken, Chaperon (Horibe 2004) }\end{array}$ & $\mathrm{DI}$ & AFUA_2G06150 \\
\hline $\begin{array}{l}\text { protein disulfid isomerase Pdi1 (AS 255-424) } \\
\text { Bildung von Disulfidbrücken, Chaperon (Horibe 2004) }\end{array}$ & $\mathrm{DI} / 4$ & AFUA_2G06150 \\
\hline $\begin{array}{l}\text { fructose bisphosphate aldolase, classll } \\
\text { (AS 251-420) } \\
\text { Glykolyse, Gluconeogenese }\end{array}$ & FBA & AFUA_3G11690 \\
\hline $\begin{array}{l}\text { Glyceraldehyd 3-phosphat dehydrogenase } \\
\text { (AS 63-240) } \\
\text { Glykolyse, Gluconeogenese }\end{array}$ & GAPD & AFUA_5G01970 \\
\hline $\begin{array}{l}\text { conserved hypothetical protein AFUA_6G07410 } \\
\text { (AS 578-742) } \\
\text { Strukturaufrechterhaltung von Chromosomen }\end{array}$ & HP10 & AFUA_6G07410 \\
\hline conserved hypothetical protein AFUA_1G13670 & HP70 & AFUA_1G13670 \\
\hline
\end{tabular}




\begin{tabular}{|c|c|c|c|}
\hline \multicolumn{2}{|l|}{ (AS 61-244) } & & \\
\hline \multicolumn{2}{|c|}{$\begin{array}{l}\text { conserved hypothetical protein AFUA_1G02290 } \\
\text { (AS 2-95) }\end{array}$} & HP90 & AFUA_1G02290 \\
\hline \multicolumn{2}{|c|}{$\begin{array}{l}\text { heat shock protein Hsp30/Hsp42 (AS 4-519) } \\
\text { Chaperon, posttranslationaler Modifikator }\end{array}$} & Hsp30 & AFUA_3G14540 \\
\hline \multicolumn{2}{|c|}{$\begin{array}{l}\text { Hsp70 chaperone Hsp88 (AS 212-533) } \\
\text { Chaperon }\end{array}$} & Hsp70 & AFUA_1G12610 \\
\hline \multicolumn{2}{|c|}{$\begin{array}{l}\text { involucrin repeat protein (AS 650-887) } \\
\text { Organisierung und Trennung von Chromosomen }\end{array}$} & Invo3/4 & AFUA_4G11410 \\
\hline \multicolumn{2}{|c|}{$\begin{array}{l}\text { myo-inositol-phosphate synthase (AS 4-210) } \\
\text { Signaltransduktion (Klig 1994) }\end{array}$} & MIPS & AFUA_2G01010 \\
\hline \multicolumn{2}{|c|}{$\begin{array}{l}\text { M protein repeat protein (AS 818-1137) } \\
\text { Organisation und Trennung von Chromosomen }\end{array}$} & Mpro5/6 & AFUA_6G08660 \\
\hline \multicolumn{2}{|c|}{$\begin{array}{l}\text { NAD+ dependent glutamate dehydrogenase } \\
\text { (AS 413-699) } \\
\text { Glutamatdehydrogenase (Bringaud 1997; Estévez 1999) }\end{array}$} & NDGD & AFUA_2G06000 \\
\hline \multicolumn{2}{|c|}{$\begin{array}{l}\text { pyruvate decarboxylase PdcA (AS 99-378) } \\
\text { Kohlenhydrattransport und -stoffwechsel }\end{array}$} & PD & AFUA_3G11070 \\
\hline \multicolumn{2}{|c|}{$\begin{array}{l}\text { phosphoglucomutase PgmA (AS 49-369) } \\
\text { Glykolyse }\end{array}$} & $P G$ & AFUA_3G11830 \\
\hline \multicolumn{2}{|c|}{$\begin{array}{l}\text { phosphoglucomutase PgmA (AS 385-548) } \\
\text { Glykolyse }\end{array}$} & PG3/4 & AFUA_3G11830 \\
\hline \multicolumn{2}{|c|}{$\begin{array}{l}\text { phosphoglycerate mutase, 2,3-bisphospho- } \\
\text { glycerate-independent (AS 22-248) } \\
\text { Hydrolyse zur Erzeugung anorganischer Phosphat-Reste } \\
\text { (Galperin 1998; Leyva-Vazquez 1994) }\end{array}$} & PGM & AFUA_3G09290 \\
\hline \multicolumn{2}{|c|}{$\begin{array}{l}\text { 6-phosphofructokinase alpha subunit (AS 254-399) } \\
\text { Enzym der Glykolyse }\end{array}$} & PK & AFUA_4G00960 \\
\hline \multicolumn{2}{|c|}{$\begin{array}{l}\text { 6-phosphofructokinase alpha subunit (AS 8-185) } \\
\text { Enzym der Glykolyse }\end{array}$} & $\mathrm{PK} 3 / 4$ & AFUA_4G00960 \\
\hline \multicolumn{2}{|c|}{$\begin{array}{l}\text { serine hydroxymethyltransferase (AS 248-439) } \\
\text { Umwandlung von Glycin zu Serin }\end{array}$} & SHMT & AFUA_3G09320 \\
\hline \multicolumn{2}{|c|}{$\begin{array}{l}\text { cytoskeleton assembly control protein Sla2 } \\
\text { (AS 427-742) } \\
\text { Exo- und/oder Endozytose }\end{array}$} & Sla & AFUA_3G06140 \\
\hline \multicolumn{2}{|c|}{$\begin{array}{l}\text { spherulin 4-like cell surface protein (AS 148-280) } \\
\text { Sporenbildung (Fronk 1994) }\end{array}$} & SP3/4 & AFUA_4G14080 \\
\hline \multicolumn{2}{|c|}{$\begin{array}{l}\text { thiamine biosynthesis protein (Nmt1) (AS 131-342) } \\
\text { Transport von Thiamin }\end{array}$} & TBP & AFUA_5G02470 \\
\hline \multicolumn{2}{|c|}{$\begin{array}{l}\text { transketolase TktA (AS 157-393) } \\
\text { Kohlenhydratstoffwechsel }\end{array}$} & TK & AFUA_1G13500 \\
\hline $\begin{array}{l}\text { 1,3-beta glucanosyl- } \\
\text { transferase Gel1 } \\
\text { AFUA_2G01170 } \\
\end{array}$ & $\begin{array}{l}\text { 6-phosphofructokinase alpha } \\
\text { subunit AFUA_4G00960 }\end{array}$ & \multicolumn{2}{|c|}{$\begin{array}{l}\text { ADAM family of metalloprotease } \\
\text { ADM-A AFUA_6G14420 } \\
\end{array}$} \\
\hline
\end{tabular}




\begin{tabular}{|c|c|c|}
\hline $\begin{array}{l}\text { ADAM family of metallo- } \\
\text { protease ADM-B } \\
\text { AFUA_4G11150 } \\
\end{array}$ & $\begin{array}{l}\text { alcohol dehydrogenase } \\
\text { AFUA_5G06240 } \\
=\end{array}$ & $\begin{array}{l}\text { aminopeptidase } \\
\text { AFUA_4G09030 } \\
\vdots\end{array}$ \\
\hline $\begin{array}{l}\text { aryl-alcohol-dehydrogenase } \\
\text { AFUA_4G00610 }\end{array}$ & $\begin{array}{l}\text { aspartate aminotransferase } \\
\text { AFUA_4G10410 }\end{array}$ & $\begin{array}{l}\text { class II aldolase/adducin domain } \\
\text { protein } \\
\text { AFUA_3G09800 } \\
\end{array}$ \\
\hline $\begin{array}{l}\text { coatomer subunit delta } \\
\text { AFUA_1G15860 } \\
\end{array}$ & $\begin{array}{l}\text { conserved hypothetical protein } \\
\text { (HP10) AFUA_6G07410 }\end{array}$ & $\begin{array}{l}\text { conserved hypo. protein (HP70) } \\
\text { AFUA_1G13670 }\end{array}$ \\
\hline $\begin{array}{l}\text { conserved hypo. protein } \\
\text { (HP90) AFUA_1G02290 }\end{array}$ & $\begin{array}{l}\text { cytoskeleton assembly control } \\
\text { protein Sla2 AFUA_3G06140 }\end{array}$ & $\begin{array}{l}\text { fructose-bisphosphate aldolase, } \\
\text { class II AFUA_3G11690 }\end{array}$ \\
\hline $\begin{array}{l}\text { Glyceraldehyd-3-phosphate } \\
\text { dehydrogenase } \\
\text { AFUA_5G01970 } \\
-\end{array}$ & $\begin{array}{l}\text { heat shock protein Hsp30/Hsp42 } \\
\text { AFUA_3G14540 }\end{array}$ & $\begin{array}{l}\text { Hsp70 chaperone Hsp88 } \\
\text { AFUA_1G12610 } \\
\end{array}$ \\
\hline $\begin{array}{l}\text { involucrin repeat protein } \\
\text { AFUA_4G11410 }\end{array}$ & $\begin{array}{l}\text { M protein repeat protein } 5 / 6 \\
\text { AFUA_6G08660 }\end{array}$ & $\begin{array}{l}\text { myo-inositol-phosphate synthase } \\
\text { AFUA_2G01010 } \\
\end{array}$ \\
\hline $\begin{array}{l}\text { NAD }^{+} \text {dep. Glu dehydro- } \\
\text { genase AFUA_2G06000 }\end{array}$ & $\begin{array}{l}\text { phosphoglucomutase } \\
\text { AFUA_3G11830 } \\
\end{array}$ & $\begin{array}{l}\text { phosphoglycerate mutase, } 2,3- \\
\text { bisphosphoglycerate-indep. } \\
\text { AFUA_3G09290 } \\
\end{array}$ \\
\hline $\begin{array}{l}\text { protein disulfide isomerase } \\
\text { Pdi1 } \\
\text { AFUA_2G06150 }\end{array}$ & $\begin{array}{l}\text { pyruvate decarboxylase PdcA } \\
\text { AFUA_3G11070 }\end{array}$ & $\begin{array}{l}\text { Ser hydroxymethyl-transferase } \\
\text { AFUA_3G09320 } \\
\end{array}$ \\
\hline $\begin{array}{l}\text { spherulin 4-like cell surface } \\
\text { protein AFUA_4G14080 }\end{array}$ & $\begin{array}{l}\text { thiamine biosynthesis protein } \\
\text { (Nmt1) AFUA_5G02470 } \\
\end{array}$ & $\begin{array}{l}\text { Transketolase TktA } \\
\text { AFUA_1G13500 } \\
\equiv \\
\vdots \\
\vdots---\end{array}$ \\
\hline
\end{tabular}

Desweiteren lagen folgende Proteine bereits zuvor exprimiert vor: allergen Asp f3, enolase/allergen Asp f22, extracellular cell wall glucanase Crf1/allergen Asp f9, extracellular lipase, Glu/Leu/Phe/Val-dehydrogenase, Mannitol-1-phosphate dehydro-genase, NAD+ dep. formate dehydrogenase AciA/Fdh, Spore-specific catalase CatA. 


\subsubsection{Produktion und Aufreinigung rekombinanter Proteine aus $\boldsymbol{P}$. pastoris}

Die Expression in $P$. pastoris führte zu in den Kulturüberstand sekretierten Proteinen, welche im Anschluss gereinigt und konzentriert wurden. Als Kontrolle wurde jeweils eine SDS-PAGE durchgeführt:
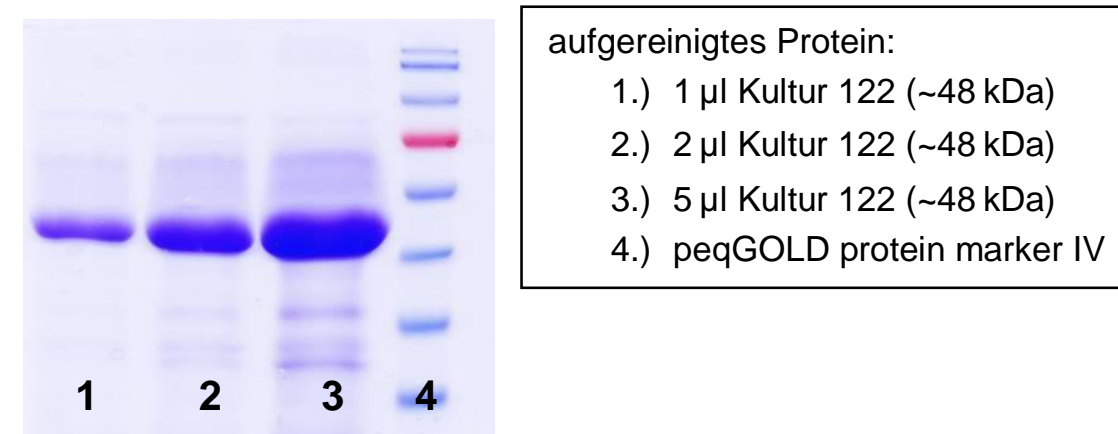

Abbildung 9: SDS-PAGE eines gereinigten Proteins aus P. pastoris (Elastinolytic metalloproteinase Mep)

In Pichia pastoris wurden folgende Proteine hergestellt und gereinigt:

Tabelle 15: rekombinante Proteine aus $P$. pastoris

\begin{tabular}{|l|l|l|}
\hline Name & Kultur-Nr. & accession-no. \\
\hline $\begin{array}{l}\text { alkaline serine protease Alp1 } \\
\text { Subtilisin-Endoprotease }\end{array}$ & $28(\&$ 128) & AFUA_4G11800 \\
\hline $\begin{array}{l}\text { extracellular dipeptidyl peptidase Dpp4 } \\
\text { Exoprotease (Beauvais 1997) }\end{array}$ & 49 & AFUA_4G09320 \\
\hline $\begin{array}{l}\text { aspartic endopeptidase Pep1/aspergillopepsin F } \\
\text { Endoprotease des Elastins (Reichard 1995) }\end{array}$ & 113 & AFUA_5G13300 \\
\hline $\begin{array}{l}\text { elastinolytic metalloprotease Mep } \\
\text { Endoprotease des Collagens (Reichard 1990 und 1994; } \\
\text { Monod 1991) }\end{array}$ & 122 & AFUA_8G07080 \\
\hline $\begin{array}{l}\text { aspartic endopeptidase Pep2 } \\
\text { Endoprotease (Reichard 2000) }\end{array}$ & 326 & AFUA_3G11400 \\
\hline $\begin{array}{l}\text { aminopeptidase Y (LAP2) } \\
\text { Protease-assoziierte Domäne }\end{array}$ & 443 & AFUA_3G00650 \\
\hline $\begin{array}{l}\text { aminopeptidase (LAP1) } \\
\text { sekretierte Leucin-Aminopeptidase }\end{array}$ & 445 & AFUA_4G04210 \\
\hline $\begin{array}{l}\text { penicillolysin/deuterolysin metalloprotease } \\
\text { wahrscheinlich sekretierte Endoprotease }\end{array}$ & 461 & AFUA_4G13750 \\
\hline
\end{tabular}




\begin{tabular}{|c|c|c|c|}
\hline $\begin{array}{l}\text { Alkaline serine } \\
\text { protease Alp1 } \\
\text { AFUA_4G11800 }\end{array}$ & $\begin{array}{l}\text { Extracellular dipeptidyl } \\
\text { peptidase Dpp4 } \\
\text { AFUA_4G09320 } \\
=\end{array}$ & $\begin{array}{l}\text { Aspartic } \\
\text { endopeptidase } \\
\text { Pep1/aspergillopepsin } \\
\text { F AFUA_5G13300 } \\
= \\
= \\
=\end{array}$ & $\begin{array}{l}\text { Elastinolytic } \\
\text { metalloproteinase Mep } \\
\text { AFUA_8G07080 }\end{array}$ \\
\hline $\begin{array}{l}\text { Aspartic } \\
\text { endopeptidase Pep2 } \\
\text { AFUA_3G11400 } \\
= \\
= \\
=\end{array}$ & $\begin{array}{l}\text { Aminopeptidase } \mathrm{Y} \\
\text { (LAP2) AFUA_3G00650 }\end{array}$ & $\begin{array}{l}\text { Aminopeptidase } \\
\text { (LAP1) AFUA_4G04210 }\end{array}$ & $\begin{array}{l}\text { Penicillolysin/deuterolysin } \\
\text { metalloprotease } \\
\text { AFUA_4G13750 } \\
\\
\vdots \\
=\end{array}$ \\
\hline
\end{tabular}

\subsection{Immunisierung durch rekombinante $A .-$ fumigatus-Proteine im}

\section{Mausmodell}

Eine Kohorte an rekombinant hergestellten Proteinen wurde NMRI-Mäusen s.c. geimpft (s. 2.16). Nach Immunsuppression wurden diese Mäuse mit einer definierten Menge A.-fumigatus-Sporen i.n. infiziert. Die täglichen Wiegungen und beobachtete Verhaltensänderungen (z.B.: erschwerte Atmung, Lethargie, vernachlässigte Fellpflege) wurden genauso in Tabellen notiert, wie die Ergebnisse der untersuchten Lungen der jeweiligen Mäuse. 
Tabelle 16: Gewichtstabelle der täglichen Wiegungen der Versuchstiere (beginnend mit Tag 1 p.i.; Angaben in Gramm (g))

\begin{tabular}{|c|c|c|c|c|c|c|c|c|c|c|}
\hline Datum & 03.04. & 04.04 & 05.04. & 06.04. & 07.04. & 08.04. & 09.04. & 10.04 & 11.04. & 12.04 \\
\hline \begin{tabular}{|l|} 
Kontroll- \\
gruppe \\
(negativ)
\end{tabular} & $\begin{array}{l}34,5 \\
30 \\
27,5 \\
33,5 \\
33,5 \\
33,5 \\
32\end{array}$ & $\begin{array}{l}26,5 \\
30 \\
30 \\
28,5\end{array}$ & $\begin{array}{l}27 \\
28 \\
31\end{array}$ & $\begin{array}{l}27 \\
30,5\end{array}$ & $\begin{array}{l}26 \\
29,5\end{array}$ & $\begin{array}{l}23,5 \\
26,5\end{array}$ & $\begin{array}{l}22,7 \\
21\end{array}$ & 22 & & \\
\hline $\begin{array}{l}\text { Positiv- } \\
\text { gruppe } \\
\text { (Aspf3/16, } \\
\text { BGT) }\end{array}$ & $\begin{array}{l}32 \\
36 \\
33 \\
36 \\
43 \\
27,5 \\
32,5\end{array}$ & $\begin{array}{l}30 \\
30,5 \\
43,5\end{array}$ & 41 & 39,5 & 35,5 & 31,5 & 28,5 & 26,5 & & \\
\hline $\begin{array}{l}\text { Vakzin- } \\
\text { gruppe }\end{array}$ & $\begin{array}{l}32 \\
35,5 \\
32,5 \\
32 \\
41 \\
36,5 \\
34\end{array}$ & $\begin{array}{l}32 \\
30,5 \\
31 \\
40,5 \\
31,5\end{array}$ & $\begin{array}{l}40 \\
29 \\
30,5\end{array}$ & $\begin{array}{l}27 \\
39\end{array}$ & $\begin{array}{l}36 \\
26\end{array}$ & $\begin{array}{l}35,5 \\
24,5\end{array}$ & 34 & 34,5 & 35 & 35 \\
\hline
\end{tabular}


Tabelle 17: Beobachtungen an den Versuchstieren und Ergebnisse der Infektionskontrollen

\begin{tabular}{|c|c|c|c|c|c|}
\hline Nummer + Impfung & $\begin{array}{l}\text { Lunge: Beurteilung } \\
\text { (Verbreitung von } \\
\text { A. fumigatus) }\end{array}$ & Lungenkultur & $\begin{array}{l}\text { Log cfu/ } \\
\text { Lunge }\end{array}$ & Grund der Abtötung & Abtötungstag \\
\hline 1 Negativkontrolle & $\begin{array}{l}\text { jedes 2.-3. Gesichtsfeld bei } \\
\text { 320x Vergrößerung }\left(\mathrm{GF}_{320}\right)\end{array}$ & $\begin{array}{|ll|}1: 10 & - \\
1: 100 & 1 / 2=91 \\
1: 1000 & 12\end{array}$ & 5,56 & (ohne Eintrag = ÜN gestorben) & \\
\hline 2 Negativkontrolle & jedes 2.-3. GF $_{320}$ & $\begin{array}{|ll|}1: 10 & - \\
1: 100 & 1 / 2=75 \\
1: 1000 & 6\end{array}$ & 5,37 & & \\
\hline 3 Negativkontrolle & jedes 2.-3. $\mathrm{GF}_{320}$ & $\begin{array}{|ll|}1: 10 & - \\
1: 100 & 1 / 2=60 \\
1: 1000 & 8\end{array}$ & 5,385 & & \\
\hline 4 Negativkontrolle & jedes GF $\mathrm{GF}_{320}$ & $\begin{array}{|ll|}1: 10 & - \\
1: 100 & 134 \\
1: 1000 & 16 \\
\end{array}$ & 5,56 & & \\
\hline 5 Negativkontrolle & $\sim$ jedes 2. $\mathrm{GF}_{320}$ & $\begin{array}{|ll|}1: 10 & - \\
1: 100 & 37 \\
1: 1000 & 1\end{array}$ & 4,675 & & \\
\hline 6 Negativkontrolle & $\sim$ jedes 1.-2. $\mathrm{GF}_{320}$ & $\begin{array}{|ll|}1: 10 & 99 \\
1: 100 & 8 \\
1: 1000 & 2 \\
\end{array}$ & 4,46 & & \\
\hline 7 Negativkontrolle & jedes 2. $\mathrm{GF}_{320}$ & $\begin{array}{|ll|}1: 10 & 43 \\
1: 100 & 6 \\
1: 1000 & 0 \\
\end{array}$ & 4,1 & $\begin{array}{l}\text { sehr schlechter Allgemein- } \\
\text { zustand }\end{array}$ & $8 \mathrm{~d}$ p.i. \\
\hline 8 Positivkontrolle & jedes 2. $\mathrm{GF}_{320}$ & $\begin{array}{|ll|}1: 10 & - \\
1: 100 & 67 \\
1: 1000 & 3 \\
\end{array}$ & 5,045 & & \\
\hline 9 Positivkontrolle & $\sim$ jedes 1.-2. GF $_{320}$ & $\begin{array}{|ll|}1: 10 & - \\
1: 100 & 52 \\
1: 1000 & 1\end{array}$ & 4,75 & & \\
\hline 10 Positivkontrolle & $\sim$ jedes 1.-2. $\mathrm{GF}_{320}$ & $\begin{array}{|ll|}1: 10 & - \\
1: 100 & 1 / 2=53 \\
1: 1000 & 7\end{array}$ & 5,33 & & \\
\hline
\end{tabular}




\begin{tabular}{|c|c|c|c|c|c|c|}
\hline 11 Positivkontrolle & $\sim$ jedes $\mathrm{GF}_{320}$ & $\begin{array}{ll}1: 10 \\
1: 100 \\
1: 1000\end{array}$ & & 5,215 & & \\
\hline 12 Positivkontrolle & $\sim$ jedes $\mathrm{GF}_{320}$ & $\begin{array}{l}1: 10 \\
1: 100 \\
1: 1000\end{array}$ & & 5,06 & & \\
\hline 13 Positivkontrolle & $\sim$ jedes 2.-3. GF $_{320}$ & \begin{tabular}{|l|}
$1: 10$ \\
$1: 100$ \\
$1: 1000$
\end{tabular} & $\begin{array}{l}- \\
61 \\
5\end{array}$ & 5,135 & & \\
\hline 14 Positivkontrolle & $\begin{array}{l}\text { +/- kein Pilz sichtbar } \\
\text { (maximal in jedem } 15 . \text { GF }_{320} \text { ) }\end{array}$ & \begin{tabular}{|l|l|}
$1: 10$ \\
$1: 100$ \\
$1: 1000$
\end{tabular} & & - & $\begin{array}{l}\text { sehr schlechter Allgemein- } \\
\text { zustand; Darm stark aufgebläht }\end{array}$ & $8 \mathrm{~d}$ p.i. \\
\hline 15 Vakzin & $\sim$ jedes $\mathrm{GF}_{320}$ & \begin{tabular}{l|l}
$1: 10$ \\
$1: 100$ \\
$1: 1000$
\end{tabular} & & 5,95 & & \\
\hline 16 Vakzin & $\sim$ jedes $\mathrm{GF}_{320}$ & \begin{tabular}{l|}
$1: 10$ \\
$1: 100$ \\
$1: 1000$
\end{tabular} & $\begin{array}{l}-1 / 4=63 \\
35\end{array}$ & 5,87 & & \\
\hline 17 Vakzin & $\sim$ jedes (2.-)3. GF $_{320}$ & \begin{tabular}{l|l}
$1: 10$ \\
$1: 100$ \\
$1: 1000$
\end{tabular} & $\begin{array}{l}- \\
50 \\
2\end{array}$ & 4,89 & & \\
\hline 19 Vakzin & $\sim$ jedes 1.-2. GF 320 & $\begin{array}{ll}1: 10 \\
1: 100 \\
1: 1000 \\
\end{array}$ & $\begin{array}{l}- \\
17 \\
1\end{array}$ & 4,5 & & \\
\hline 20 Vakzin & $\sim$ jedes 1.-2. GF $_{320}$ & \begin{tabular}{l|}
$1: 10$ \\
$1: 100$ \\
$1: 1000$
\end{tabular} & $\begin{array}{l}- \\
89 \\
1\end{array}$ & 4,86 & $\begin{array}{l}\text { sehr schlechter Allgemein- } \\
\text { zustand }\end{array}$ & 6d p.i. \\
\hline 21 Vakzin & $\begin{array}{l}+/- \text { kein Pilz sichtbar (1x pro } \\
5 \mu \text { l Probe) }\end{array}$ & \begin{tabular}{l|l|}
$1: 10$ \\
$1: 100$ \\
$1: 1000$
\end{tabular} & $\begin{array}{l}0 \\
0 \\
0\end{array}$ & - & $\begin{array}{l}\text { schwere und geräuschvolle } \\
\text { Atmung/Versuchsende }\end{array}$ & $10 \mathrm{~d}$ p.i. \\
\hline
\end{tabular}

Auch wenn in den kontrollierten Lungen sowohl mikroskopisch mit Blankophor als auch in gewachsener Kultur eine Besiedelung mit A. fumigatus nachgewiesen wurde, so traf dies bei allen drei Gruppen +/- gleichmäßig zu. 
Dies wird auch deutlich, wenn man die Überlebensraten der verschiedenen Gruppen betrachtet (angegeben sind Tage post infectionem):

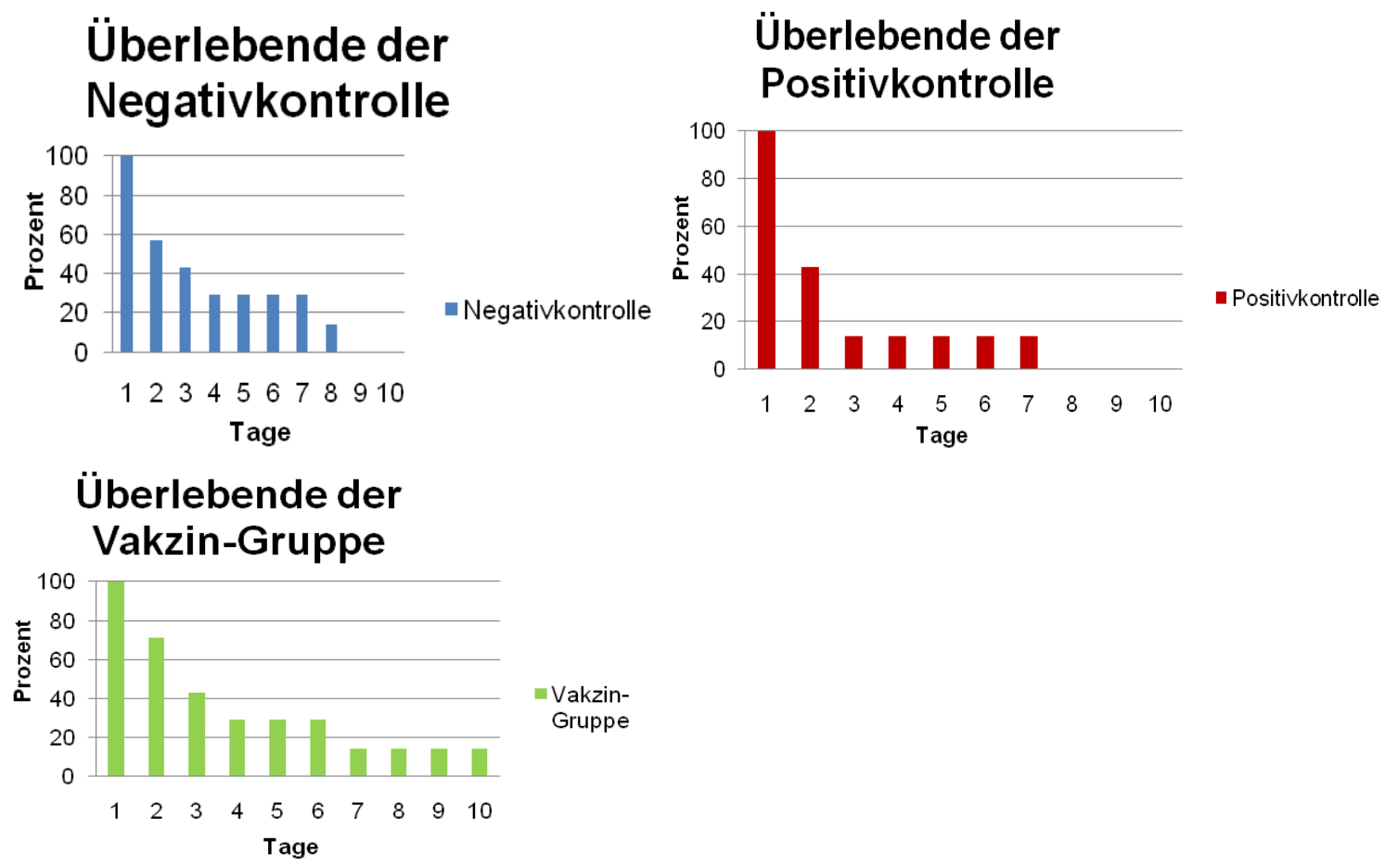

Abbildung 10: Prozentualer Anteil an überlebenden Mäusen je Versuchsgruppe und Tag

Stellt man alle drei Gruppen direkt nebeneinander, wird deutlich, dass in jeder Gruppe eine heftige und schnelle Infektion mit $A$. fumigatus erzeugt wurde.

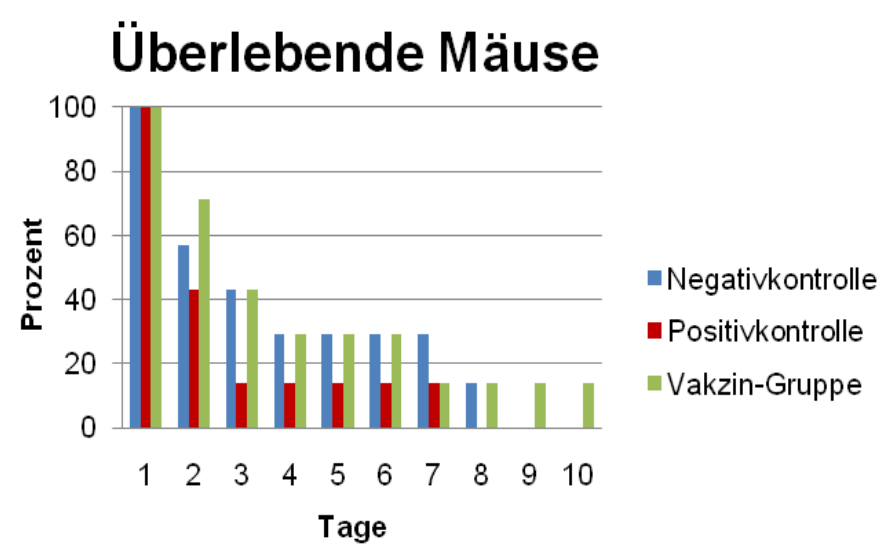

Abbildung 11: Prozentualer Anteil überlebender Mäuse gegenüber gestellt

Lediglich eine Maus der Positiv- und eine Maus der Vakzin-Gruppe zeigten keine Besiedlung mit dem Erreger, wie nach Obduktion der Lunge und der folgenden Kontrollen festgestellt werden konnte.

Zusätzlich war der Gesundheitszustand der überlebenden Vakzin-Maus ab Tag fünf p.i. relativ und ab Tag sieben p.i. deutlich stabil. Sie nahm sogar wieder etwas an Körpergewicht zu (s. Tab. 16). 


\subsection{Herstellung von Gen-Deletionsmutanten in Asperqillus fumigatus}

\subsubsection{Herstellung von $\triangle A D A M-A$}

\subsubsection{Herstellung des Deletionsplasmids}

Zu Beginn wurden flankierende Bereiche des zu deletierenden Gens über nested PCR amplifiziert (Primer: AA1 bis AA8). Diese wurden in pBlueskript II SK+ Pacl kloniert. Zwischen die vorbereiteten flankierenden Bereiche wurde das Resistenzliefernde Insert aus pSK397 (s. Anhang) kloniert. Das so erstellte Deletionsplasmid wurde über Restriktionsanalysen und Agarosegel kontrolliert:

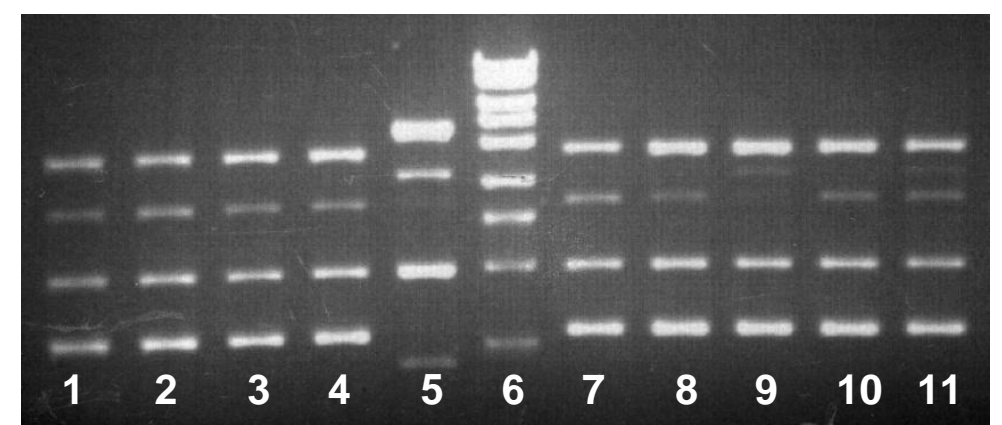

Deletionsplasmid-Kontrolle: 1-5 und 7-11) extrahierte Plasmide aus verschiedenen E.-coli-Kulturen EcoRIverdaut

6.) Molekulargewichtstandard ladder high

Abbildung 12: Kontrolle des Deletionsplasmids pADAM-A-del (EcoRI-verdaut)

Die erwarteten Fragmentgrößen bei korrekt angefertigtem pADAM-A-del waren: 1558bp, 1594bp, 1938bp und 3660bp. Die unterste Bande in Abbildung 12 beinhaltete zwei Fragmente, die auf Grund des geringen Größenunterschieds nicht voneinander getrennt wurden. Lediglich die Nummern 5 und 9 zeigten nicht korrekte Schnittmuster.

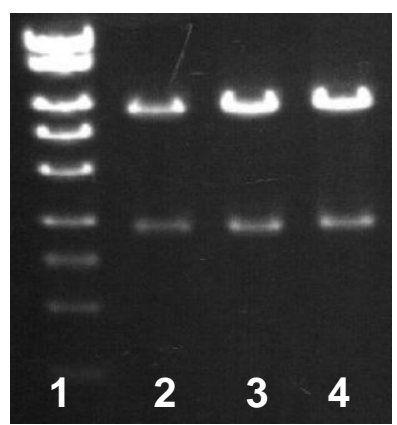

Deletionsplasmid-Kontrolle:

1.) Molekulargewichtstandard ladder high

2-4.) extrahierte Plasmide aus verschiedenen E. coli-

Kulturen Notl und Pacl -verdaut

Abbildung 13: Kontrolle des Deletionsplasmids pADAM-A-del (Notl- und Pacl-verdaut)

An den beiden Bildern erkannte man, ob die extrahierten Plasmide richtig kloniert wurden. In dem unteren Bild stimmten alle Klone mit den erwarteten Fragmentgrößen (2899bp, 5866bp) überein.

\subsubsection{Kontrolle der A.-fumigatus- $\triangle$ ADAM-A-Klone nach Transformation}

Kontrolle mittels Southern-Blot

Kontrolliert wurde die aus der erzeugten Deletionsmutante isolierte DNA mit spezifisch ausgesuchten Restriktionsenzymen. Die im Southern-Blot verwendete 
DNA-Sonde hatte den A. nidulans Promotor des Resistenz-liefernden Inserts als Ziel. Der theoretische Aufbau der Gen-Deletion über homologe Rekombinationen war wie folgt; wobei folgende Komponenten verwendet wurden: loxP = Schnittstelle für eine cre-Rekombinase, pgpdA = Promotor, HSV1TK = Thymidinkinase, $\operatorname{ttrpC}=$ Terminator, Sonde $=$ DNA-Sonde des Southern-Blots, gestrichelte Linien $=$ Orte der homologen Rekombination, $\mathrm{ADAM}-\mathrm{A}^{*}=$ minimalste Reste des deletierten Gens

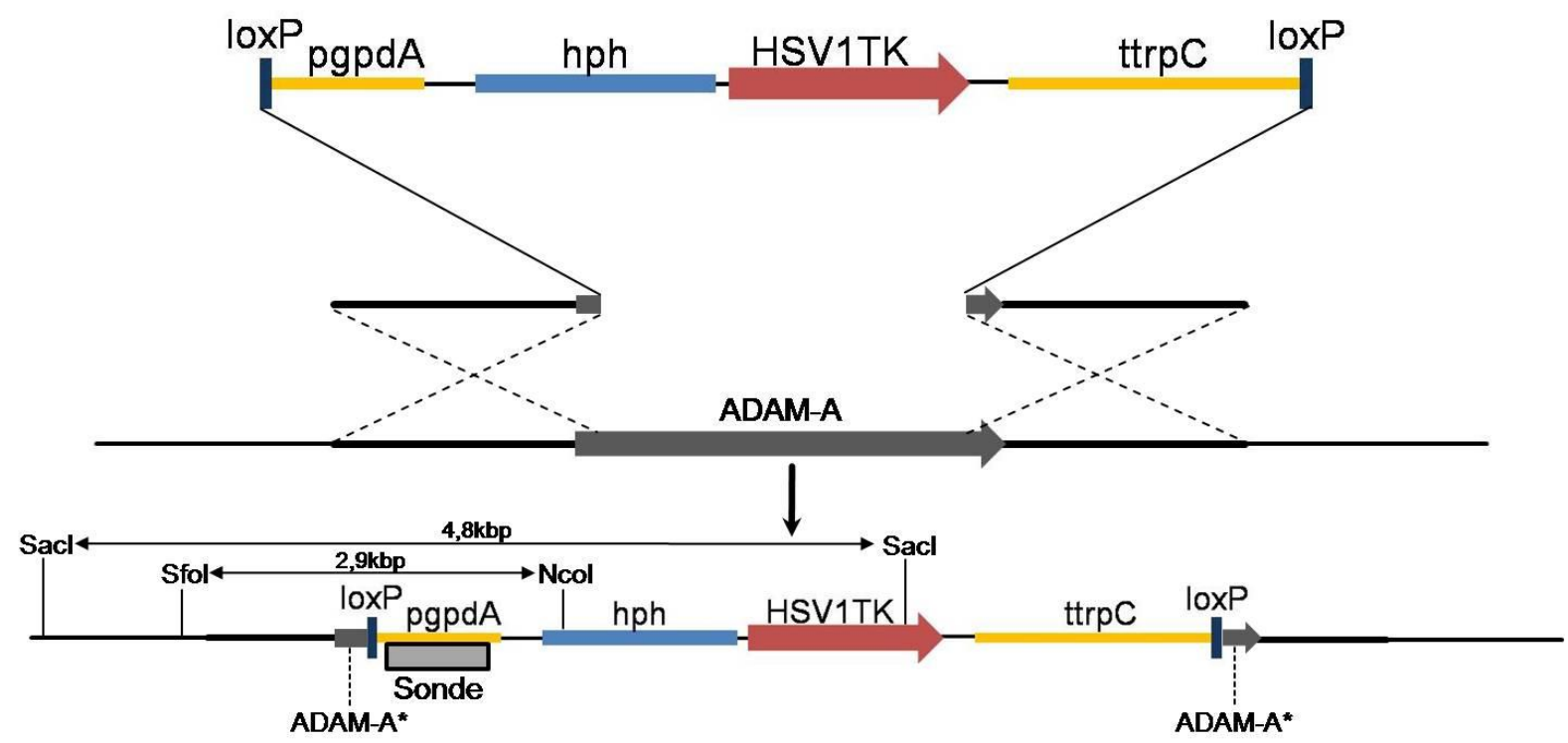

Abbildung 14: schematischer Aufbau des Austausches des ADAM-A-Gens

Tabelle 18: bei $\triangle$ ADAM-A zur Kontrolle verwendete Restriktionsenzyme

\begin{tabular}{|l|l|l|}
\hline Mutante & Restriktionsenzym & erwartete Fragmentgröße \\
\hline \multirow{2}{*}{ ADAM-A } & Sacl & $4,8 \mathrm{~kb}$ \\
\cline { 2 - 3 } & Sfol/Ncol & $2,9 \mathrm{~kb}$ \\
\hline
\end{tabular}

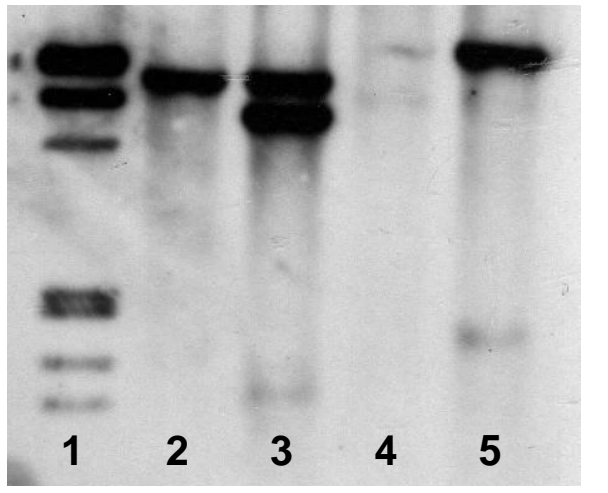

Southern-Blot auf $\triangle$ ADAM-A:

1.) Molekulargewichtstandard peqGold Prestained Protein-Marker III

2.) $\triangle$ ADAM-A 6 Sacl verdaut

3.) $\triangle$ ADAM-A 8 Sacl verdaut

4.) $\triangle$ ADAM-A 6 Sfol/Ncol verdaut

5.) $\triangle$ ADAM-A 8 Sfol/Ncol verdaut

Abbildung 15: Southern-Blot auf $\triangle$ ADAM-A

$\triangle$ ADAM-A 6 mit Sacl verdaut zeigte die erwartete Fragmentgröße. Der zweite Verdau mit Sfol/Ncol brachte keine verwertbaren Ergebnisse.

Kontrolle mittels PCR

Im Anschluss an eine durchgeführte Transformation in A. fumigatus wurden die erhaltenen Klone auf die erfolgreiche Deletion mittels mehrerer PCR-Reaktionen mit 
spezifisch designten Primern auf die korrekte Gen-Deletion hin überprüft (s. Tab. 10: Kontrollprimer der Deletionsmutanten).

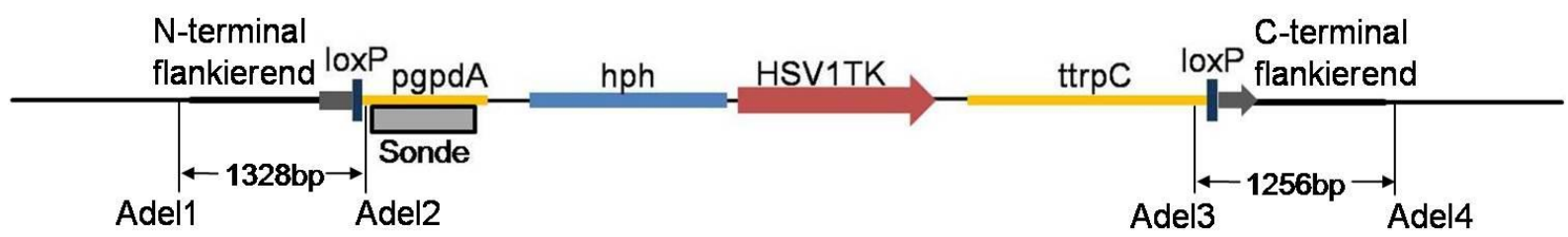

Abbildung 16: Schema der Lage der Kontrollprimer nach Deletion von ADAM-A

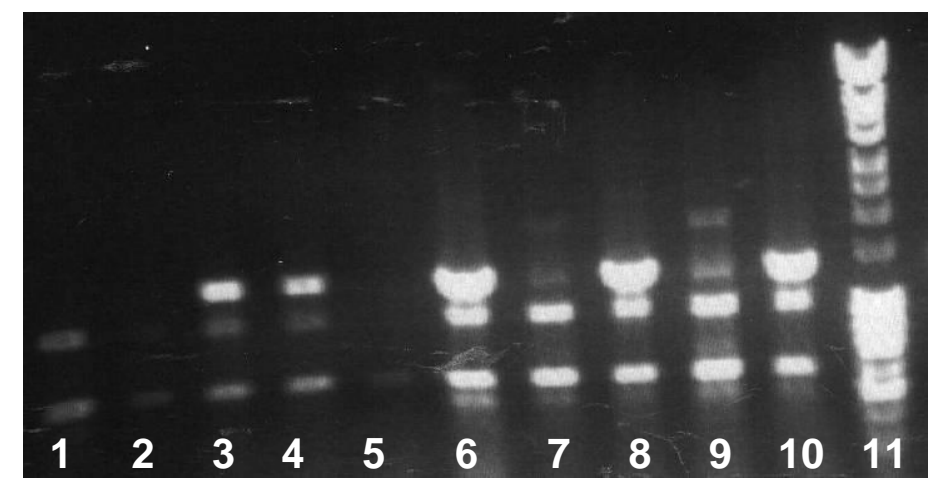

A.-fumigatus-Klone nach Deletion von ADAM-A: 10 Mutanten $(1-10)$, Molekulargewichtstandard ladder mix (Nr. 11)

Abbildung 17: Mutanten nach Deletion von ADAM-A; Primerpaar Adel1/2

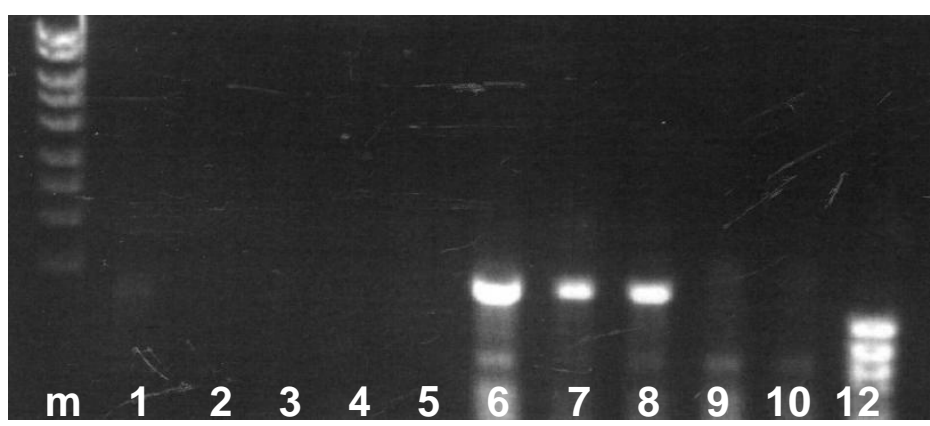

A.-fumigatus-Klone nach Deletion von ADAM-A: 10 Mutanten (1 - 10), Molekulargewichtstandard ladder high $(\mathrm{m})$ und low (Nr. 12)

Abbildung 18: Mutanten nach Gen-Deletion von ADAM-A; Primerpaar Adel3/4

Anhand beider Bilder ließ sich erkennen, dass laut erster Kontrolle (Adel1/2) die Klone 6,8 und 10 Banden in erwarteter Größe zeigten, welche 1328 bp betragen sollte. Die gleichen Klone wurden zusätzlich mit den zweiten Primern (Adel3/4) kontrolliert, wonach die Klone 6,7 und 8 Banden in richtiger Größe lieferten. Diese sollte 1256 bp betragen. Zusammen betrachtet waren also lediglich die Klone Nummer 6 und 8 (laut Abbildungen 17 und 18) als positiv anzusehen.

Als zusätzliche Kontrolle wurden Primer in einer PCR verwendet, die spezifische Fragmente des ADAM-A- oder ADAM-B-Gens direkt amplifizierten (pADAMA1/2 oder pADAMB1/2). Mit diesen wurde der zuvor positiv getestete Klon erneut kontrolliert: 


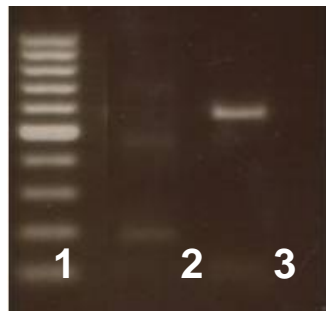

PCR-Kontrollen nach Gen-Deletion von ADAM-A

1.) Molekulargewichtstandard ladder low

2.) $\triangle \mathrm{ADAM}-\mathrm{A} 6$ mit Primern auf Gen-ADAM-A

3.) $\triangle \mathrm{ADAM}-\mathrm{A} 6$ Primern auf Gen-ADAM-B

Abbildung 19: PCR Kontrolle nach Gen-Deletion (ADAM-A)

Die verwendeten Primer lieferten folgende Fragmentgrößen: Primer auf das Gen zu ADAM-A (pADAMA1/2) sollten 554 bp große Fragmente ergeben und Primer auf das ADAM-B-Gen (pADAMB1/2) 538 bp. Dadurch war ersichtlich, dass das ADAM-A-Gen wirklich nicht mehr vorhanden war.

\subsubsection{Herstellung von $\triangle A D A M-B$}

\subsubsection{Herstellung des Deletionsplasmids}

Zu Beginn wurden flankierende Bereiche des zu deletierenden Gens über nested PCR amplifiziert (Primer: AB1 bis AB8). Diese wurden in pBlueskript II SK+ Pacl kloniert. Zwischen die vorbereiteten flankierenden Bereiche wurde das Resistenzliefernde Insert aus pSK397 (s. Anhang) kloniert. Das so erstellte Deletionsplasmid wurde über Restriktionsanalysen und Agarosegel kontrolliert:

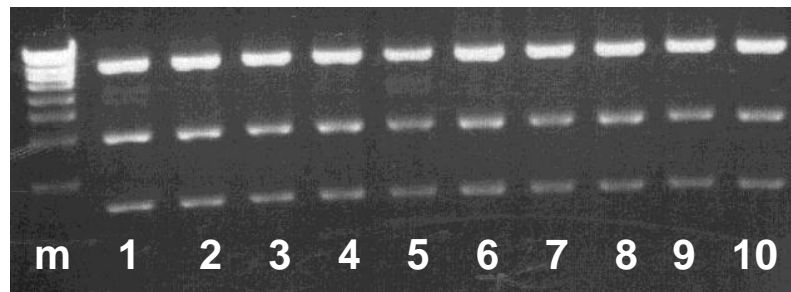

Deletionsplasmid-Kontrolle:

m)Molekulargewichtstandard ladder high

1 bis 10) extrahierte Plasmide aus

verschiedenen E.-coli-Kulturen EcoRI-verdaut

Abbildung 20: Kontrolle von Deletionsplasmiden (pADAM-B-del EcoRI-verdaut)

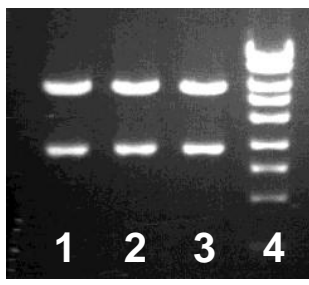

Deletionsplasmid-Kontrolle:

1-3.) extrahierte Plasmide aus verschiedenen E. coli-

Kulturen Notl und Pacl-verdaut

4.) Molekulargewichtstandard ladder high

Abbildung 21: Kontrolle von Deletionsplasmiden (pADAM-B-del Notl- und Pacl-verdaut)

Anhand dieser beiden Bilder erkannte man, ob die extrahierten Plasmide richtig kloniert wurden. In beiden Bildern stimmten alle Klone mit den erwarteten Fragmentgrößen überein: oben 1311 bp, 1938 bp, 5516 bp und unten 2899 bp, 5866 bp.

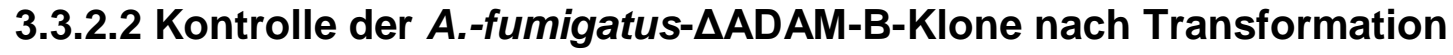

Kontrolle mittels Southern-Blot

Kontrolliert wurde die aus den erzeugten Deletionsmutanten isolierte DNA mit spezifisch ausgesuchten Restriktionsenzymen. Die im Southern-Blot verwendete DNA-Sonde hatte den A. nidulans Promotor des Resistenz-liefernden Inserts als Ziel. 
Der theoretische Aufbau der Gen-Deletion über homologe Rekombinationen war wie folgt; wobei folgende Komponenten verwendet wurden: loxP = Schnittstelle für eine cre-Rekombinase, pgpdA = Promotor, HSV1TK = Thymidinkinase, $\operatorname{trpC}=$ Terminator, Sonde $=$ DNA-Sonde des Southern-Blots, gestrichelte Linien $=$ Orte der homologen Rekombination, ADAM-B ${ }^{*}=$ minimalste Reste des deletierten Gens

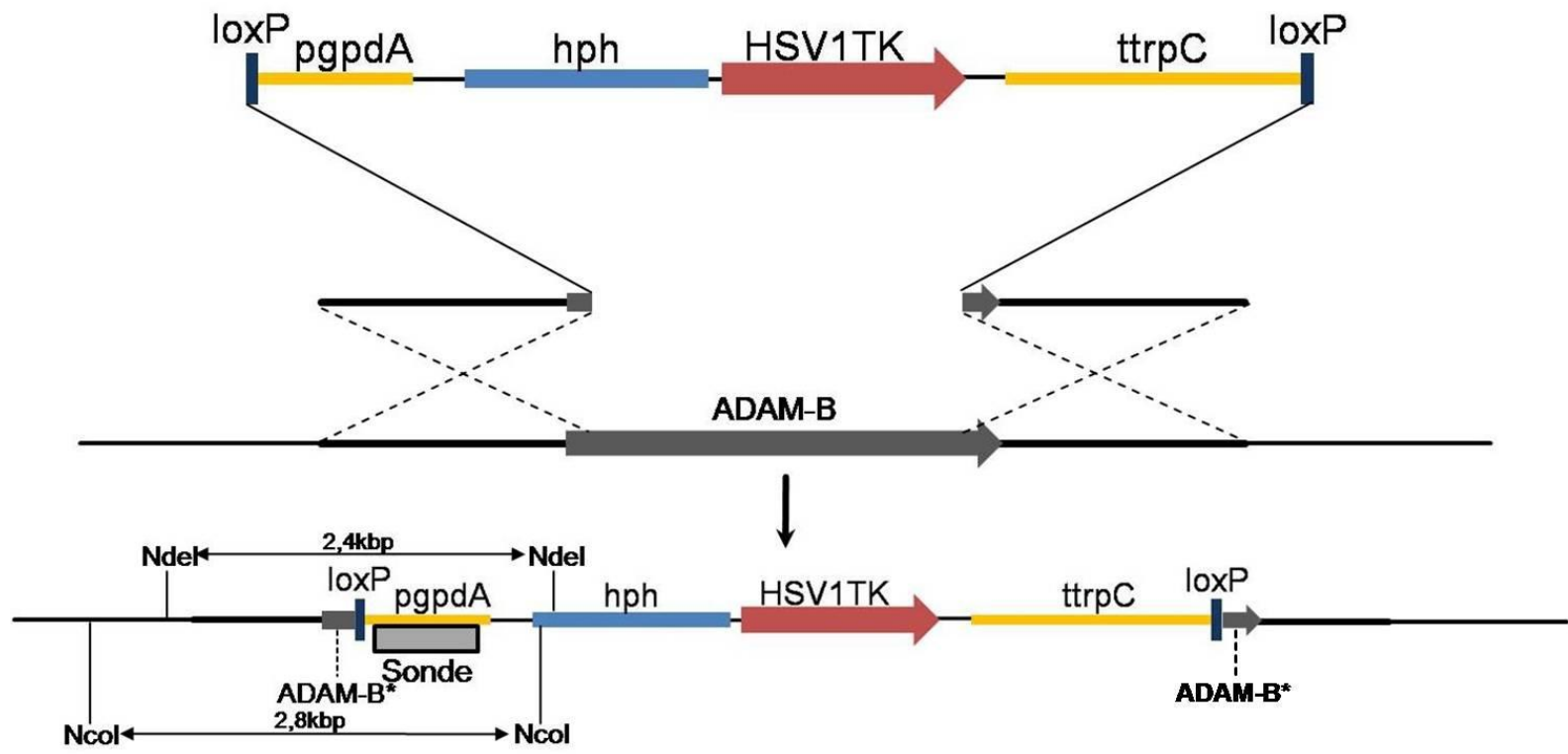

Abbildung 22: schematischer Aufbau des Austausches des ADAM-B-Gens

Tabelle 19: bei $\triangle$ ADAM-B zur Kontrolle verwendete Restriktionsenzyme

\begin{tabular}{|l|l|l|}
\hline Mutante & Restriktionsenzym & erwartete Fragmentgröße \\
\hline \multirow{2}{*}{ ADAM-B } & Ncol & $2,8 \mathrm{~kb}$ \\
\cline { 2 - 3 } & Ndel & $2,4 \mathrm{~kb}$ \\
\hline
\end{tabular}
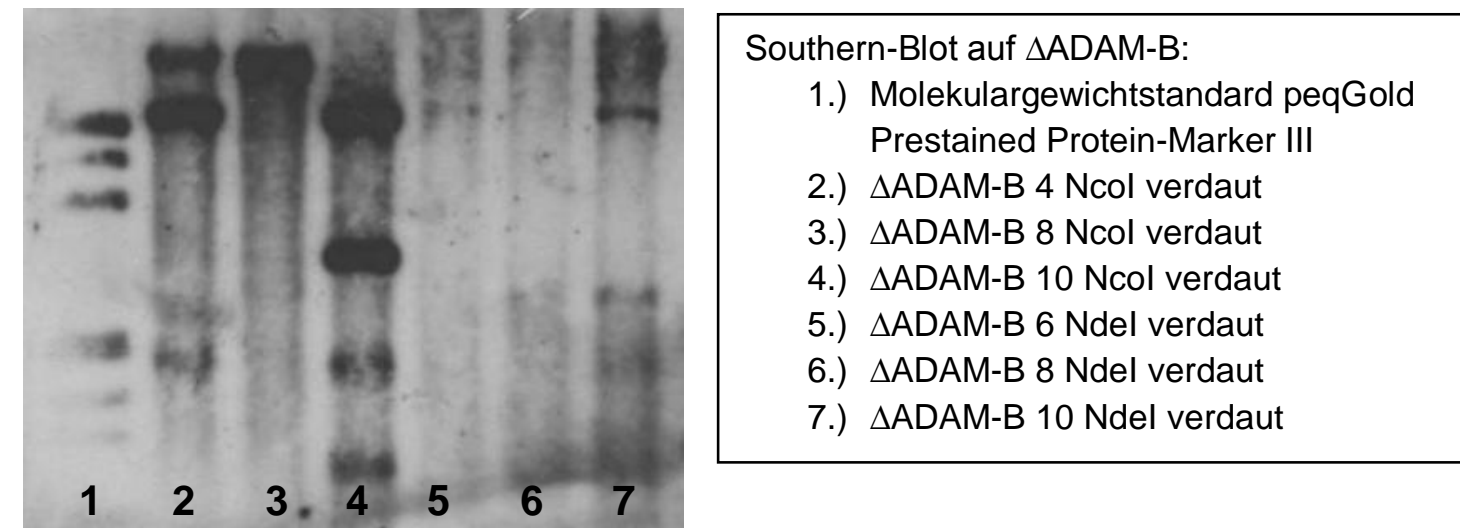

Abbildung 23: Southern-Blot auf $\triangle$ ADAM-B

$\triangle$ ADAM-B 10 mit Ncol verdaut zeigte die erwartete Fragmentgröße zuzüglich einer weiteren Bande, die vermutlich unzureichend verdaute DNA enthält. Die beiden anderen Klone zeigten keine Bande im erwarteten Bereich. Der zweite Verdau mit Ndel brachte keine verwertbaren Ergebnisse. 
Kontrolle mittels PCR

Im Anschluss an eine durchgeführte Transformation in A. fumigatus wurden die erhaltenen Klone auf die erfolgreiche Deletion mittels mehrerer PCR-Reaktionen mit spezifisch designten Primern auf die korrekte Gen-Deletion hin überprüft (s. Tab. 10: Kontrollprimer der Deletionsmutanten).

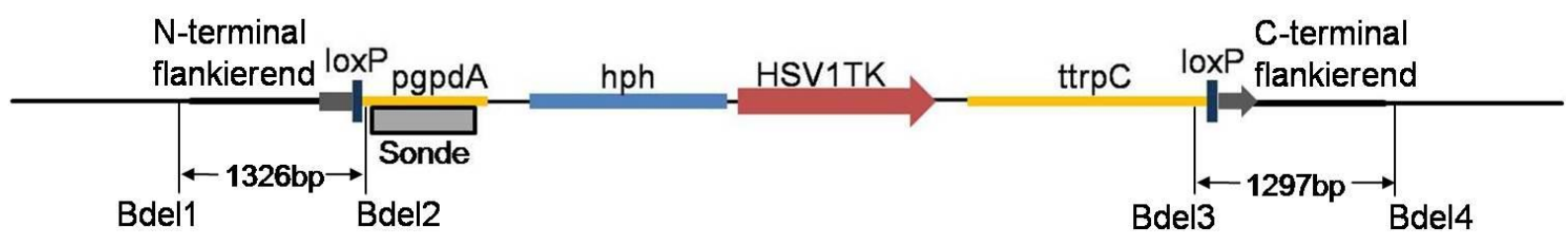

Abbildung 24: Schema der Lage der Kontrollprimer nach Deletion von ADAM-B

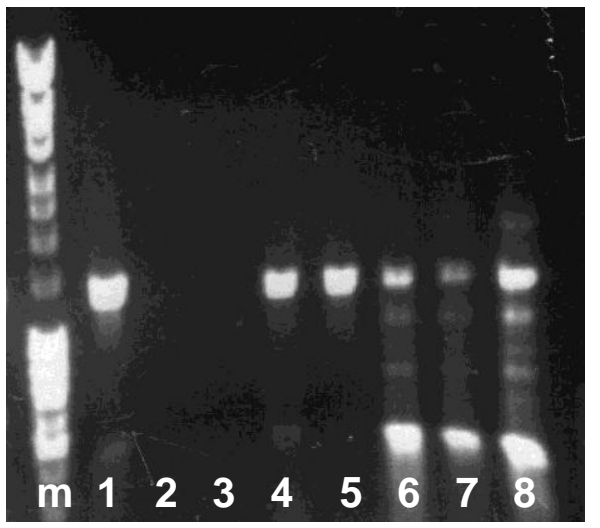

A.-fumigatus-Klone nach Deletion von ADAM-B:

8 Mutanten ( $1-8)$,

Molekulargewichtstandard ladder mix (m)

Abbildung 25: Mutanten nach Gen-Deletion von ADAM-B; Primerpaar Bdel1/2

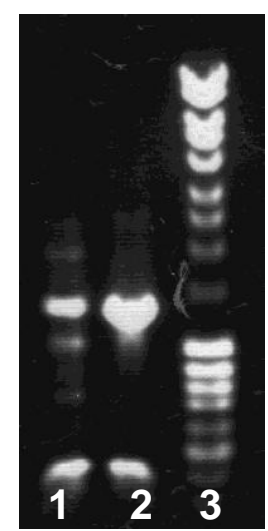

A.-fumigatus-Klone nach Deletion von ADAM-B:

Mutanten Nr. 9 und 10 (1 und 2),

Molekulargewichtstandard ladder mix (Nr. 3)

Abbildung 26: Mutanten nach Gen-Deletion von ADAM-B; Primerpaar Bdel1/2 


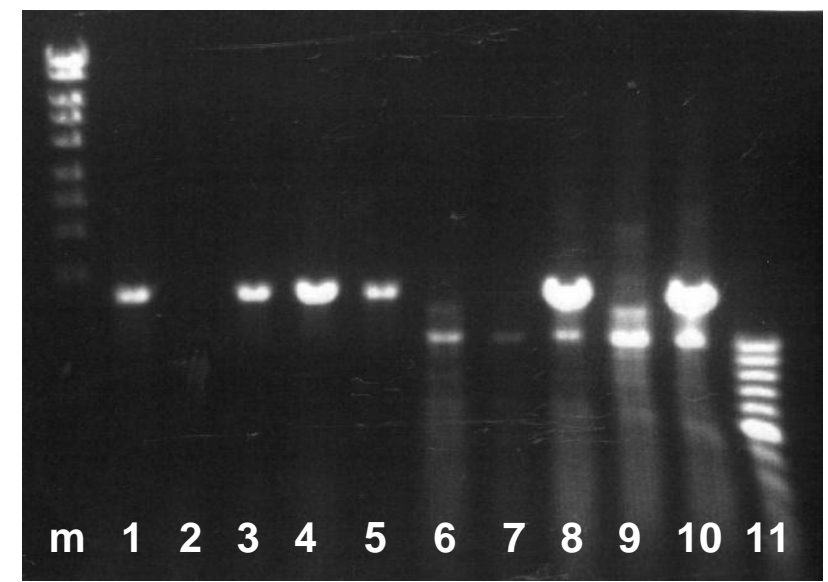

A.-fumigatus-Klone nach Deletion von ADAM-B:

10 Mutanten (1 -10),

Molekulargewichtstandards ladder

high $(\mathrm{m})$ und ladder low (Nr. 11)

Abbildung 27: Mutanten nach Gen-Deletion von ADAM-B; Primerpaar Bdel3/4

Anhand der beiden oberen Bilder ließ sich erkennen, dass laut erster Kontrolle (Bdel1/2) die Klone 1, 4, 5, 8, 9 und 10 Banden in erwarteter Größe zeigten (evtl. auch noch Klone 6 und 7), welche 1328 bp betragen sollten. Die gleichen Klone wurden zusätzlich mit den zweiten Primern (Bdel3/4) kontrolliert, wonach die Klone 1, 3, 4, 5, 8 und 10 Banden in richtiger Größe lieferten. Diese sollte 1297 bp betragen. Zusammen betrachtet waren also die Klone Nummer 1, 4, 5, 8 und 10 als positiv anzusehen. Wegen der Intensität wurden nur die Klone 4, 8 und 10 weiter verwendet.

Als zusätzliche Kontrolle wurden Primer in einer PCR verwendet, die spezifische Fragmente des ADAM-A- oder ADAM-B-Gens direkt amplifizierten (pADAMA1/2 oder pADAMB1/2). Mit diesen wurden die zuvor positiv getesteten Klone erneut kontrolliert:

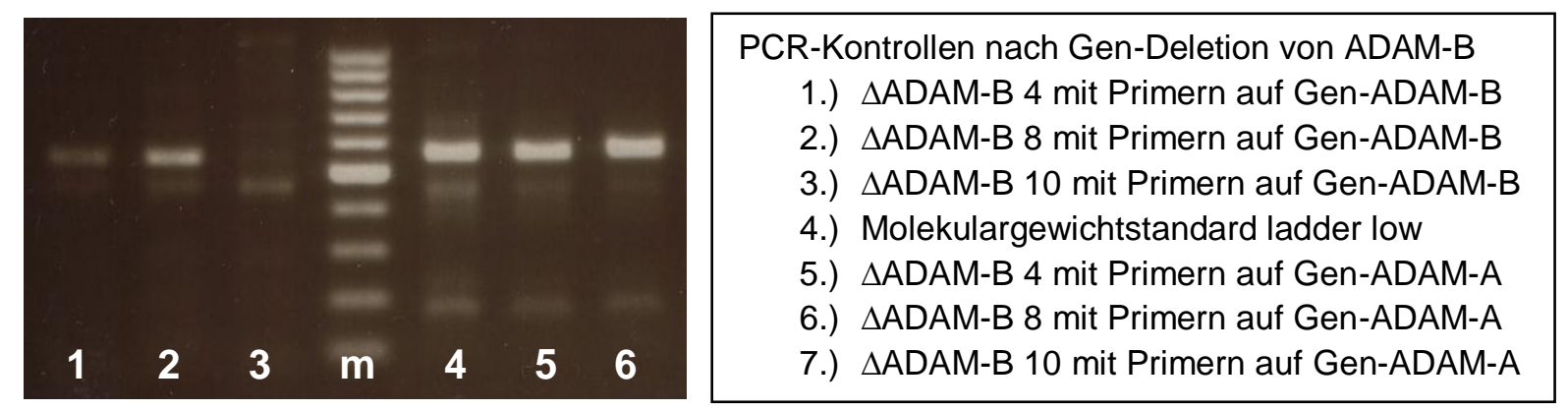

Abbildung 28: PCR Kontrolle nach Gen-Deletion (ADAM-B)

Die verwendeten Primer lieferten folgende Fragmentgrößen: Primer auf das Gen zu ADAM-A (pADAMA1/2) sollten 554 bp große Fragmente ergeben und Primer auf das ADAM-B-Gen (pADAMB1/2) 538 bp. Dadurch war ersichtlich, dass das ADAM-B-Gen des Klons Nr. 10 wirklich nicht mehr vorhanden war, während bei den anderen beiden Klonen die Deletion nicht funktionierte.

\subsubsection{Herstellung von $\triangle A D A M-A B$}

Die Deletionsplasmide wurden mit dem Plasmid pSK397 als Resistenz-lieferndes Insert hergestellt. Ebenfalls in diesem Insert enthalten waren Rekombinationsstellen der cre-Rekombinase - die loxP-sites. 
Als Basis für die Herstellung einer Doppel-Gen-Deletionsmutante wurde zunächst das Insert der ersten homologen Rekombination (s. Abb. 14) entfernt. Hierfür würde das Plasmid pSK215 in $\triangle$ ADAM-A 6 transformiert. Dieses Plasmid kodierte $u$. a. für die soeben erwähnte cre-Rekombinase. Dadurch wurde das Insert an den loxPSchnittstellen aus dem Genom entfernt. Im Anschluss erfolgte eine Transformation mit pADAM-Bdel, um das zweite Gen zu deletieren.

\subsubsection{Kontrolle von A.-fumigatus- $\triangle$ ADAM-A-KIonen nach marker rescue}

Es wurde kontrolliert, ob das Entfernen des Resistenz-liefernden Inserts tatsächlich stattgefunden hatte. Hierfür wurden zum einen Wachstumskontrollen auf Nährmedium mit Hygromycin durchgeführt. Dies geschah ausgehend von zunächst auf MM-Agar gewachsenen Transformationsklonen. Es wurde kein Wachstum erwartet, wenn Hygromycin im Medium enthalten war. Aus mehreren der so kontrollierten Kulturen wurde DNA aufgereinigt, welche als Template in einer PCR mit den Primern ADAMA-Lox1/2 eingesetzt wurde.

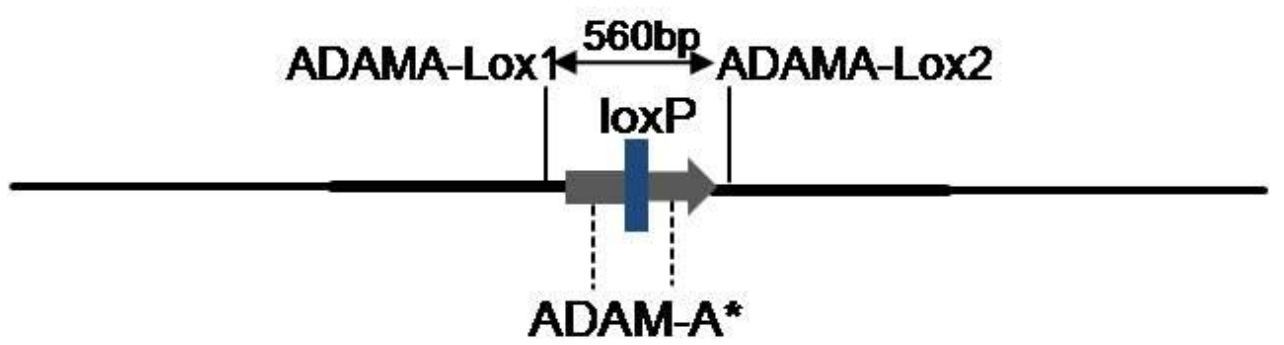

Abbildung 29: schematische Darstellung des genomischen Bereiches nach Entfernung des Resistenz-liefernden Inserts mit angegebener Lage der zur Kontrolle verwendeten Primer

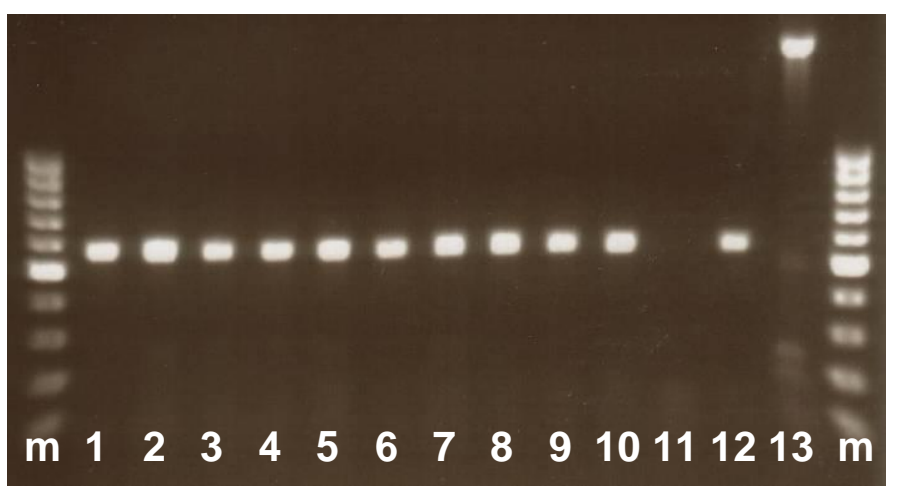

PCR-Kontrolle nach marker-rescue: 1-13) verschiedene $A$-fumigatus -Klone m) Molekulargewichtstandard ladder low

Abbildung 30: PCR-Kontrolle nach marker-rescue; Primerpaar ADAMA-Lox1/2

Durch diese Kontrolle wurde erkannt, dass bis auf Klon 11 und 13 alle anderen positiv und somit erfolgreich restauriert wurden. Die erwartete Fragmentgröße sollte, wie in Abbildung 29 angedeutet ist, 560 bp betragen.

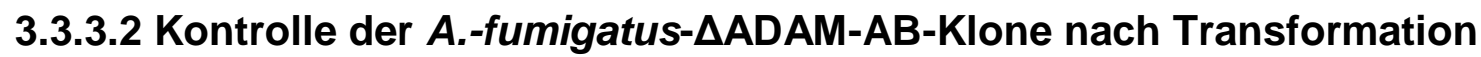
Die Transformation zur Erzeugung einer Doppel-Gen-Deletionsmutante verlief genauso wie es bei der Herstellung der $\triangle$ ADAM-B-Mutante geschah. Doch wurde als zu transformierender Stamm die Aspergillus-fumigatus-Mutante verwendet, der der Resistenz-Marker entfernt wurde (s. 3.3.3.1). 
Kontrolle mittels Southern-Blot

Der schematische Aufbau wie auch die Lage der im Southern-Blot verwendeten

Restriktionsenzyme entspricht denen der Kontrollen der $\triangle$ ADAM-B-Mutante (s. Abb.

22)

Tabelle 20: bei $\triangle A D A M-A B$ zur Kontrolle verwendete Restriktionsenzyme

\begin{tabular}{|l|l|l|}
\hline Mutante & Restriktionsenzym & erwartete Fragmentgröße \\
\hline$\triangle A D A M-A B$ & Ncol & $2,8 \mathrm{~kb}$ \\
\hline
\end{tabular}

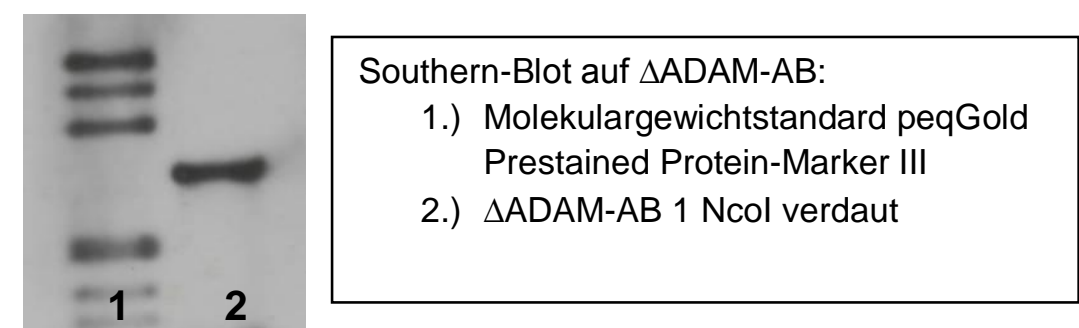

Abbildung 31: Southern-Blot auf $\triangle \mathrm{ADAM}-\mathrm{AB}$

Der kontrollierte $\triangle A D A M-A B-K l o n$ zeigte eine Bande in erwarteter Höhe (2,8 kbp).

Kontrolle mittels PCR

Im Anschluss an die durchgeführte Transformation in A. fumigatus wurden die erhaltenen Klone auf die erfolgreiche Deletion mittels mehrerer PCR-Reaktionen mit spezifisch designten Primern auf die korrekte Deletion hin überprüft (s. Tab. 10: Kontrollprimer der Deletionsmutanten).

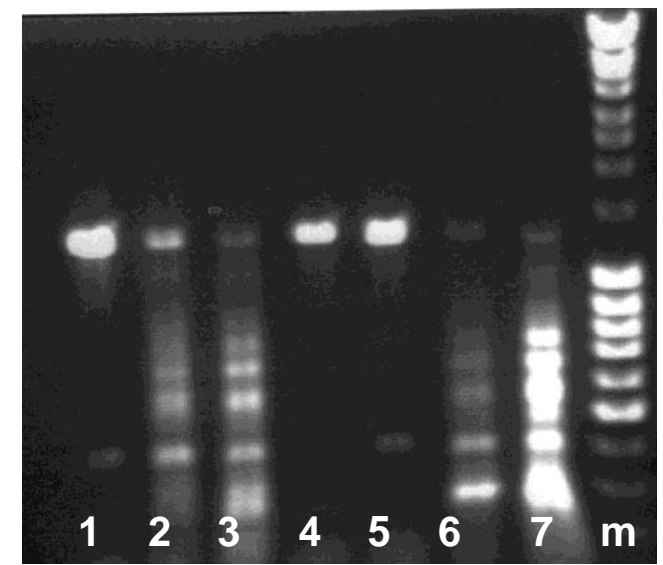

A.-fumigatus-Klone nach Deletion von ADAM-AB:

7 Mutanten ( $1-7)$,

Molekulargewichtstandard ladder mix (m)

Abbildung 32: Mutanten nach Gen-Deletion zu $\triangle A D A M-A B ;$ Primerpaar Bdel1/2

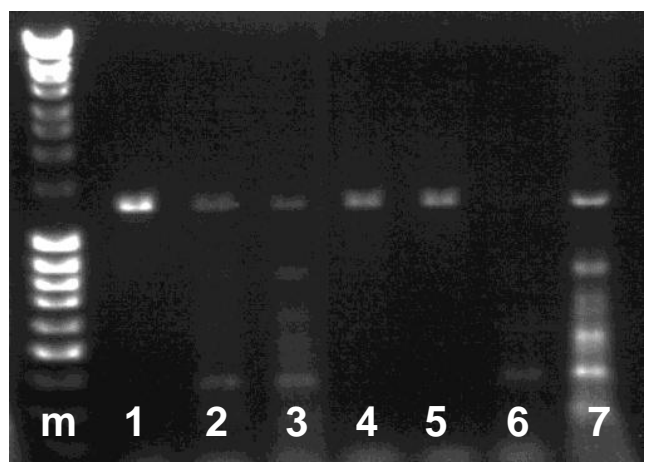

A.-fumigatus-Klone nach Deletion von ADAM-AB:

7 Mutanten (1 - 7),

Molekulargewichtstandards ladder mix (m)

Abbildung 33: Mutanten nach Gen-Deletion zu $\triangle$ ADAM-AB; Primerpaar Bdel3/4 
Nach Kontrolle mit dem ersten Primerpaar (Bdel1/2) zeigten die Klone 1, 4 und 5 deutliche Banden in erwarteter Größe (1326 bp). Die zweite Kontrolle mit Bdel3/4 zeigte für die gleichen Klone Banden in der erwarteten Größe von 1297 bp.

\subsubsection{Herstellung von $\Delta$ Aspf3}

\subsubsection{Herstellung des Deletionsplasmids}

Zu Beginn wurden flankierende Bereiche des zu deletierenden Gens über nested PCR amplifiziert (Primer: AB1 bis AB8). Diese wurden in pBlueskript II SK+ Pacl kloniert. Zwischen die vorbereiteten flankierenden Bereiche wurde das Resistenzliefernde Insert aus pSK397 (s. Anhang) kloniert. Das so erstellte Deletionsplasmid wurde über Restriktionsanalysen und Agarosegel kontrolliert:

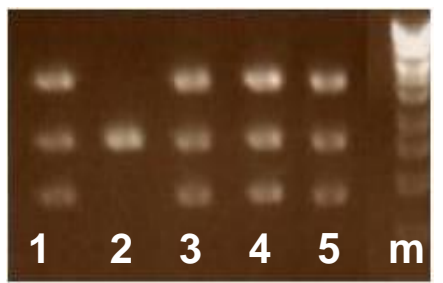

Deletionsplasmid-Kontrolle:

m) Molekulargewichtstandard ladder high

1 bis 5) extrahierte Plasmide aus

verschiedenen E.-coli-Kulturen Pvull-verdaut

Abbildung 34: Kontrolle von Deletionsplasmiden (pAspf3-del Pvull-verdaut)

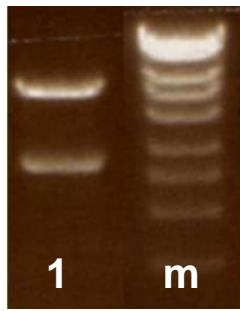

Deletionsplasmid-Kontrolle:

m)Molekulargewichtstandard ladder high

1) extrahierte Plasmide aus verschiedenen

E.-coli-Kulturen Notl und Pacl-verdaut

Abbildung 35: Kontrolle eines Deletionsplasmids (pAspf3-del Notl- und Pacl-verdaut)

Anhand dieser beiden Bilder erkannte man, ob die extrahierten Plasmide richtig kloniert wurden. In beiden Bildern stimmten bis auf Klon 2 aus dem oberen Bild alle Klone mit den erwarteten Fragmentgrößen überein: oben 1808 bp, 2513 bp, 4368 bp und unten $2899 \mathrm{bp}, 5790 \mathrm{bp}$.

\subsubsection{Kontrolle der A.-fumigatus-Aspf3-Klone nach Transformation}

Kontrolle mittels Southern-Blot

Kontrolliert wurde die aus den erzeugten Deletionsmutanten isolierte DNA mit spezifisch ausgesuchten Restriktionsenzymen. Die im Southern-Blot verwendete DNA-Sonde hatte den A. nidulans Promotor des Resistenz-liefernden Inserts als Ziel. Der theoretische Aufbau der Gen-Deletion über homologe Rekombinationen war wie folgt; wobei folgende Komponenten verwendet wurden: loxP = Schnittstelle für eine cre-Rekombinase, pgpdA $=$ Promotor, HSV1TK $=$ Thymidinkinase, $\operatorname{ttrpC}=$ Terminator, Sonde $=$ DNA-Sonde des Southern-Blots, gestrichelte Linien $=$ Orte der homologen Rekombination, ADAM-B ${ }^{*}=$ minimalste Reste des deletierten Gens 


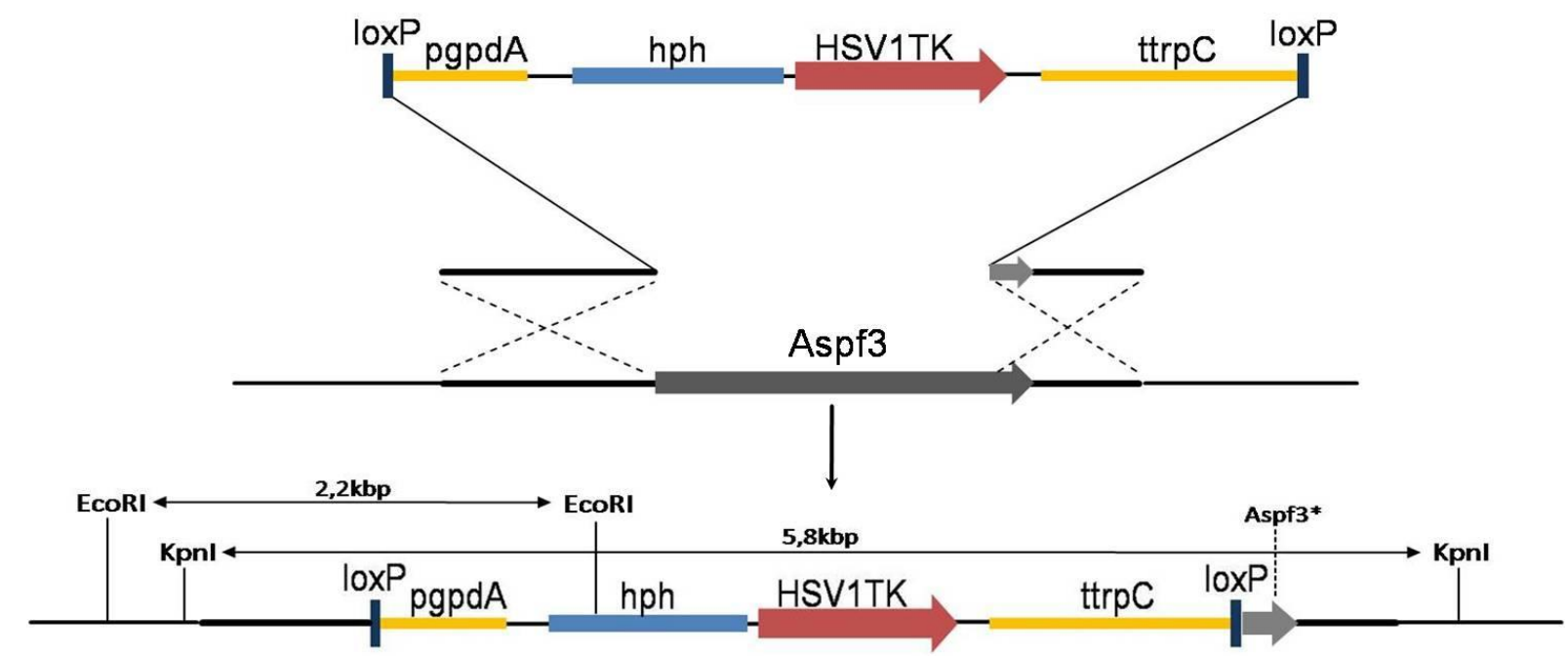

Abbildung 36: schematischer Aufbau des Austausches des Aspf3-Gens

Tabelle 21: bei $\triangle$ ADAM-Aspf3 zur Kontrolle verwendete Restriktionsenzyme

\begin{tabular}{|l|l|l|}
\hline Mutante & Restriktionsenzym & erwartete Fragmentgröße \\
\hline \multirow{2}{*}{ Aspf3 } & EcoRI & $2,2 \mathrm{~kb}$ \\
\cline { 2 - 3 } & Kpnl & $5,8 \mathrm{~kb}$ \\
\hline
\end{tabular}

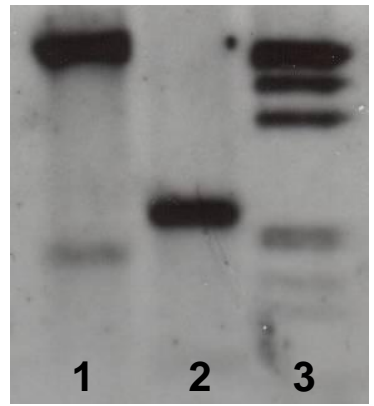

Southern-Blot auf $\triangle$ Aspf3:

1.) $\triangle$ Aspf3 $5 \mathrm{Kpnl}$ verdaut

2.) $\triangle$ Aspf3 $5 \mathrm{EcoRI}$ verdaut

3.) Molekulargewichtstandard peqGold

Prestained Protein-Marker III

Abbildung 37: Southern-Blot auf $\Delta$ Aspf3

Die Kontrolle der Mutante $\Delta$ Aspf3 zeigte mit beiden verwendeten Restriktionsenzymen Banden in erwarteter Höhe.

Kontrolle mittels PCR

Im Anschluss an eine durchgeführte Transformation in A. fumigatus wurden die erhaltenen Klone auf die erfolgreiche Deletion mittels mehrerer PCR-Reaktionen mit spezifisch designten Primern auf die korrekte Gen-Deletion hin überprüft (s. Tab. 10: Kontrollprimer der Deletionsmutanten).

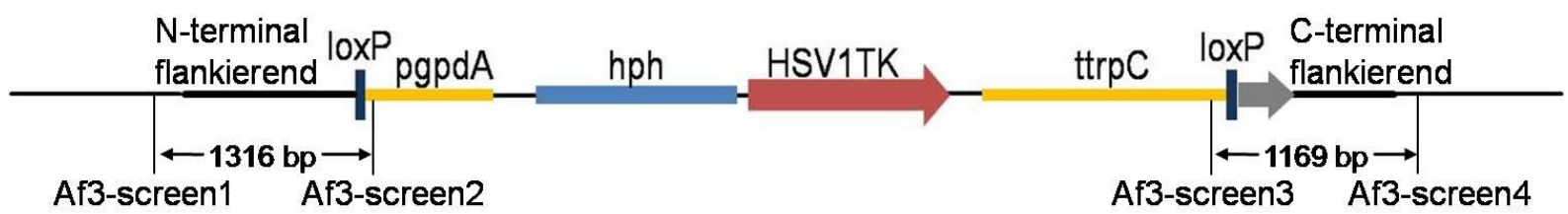

Abbildung 38: Schema der Lage der Kontrollprimer nach Deletion von Aspf3 


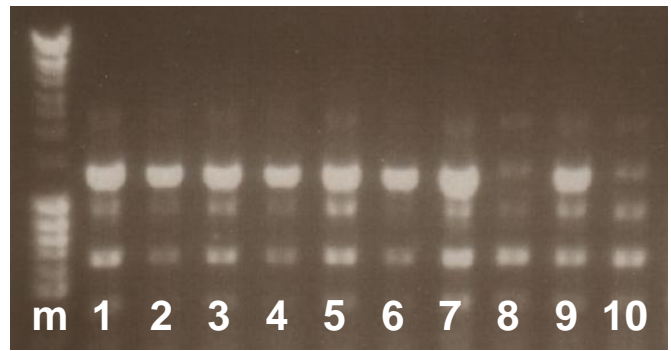

A.-fumigatus-Klone nach Deletion von Aspf3:

Mutanten Nr. 1 bis 10,

Molekulargewichtstandard ladder mix (m)

Abbildung 39: Mutanten nach Gen-Deletion zu $\Delta$ Aspf3; Primerpaar Af3-screen1/2

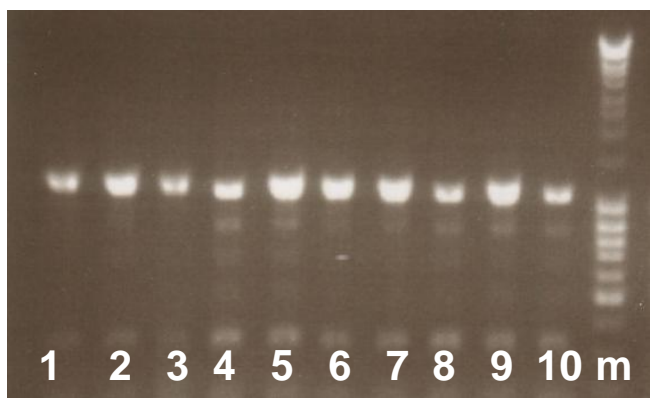

A.-fumigatus-Klone nach Deletion von Aspf3:

Mutanten Nr. 1 bis 10,

Molekulargewichtstandard ladder mix (m)

Abbildung 40: Mutanten nach Gen-Deletion zu $\Delta$ Aspf3; Primerpaar Af3-screen3/4

Anhand der beiden oberen Bilder ließ sich erkennen, dass fast alle Klone Banden in erwarteter Größe zeigten. Diese waren für Af3screen1/2 1316 bp und für Af3screen3/4 1169 bp. Lediglich Klone 8 und 10 zeigten mit dem ersten Primerpaar keine deutliche Bande.

Als zusätzliche Kontrolle wurden Primer in einer PCR verwendet, die spezifische Fragmente des Aspf3-Gens direkt amplifizierten (pAspf3-1/2). Mit diesen wurden die zuvor positiv getesteten Klone erneut kontrolliert:

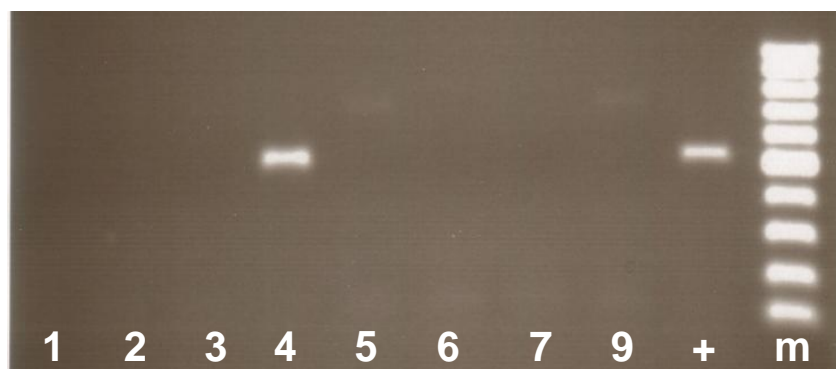

PCR-Kontrollen nach Gen-Deletion von Aspf3:

1 bis 9$) \Delta$ Aspf3-Mutanten 1 bis 9

(ohne Nr. 8) mit Primern auf Aspf3

+ ) Positivkontrolle (D141)

m) ladder low

Abbildung 41: PCR Kontrolle nach Gen-Deletion (Aspf3)

Lediglich in Klon Nummer vier war Aspf3 noch vorhanden. Die restlichen Mutanten zeigten keine Banden, was bedeutet, dass das Gen nicht mehr vorhanden war. Wenn eine Bande erschien, wurde die Größe 506 bp erwartet.

\subsection{Charakterisierungen der Gen-Deletionsmutanten}

\subsubsection{Western-Blot der ADAM-Deletionsmutanten}

Wie beschrieben wurden die extrahierten, zytosolischen Proteine aufgetrennt (s. 2.14.3.2) und nach dem Transfer auf eine Nitrozellulosemembran von Antikörpern gebunden. Die entweder gegen ADAM-A oder ADAM-B gerichteten Antikörper wurden von einer kooperierenden Arbeitsgruppe in Kaninchen erzeugt und zur 
Verfügung gestellt (AG Monod (Laboratoire de Mycologie, Université Lausanne)). Diese ersten Antikörper wurden über einen spezifisch gegen Kaninchenproteine gerichteten zweiten Antikörper, welcher an Peroxidase gekoppelt vorlag, gebunden. Diese wurde über Chemilumineszenzreaktion mit den ECL-Reagenzien nachgewiesen.

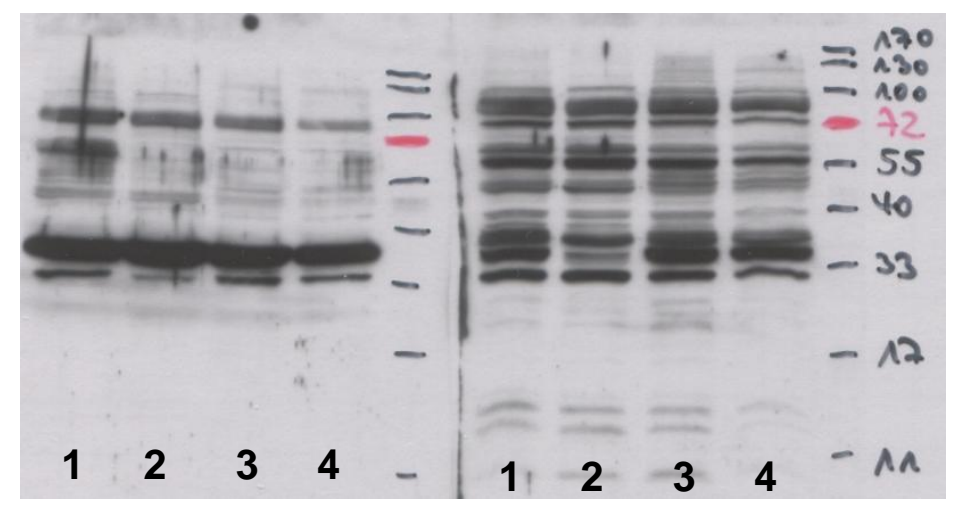
Western-Blot auf zytosolische Proteine:
1.) $\mathrm{D} 141(\mathrm{WT})$
2.) $\triangle \mathrm{ADAM}-\mathrm{A}$
3.) $\triangle A D A M-B$
4.) $\triangle \mathrm{ADAM}-\mathrm{AB}$
links: Antikörper gegen ADAM-A rechts: Antikörper gegen ADAM-B Größeneinteilung des Markers ist in $\mathrm{kDa}$ angegeben

Abbildung 42: Western-Blot auf zytosolische Proteine von D141, $\triangle A D A M-A,-B$ und -AB; 5 Min belichtet

Außerdem wurden Proteine aus den Zellmembranen von Aspergillus fumigatus isoliert (s. 2.14.5) und ebenfalls auf Nitrozellulosemembranen überführt. Die Detektion erfolgte wie zuvor. Bei dieser Extraktion wurde eine wässrige Phase erhalten, die aus der Membran herausgelöste Proteine enthält und einen Anteil an Proteinen, der sich nicht von der lipidhaltigen Membran trennen ließ (DetergenzPhase).

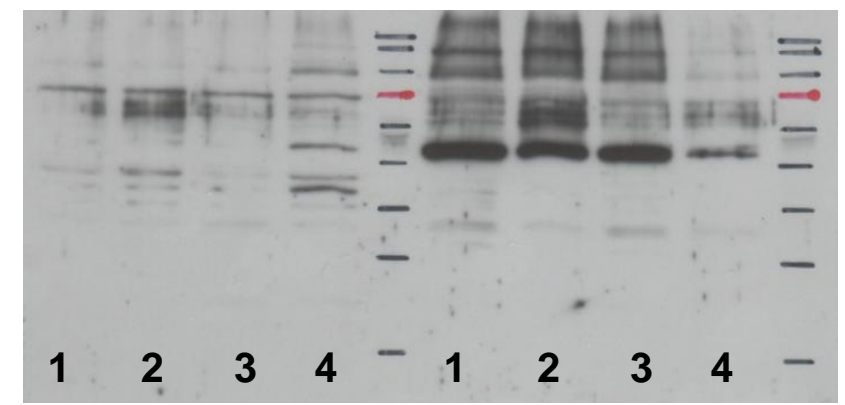

Western-Blot auf Membran- Proteine mit Anti-ADAM-A-Antikörper:

1.) D141 (WT)

2.) $\triangle \mathrm{ADAM}-\mathrm{A}$

3.) $\triangle A D A M-B$

4.) $\triangle \mathrm{ADAM}-\mathrm{AB}$

links: wässrige Phase

rechts: Detergenz-Phase

Abbildung 43: Western-Blot mit Anti-ADAM-A-Antikörper auf Membran- Proteine von D141, $\triangle$ ADAM-A, -B und -AB; 5 Min belichtet

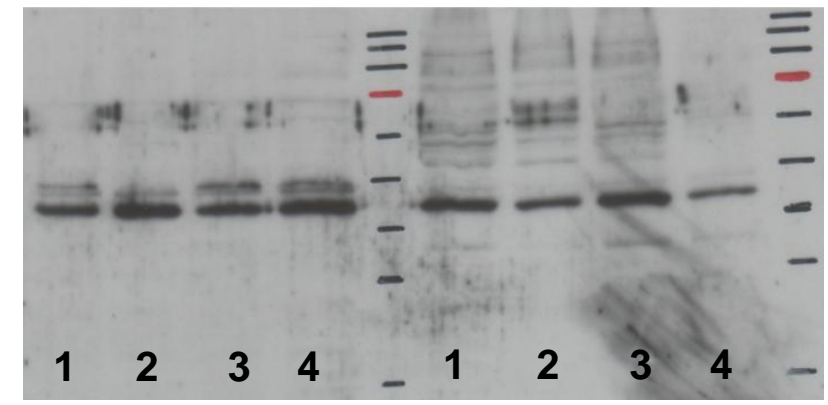

Western-Blot auf Membran- Proteine mit Anti-ADAM-B-Antikörper:
1.) $\mathrm{D} 141(\mathrm{WT})$
2.) $\triangle A D A M-A$
3.) $\triangle \mathrm{ADAM}-\mathrm{B}$
4.) $\triangle \mathrm{ADAM}-\mathrm{AB}$

links: wässrige Phase

rechts: Detergenz-Phase

Abbildung 44: Western-Blot mit Anti-ADAM-B-Antikörper auf Membran- Proteine von D141, $\triangle A D A M-A,-B$ und -AB; 5 Min belichtet 
Insgesamt lassen sich weniger detektierte Banden bei der Proteinextraktion aus Membranen erkennen als bei dem Western-Blot auf zytosolische Proteine. Erwartet wurde jeweils fehlende Detektion in den korrelierenden Deletionsmutanten.

Beispielsweise sollte die Detektion mit Anti-ADAM-A-Antikörper bei $\triangle$ ADAM-A und bei $\triangle A D A M-A B$ keine Bande liefern. Banden sollten jedoch bei D141 und $\triangle A D A M-B$ ersichtlich sein. Die erwarteten Größen für ADAM-A war 67 kDa und für ADAM-B $82 \mathrm{kDa}$.

\subsubsection{Biochemische Charakterisierungen der ADAM-Gen-Deletionsmutanten}

Im Rahmen der deletierten ADAM-Gene waren lediglich Vorkenntnisse zu homologen Proteinen vorhanden, so dass die hier erzeugten Mutanten auf verschiedene Funktionen hin untersucht wurden (z.B.: Einfluss auf Zellwand, Einfluss auf Stoffwechsel/Ernährung).

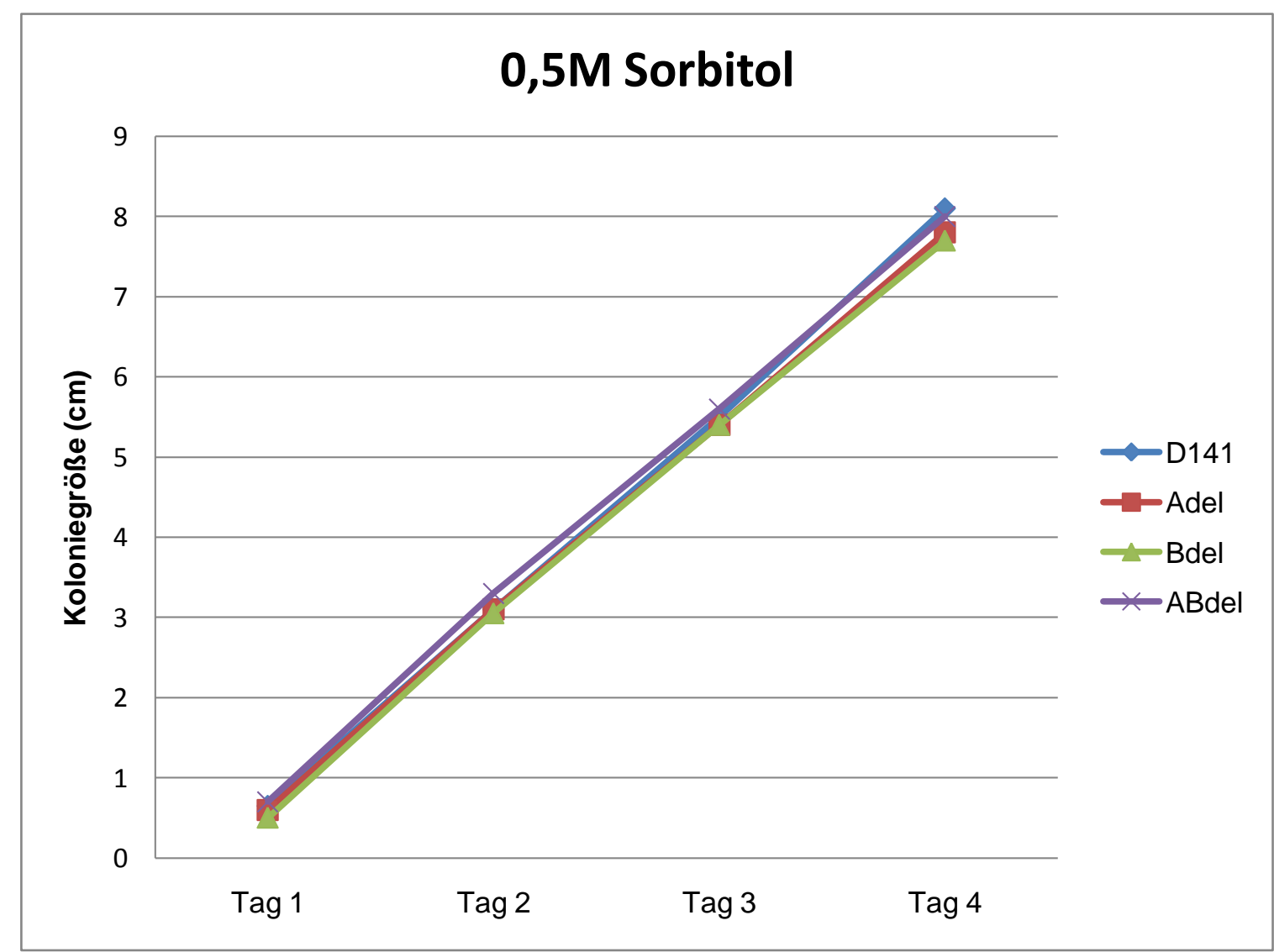

Abbildung 45: Wachstumsgraph der ADAM-Deletionsmutanten im Vergleich zu D141

Dieser Graph zeigt beispielhaft das Ergebnis der verschiedenen untersuchten Zusätze zum Medium (s. 2.15.1). Es war bei den ADAM-Deletionsmutanten keinerlei Unterschied zum Wildtyp zu erkennen.

\subsubsection{Biochemische Charakterisierungen der Aspf3-Gen-Deletionsmutante}

Die Aspf3-Mutante wurde speziell gegen oxidativen Stress hin untersucht, weil das korrelierende Protein (Peroxiredoxin) in der Entgiftung von ROI mitwirken könnte. 


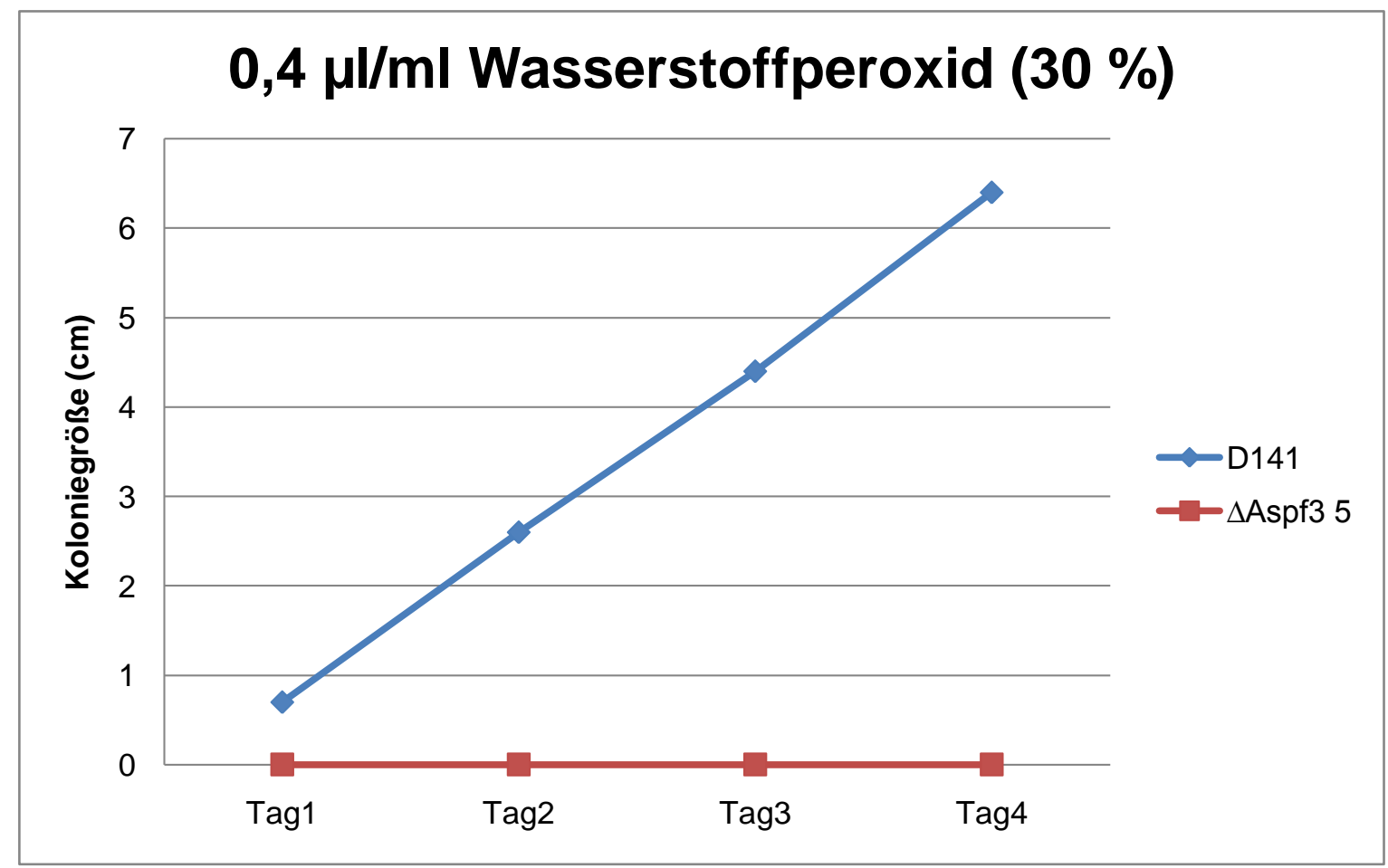

Abbildung 46: Wachstumsgraph der Aspf3-Deletionsmutante im Vergleich zu D141

Die $\Delta$ Aspf3-Mutante zeigte bereits bei sehr niedrigen $\mathrm{H}_{2} \mathrm{O}_{2}$-Konzentrationen kein Wachstum mehr. Der durch Natriumhypochlorid ausgelöste, oxidative Stress zeigte hingegen keinen Wachstumsunterschied; der Graph hierzu glich dem der ADAMMutanten (s. o.).

\subsubsection{Agardiffusionstest Aspf3-Gen-Deletionsmutante}

Um einen besseren Überblick über die $\mathrm{H}_{2} \mathrm{O}_{2}$-Sensibilität der $\Delta$ Aspf3-Mutante zu erhalten wurde der Agar-Diffusionstest (s. 2.15.2.1) durchgeführt.

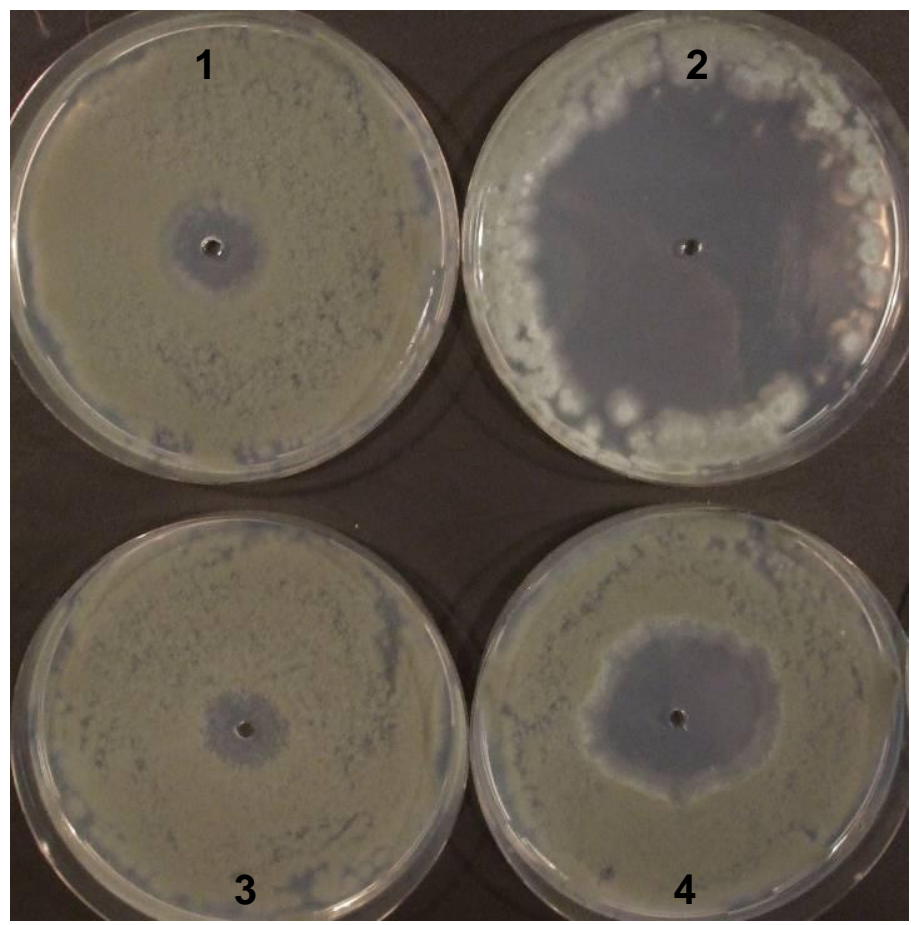

Agar-Diffusionstest von $\Delta$ Aspf3 $(2 \& 4)$ gegenüber WT (1 \& 3):

1.) D141 mit $20 \mu \mathrm{l} 0,75 \% \mathrm{H}_{2} \mathrm{O}_{2}$

2.) $\Delta$ Aspf3 mit $20 \mu \mathrm{l} 0,75 \% \mathrm{H}_{2} \mathrm{O}_{2}$

3.) D141 wie 1 aber $24 \mathrm{~h}$ inkubiert vor $\mathrm{H}_{2} \mathrm{O}_{2}$-Gabe

4.) $\triangle$ Aspf3 wie $\mathrm{Nr} .2$ aber $24 \mathrm{~h}$ inkubiert vor $\mathrm{H}_{2} \mathrm{O}_{2}$-Gabe

Abbildung 47: Agardiffusionstest mit $20 \mu$ einer 0,75 \% $\mathrm{H}_{2} \mathrm{O}_{2}$-Lösung von $\Delta$ Aspf3 und D141 
Wie zu erkennen war, war ein deutlich größerer Hemmhof bei der Deletionsmutante zu sehen, als dies beim WT der Fall war. Betrachtete man eine $24 \mathrm{~h}$ vorher inkubierte Kultur, so war immer noch ein größerer Hemmhof ersichtlich, auch wenn dieser nicht solch beeindruckende Ausmaße annahm, wie es ohne Vorinkubation gewesen ist.

Agardiffusionstest mehrerer verschiedener Mutanten mit Bezug zur Entgiftung von $\underline{\mathrm{ROI}}$

Dank mehrerer Arbeitsgruppen (AG Krappmann (Zentrum für Infektionsforschung der Universität Würzburg) und AG Brakhage (Leibniz Institut für Naturstoff-Forschung und Infektionsbiologie e.V. Hans-Knöll-Institut (HKI), Jena)) konnten verschiedene Mutanten gegeneinander mit dem Agar-Diffusionstest getestet werden. Die Produkte dieser Mutanten spielen alle bei der $\mathrm{H}_{2} \mathrm{O}_{2}$-Entgiftung eine Rolle: WT (D141 und ATC 46645), $\Delta$ Aspf3, $\Delta$ Aspf3::Aspf3, $\Delta$ AfYap1, $\Delta$ AfYap1::AfYap1, $\Delta$ Skn7.

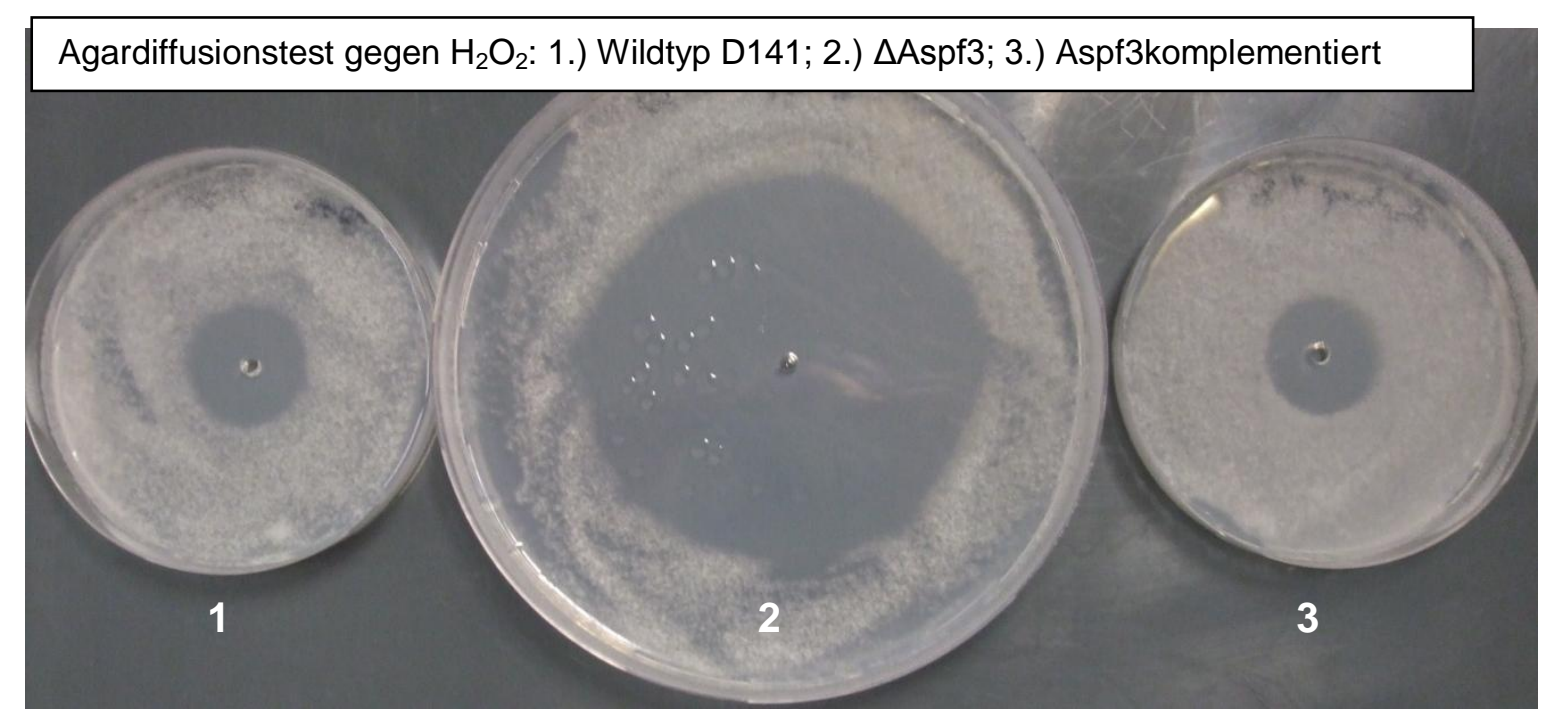

Abbildung 48: Agardiffusionstest mit $20 \mu$ leiner $1 \%$ Wasserstoffperoxid-Lösung von D141, $\Delta$ Aspf3 und Aspf3komplementiert

Die zuvor aufgelisteten Mutanten wurden kollektiv gegen verschiedene Konzentrationen an Wasserstoffperoxid getestet. Das Ergebnis der beobachteten Hemmhofdurchmesser ist graphisch dargestellt: 


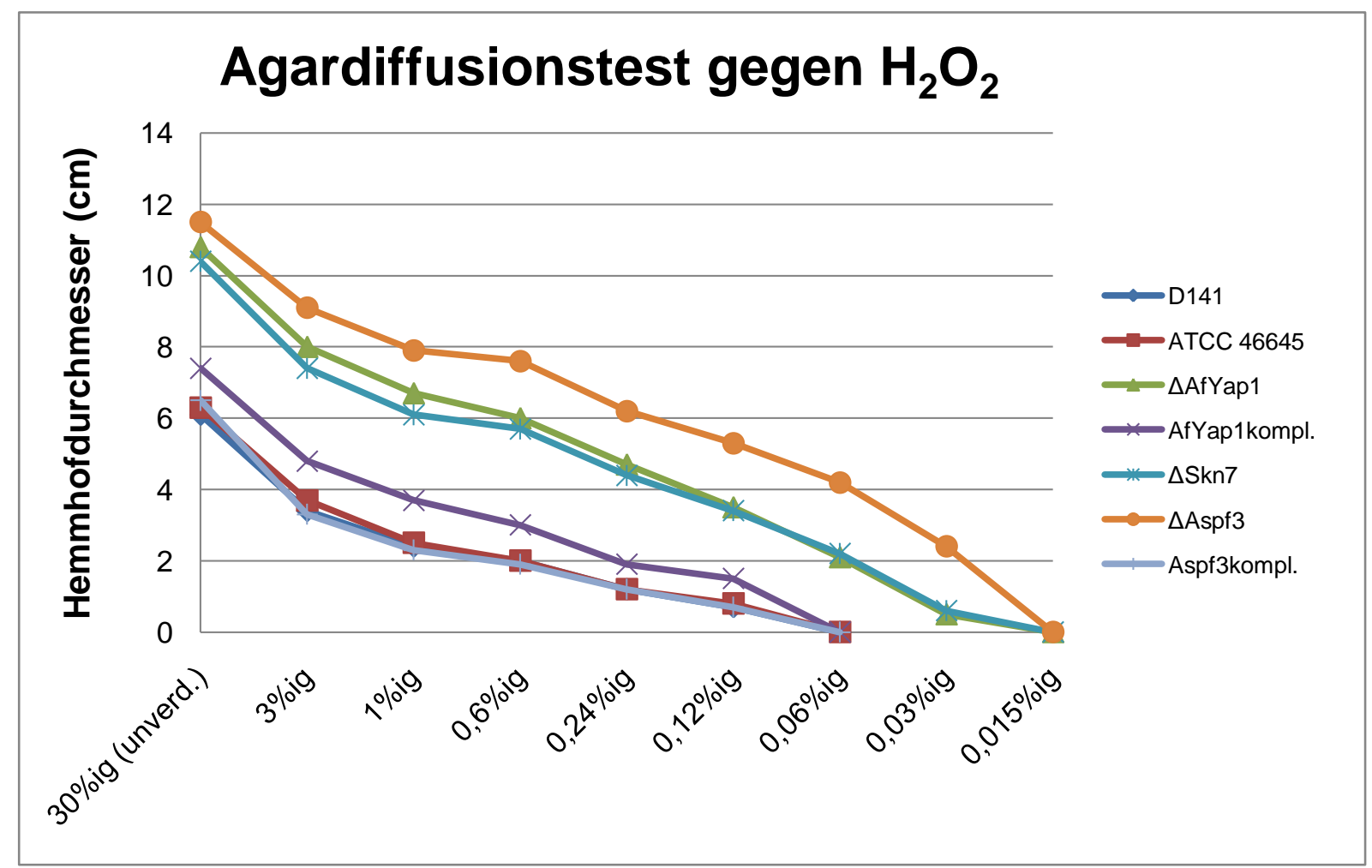

Abbildung 49: Wachstumsgraph des Agardiffusionstests gegen ungefähr logarithmische Konzentrationen an Wasserstoffperoxid

Der drastische Effekt auf das Wachstum der Kulturen ist hingegen besser sichtbar, wenn der Graph nicht halblogarithmisch dargestellt wird:

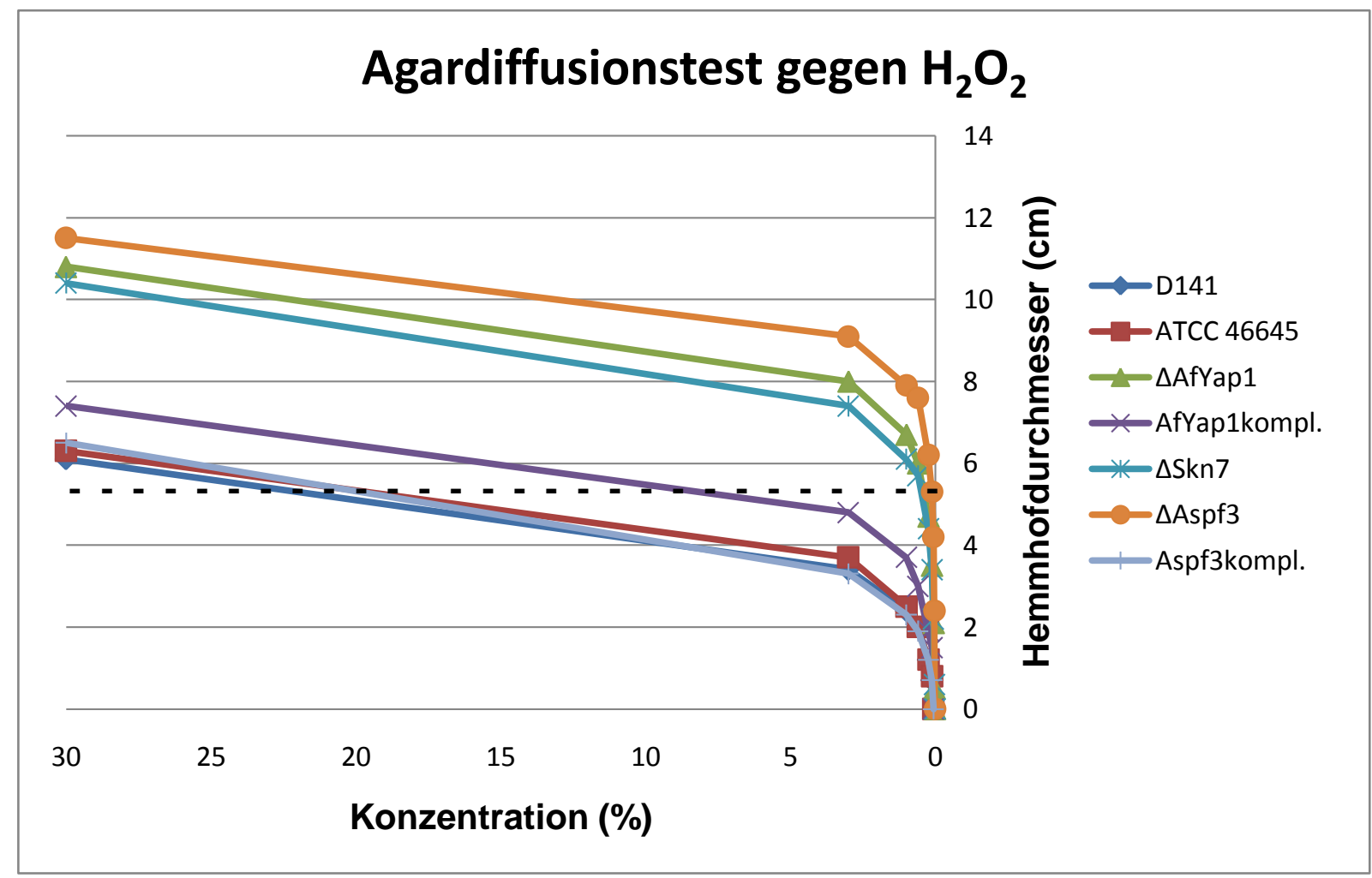

Abbildung 50: Wachstumsgraph des Agardiffusionstests gegen etwa logarithmische Konzentrationen an Wasserstoffperoxid nicht logarithmisch aufgetragen 
Wie an dieser Darstellung erkennbar ist, liegt der maximal erreichbare Hemmhof bei $11,5 \mathrm{~cm}$ bei der Deletionsmutante $\Delta$ Aspf3. Vergleichsweise würde man für den halbmaximalen Hemmhof (gestrichelte Linie in Abbildung 50) bei dieser Mutante lediglich eine $\sim 0,12 \%$ Wasserstoffperoxid-Lösung benötigen. Um den halb-maximalen Hemmhof bei den Wildtypen (D141 bzw. ATCC 46645) zu erzielen werden 26\% bzw. 24 \% $\mathrm{H}_{2} \mathrm{O}_{2}$-Lösungen benötigt. Anders ausgedrückt: es wird eine über 200fach höher konzentrierte Lösung für den gleichen Effekt benötigt.

Wie bei dem Vorversuch wurde auch dieses Mal der Einfluss von Wasserstoffperoxid nicht nur auf die Keimung der Konidien sondern auch auf das Wachstum der Hyphen selbst getestet. Dies geschah indem zuvor $24 \mathrm{~h}$ bei $37^{\circ} \mathrm{C}$ inkubierte Kulturen dem oxidativen Stress durch $\mathrm{H}_{2} \mathrm{O}_{2}$ ausgesetzt wurden.

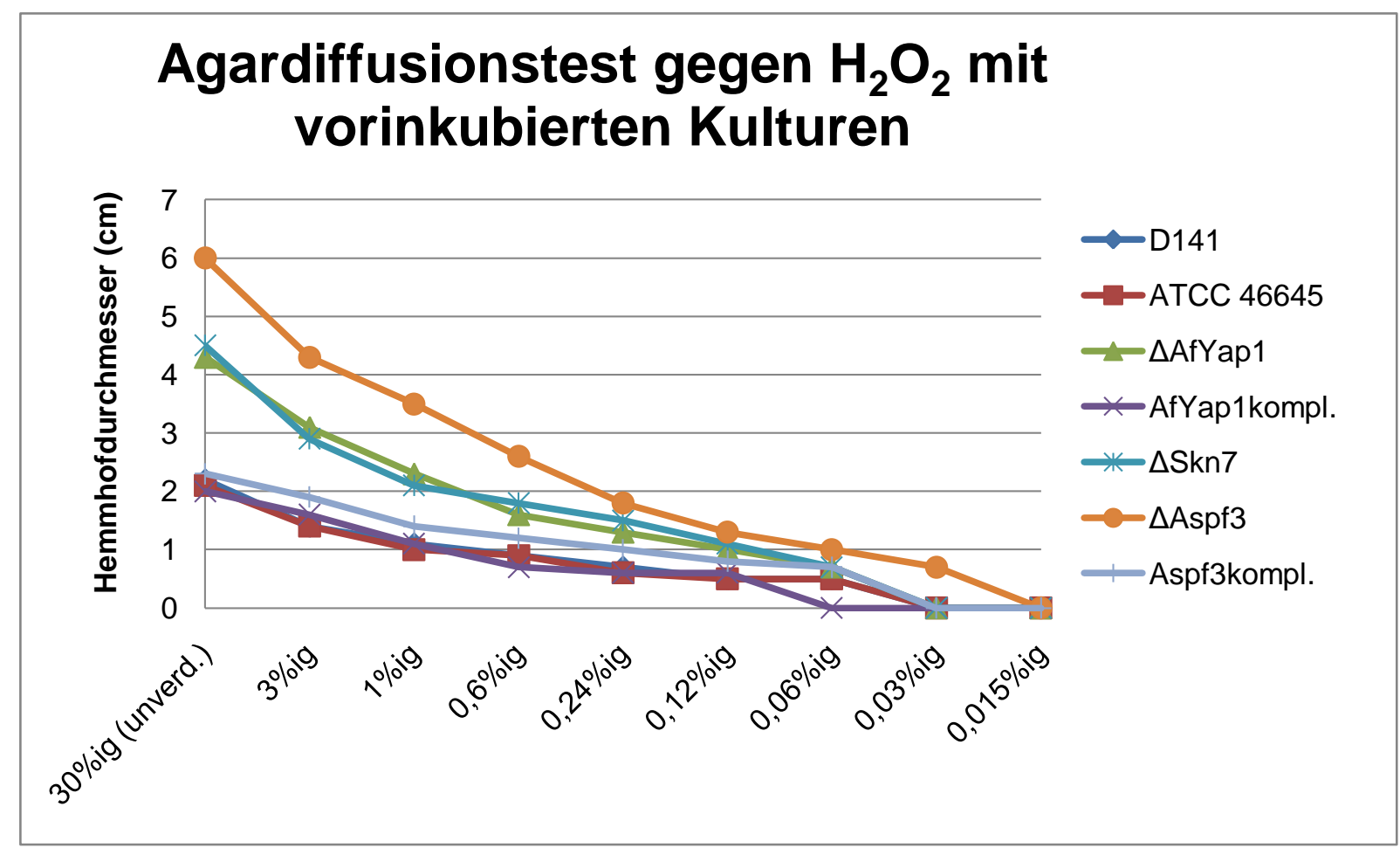

Abbildung 51: Wachstumsgraph des Agardiffusionstests gegen ungefähr logarithmische Konzentrationen an Wasserstoffperoxid bei $24 \mathrm{~h}$ zuvor inkubierten Kulturen

Der maximal erreichbare Hemmhof betrug bei diesem Versuch lediglich $6 \mathrm{~cm}$ bei der Gen-Deletionsmutante $\Delta$ Aspf3. Er erreichte somit nur etwa die Hälfte der zuvor erreichten Hemmhofgröße. Die Wildtypen zeigten einen maximalen Hemmhof von etwa $2 \mathrm{~cm}$ Durchmesser. Sie erreichen somit überhaupt nicht den halbmaximalen Hemmhofdurchmesser $(3 \mathrm{~cm})$.

Wie zuvor ist in einer Darstellung mit nicht logarithmischer Skala der Einfluss von Wasserstoffperoxid auf das Wachstum der Aspergillus-fumigatus-Kulturen besser zu erkennen: 


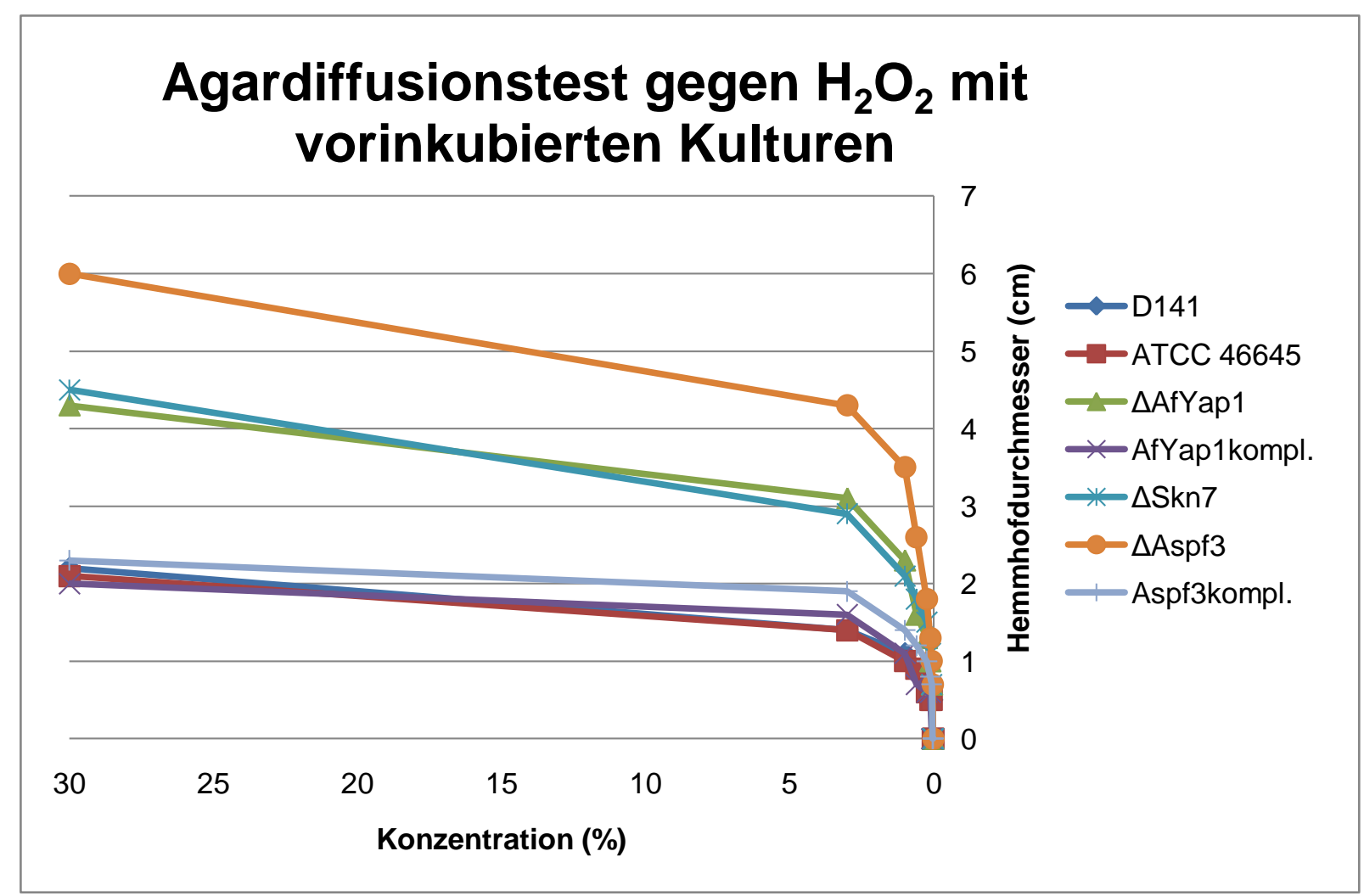

Abbildung 52: Wachstumsgraph des Agardiffusionstests gegen etwa logarithmische Konzentrationen an Wasserstoffperoxid bei $24 \mathrm{~h}$ zuvor inkubierten Kulturen nicht logarithmisch aufgetragen

Die hergestellte $\Delta$ Aspf3-Mutante ist deutlich am stärksten durch Wasserstoffperoxid beeinflusst. Bei vorinkubierten Kulturen ist der maximal erreichbare Hemmhof nur $6 \mathrm{~cm}$ groß. Die ist gerade mal ungefähr $50 \%$ des Hemmhofdurchmessers bei nicht vorinkubierten Kulturen. Die Wildtypen hingegen sind nach erfolgter Keimung kaum im Wachstum gehemmt. Die $30 \%$ Wasserstoffperoxid-Lösung erzeugt nach Vorinkubation lediglich etwa $2 \mathrm{~cm}$ Hemmhofdurchmesser. Bei Einfluss während der Keimung wird ein $3 x$ so großer Hemmhof $(6 \mathrm{~cm})$ erzielt.

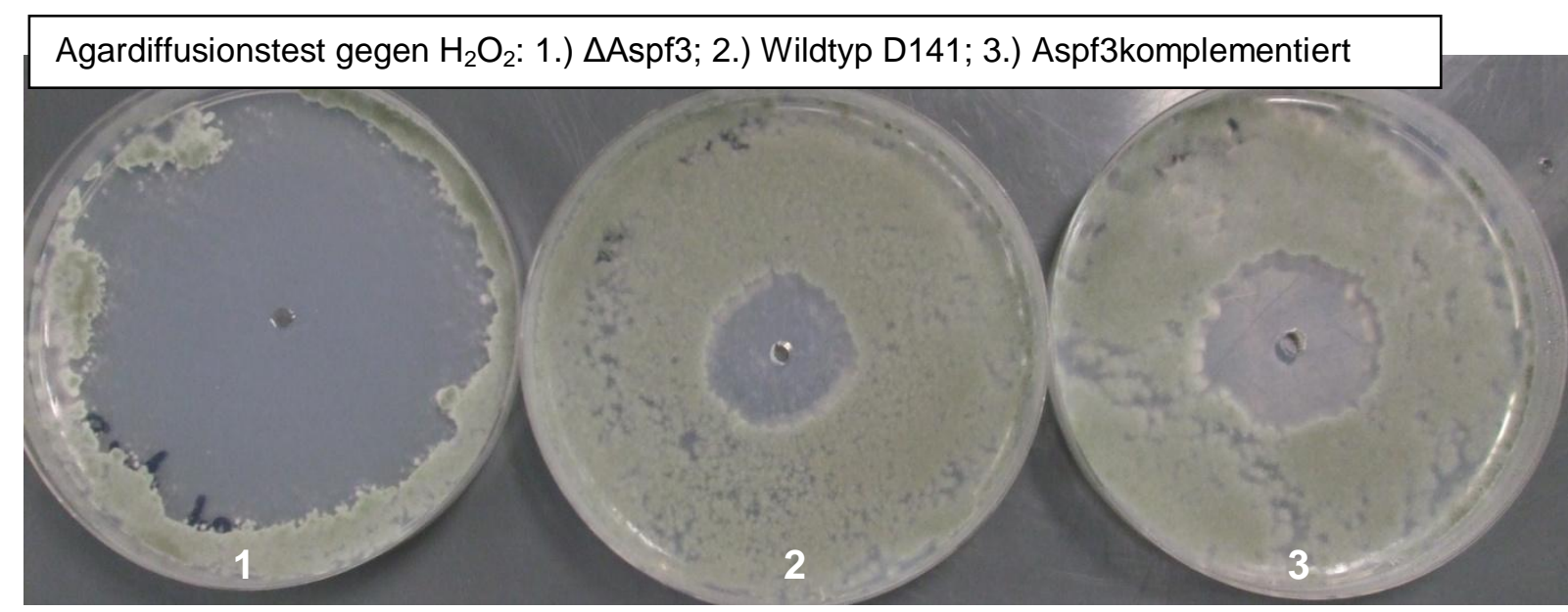

Abbildung 53: vorinkubierte Kulturen von $\Delta$ Aspf3, D141,und Aspf3komplementiert im Agardiffusionstest mit $20 \mu$ leiner $30 \%$ Wasserstoffperoxid-Lösung 


\section{Diskussion}

Aspergillus fumigatus ist lediglich ein fakultativ pathogener Schimmelpilz. Jedoch ruft er bei stark immunsupprimierten Menschen - und hierbei insbesondere bei Individuen mit Leukämie, Organtransplantat-Empfängern oder generell unter immunsuppressiver Therapie stehenden Patienten - die gravierende Krankheit der invasiven Aspergillose hervor (Segal 2009). Die Diagnose der Erkrankung ist meist schwierig, unsicher oder langwierig. So dient die Isolierung und Kultivierung des Erregers als Standard der sicheren Diagnose (Kradin 2008). Dadurch kommt es erst spät im Infektionsverlauf zu einer Einleitung therapeutischer Maßnahmen, welche zu einem großen Anteil der Fälle ohne Wirkung bleiben (Lin 2001). Es gibt deswegen viele Todesfälle bedingt durch die IA. Die Identifizierung von Antigenen von Aspergillus fumigatus, die bei der Infektion im Menschen anders als während seiner Existenz in z. B. Komposthaufen exprimiert werden, ist deswegen von großem Interesse. Diese Antigene könnten bei der Verbesserung diagnostischer Mittel behilflich sein. Auch könnten sie im Rahmen der Entwicklung neuer Arzneimittel als potenzielle neue Ziele dienen oder aber als Basis für die Herstellung eines Impfstoffs fungieren; in mehreren Tierversuchen konnte bereits die Erzeugung von protektiver Immunität gegen eine Infektion mit A. fumigatus demonstriert werden (Bozza 2002 und 2009; Ito 2006; Stevens 2004).

Das Ziel dieser Arbeit war es, mehrere Antigene zu evaluieren und diese auf rekombinantem Wege in E. coli oder P. pastoris zu exprimieren. Die Verwendbarkeit der produzierten Antigene als potenzielles Vakzin sollte im Tierversuch untersucht werden. Außerdem sollten zu ausgewählten Antigenkandidaten Gen-

Deletionsmutanten erzeugt werden, welche daraufhin durch biochemische Charakterisierung näher untersucht werden sollten.

In einem vorangegangenen Projekt (Denikus 2005) wurden Infektionsseren aus gegen $A$. fumigatus immunen Tieren eines subletalen Kaninchenmodells verwendet, um eine Aspergillus-fumigatus-cDNA-Expressionsbank zu screenen. Hierbei wurden 36 verschiedene Antigene gefunden, die durch das mittlerweile sequenzierte Genom des Pilzes Genen und Proteinen zugeordnet werden konnten (Nierman 2005). Aus diesen Proteinen wurden einige ausgewählt, um sie rekombinant in E. coli oder $P$. pastoris zu exprimieren. Es ist davon auszugehen, dass die bereits bewiesene Immunreaktion in Kaninchen auch Wirkung auf die gewünschte Stärkung des bzw. die Protektion durch das Immunsystem hat. Die Daten des sequenzierten Genoms wurden verwendet, um an die mit den Proteinen korrelierenden cDNA-Sequenzen zu gelangen. Auf Basis dieser wurden Oligonukleotide für die PCR entworfen, so dass die zu erwartenden Größen erstens gut zu exprimieren und zweitens zur Kontrolle bekannt waren. Sie sollten deswegen zwischen 270 und 2700 bp bzw. 10000 und 100000 kDa liegen (Qiagen 2003); zu kleine exprimierte Proteine werden gehäuft proteolytisch degradiert, während zu große Expressionsprodukte zu einem frühzeitigen Ende der Expression führen.

Als wichtiges Indiz dafür, dass die identifizierten und nun rekombinant hergestellten 
Antigene wirkungsvoll sein könnten, ist anzuführen, dass in dieser Arbeit (Denikus 2005) Antigene gefunden wurden (Aspf16, Aspf3), die als Einzelantigene im Tierversuch Immunität erzeugen konnten (Bozza 2002; Ito 2006). Dies dient als Beweis des zugrunde liegenden Gedankens und hebt die Wichtigkeit der anderen Antigene hervor. Als Einschränkung bei der Antigen-Suche mittels cDNA-Banken ist anzumerken, dass immer nur die mRNA-Population präsentiert wird, die zu einer bestimmten Wachstumsphase unter bestimmten in-vitro-Bedingungen vorhanden ist. In einem anderen Projekt wurden Proteine ebenfalls mit Hilfe von Infektionsseren aus Kaninchen detektiert, die nach einer überlebten IA immun waren. Diese wurden mittels massenspektrometrischer Methoden nach Auftrennung auf zweidimensionaler SDS-PAGE und folgendem Immunblot identifiziert. In diesem Projekt wurden ebenfalls mehrere der protektiven Einzelantigene (Aspf3, Gel1) entdeckt (Asif 2010). Es wurden zusätzlich Proteine aus einem dritten Projekt gewählt. In diesem wurden Proteine der Konidienoberfläche von A. fumigatus untersucht, welche ebenfalls massenspektrometrisch identifiziert wurden. Diese Proteine stellen die erste Möglichkeit eines Kontaktes zwischen dem Pilz und dem Wirt dar (Asif 2006). Somit sind sie ebenfalls wichtige Kandidaten im Rahmen der Antigen-Suche.

Als letztes wurden zwei Proteine ausgewählt, die auf Grund eines systematischtheoretischen Ansatzes Interesse erweckten. So wurden in Aspergillus fumigatus vor kurzem zwei ADAM-Proteine (a disintegrin and metalloprotease) gefunden (Lavens 2005). Bei diesen wird eine Funktion als Sheddase vermutet. Dieser Einfluss auf andere Proteine könnte während einer Infektion entscheidend sein.

Insgesamt gelang die Herstellung von 30 Proteinen (teilweise in Form mehrerer Peptide) in E. coli. Innerhalb dieser Gruppe befanden sich etliche Proteine, die nach Kontrolle mit speziellen Analyseprogrammen (Hydrophobizitätsplot) mehrere Bereiche mit hydrophoben Aminosäuren zeigten; also potentiellen Transmembranregionen. Es kann also davon ausgegangen werden, dass ein Großteil der hergestellten Proteine möglicherweise mit Zellmembran oder -wand interagiert. In $P$. pastoris konnten 8 Proteine erzeugt werden, wobei die Klonierungsarbeiten von einer kooperierenden Arbeitsgruppe übernommen wurden (Arbeitsgruppe Monod, Schweiz). Die Proteine lassen sich insgesamt in wenige Gruppen einteilen: Zum einen Proteine mit Enzymfunktion - dies ist die größte Gruppe -, zum anderen Proteine mit unbekannter Funktion und als dritte Gruppe Proteine mit Chaperon-Funktion.

\subsection{Immunisierung mit rekombinant hergestellten A.-fumigatus-} Antigenen

\subsubsection{Rekombinant hergestellte Proteine}

Es ist aus einigen Arbeiten bekannt, dass die Möglichkeit besteht, mit Vakzinen gegen eine invasive Aspergillose durch Erzeugung einer protektiven Immunreaktion vorzubeugen. Bislang wurde mit vier verschiedenen Einzelantigenen in Tierversuchen Immunität gegen diese Erkrankung erzeugt (Bozza 2002 und 2009; Ito 2006). Als Vorbereitung für die im Rahmen dieser Arbeit durchgeführten 
Tierversuche wurden 38 verschiedene Antigene rekombinant hergestellt (s. Tab. 14 und 15). Die Auswahl der verschiedenen Antigene wurde hierbei auf Basis mehrerer Ergebnisse aus anderen Arbeiten getroffen. In zwei veröffentlichten Studien wurden infektionsrelevante Antigene bestimmt, indem Infektionsseren aus Kaninchen gewonnen wurden, welche nach einer subletalen Aspergillus-Infektion immun gegen folgende Infektionen geworden waren. Einerseits wurden mit diesen Seren Proteine mittels einer A.-fumigatus-cDNA-Expressionsbank identifiziert (Denikus 2005), andererseits wurden Proteine des zellulären Proteoms dieses Erregers auf zweidimensionalen SDS-PAGE aufgetrennt, welche daraufhin im Immunoblot mit den Kaninchenseren reagierten. Identifiziert wurden diese Proteine durch Analysen über massenspektrometrische Methoden (Asif 2010). Durch die Verwendung von Tierseren, die aus gegen $A$. fumigatus immunen Tieren gewonnen wurden, und deren Bindung an Proteine wird die Wichtigkeit dieser Antigene aus diesen Arbeiten verstärkt.

In einem anderen Projekt wurde das Proteom von Kondienoberflächen untersucht (Asif 2006). Da die Proteine dieser Lokalisation zuerst mit dem infizierten Organismus in Kontakt kommen sollten, sind diese Proteine ebenfalls wichtige Kandidaten, die es im Rahmen dieser Arbeit zu untersuchen galt.

\subsubsection{Immunisierung von Mäusen mit rekombinant hergestellten Proteinen}

Tierversuche sind bei der Erforschung von Aspergillosen eine unverzichtbare Methode. Nicht nur können neu entwickelte Medikamente vor klinischen Studien auf ihre Wirksamkeit überprüft werden, es können auch Versuche durchgeführt werden, bei denen klinische Studien am Menschen unangebracht sind, wie es bei der Erforschung von präventiven Vakzinen der Fall ist. Zusätzlich ist die Variabilität von Versuchen an Tieren ein großer Vorteil. So können verschiedene Stämme des Erregers getestet werden inklusive im Labor erzeugter Gen-Deletionsmutanten. Auch kann die Art und Weise der Immunsuppression oder der Ort der Infektion geändert werden (Clemons 2006). So kann der Tierversuch der jeweiligen Fragestellung angepasst werden.

Die Abwehr gegen Aspergillus fumigatus in immunkompetenten Individuen verläuft hauptsächlich über die Zellen der angeborenen Immunität (Cenci 2000; Lessing 2007; Segal 2009). Hierbei ist die Funktion von Makrophagen und neutrophilen Granulozyten kaum bestreitbar. Diese sind zum einen als residente Alveolarmakrophagen Bestandteil der angeborenen Immunität. Andererseits werden diese Zellen im Rahmen der adaptiven Immunabwehr aktiviert. Hierbei sind bei der invasiven Aspergillose besonders die $\mathrm{T}_{H}$ 1-Lymphozyten mit ihren Zytokinen an der Verstärkung der Abwehrwirkung der Makrophagen beteiligt - sowohl die Phagozytoserate als auch die Produktion biozider Substanzen werden verstärkt (Martin 2009). Diese T-Zellen werden aktiv, wenn sie einen Antigen präsentierenden Antigen-MHC-II-Komplex erkennen. Die Signalgeber stellen in dem Komplex enthaltene, kurze Peptide (T-Zell-Epitope) dar. Es ist also nicht nötig, komplette Proteine als Vakzin zu verwenden, weil diese in den präsentierenden Zellen generell zerkleinert werden. In einer Arbeit an Aspergillus fumigatus wurde demonstriert, dass 
verwendete Bruchstücke von dem Allergen Aspf16 ausreichten, um bei einer Präsentation auf dendritischen Zellen eine $T_{H}$ 1-Zell-Aktivierung auszulösen (Ramadan 2005).

Die verwendeten Versuchstiere wurden in drei Gruppen eingeteilt. Eine der Gruppen stellte eine Negativkontrolle dar, der nur Adjuvans in PBS injiziert wurde. Bei dieser Gruppe wurde nach erfolgter Infektion starkes, invasives Wachstum mit dem Erreger und folgend der Tod erwartet. Die zweite Gruppe diente als Positivkontrolle. Den Mäusen dieser Gruppe wurden die Proteine Aspf3, Aspf16 und Gel1 in PBS zusammen mit dem verwendeten Adjuvans gespritzt; es wurden drei der vier bekannten Antigene verwendet, die laut bisheriger Veröffentlichungen Immunität verleihen (Bozza 2002 und 2009, Ito 2006). Erwartet wurde, dass diese Tiere vor der folgenden Infektion mit Aspergillus-fumigatus-Konidien geschützt waren, und dass sie deswegen überleben. In der dritten Gruppe wurde eine Kohorte von sechs der hergestellten Proteine in PBS mit dem Adjuvans AS03 als zu testendes Vakzin appliziert. In dieser Gruppe hätte ein Überleben der Tiere die Ausbildung einer protektiven Immunreaktion gezeigt, ein Sterben, dass dies nicht geschah. Da jedoch in allen Versuchstiergruppen in etwa die gleiche Anzahl an Tieren starben, kann keine definitive Aussage getroffen werden.

Durch den Tod der Tiere und der Kontrolle auf invasives Wachstum durch Aspergillus fumigatus wurde deutlich, dass eine Immunsuppression und die folgende Infektion stattgefunden hatten. Die erwünschte Immunität innerhalb der Positiv- und der Vakzingruppe konnte jedoch nicht erzeugt werden. Hierbei lassen sich mehrere Vermutungen aufstellen, wo mit Verbesserungen anzusetzen sein könnte. Zum einen ist zu vermuten, dass durch die verwendete, starke Immunsuppression die Zellen des Immunsystems so stark in ihrer Funktion gehindert wurden, dass deswegen keine $\mathrm{T}_{\mathrm{H}}$ 1-Immunantwort aktiviert werden konnte, woraufhin es ebenfalls nicht zur Ausbildung einer protektiven Immunreaktion kam. Vergleichsweise nutzte Ito (2006) sechs Dosen à 2,5 mg je Maus (15 mg Cortisonacetat gesamt), während in dieser Arbeit dreimal $7,5 \mathrm{mg}$ s.c. gespritzt wurden ( $22,5 \mathrm{mg}$ gesamt). Dementsprechend könnte eine etwas schwächere Suppression sinnvoll sein.

Zum anderen ist die Infektionsdosis an Konidien, mit denen die Tiere infiziert wurden, variabel; wobei diese noch unter der von Bozza (2002 und 2009) verwendeten Dosis lag ( $2 \times 10^{7}$ Konidien pro Maus). In der Arbeit von Ito (2006) wurden hingegen mit $3 \times 10^{6}$ Konidien pro Maus weniger Sporen verwendet. Es könnte also hilfreich sein eine etwas niedrigere Dosierung zu wählen. In diesem Rahmen muss auch beachtet werden, dass die in verschiedenen Arbeiten verwendeten Stämme von Aspergillus fumigatus unterschiedlich virulent sind (persönliche Mitteilung von Utz Reichard).

Fraglich ist auch, ob das verwendete Adjuvans AS03 in diesem Versuchsrahmen wirksam ist. Klar von Vorteil für weitere Ansätze ist, dass es bereits für die Verwendung bei humanen Impfungen zugelassen ist. Durch den ähnlichen Aufbau der Komponenten zu denen des bei Ito (2006) verwendeten Adjuvans TiterMax, sollte auch hier eine ähnliche Wirkung erzielt werden. Dies wird durch den Fakt 
unterstützt, dass der Bestandteil Squalen beider Adjuvantien im Rahmen einer TZell-Aktivierung mitwirken kann (Carlson 2000).

Als positiver Ergebnisteil ist hervorzuheben, dass die beiden einzigen Mäuse, in denen überhaupt kein invasives Wachstum mit Aspergillus fumigatus stattgefunden hatte, zu den Gruppen der Positivkontrolle und der Vakzingruppe gehörten. Dies ist ein positiver Anhaltspunkt, den es auszubauen gilt.

\subsection{Deletionsmutanten ausgewählter Gene in Aspergillus fumigatus}

\subsubsection{Deletionsmutanten der ADAM-Gene}

Es existieren in Säugetieren mehr als 30 verschiedene Proteine, die alle zu der Familie der ADAMs (a disintegrin and metalloprotease) zählen. Sie sind nach folgendem Schema aufgebaut: Prodomäne, Metalloprotease-Domäne, DisintegrinDomäne, Cystein-reiche Domäne und eine dem epidermal-growth-factor ähnliche Domäne. Außerdem haben sie eine Transmembran-Region, ein Signalpeptid, durch das diese Proteine über das Endoplasmatische Retikulum in die Plasma-Membran und großteils an die Zelloberfläche gelangen, und einen cytoplasmatischen Schwanz (Black 1998). Die grundlegenden Funktionen liegen in der Proteolyse (Protease), der Adhäsion (Disintegrin), Signalgebung und Fusion. Spezifischer betrachtet finden sich ADAMs bei wichtigen Interaktionsschritten. So wirken die Proteine ADAM 1 bis 6 bei der Spermatogenese, der Sperma-Eizell-Bindung und -Fusion aber auch bei anderen proteolytischen und adhäsiven Reaktionen (Wolfsberg 1995) wie der Verknüpfung neu entstehender Nervenzellen mit (ADAM-10; Hartmann 2002). Andere ADAMs finden sich z. B. auf Makrophagen-Oberflächen (Yoshida 1990), in Gehirnen von Rindern, in menschlichen Myeloblasten, oder sie wirken im Menschen als Brustkrebs-Suppressor (Katagiri 1995). In Säugetieren übernehmen besonders ADAM-10 und -17 wichtige Rollen. Sie sind die Haupt-Enzyme, die die Freisetzung von an Membranen assoziierter Proteine von der Zelloberfläche katalysieren (Caescu 2009; Moss 2002), was durch den Begriff Sheddase beschrieben wird. Während ADAM-17 auch als TACE (TNF- $\alpha$ converting enzyme) bekannt ist, ist die Funktion von ADAM-10 mit der Signalgebung durch „Notch“ in Verbindung zu bringen. Einen Nachweis hierfür erbrachte Hartmann (2002) durch die Erzeugung von ADAM-10defizienten Mäusen, welche bereits während der Embryogenese an Tag 9,5 mit multiplen Defekten im zentralen Nervensystem und kardiovaskulären System starben.

Auch in Pilzen wurden einige Vertreter dieser wichtigen Proteinfamilie gefunden. Je zwei ADAM-Proteine wurden in Aspergillus fumigatus, A. nidulans, Cryptococcus neoformans und Magnaporthe grisea gefunden. Lediglich je ein Vertreter dieser Proteinfamilie war in Neurospora crassa, Ustilago maydis und Fusarium graminearum zu finden. In den als Hefe wachsenden Pilzen Candida albicans und Saccharomyces cerevisiae wurden keine ADAMs gefunden (Lavens 2005). Es wurde dadurch gezeigt, dass ADAMs generell in Pilzen existieren; auch wenn sie einigen als Hefen wachsenden Pilzen fehlen oder im Laufe ihrer Entwicklung verloren gingen und insgesamt mit einer geringeren Anzahl in ihrer Variabilität vorliegen. 
Sequenzvergleiche der in Aspergillus fumigatus gefundenen ADAM-Proteine mit bekannten Sequenzen aus Datenbanken zeigten zusammen mit Vertretern aus anderen Pilzen Verwandtschaft zu ADAM-10 und ADAM-17 aus Menschen und Caenorhabditis elegans, für welche die Sheddase-Funktion belegt ist (Caescu 2009). Deswegen wird vermutet, dass die ADAMs in Aspergillus fumigatus und anderen Pilzen ebenfalls Funktion als Sheddase haben. Für die beiden Proteine aus

A. fumigatus zeigt sich diese Annahme darin bestärkt, dass eine generelle Sequenzhomologie zu den menschlichen ADAMs von 17 - 24\% existiert. Im Bereich der Protease-Domäne hingegen steigt diese Homologie auf 24 - 35\% an (Lavens 2005). Da sich die menschlichen ADAMs (und hierbei besonders ADAM-10 und -17) an der Zelloberfläche befinden, könnten die beiden in A. fumigatus gefundenen ADAM-Proteine ebenfalls an der Zelloberfläche lokalisiert sein, was sie zu potenziellen Zielen der Suche nach Vakzinekandidaten macht.

Wegen der wahrscheinlichen Sheddase-Funktion wurden zunächst Versuche durchgeführt, die eine mögliche durch ADAM-Proteine verursachte Prozessierung von am Zellwandmetabolismus beteiligter Enzyme untersuchen sollten. Hierbei zeigten die Einzel- und Doppel-Gen-Deletionsmutanten der ADAM-Gene in A. fumigatus unter den untersuchten Bedingungen (s. 2.15.1) keinerlei veränderten Phänotyp. Weder erbrachte Wachstum unter erhöhtem osmotischem Stress durch Natrium- oder Kaliumchlorid noch durch Sorbitol einen Wachstumsunterschied im Vergleich zum Wildtyp. Auch zeigten die Stoffe SDS und Koffein, welche beide die Signaltransduktion im Rahmen der Zellwandsynthese hemmen, keinen Unterschied zwischen Deletionsmutanten und D141. Kongo Rot, welches Glucan-Fibrillen komplexiert, konnte genauso wenig wie Calcofluor-White, welches Chitin komplexiert, einen Wachstumsunterschied hervorrufen.

Weiterhin wurde untersucht, ob eine Prozessierung der an der Ernährung beteiligter Enzyme durch ADAMs vorliegt. Hierfür wurden Versuche unternommen, verschiedene Substanzen (BSA, Casein und Gelatine; s. 2.15.1) als Nährstoff verwerten zu lassen. Es wurde im Rahmen der untersuchten Bedingungen getestet, ob diese Stoffe als Nährstoffquellen verwendet werden können. Hierbei wurde die Verwendung von Albumin, Casein und Gelatine zum einen als einzige Kohlenstoffquelle, zum anderen als einzige Stickstoffquelle oder zum dritten als einzige Kohlenstoff-und-Stickstoffquelle getestet. Es zeigte sich jedoch kein Unterschied im Wachstum der Mutanten gegenüber dem Wildstamm. Dies lässt darauf schließen, dass die Umsetzung der verwendeten Substanzen als Nährstoffe offensichtlich nicht durch Enzyme geschieht, an deren Aktivierung ADAM-Proteine als Sheddase beteiligt sind.

Da die Überlegungen zu den ADAM-Proteinen aus Aspergillus fumigatus auf Grund der Ähnlichkeit zu humanen ADAMs angestellt wurden, ist nicht sicher, ob zum Beispiel die Lokalisation die gleiche ist. Eine kooperierende Arbeitsgruppe (AG Monod (Laboratoire de Mycologie, Université Lausanne)) stellte polyklonale Antikörper gegen zum einen ADAM-A, zum anderen ADAM-B zur Verfügung. Mit diesen wurde versucht die Lokalisation der ADAM-Proteine in A. fumigatus D141 und 
vergleichend in den ADAM-Deletionsmutanten über Western-Blot in verschiedenen Zellkompartimenten zu bestimmen (Zytosol oder Membranfraktion). Sowohl der Wildtyp als auch die Deletionsmutanten zeigten hierbei das gleiche Bandenmuster; dies deutet unspezifische Bindung an. Dadurch bleibt die Lokalisation der ADAMs weiterhin ungeklärt. Ob nun die erwarteten Banden durch andere überdeckt wurden, oder ob die ADAM-Proteine eventuell gar nicht exprimiert wurden, bleibt unklar. Lavens (2005) zeigte hierzu, dass die zu ADAM-B zugehörige mRNA in frühen Wachstumsstadien einer $A$.-fumigatus-Kultur vorhanden ist. Allerdings wurde für das in S. pombe identifizierte ADAM-Protein, welches den ADAMs aus Aspergillus fumigatus ähnelt, gezeigt, dass es nur vorrübergehend während der Meiose akkumuliert (Nakamura 2004) und außerhalb der sexuellen Fortpflanzung nicht nachweisbar ist.

Weitere Funktionen von menschlichen ADAM-Proteinen liegen häufig in der Vermittlung von Zell-Zell-Kontakten und in reproduktiven Prozessen. Auch das in Schizosaccharomyces pombe identifizierte ADAM-Protein (Mde10), ist im Rahmen der Meiosporen-Entwicklung beteiligt (Nakamura 2004). Deletionsmutanten dieses Proteins führten zu Meiosporen, bei denen die äußeren Sporenwände fehlten. Die beiden aus $A$. fumigatus identifizierten Proteine ADAM-A und ADAM-B sind mit $85 \%$ (ADAM-B) bzw. $68 \%$ (ADAM-A) dem Mde10 aus S. pombe homolog. Es liegt also der Gedanke nahe, dass die ADAM-Proteine aus Aspergillus fumigatus ebenfalls an der Meiosporenentwicklung beteiligt sind. Im Vergleich zu den menschlichen ADAMs kann man sagen, dass diese Proteingruppe wie Archetypen von an generativen Prozessen beteiligten Proteinen erscheinen. Die Beteiligung von ADAM-A und -B an der Bildung von während der Meiose gebildeter Sporen erscheint dementsprechend plausibel. Besonders für die Doppel-Gen-Deletionsmutante beider ADAM-Proteine wäre es wahrscheinlich lohnend, Versuche hinsichtlich der Induktion der Meiose und dadurch auch der Sporenbildung zu unternehmen; auch wenn dies in Aspergillus fumigatus nur schwierig durchführbar ist. Der Vollzug der sexuellen Entwicklung in vitro dauert nämlich mehrere Monate (O'Gorman 2009), was eine Handhabung im Labor wesentlich erschwert.

Zusätzlich besteht die Möglichkeit, dass die Expression der ADAM-Proteine erst während einer Infektion in Mensch oder Tier stattfindet. Dadurch besteht weiterhin die Chance eine wahrscheinliche Sheddase-Funktion während einer Infektion zu unterbinden. Dies lässt weiterhin die Möglichkeit offen, dass die ADAMs als Vakzin verwendet werden können.

\subsubsection{Deletionsmutante des Aspf3-Gens}

Die Abwehr gegen Konidien von Aspergillus fumigatus wird einerseits in der Lunge vom Flimmerepithel übernommen, welches mechanisch Konidien aus der Lunge heraus befördert. Andererseits werden die Konidien vom Komplementsystem und den residenten Alveolarmakrophagen bekämpft (Phillippe 2003). In letzteren werden die phagozytierten Konidiosporen unter Mitwirkung reaktiver Sauerstoffintermediate (ROI) eliminiert (Aratani 2002). Bei der genetisch bedingten Krankheit der Septischen Granulomatose (CGD, „chronic granulomatous disease“) ist das Enzym, das 
einleitend an der Produktion der ROI beteiligt ist, in seiner Funktion gestört.

Menschen und Tiere mit dieser Erkrankung entwickeln vermehrte und chronische Erkrankungen (Lambeth 2004). Hierbei sind besonders häufige und schwere Fälle von durch Aspergillus verursachte Lungenentzündungen zu beobachten (Babior 2000). Es existiert also ein klinischer Beleg dafür, dass die reaktiven

Sauerstoffintermediate entscheidend an der Abwehr von Aspergillen beteiligt sein müssen. Ein wichtiger Teil der ROI ist Wasserstoffperoxid, für dessen Entgiftung unter anderem Aspf3 verantwortlich ist, was in dieser Arbeit anhand der Deletionsmutante $\Delta$ Aspf3 deutlich gezeigt wurde (s. Abb. 46 und 47). Zusätzlich wurde die Produktion von Aspf3 durch Aspergillus-fumigatus-Hyphen in dem Projekt von Denikus (2005) in fünf von sechs Kaninchen nachgewiesen, welche nach überlebter Aspergillose immun gegen A. fumigatus waren. Eben weil Aspf3 während einer Erkrankung - also in Hyphen - exprimiert wird, und weil es $u$. a. auch schon in der Konidiosporenwand lokalisiert ist (Asif 2006), wurde seine Funktion untersucht. Außerdem ist bekannt, dass rekombinantes Aspf3 im Tierversuch als Vakzin verabreicht zu der Ausbildung einer protektiven Immunreaktion führt (Ito 2006).

Es existieren verschiedene Substanzen, die zu den ROI gezählt werden. Zunächst entsteht von molekularem Sauerstoff ausgehend durch die NADPH-Oxidase enzymatisch katalysiert das Superoxidanion $\left(\mathrm{O}_{2}{ }^{-}\right)$. Dieses reagiert als erstes der $\mathrm{ROI}$ besonders mit Eisen-Schwefel-Clustern aus verschiedenen Proteinen (z. B. denen der mitochondrialen Atmungskette; Lambeth 2004) und schädigt dadurch deren Funktion. Dieses Anion stellt die Vorstufe zu anderen Sauerstoffspezies dar, welche ebenfalls enzymatisch hergestellt werden. Beispielsweise wird das Superoxidanion über das Enzym Superoxiddismutase zu Wasserstoffperoxid $\left(\mathrm{H}_{2} \mathrm{O}_{2}\right)$ umgewandelt. $\mathrm{O}_{2}{ }^{-}$kann aber auch zu einem geringen Anteil spontan ohne Enzymeinwirkung zu Wasserstoffperoxid reagieren (Babior 2000). $\mathrm{H}_{2} \mathrm{O}_{2}$ selbst kann über die FentonReaktion zusammen mit $\mathrm{Fe}^{2+}$ zu dem Hydroxylradikal $\mathrm{OH} \cdot$ reagieren. Wie andere Radikale auch ist dieses sehr reaktionsfreudig, weswegen unspezifisch sämtliche Biomoleküle in der näheren Umgebung angegriffen werden. Sofern ein Radikal mit einem anderen Molekül reagiert hat, entsteht aus diesem erneut ein Radikal. Diese Reaktionen werden auch als Freie-Radikale-Kettenreaktion betitelt. Zu einem Ende kommt es dabei nur, wenn zwei Radikale miteinander reagieren, oder wenn sie als Reaktionspartner auf ein Übergangsmetall stoßen, denn diese haben die Kapazität, ungebundene Elektronen aufzunehmen (Babior 2000). Von Wasserstoffperoxid ausgehend kann es im Rahmen der Produktion von ROI über die Myeloperoxidase zur Entstehung von Hypochloriger Säure (HOCl) kommen, aus welcher wiederum auch Hydroxylradikale entstehen können. Außerdem kann über NADPH-Oxidase und Myeloperoxidase auch Singulett-Sauerstoff $\left({ }^{1} \mathrm{O}_{2}\right)$ entstehen (Kanofsky 1989).

Besonders häufig werden durch dieses ROI Doppelbindungen in ungesättigten Fettsäuremolekülen angegriffen (Lambeth 2004).

Als Gesamtheit betrachtet wurde lange Zeit angenommen, dass ROI ein unvermeidbares Übel eines aeroben Lebensstils seien. Die Erkenntnis, dass Enzyme 
existieren, deren hauptsächliche Funktionen die direkte Herstellung dieser Sauerstoffintermediate sind, änderte diese Sichtweise (Suh 1999). Die ROIproduzierenden Enzyme bilden mit deren Entgiftern ein System sich gegenseitig kontrollierender Proteine. Die Funktionen von ROI verteilen sich nach heutigem Wissensstand auf Aufgaben innerhalb phagozytierender Zellen, Signalgebung bei der Zellteilung und Modifikation extrazellulärer Matrix (Wood 2003); ferner ist die Beteiligung an verschiedenen Krankheiten möglich (Babior 2000). Außerdem sind einige der ROI durch ihre ungezielten Attacken auch für Schäden an der DNA verantwortlich, wegen derer es zu Mutationen kommt. Zusätzlich kann es dadurch zur Entstehung von Krebs kommen, was beispielsweise passieren kann, wenn Menschen Strahlung ausgesetzt werden (Shacter 1988). Weitere ungewollte Entstehung von ROI ist generell dort in Zellen lokalisiert, wo verstärkt Sauerstoff vorhanden ist. Dies ist zum einen in Mitochondrien (Lambeth 2004) und zum anderen in den Chloroplasten von Pflanzenzellen der Fall (Shaikhali 2008). Die bereits erwähnte NADPH-Oxidase ist ein essentielles Enzym bei der Entstehung der ROI und der dadurch folgenden Abwehr gegenüber Pathogenen. Dieser Punkt wird sehr deutlich, wenn man Menschen mit septischer Granulomatose (CGD) betrachtet. Patienten mit dieser seltenen Erbkrankheit können in ihren Zellen keine funktionstüchtige NADPH-Oxidase exprimieren, wodurch sie häufige und chronische Erkrankungen entwickeln (Lambeth 2004); auch Mutationen oder Defekte in den verschiedenen Komponenten der NADPH-Oxidase führen zu dem Krankheitsbild der CGD (Segal 1996; Sheppard 2005).

Die Wichtigkeit der ROI im Zusammenhang mit der Abwehr pathogener Mikroorganismen zeigt sich unter anderem darin, dass eine Gen-Deletionsmutante des Bakteriums Mycobacterium bovis, der die Möglichkeit zur Entgiftung von Peroxiden fehlte, nicht mehr virulent war (Wilson 1998).

Die zuvor beschriebene Relevanz von reaktiven Sauerstoffintermediaten bei der Eliminierung von Krankheitserregern muss bezüglich der von Pilzpathogenen eingeschränkt werden. Es ist mittlerweile bekannt, dass bei pulmonalen Erkrankungen mit Candida albicans oder Aspergillus fumigatus das Superoxidanion oder das folgend hergestellte Wasserstoffperoxid und nicht die daraufhin gebildete Hypochlorigen Säure oder deren Folgeprodukte eine entscheidende Rolle bei der Vernichtung der Erreger spielt (Aratani 2002). Diese Erkenntnisse wurden über Tierversuche erzielt, in denen zum einen Mäuse mit fehlender NADPH-Oxidase oder fehlender Myeloperoxidase und zum anderen mit Mäusen, denen beide Enzyme fehlten, infiziert wurden. Bei fehlender Myeloperoxidase war keine verstärkte Anfälligkeit gegenüber den Pathogenen ersichtlich. Eine Defizienz der NADPHOxidase zeigte den gleichen Phänotyp wie ein Fehlen beider Proteine. Dieser Phänotyp äußerte sich dadurch, dass eine höhere Mortalität und eine stärkere Besiedlung der Versuchstiere mit den Erregern zu beobachten war. Aratani (2002) schließt daraus folgernd auf die Wichtigkeit des Myeloperoxidase-bedingten Pfads der Bildung von ROI. Betrachtet man nun die Abbildungen 48 und 50 wird deutlich, dass bereits Wasserstoffperoxid allein einen beachtlichen Einfluss auf das Wachstum 
von Aspergillus fumigatus hat, sofern es nicht entgiftet wird. Und dies ist trotz vorhandener Katalasen in Konidien und Hyphen offenbar nicht ausreichend der Fall. Allerdings ist die Resistenz von Hyphen gegen $\mathrm{H}_{2} \mathrm{O}_{2}$ deutlich höher, als es bei keimenden Konidien der Fall ist, was durch einen geringeren Hemmhofdurchmesser deutlich wird (s. Abb. 52 und 53). Wahrscheinlich ist dieser Schutz in wachsenden Hyphen durch die bereits aktivierte Proteinsynthese und die Bildung von Katalasen (cat1 und cat2) oder anderen Enzymen besser gewährleistet. Eine Aspergillusfumigatus-Mutante, der diese beiden Katalasen fehlten, benötigte länger, um eine Infektion im Tiermodell hervorzurufen, bzw. der Wirtsorganismus konnte die Infektion effektiver bekämpfen (Paris 2003). Somit scheint Wasserstoffperoxid einen Einfluss auf die Infektion mit $A$. fumigatus zu haben. Eine Deletionsmutante der in Konidiosporen vorhandenen Katalase (catA) zeigte hingegen keine erniedrigte Infektiösität (Paris 2003), was wahrscheinlich an dem in Sporen vorhandenen Aspf3 liegt. Aspf3 ist ein Peroxiredoxin-ähnliches Allergen und ist zusätzlich zu anderen Lokalisationen bereits in der Sporenwand vorhanden (Asif 2006). Dadurch werden schädliche Peroxide offensichtlich direkt bei der Keimung eliminiert; und deren Entgifter müssen nicht erst auf einen Stimulus hin neu synthetisiert werden. So kann durch das Fehlen dieses Peroxiredoxins in der erzeugten Deletionsmutante die Funktion von keinem anderen Enzym in vergleichbarer Effizienz übernommen werden.

Die erzeugte Deletionsmutante von Aspf3 konnte im Agardiffusionstest (s. 2.15.2.1) gegen weitere Mutanten verglichen werden ( $\Delta$ AfYap1, $\Delta$ AfYap1::AfYap1, $\Delta S k n 7)$, in welchen Transkriptionsfaktoren ausgeschaltet waren, die an der Regulation einer Zellantwort auf oxidativen Stress beteiligt sind (Lamarre 2007; Lessing 2007). Für den Transkriptionsfaktor AfYap1 wurde gezeigt, dass eine A.-fumigatus-Mutante ohne diesen Faktor anfällig gegen Wasserstoffperoxid und einen Superoxidanionbildenden Stoff ist. Außerdem wurde festgestellt, dass die $\Delta$ AfYap1-Mutante keine veränderte Virulenz in einem Tiermodell im Vergleich zu dem Aspergillus-fumigatusWildtyp hat (Lessing 2007). Im Gegenzug zeigte Lamarre (2007), dass eine $\Delta$ Skn7Mutante zwar ebenfalls erhöhte Sensitivität gegen Wasserstoffperoxid hatte, jedoch keinen Unterschied im Einfluss von $\mathrm{O}_{2}{ }^{-}$erkennen ließ. Ebenfalls hatte das Fehlen dieses Transkriptionsfaktors keinen Einfluss auf die Virulenz von A. fumigatus im Tierversuch (Lamarre 2007).

Betrachtet man nun Abbildungen 49 und 50, so erkennt man, dass auch in dieser Arbeit eine deutlich höhere Sensitivität beider Deletionsmutanten gegen Wasserstoffperoxid gegenüber dem Wildtyp gezeigt werden konnte. Allerdings sind beide nicht so stark sensitiv wie der Klon der Deletion eines einzelnen Gens - Aspf3. Vergleichend wird der halbmaximale Hemmhofdurchmesser betrachtet bzw. die Menge an Wasserstoffperoxid, die zum Erreichen dieses von Nöten war: Während $\triangle$ Aspf3 eine $0,15 \% \mathrm{H}_{2} \mathrm{O}_{2}$-Lösung benötigte um den halbmaximalen Hemmhofdurchmesser zu erreichen, musste bei den Deletionsmutanten der Transkriptionsfaktoren eine 0,6\% Lösung verwendet werden - also eine 4-mal so 
hoch konzentrierte Lösung - um den gleichen Durchmesser zu erreichen. Ein Unterschied zwischen diesen drei Mutanten wurde ebenfalls beobachtet, wenn die vor dem Test vorinkubierten Kulturen verglichen wurden (s. Abb. 51 und 52). Hier liegt der erreichte halbmaximale Hemmhofdurchmesser von $\Delta$ AfYap1 und $\Delta S k n 7$ bei einer Wasserstoffperoxidkonzentration von $3 \%$. $\Delta$ Aspf3 hingegen benötigt nur eine $0,75 \% \mathrm{H}_{2} \mathrm{O}_{2}$-Lösung - ebenfalls ein Unterschied um den Faktor 4.

Für die Mutante $\triangle A f Y a p 1$ wurde jedoch veröffentlicht, dass zu den vermutlich von AfYap1 beeinflussten Genen nicht nur Aspf3, sondern auch die in Hyphen exprimierten Katalasen cat1 und cat2 zählen (Lessing 2007). Dementsprechend würde erwartet werden, dass der Hemmhof der $\triangle$ AfYap1-Mutante im Test der vorinkubierten Kulturen größer ist als der von $\triangle$ Aspf3. Da dies jedoch nicht der Fall ist, erhöht es die Bedeutung des Proteins Aspf3 bzw. Peroxiredoxin bezüglich der Entgiftung von Wasserstoffperoxid deutlich. Ebenfalls würde bei einer stärkeren Kontrolle des Aspf3 durch AfYap1 erwartet werden, dass die Auswirkung von $\mathrm{H}_{2} \mathrm{O}_{2}$ bei $\Delta$ AfYap1 mindestens der Auswirkung bei $\Delta$ Aspf3 gleich ist. Da dies nicht der Fall ist, kann man davon ausgehen, dass eine ausschließliche Regulation von Aspf3 über AfYap1 auszuschließen ist.

Als weiterer Gedanke drängt sich derjenige auf, ob den Sauerstoffintermediaten in Aspergillus fumigatus ebenfalls Signal-gebende Funktionen zuzuordnen sind (z. B. bei Zellteilung), wie es für menschliche Zellen bekannt ist (Wood 2003; Lambeth 2004). Und wenn dies der Fall ist, ob Aspf3 oder die verschiedenen Katalasen daran beteiligt sind.

Die NADPH-Oxidase als Enzym, welches die Produktion von ROI startet, besteht aus mehreren Anteilen, die vor der Aktivierung getrennt voneinander zum einen an die Membran gebunden und zum anderen gelöst im Zytosol vorliegen. Dieses Enzym funktioniert erst, wenn alle Teile zusammengelagert und aktiviert an der Vesikelmembran angelagert vorliegen. Einer dieser Anteile ist das p29peroxiredoxin. Dieser Teil hat Phospholipase- und Peroxidase-Aktivität. Außerdem ist er direkt an den Oxidase-Anteil p67 assoziiert (Sheppard 2005; Wyman 2002). Es ist zu vermuten, dass p29peroxiredoxin als Schutz der Zelle dient, weil es mit der Funktion Peroxide unschädlich zu machen direkt neben einer potenziellen Quelle für eine Vorstufe für eben diesen Stoff existiert. Proteine der Peroxiredoxin-Familie wurden ubiquitär in fast allen Lebewesen identifiziert; so z. B. in Pflanzen, Tieren, Bakterien und in Pilzen. Sie werden über verschiedene Weisen reguliert. Diese sind u. a. Phosphorylierung, Änderung des Redoxstatus und Oligomerisierung (Wood 2003). Die Peroxiredoxine werden in drei funktionelle Gruppen gegliedert: 1. die typischen 2-Cystein-Peroxiredoxine, 2. die atypischen 2-Cystein-Peroxiredoxine und 3. die Gruppe der 1-Cystein-Peroxiredoxine; Aspf3 gehört wahrscheinlich zu der Gruppe der atypischen 2-Cystein-Peroxiredoxinen (s. u.). Allen drei Gruppen ist der erste Katalyseschritt gemein. Bei diesem reagiert die Thiol-Gruppe (Cys-SH) des katalysierenden Cysteins mit Wasserstoffperoxid und bildet Sulfensäure (Cys-SOH). Die weitere Rückführung der Sulfensäure zu normalem Cystein findet ebenfalls bei 
allen drei Gruppen über die Ausbildung von Disulfidbrücken statt (Wood 2003). Jedoch unterscheiden sich die Proteine über die Art, wie und wo diese Brücken entstehen. Bei den typischen 2- und den 1-Cystein-Peroxiredoxinen werden intermolekulare Disulfidbrücken gebildet; diese Enzyme sind obligate Homodimere oder sogar Homooligomere (Seo 2000). Bei den atypischen 2-Cystein-

Peroxiredoxinen entstehen hingegen intramolekulare Disulfidbrücken. Diese Enzyme funktionieren als Monomere. Zur Auflösung der Disulfide kommt es durch zelleigene Disulfid-Reductasen (Wood 2003). Die Gruppe der Peroxiredoxine hat Funktionen bei der Entgiftung von überschüssigem oder ungewollt entstandenem Wasserstoffperoxid. Aber da andererseits von $\mathrm{H}_{2} \mathrm{O}_{2}$ bekannt ist, dass es Funktionen als Signalgeber bei Zellteilung oder Zelldifferenzierung und sogar bei der Apoptose hat, wird die Aufgabe der Peroxiredoxine über die der Antioxidantien hinaus als Regulatoren für diese Signalwege angesehen (Ross 2000; Hofmann 2002). Auch wenn die in Menschen identifizierten Peroxiredoxine eher schlechte antioxidative Fähigkeiten haben - besser bzw. schneller arbeiten Katalasen und GlutathionPeroxidase - (Wood 2003), so sind in Bakterien nicht Katalasen sondern das identifizierte Peroxiredoxin (AhpC) für den Schutz gegen zu viel Wasserstoffperoxid verantwortlich (Seaver 2001). Beispielsweise war der Organismus Mycobacterium bovis nach Deletion von AhpC nicht mehr virulent (Wilson 1998), was die Funktion von $\mathrm{H}_{2} \mathrm{O}_{2}$ bei der Eliminierung von Pathogenen wiederum betont.

Gegenüber den deutlichen Unterschieden binnen der Peroxiredoxine ist es jedoch immer der Cysteinrest im Bereich des N-terminalen-Anteils der Peptidkette, der das katalytische Zentrum darstellt. Dies mag auch der Grund sein, aus dem die Aminosäuresequenz um dieses Cystein herum hoch konserviert ist:

KGKYVVLFFYPLDFTFVCP (Peroxiredoxin II; Seo 2000). Die atypischen 2-CysteinPeroxiredoxine stimmen in ihrer Aminosäuresequenz insgesamt nur zu ungefähr $10 \%$ mit anderen Peroxiredoxinen überein, die Homologie innerhalb dieser katalytischen Region hingegen stimmt mit 10 von 19 Aminosäuren zu etwa 52\% überein (Seo 2000).

Das aus Aspergillus fumigatus stammende Allergen Aspf3 kodiert für ein Peroxiredoxin, welches am ehesten mit etwa $32 \%$ dem humanen Peroxiredoxin des Typs V ähnelt (s. Abb. 54). Besonders hoch sind die Homologien im Bereich des katalytischen, $\mathrm{N}$-terminalen Cysteins, wie es von anderen Peroxiredoxinen her bekannt ist. 


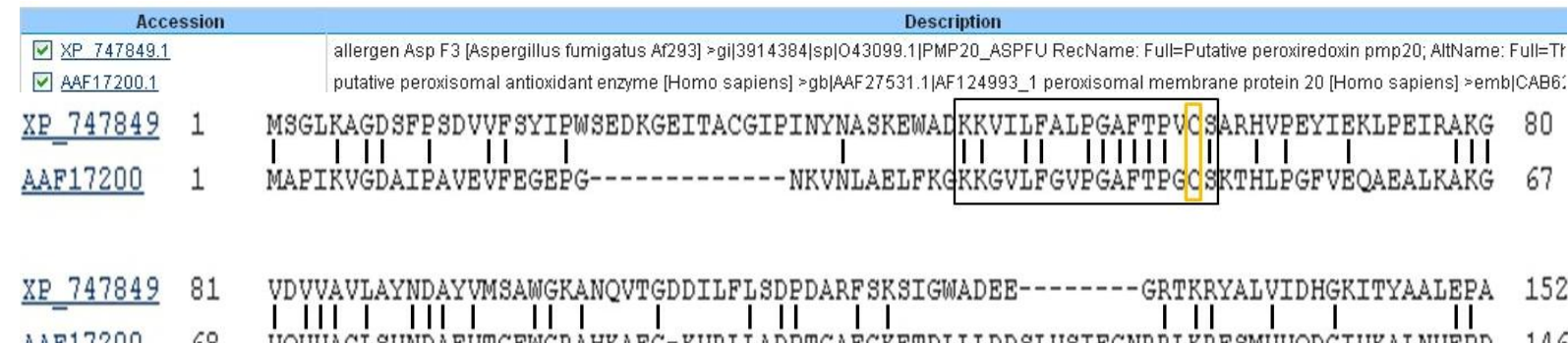

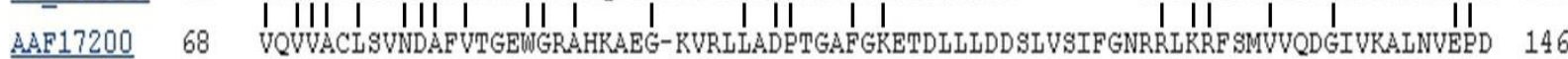

XP 747849 153 KNHLEFSSAETVLKHL 168

AAF17200 147 GTGLTCSLAPNIISQI 162

Abbildung 54: Sequenzvergleich von Aspf3 gegenüber menschlichem Peroxiredoxin V (Synonym: peroxisomal membrane protein 20); das katalytische Cystein ist mit orangefarbenem Rahmen gekennzeichnet, die konservierte Region um das katalytische Cystein mit einem schwarzen Rahmen

Die konservierte Region des Aspf3 ähnelt der von Seo (2000) angegebenen konservierten Sequenz der Peroxiredoxin-Familie zu etwa 47 \% (9 von 19 Aminosäuren). Die Homologie zu der konservierten Region des Peroxiredoxins $V$ ist mit ungefähr 63 \% (12 von 19 Aminosäuren) größer. Durch diese Sequenzvergleiche der katalytischen Region und der kompletten Sequenz (s. Abb. 54) ist die Verwandtschaft von Aspf3 zu den Peroxiredoxinen und im Speziellen zu Peroxiredoxin V verdeutlicht.

Ein großer Unterschied ist jedoch, dass das Peroxiredoxin $\mathrm{V}$ aus Menschen in Zytosol und Organellen im Verhältnis 1 zu 2 lokalisiert ist (Seo 2000). Das Allergen Aspf3 aus Aspergillus fumigatus ist hingegen nachweislich auch an der Zelloberfläche und spezieller auf der Oberfläche von Konidien nachgewiesen worden (Asif 2006). Eine BLAST-Suche (Geer 2010) der Aminosäureabfolge von Aspf3 im Reich der Pilze lieferte etliche Treffer. Die am stärksten homologen Proteine gehören zu den folgenden Spezies: Neosartorya fischeri, Aspergillus clavatus, Aspergillus terreus, Aspergillus nidulans, Aspergillus niger. Die Sequenzen gleichen sich von $97 \%$ bis zu 90\%, was einer starken Konservierung entspricht. Alle diese Arten sind als fakultativ pathogen bekannt. Dies könnte ein wichtiger Hinweis darauf sein, dass das Allergen Aspf3 generelle und identische Funktionen während der Pathogenese von Mykosen einnimmt, welche in der Entgiftung von Sauerstoffradikalen liegen. Das humane Peroxiredoxin V zählt zu den atypischen 2-Cystein-Peroxiredoxinen (Seo 2000). Diese Gruppe bildet intramolekulare Disulfidbrücken zwischen dem Nterminalen und dem C-terminalen Cystein aus; ist also im Rahmen seiner Aufgaben ein funktionelles Monomer. Dieses zweite Cystein $\left(C_{y s}{ }^{152}\right)$ ist für die Ausbildung der Disulfidbrücke essentiell. Betrachtet man nun die Sequenz von Aspf3, so findet sich in dieser kein C-terminales Cystein. Hingegen ist ein zweites Cystein noch weiter Richtung des N-Terminus zu finden $\left(\mathrm{Cys}^{31}\right)$. Fraglich ist, ob dieses ausreicht um eine solche Disulfidbrücke entstehen zu lassen, denn der Abstand zwischen den aktiven Cysteinen beträgt normalerweise 120 bis 123 Aminosäuren (Seo 2000) und ist in Aspf3 mit nur 20 AS deutlich geringer. 
Insgesamt wurde gezeigt, dass Aspf3 bei der Entgiftung von Wasserstoffperoxid in vitro herausragende Bedeutung hat. Die Erzeugung einer protektiven Immunreaktion gegen Aspergillus fumigatus im Tiermodell mit diesem Protein war aus einer früheren Arbeit bekannt (Ito 2006). Aspf3 gehört zu der Proteingruppe der Peroxiredoxine, wie der Vergleich der Aminosäuresequenz zu humanem Peroxiredoxin $\vee$ zeigt. Der Phänotyp der Deletionsmutante lässt zusätzlich vermuten, dass es sich bei diesem Protein um ein mögliches Ziel für eine medikamentöse Therapie bei der Behandlung von Aspergillosen handeln könnte, wodurch eventuell die Restaktivität von Zellen des Immunsystems von immunsupprimierten Individuen unterstützt werden kann. Sofern sich eine Therapiemöglichkeit bestätigt, dürfte die relativ geringe Homologie zu menschlichen Proteinen dafür Sorge tragen, dass allenfalls geringe Nebenwirkungen auftreten.

\subsection{Ausblick - zukünftige Versuche}

Fortführende Untersuchungen involvieren großteils erneut Versuche im Tiermodell. In einer Richtung sollte das Tiermodell zur Überprüfung der rekombinant hergestellten Proteine voll etabliert werden. Nachdem die Antigene in mehreren Kohorten auf ihre Fähigkeit Immunität zu erzeugen getestet wurden, müssen die Einzelantigene bestimmt werden, die für den Schutz verantwortlich sind. Sofern dies gelingt, sollten Gen-Deletionsmutanten der zu den Proteinen korrelierenden Gene angefertigt werden. Diese sollten dann neben eventuellen biochemischen Charakterisierungen ebenfalls im Tierversuch untersucht werden. Unter Verwendung des evaluierten, schützenden Antigens als Vakzin sollte sich nach folgender Infektion mit der jeweiligen A.-fumigatus-Gen-Deletionsmutante keine protektive Immunantwort aufbauen. Dies wäre dann ein Beweis für die Potenz des Vakzins im übertragenen Sinne gemäß den Henle-Koch-Postulaten. Ursprünglich wird das Pathogen identifiziert und mit der Krankheit obligat assoziiert, in Reinkultur gezüchtet, mit welcher dann in einem gesunden Individuum erneut die Krankheit ausgelöst werden kann. Im Rahmen der Vakzinsuche würde dies den Schritten entsprechen, dass ein Antigen des Erregers identifiziert wird, welches als Vakzin appliziert protektive Immunität auslöst. Der Punkt der Züchtung in Reinkultur fließt zusammen mit der Reinfektion. Dies geschieht in dem Sinne, dass eine Deletionsmutante des Erregers erstellt wird. Mit dieser darf keine protektive Immunität entstehen, wenn das zugehörige Antigen/Vakzin zuvor verabreicht wurde.

Die erzeugte Deletionsmutante von Aspf3 sollte generell auf ihre Virulenz getestet werden. Dadurch ließen sich weitere Erkenntnisse über die Abwehr des Immunsystems gegen Aspergillus fumigatus als Krankheitserreger gewinnen. Denn bisherige Veröffentlichungen umfassten nur Untersuchungen der Wirkung des Superoxidanions oder der Hypochlorigen Säure, nicht jedoch die der Zwischenstufe Wasserstoffperoxid selbst (Aratani 2002). Durch das Fehlen eines offenbar wichtigen Enzyms der Entgiftung dieses Stoffes, würden Virulenzversuche weiteres Verständnis dieser Abwehrkomponente des Immunsystems liefern. 
In diesem Rahmen wäre die Konstruktion einer Doppel-Gen-Deletionsmutante von Aspf3 und der Katalase aus Sporen (catA) hilfreich. Mit einer solchen Mutante würden Tierversuche weitere wertvolle Hinweise auf mögliche Faktoren der Pathogenität liefern.

Durch den Phänotyp der Aspf3-Deletionsmutante und des dadurch erweckten Interesses an etwaigen Inhibitoren, dürfte dies ebenfalls ein Feld sein, welches weitere Arbeiten erfordert. Außerdem dürften potenzielle Inhibitoren keine Nebenwirkungen auf das menschliche Peroxiredoxin $\vee$ zeigen, weil die Homologien dafür wahrscheinlich zu gering sind.

Ein weiteres zukünftiges Projekt wäre die Untersuchung des Proteoms von Aspergillus fumigatus unter Bedingungen, die denen des Habitates ähneln, welches der Erreger in der menschlichen Lunge vorfindet. Hierbei wäre eine Begrenzung des Stickstoffangebotes eine der möglichen Variablen. Auch könnte man in geeigneten Versuchsanlagen einen erhöhten Kohlenstoffdioxidpartialdruck der Luft erzeugen. Die so erhaltenen Proteine könnten über zweidimensionale Gelektrophorese aufgetrennt und über massenspektrometrische Methoden identifiziert werden. Diese Proteine dürften wahrscheinlich ebenfalls sehr ergiebige Ziele bei der Vakzinsuche sein.

Auch wenn die homologen Bereiche von Aspf3 Verwandtschaft zu humanem Peroxiredoxin V nahe legen, so fehlt Aspf3 doch ein entscheidender Cystein-Rest, der eigentlich für die Funktion essentiell sein müsste. Dieser Unterschied ist definitiv weitere Untersuchungen wert. Eventuell könnte es entgegen der angenommenen Arbeitsweise mittels intramolekularer Disulfidbrücken, wie es bei Peroxiredoxin $\mathrm{V}$ als atypisches 2-Cystein-Peroxiredoxin der Fall wäre, ein funktionell obligates Homodimer (oder Oligomer) sein und diese Disulfidbrücken intermolekular ausbilden, wie es bei typischen 2-Cystein-Peroxiredoxinen geschieht. Es ist aber auch ein gänzlich anderer Wirkmechanismus möglich. Nähere Erkenntnisse würden Vorteile bringen, wenn es darum geht, ein potenzielles Ziel medikamentöser Therapie genauer abzugrenzen. 


\section{Zusammenfassung}

Aspergillus fumigatus ist der häufigste Erreger invasiver, meist tödlich verlaufender Schimmelpilzmykosen stark immunsupprimierter Patienten. Besonders betroffen sind hierbei Leukämie-Patienten. Die angeborene Resistenz gegen Aspergillen versagt, bedingt durch den Mangel an Granulozyten bzw. durch die starke Immunsuppression. Im Tierversuch stellt sich jedoch nach überlebter invasiver Aspergillose eine erworbene Immunität ein. Wie bereits in wenigen Arbeiten gezeigt werden konnte, exprimieren Aspergillen während der Infektion Antigene, die eine schützende Immunantwort induzieren können, wenn sie isoliert vakziniert werden. Die Identifizierung weiterer solcher Antigene könnte die Basis für die spätere Entwicklung von Impfstoffen sein, denn bislang ist lediglich eine geringe Anzahl Antigene bekannt, die in immunsuppremierten Tieren eine protektive Immunantwort auslösen können.

Als eines der Ziele dieser Arbeit wurden weitere Antigene gesucht. Die identifizierten Proteine dreier verschiedener Arbeiten wurden hierfür evaluiert und rekombinant in E. coli und $P$. pastoris hergestellt.

Ein Projekt etablierte ein subletales Tiermodell (Kaninchen) einer invasiven Aspergillose, bei dem Tiere immun gegen den Erreger wurden. Mit Infektionsseren dieser Tiere wurde eine Aspergillus-fumigatus-cDNA-Expressionsbank gescreent (Denikus 2005).

Eine andere Arbeit nutzte ebensolche Infektionsseren immuner Kaninchen. Mit diesen wurden Antigene nach Auftrennung über zweidimensionale Gelelektrophorese mittels massenspektrometrischer Analysen identifiziert (Asif 2010).

In einem dritten Projekt wurde das Proteom von Konidienoberflächen aus

A. fumigatus untersucht. Die darin enthaltenen Proteine stellen den ersten Kontakt zum menschlichen Immunsystem dar und sind deswegen von Interesse (Asif 2006). Zwei weitere Antigene (ADAM-A und -B) wurden abseits der soeben erwähnten Projekte wegen ihrer Homologien zu humanen Proteinen untersucht. Diese Proteine sind membranständig, häufig an Zelloberflächen lokalisiert und an wichtigen Entwicklungsschritten prozessierend beteiligt, weswegen eine solche Funktion auch für die Proteine in A. fumigatus angenommen wird.

Ein zweites Ziel dieser Arbeit war es, die produzierten Antigene im Tiermodell (Maus) auf die Induktion einer protektiven Immunantwort hin zu untersuchen. Ein erster Tierversuch zeigte je ein nicht infiziertes Tier in der Vakzin- und der Positivkontrollgruppe. Alle anderen Tiere starben und zeigten in Kontrollen post mortem starkes, invasives Wachstum in den Lungen.

Die dritte Absicht dieser Arbeit lag darin, Gen-Deletionsmutanten ausgewählter Antigene zu erzeugen, welche durch ihre Funktion und/oder Lokalisation von besonderem Interesse waren. Die Wahl fiel hierbei auf das Allergen Aspf3 und die neuerdings identifizierten ADAMs (a disintegrin and metalloprotease) ADAM-A und ADAM-B. Von den letzten beiden wurde zusätzlich eine Doppel-Gen- 
Deletionsmutante hergestellt. Die Mutanten wurden zum einen auf einen etwaigen Phänotyp hin untersucht und dienten als Möglichkeit für weiterführende, spätere Tierversuche (auf etwaige verminderte Virulenz hin).

Die ADAM-Deletionsmutanten wurden daraufhin getestet, ob prozessierender Einfluss auf Enzyme der Zellwandbiosynthese besteht - jedoch ohne einen Phänotyp zu erzielen. Weiterhin wurde untersucht, ob die ADAMs Proteine aktivieren, die an der Bewältigung osmotischen Stresses beteiligt sind. Es fand sich hierbei ebenfalls kein erkennbarer Einfluss; wie es ebenfalls nicht der Fall war, wenn die ADAMs auf prozessierende Wirkung auf der Ernährung dienende Enzyme getestet wurden. Homologie zu einem ADAM-Protein aus $S$. pombe lässt vermuten, dass die ADAMs aus $A$. fumigatus wie in der Spalthefe an der sexuellen Fortpflanzung beteiligt sein könnten.

Die Deletionsmutante zu Aspf3 zeigte stark vermindertes Wachstum im Vergleich zum Wildstamm, wenn Wasserstoffperoxid im Medium war. Hierbei war die Mutante ungefähr 200-mal sensitiver als der WT, wenn der Einfluss von $\mathrm{H}_{2} \mathrm{O}_{2}$ auf die Keimung untersucht wurde. Wenn $\mathrm{H}_{2} \mathrm{O}_{2}$ auf Hyphen einwirkte, war die Mutante $\triangle$ Aspf3 noch $\sim 85$-mal sensitiver als der Wildstamm. Ein Vergleich zu Deletionsmutanten von Transkriptionsfaktoren, welche im Rahmen der Bewältigung von oxidativem Stress beteiligt sind, zeigte, dass diese Mutanten ( $\triangle$ AfYap1 und $\Delta$ Skn7) geringer von $\mathrm{H}_{2} \mathrm{O}_{2}$ im Wachstum gehemmt werden, als es die Deletionsmutante eines einzelnen Gens war. 


\section{$\underline{\text { 6. Literaturverzeichnis }}$}

Altschul, S.F., Madden, T.L., Schäffer, A.A., Zhang, J., Zhang, Z., Miller, W., Lipman, D.J. (1997) Gapped BLAST and PSI-BLAST: a new generation of protein database search programs

Nucleic Acids Res. 25(17), 3389-3402

Aratani, Y., Kura, F., Watanabe, H., Akagawa, H., Takano, Y., Suzuki, K., Dinauer, M.C., Maeda, N., Koyama, H. (2002) Relative contributions of myeloperoxidase and NADPH-oxidase to the early host defense against pulmonary infections with Candida albicans and Aspergillus fumigatus

Med. Mycol. 40(6), 557-563

Armstrong-James, D.P.H., Turnbull, S.A., Teo, I., Stark, J., Rogers, N.J., Rogers, T.R.F., Bignell, E., Haynes, K. (2009) Impaired Interferon-y Responses, Increased Interleukin-17 Expression, and a Tumor Necrosis Factor- $\alpha$ Transcriptional Program in Invasive Aspergillosis

J. Infect. Dis. 200(8), 1341-51

Asif, A.R., Oellerich, M., Armstrong, V.W., Riemenschneider, B., Monod, M., Reichard, U. (2006) Proteome of conidial surface associated proteins of Aspergillus fumigatus reflecting potential vaccine candidates and allergens J. Proteome Res. 5(4), 954-62

Asif, A.R., Oellerich, M., Armstrong, V.W., Groß, U., Reichard, U. (2010) Analysis of the cellular Aspergillus fumigatus proteome that reacts with sera from rabbits developing an acquired immunity after experimental aspergillosis zur Veröffentlichung angenommen (2010)

Babior, B.M. (2000) Phagocytes and oxidative stress Am. J. Med. 109(1), 33-44

Beauvais, A., Monod, M., Debeaupuis, J.P., Diaquin, M., Kobayashi, H., Latgé, J.P. (1997a) Biochemical and antigenic characterization of a new dipeptidylpeptidase isolated from Aspergillus fumigatus J. Biol. Chem. 272(10), 6238-6244

Beauvais, A., Monod, M., Wyniger, J., Debeaupuis, J.P., Grouzmann, E., Brakch, N., Svab, J., Hovanessian, A.G., Latgé, J.P. (1997b) Dipeptidyl-peptidase IV secreted by Aspergillus fumigatus, a fungus pathogenic to humans Infect. Immun. 65(8), 3042-3047 
Bellocchio, S., Bozza, S., Montagnoli, C., Perruccio, K., Gaziano, R., Pitzurra, L., Romani, L. (2005) Immunity to Aspergillus fumigatus: the basis for immunotherapy and vaccination

Med. Mycol. 43, Suppl 1, 181-8

Bergmann, A., Hartmann, T., Cairns, T., Bignell, E.M., Krappmann, S. (2009) A regulator of Aspergillus fumigatus extracellular proteolytic activity is dispensable for virulence

Infect. Immun. 77(9), 4041-50

Black, R.A., White, J.M. (1998) ADAMs: focus on the protease domain Curr. Opin. Cell Biol. 10(5), 654-659

Bodey, G.P., Bueltmann, B., Duguid, W., Gibbs, D., Hanak, H., Hotchi, M., Mall, G., Martino, P., Meunier, F., Milliken, S. (1992) Fungal infections in cancer patients: an international autopsy survey

Eur. J. Clin. Microbiol. Infect. Dis. 11, 99-109

Böhme, A., Ruhnke, M., Buchheidt, D., Cornely, O.A., Einsele, H., Enzensberger, R., Hebart, H., Heinz, W., Junghanss, C., Karthaus, M., Krüger, W., Krug, U., Kubin, T., Penack, O., Reichert, D., Reuter, S., Silling, G., Südhoff, T., Ullmann, A.J., Maschmeyer, G., Infectious Diseases Working Party (AGIHO) of the German Society of Hematology and Oncology (DGHO) (2009) Treatment of invasive fungal infections in cancer patients--recommendations of the Infectious Diseases Working Party (AGIHO) of the German Society of Hematology and Oncology (DGHO)

Ann. Hematol. 88(2), 97-110

Bozza, S., Gaziano, R., Lipford, G.B., Montagnoli, C., Bacci, A., Di Francesco, P., Kurup, V.P., Wagner, H., Romani, L. (2002) Vaccination of mice against invasive aspergillosis with recombinant Aspergillus proteins and $\mathrm{CpG}$ oligodeoxynucleotides as adjuvants

Microbes Infect. 4(13), 1281-1290

Bozza, S., Perruccio, K., Montagnoli, C., Gaziano, R., Bellocchio, S., Burchielli, E., Nkwanyuo, G., Pitzurra, L., Velardi, A., Romani, L. (2003) A dendritic cell vaccine against invasive aspergillosis in allogeneic hematopoietic transplantation Blood 102(10), 3807-3814

Bozza S, Clavaud C, Giovannini G, Fontaine T, Beauvais A, Sarfati J, D'Angelo C, Perruccio K, Bonifazi P, Zagarella S, Moretti S, Bistoni F, Latgé JP, Romani L. (2009) Immune sensing of Aspergillus fumigatus proteins, glycolipids, and polysaccharides and the impact on Th immunity and vaccination J. Immunol. 183, 2407-2414 
Bringaud, F., Stripecke, R., Frech, G.C., Freedland, S., Turck, C., Byrne, E.M., Simpson, L. (1997) Mitochondrial glutamate dehydrogenase from Leishmania tarentolae is a guide RNA-binding protein

Mol. Cell. Biol. 17(7), 3915-3923

Caescu, C.I., Jeschke, G.R., Turk, B.E. (2009) Active-site determinants of substrate recognition by the metalloproteinases TACE and ADAM10

Biochem. J. 424(1), 79-88

Carlson, B.C., Jansson, A.M., Larsson, A., Bucht, A., Lorentzen, J.C. (2000) The endogenous adjuvant squalene can induce a chronic T-cell-mediated arthritis in rats Am. J. Pathol. 156(6), 2057-2065

Casadevall, A., Feldmesser, M., Pirofski, L.A. (2002) Induced humoral immunity and vaccination against major human fungal pathogens

Curr. Opin. Microbiol. 5(4), 386-391

Catterall, J.B., Cawston, T.E. (2003) Assays of matrix metalloproteinases (MMPs) and MMP inhibitors: bioassays and immunoassays applicable to cell culture medium, serum, and synovial fluid

Methods Mol. Biol. 225, 353-364

Cenci, E., Mencacci, A., Bacci, A., Bistoni, F., Kurup, V.P., Romani, L. (2000) $\mathrm{T}$ cell vaccination in mice with invasive pulmonary aspergillosis

J. Immunol. 165(1), 381-388

Clemons, K.V., Stevens, D.A. (2006) Animal models of Aspergillus infection in preclinical trials, diagnostics and pharmacodynamics: what can we learn from them? Med. Mycol. Supplement1 44, 119-126

Corbel, M.J., Eades, S.M. (1977) Examination of the effect of age and acquired immunity on the susceptibility of mice to infection with Aspergillus fumigatus Mycopathologia. 60(2), 79-85

Denikus, N., Orfaniotou, F., Wulf, G., Lehmann, P.F., Monod, M., Reichard, U. (2005) Fungal antigens expressed during invasive aspergillosis Infect. Immun. 73(8), 4704-4713

Denning, D.W., Ward, P.N., Fenelon, L.E., Benbow, E.W. (1992) Lack of vessel wall elastolysis in human invasive pulmonary aspergillosis

Infect. Immun. 60(12), 5153-5156

Denning, D. W. (1998) Invasive aspergillosis 
Clin. Infect. Dis. 26, 781-805

Denning, D.W. (2000) Aspergillus species

in: G. L. MANDELL, J. E. BENETT u. R. DOLIN (Hrsg.):

Principles and Practice of Infectious Diseases

Churchill Livingstone, Philadelphia, London, Toronto, 2, 2674-2685

Dixon, D.M., Polak, A., Walsh, T.J. (1989) Fungus dose-dependent primary pulmonary aspergillosis in immunosuppressed mice Infect. Immun. 57(5), 1452-1456

Dubourdeau, M., Athman, R., Balloy, V., Huerre, M., Chignard, M., Philpott, D.J., Latgé, J.P., Ibrahim-Granet, O. (2006) Aspergillus fumigatus induces innate immune responses in alveolar macrophages through the MAPK pathway independently of TLR2 and TLR4 J. Immunol. 177(6), 3994-4001

Estévez, A.M., Kierszenbaum, F., Wirtz, E., Bringaud, F., Grunstein, J., Simpson, L. (1999) Knockout of the glutamate dehydrogenase gene in bloodstream Trypanosoma brucei in culture has no effect on editing of mitochondrial mRNAs Mol. Biochem. Parasitol. 100(1), 5-17

Fronk, J., Magiera, R. (1994) DNA methylation during differentiation of a lower eukaryote, Physarum polycephalum Biochem. J. 304 (Pt 1),101-104

Fukuchi, Y., Kumagai, T., Ebina, K., and Yokota, K. (1996) Apolipoprotein B inhibits the hemolytic activity of asp-hemolysin from Aspergillus fumigatus Biol. Pharm. Bull. 19, 547-550

Galperin, M.Y., Bairoch, A., Koonin, E.V. (1998) A superfamily of metalloenzymes unifies phosphopentomutase and cofactor-independent phosphoglycerate mutase with alkaline phosphatases and sulfatases

Protein Sci. 7(8), 1829-1835

Geer, L.Y., Marchler-Bauer, A., Geer, R.C., Han, L., He, J., He, S., Liu, C., Shi, W., Bryant, S.H. (2010) The NCBI BioSystems database

Nucleic Acids Res. 38(Database issue), D492-6

Geiser, D.M., Klich, M.A., Frisvad, J.C., Peterson, S.W., Varga, J., Samson, R.A. (2007) The current status of species recognition and identification in Aspergillus Stud. Mycol. 59, 1-10

Gibson, P.G. (2006) Allergic bonchopulmonary aspergillosis 
Semin. Respir. Crit. Care Med. 27, 185-191

Gil, M.L., Penalver, M.C., Lopez-Ribot, J.L., O'Connor, J.E., Martinez, J.P. (1996) Binding of extracellular matrix proteins to Aspergillus fumigatus conidia Infect. Immun. 64: 5239-5247

van de Graaf, E.A., Jansen, H.M., Bakker, M.M., Alberts, C., Eftinck, J.K. Schattenkerk, Out, T.A. (1992) ELISA of complement C3a in bronchoalveolar lavage fluid J. Immunol. Methods 147, 241-250

Greenberger, P. A. (2002) Allergic bronchopulmonary aspergillosis J. Allergy Clin. Immunol. 110, 685-692

Hamilton, A.J., Holdom, M.D. (1999) Antioxidant systems in the pathogenic fungi of man and their role in virulence

Med. Mycol. 37(6), 375-389

Hartmann, D., de Strooper, B., Serneels, L., Craessaerts, K., Herreman, A., Annaert, W., Umans, L., Lübke, T., Lena Illert, A., von Figura, K., Saftig, P. (2002) The disintegrin/metalloprotease ADAM 10 is essential for Notch signalling but not for alpha-secretase activity in fibroblasts

Hum. Mol. Genet. 11(21), 2615-2624.

Henderson, V.J., Hirvela, E.R. (1996) Emerging and reemerging microbial threats Nosocomial fungal infections

Arch. Surg. 131, 330-337

Hofmann, B., Hecht, H.J., Flohé, L. (2002) Peroxiredoxins

Biol. Chem. 383(3-4), 347-364

Hohl, T.M., Feldmesser, M. (2007) Aspergillus fumigatus: principles of pathogenesis and host defense

Eukaryot. Cell 6: 1953-1963

Horibe, T., Iguchi, D., Masuoka, T., Gomi, M., Kimura, T., Kikuchi, M. (2004) Replacement of domain $\mathrm{b}$ of human protein disulfide isomerase-related protein with domain b' of human protein disulfide isomerase dramatically increases its chaperone activity FEBS Lett. 566(1-3), 311-315

Hospenthal, D. R., Kwon-Chung, K. J. u. Benett, J. E. (1998) Concentrations of airborne Aspergillus compared to the incidence of invasive aspergillosis: lack of 
correlation.

Med. Mycol. 36, 165-168

Igea, J.M., Cuevas, M., Marcos, C., Lázaro, M., Compaired, J.A., Sánchez-Cano, M. (1993) IgG subclass response to Aspergillus fumigatus Int. Arch. Allergy Immunol. 101(3), 277-282

Ito, J.I., Lyons, J.M. (2002) Vaccination of corticosteroid immunosuppressed mice against invasive pulmonary aspergillosis

J. Infect. Dis. 186(6), 869-871

Ito, J.I., Lyons, J.M., Hong, T.B., Tamae, D., Liu, Y.K., Wilczynski, S.P., Kalkum, M. (2006) Vaccinations with recombinant variants of Aspergillus fumigatus allergen Asp $f 3$ protect mice against invasive aspergillosis Infect. Immun. 74(9), 5075-5084

Jackson, J.C., Higgins, L.A., Lin, X. (2009) Conidiation color mutants of Aspergillus fumigatus are highly pathogenic to the heterologous insect host Galleria mellonella PLoS One. 4(1), e4224

Kanofsky, J.R. (1989) Singlet oxygen production by biological systems Chem. Biol. Interact. 70(1-2), 1-28

Katagiri, T., Harada, Y., Emi, M., Nakamura, Y. (1995) Human metalloprotease/ disintegrin-like (MDC) gene: exon-intron organization and alternative splicing Cytogenet. Cell Genet. 68(1-2), 39-44

Klig, L.S., Zobel, P.A., Devry, C.G., Losberger, C. (1994) Comparison of INO1 gene sequences and products in Candida albicans and Saccharomyces cerevisiae Yeast 10(6), 789-800

Kogan, T.V., Jadoun, J., Mittelman, L., Hirschberg, K., Osherov, N. (2004) Involvement of secreted Aspergillus fumigatus proteases in disruption of the actin fiber cytoskeleton and loss of focal adhesion sites in infected A549 lung pneumocytes J. Infect. Dis. 189(11), 1965-1973

Kradin, R.L., Mark, E.J. (2008) The pathology of pulmonary disorders due to Aspergillus spp.

Arch. Pathol. Lab. Med. 132(4), 606-614

Krappmann, S., Bignell, E.M., Reichard, U., Rogers, T., Haynes, K., Braus, G.H. (2004) The Aspergillus fumigatus transcriptional activator CpcA contributes significantly to the virulence of this fungal pathogen 
Mol. Microbiol. 52(3), 785-799

Krieg, A.M., Kline, J.N. (2000) Immune effects and therapeutic applications of CpG motifs in bacterial DNA

Immunopharmacology 48(3), 303-305

Krieg, A.M. (2006) Therapeutic potential of Toll-like receptor 9 activation Nat. Rev. Drug Discov. 5(6), 471-484

Kubota, T., Kubota, E., Matsumoto, A., Kawai, Y., Saito, H., Mikuni-Takagaki, Y., Sato, S. (1998) Identification of matrix metalloproteinases (MMPs) in synovial fluid from patients with temporomandibular disorder

Eur. J. Oral Sci. 106(6), 992-998

Kupfahl C, Heinekamp T, Geginat G, Ruppert T, Härtl A, Hof H, Brakhage AA (2006) Deletion of the gliP gene of Aspergillus fumigatus results in loss of gliotoxin production but has no effect on virulence of the fungus in a low-dose mouse infection model

Mol. Microbiol. 62(1), 292-302

Lamarre, C., Ibrahim-Granet, O., Du, C., Calderone, R., Latgé, J.P. (2007)

Characterization of the SKN7 ortholog of Aspergillus fumigatus

Fungal Genet. Biol. 44(7), 682-690

Lambeth, J.D. (2004) NOX enzymes and the biology of reactive oxygen Nat. Rev. Immunol. 4(3), 181-189

Latgé, J.P., Paris, S., Sarfati, J., Debeaupuis, J.P., Diaquin, M., Girardin, H. (1994) Tools, progress and questions in the molecular study of Aspergillus fumigatus and invasive aspergillosis

Pathol. Biol. (Paris).42(7), 632-639

Latgé, J. P. (1999) Aspergillus fumigatus and aspergillosis

Clin. Microbiol. Rev. 12, 310-350

Lavens, S.E., Rovira-Graells, N., Birch, M., Tuckwell, D. (2005) ADAMs are present in fungi: identification of two novel ADAM genes in Aspergillus fumigatus FEMS Microbiol. Lett.248(1), 23-30

Lehmann, P.F., White, L.O. (1976) Acquired immunity to Aspergillus fumigatus Infect. Immun. 13(4), 1296-1298

Lessing, F., Kniemeyer, O., Wozniok, I., Loeffler, J., Kurzai, O., Haertl, A., Brakhage, A.A. (2007) The Aspergillus fumigatus transcriptional regulator AfYap1 
represents the major regulator for defense against reactive oxygen intermediates but is dispensable for pathogenicity in an intranasal mouse infection model

Eukaryot. Cell 6(12), 2290-2302

Leyva-Vazquez, M.A., Setlow, P. (1994) Cloning and nucleotide sequences of the genes encoding triose phosphate isomerase, phosphoglycerate mutase, and enolase from Bacillus subtilis

J Bacteriol. 176(13), 3903-3910

Lin, S.-J., Schranz, J., Teutsch, S.M. (2001) Aspergillosis Case-Fatality Rate: Systematic Review of the Literature

Clin. Inf. Dis. 32, 358-366

Lorenz, M.C., Fink, G.R. (2002) Life and death in a macrophage: role of the glyoxylate cycle in virulence

Eukaryot. Cell 1(5), 657-662

Malicev, E., Chowdhury, H.H., Macek, P., Sepcic, K. (2007) Effect of ostreolysin, an Asp-hemolysin isoform, on human chondrocytes and osteoblasts, and possible role of Asp-hemolysin in pathogenesis

Med. Mycol. 45: 123-130

Markaryan, A., Morozova, I., Yu, H., Kolattukudy, P.E. (1994) Purification and characterization of an elastinolytic metalloprotease from Aspergillus fumigatus and immunoelectron microscopic evidence of secretion of this enzyme by the fungus invading the murine lung Infect. Immun. 62(6), 2149-2157

Martin, M., Resch, K. (2009) Das adaptive Immunsystem In: Michael Martin, Klaus Resch (Hrsg.): Immunologie 1. Auflage, Verlag Eugen Ulmer, Stuttgart, 91-199

McKinney, J.D., Höner zu Bentrup, K., Muñoz-Elías, E.J., Miczak, A., Chen, B., Chan, W.T., Swenson, D., Sacchettini, J.C., Jacobs, W.R. Jr., Russell, D.G. (2000) Persistence of Mycobacterium tuberculosis in macrophages and mice requires the glyoxylate shunt enzyme isocitrate lyase

Nature 406(6797), 735-738

Micheli, P.A. (1729) Nova plantarum genera juxta Tournefortii methodum disposita Florence 1729

Monod, M., Togni, G., Rahalison, L., Frenk, E. (1991) Isolation and characterisation of an extracellular alkaline protease of Aspergillus fumigatus J. Med. Microbiol. 35(1), 23-28 
Monod, M., Paris, S., Sarfati, J., Jaton-Ogay, K., Ave, P., Latgé, J.P. (1993)

Virulence of alkaline protease-deficient mutants of Aspergillus fumigatus

FEMS Microbiol. Lett. 106(1), 39-46

Monod, M., Fatih, A., Jaton-Ogay, K., Paris, S., Latgé, J.P. (1995) The secreted proteases of pathogenic species of Aspergillus and their possible role in virulence Can. J. Bot. 73, 1081-1086

Moos, M., Heising, P. (2005) Wasserhaltiges Aluminiumhydroxid zur Adsorption Kommentar zum Europäischen Arzneibuch 4.08, Loseblattsammlung, 21. Lfg. 2005

Moss, M.L., Lambert, M.H. (2002) Shedding of membrane proteins by ADAM family proteases

Essays Biochem. 38, 141-153

Mülhardt, C. (2006) RNA-Interferenz (RNAi)

In: C. Mülhardt (Hrsg.): Der Experimentator: Molekularbiologie/Genomics

5. Auflage, Verlag Elsevier, München, 125-129

Nakamura, T., Abe, H., Hirata, A., Shimoda, C. (2004) ADAM family protein Mde10 is essential for development of spore envelopes in the fission yeast

Schizosaccharomyces pombe

Eukaryot. Cell. 3(1), 27-39

Nierman, W.C., Pain, A., Anderson, M.J., Wortman, J.R., Kim, H.S., Arroyo, J., Berriman, M., Abe, K., Archer, D.B., Bermejo, C., Bennett, J., Bowyer, P., Chen, D., Collins, M., Coulsen, R., Davies, R., Dyer, P.S., Farman, M., Fedorova, N., Feldblyum, T.V., Fischer, R., Fosker, N., Fraser, A., Garcia, J.L., Garcia, M.J., Goble, A., Goldman, G.H., Gomi, K., Griffith-Jones, S., Gwilliam, R., Haas, B., Haas, H., Harris, D., Horiuchi, H., Huang, J., Humphray, S., Jimenez, J., Keller, N., Khouri, H., Kitamoto, K., Kobayashi, T., Konzack, S., Kulkarni, R., Kumagai, T., Lafton, A., Latge, J.P., Li, W., Lord, A., Lu, C., Majoros, W.H., May, G.S., Miller, B. L., Mohamoud, Y., Molina, M., Monod, M., Mouyna, I., Mulligan, S., Murphy, L., O’Neil, S., Paulsen, I., Penalva, M. A., Pertea, M., Price, C., Pritchard, B.L., Quail, M.A., Rabbinowitsch, E., Rawlins, N., Rajandream, M.A., Reichard, U., Renauld, H., Robson, G. D., Rodriguez de Cordoba, S., RodriguezPena, J.M., Ronning, C. M., Rutter, S., Salzberg, S.L., Sanchez, M., SanchezFerrero, J.C., Saunders, D., Seeger, K., Squares, R., Squares, S., Takeuchi, M., Tekaia, F., Turner, G., Vazquez de Aldana, C.R., Weidman, J., White, O., Woodward, J., Yu, J.H., Fraser, C., Galagan, J.E., Asai, K., Machida, M., Hall, N., Barrell, B., Denning, D.W. (2005) Genomic sequence of the pathogenic and allergenic filamentous fungus Aspergillus fumigatus Nature 438, 1151-1156 
O'Gorman, C.M., Fuller, H.T., Dyer, P.S. (2009) Discovery of a sexual cycle in the opportunistic fungal pathogen Aspergillus fumigatus

Nature 457, 471-475

Pagano, L., Ricci, P., Nosari, A., Tonso, A., Buelli, M., Montillo, M., Cudillo, L., Cenacchi, A., Savignana, C., Melillo, L. (1995) Fatal haemoptysis in pulmonary filamentous mycosis: an underevaluated cause of death in patients with acute leukaemia in haematological complete remission. A retrospective study and review of the literature

Br. J. Haematol. 89, 500-505

Paris, S., Wysong, D., Debeaupuis, J.P., Shibuya, K., Philippe, B., Diamond, R.D., and Latgé, J.P. (2003) Catalases of Aspergillus fumigatus Infect. Immun. 71, 3551-3562

Philippe, B., Ibrahim-Granet, O., Prévost, M.C., Gougerot-Pocidalo, M.A., Sanchez Perez, M., Van der Meeren, A., Latgé, J.P. (2003) Killing of Aspergillus fumigatus by alveolar macrophages is mediated by reactive oxidant intermediates Infect. Immun. 71(6), 3034-3042

Punt, P.J., Oliver, R.P., Dingemanse, M.A., Pouwels, P.H., van den Hondel, C.A. (1987) Transformation of Aspergillus based on the hygromycin B resistance marker from Escherichia coli

Gene 56(1), 117-124

Qiagen (2003) The Expressionist

Fünfte Edition

Ramadan, G., Davies, B., Kurup, V.P., Keever-Taylor, C.A. (2005) Generation of Th1 T cell responses directed to a HLA Class II restricted epitope from the Aspergillus $\mathrm{f} 16$ allergen

Clin. Exp. Immunol. 139(2), 257-267

Reichard, U., Büttner, S., Eiffert, H., Staib, F., Rüchel, R. (1990) Purification and characterization of an extracellular serine proteinase from Aspergillus fumigatus and its detection in tissue J. Med. Microbiol. 33(4), 243-251

Reichard, U., Eiffert, H., Rüchel, R. (1994) Purification and characterization of an extracellular aspartic proteinase from Aspergillus fumigatus J. Med. Vet. Mycol. 32(6), 427-436 
Reichard, U., Monod, M., Rüchel, R. (1995) Molecular cloning and sequencing of the gene encoding an extracellular aspartic proteinase from Aspergillus fumigatus FEMS Microbiol. Lett. 130(1), 69-74

Reichard, U., Monod, M., Odds, F., Rüchel, R. (1997) Virulence of an aspergillopepsin-deficient mutant of Aspergillus fumigatus and evidence for another aspartic proteinase linked to the fungal cell wall J. Med. Vet. Mycol. 35(3), 189-196

Reichard, U., Cole, G.T., Rüchel, R., Monod, M. (2000) Molecular cloning and targeted deletion of PEP2 which encodes a novel aspartic proteinase from Aspergillus fumigatus Int. J. Med. Microbiol. 290(1), 85-96

Reichard, U., Monod, M., Odds, F., Rüchel, R. (1997) Virulence of an aspergillopepsin-deficient mutant of Aspergillus fumigatus and evidence for another aspartic proteinase linked to the fungal cell wall J. Med. Vet. Mycol. 35, 189-196

Reichard, U., Cole, G.T., Rüchel, R., Monod, M. (2000) Molecular cloning and targeted deletion of PEP2 which encodes a novel aspartic proteinase from Aspergillus fumigatus Int. J. Med. Microbiol. 290(1), 85-96

Reiss, J. (1997) Schimmelpilze

2. Aufl. Verlag Springer, Heidelberg

de Repentigny, L., Petitbois, S., Boushira, M., Michaliszyn, E., Sénéchal, S., Gendron, N., Montplaisir, S. (1993) Acquired immunity in experimental murine aspergillosis is mediated by macrophages

Infect. Immun. 61(9), 3791-3802

Reeves, E.P., Lu, H., Jacobs, H.L., Messina, C.G., Bolsover, S., Gabella, G., Potma, E.O., Warley, A., Roes, J., Segal, A.W. (2002) Killing activity of neutrophils is mediated through activation of proteases by $\mathrm{K}^{+}$flux

Nature 416(6878), 291-297

Rogers, T.R. (1995) Epidemiology and control of nosocomial fungal infections Curr. Opin. Infect. Dis. 8, 287-290

Rolle, M., Mayr, A. (1993) In: Medizinische Mikrobiologie, Infektions- und Seuchenlehre

6. Aufl. Verlag Enke, Stuttgart, S. 500, 836-840 
Roman, F., Vaman, T., Gerlach, B., Markendorf, A., Gillard, P., Devaster, J.M. (2010) Immunogenicity and safety in adults of one dose of influenza A H1N1v 2009 vaccine formulated with and without AS03A-adjuvant: preliminary report of an observer-blind, randomised trial Vaccine 28(7), 1740-1745

Romani, L. (2004) Immunity to fungal infections Nat. Rev. Immunol. 4(1), 1-23

Roos, D., Winterbourn, C.C. (2002) Immunology. Lethal weapons Science 296(5568), 669-671

Ross, S.J., Findlay, V.J., Malakasi, P., Morgan, B.A. (2000) Thioredoxin peroxidase is required for the transcriptional response to oxidative stress in budding yeast

Mol. Biol. Cell 11(8), 2631-2642

Rüchel, R., Reichard, U. (1999) Pathogenesis and clinical presentation of Aspergillosis

Contrib. Microbiol. 2, 21-43

Salez, F., Lamblin, C., Wallaert, B. (2000) Allergic bronchopulmonary aspergillosis Rev. Mal. Respir. 17, 265-278

Sarfati, J., Monod, M., Recco, P., Sulahian, A., Pinel, C., Candolfi, E., Fontaine, T., Debeaupuis, J.P., Tabouret, M., Latgé, J.P. (2006) Recombinant antigens as diagnostic markers for aspergillosis

Diagn. Microbiol. Infect. Dis. 55(4), 279-291

Schaffner, A. (1994) Macrophage-Aspergillus interactions Immunol. Ser. 60, 545-552

Schmidt, P.C. (2007) in Hoepfner, E.M., Reng, A., Schmidt, P.C.

Fiedler Encyclopedia of Excipients

Editio Cantor, Aulendorf, 2007, S.154

Seaver, L.C., Imlay, J.A. (2001) Alkyl hydroperoxide reductase is the primary scavenger of endogenous hydrogen peroxide in Escherichia coli J. Bacteriol. 183(24), 7173-7181

Segal, A.W. (1996) The NADPH oxidase and chronic granulomatous disease Mol. Med. Today 2(3), 129-135

Segal, B.H. (2009) Aspergillosis 
Seo, M.S., Kang, S.W., Kim, K., Baines, I.C., Lee, T.H., Rhee, S.G. (2000) Identification of a new type of mammalian peroxiredoxin that forms an intramolecular disulfide as a reaction intermediate J. Biol. Chem. 275(27), 20346-20354

Serrano-Gómez, D., Dominguez-Soto, A., Ancochea, J., Jimenez-Heffernan, J.A., Leal, J.A., Corbi, A.L. (2004) Dendritic cell-specific intercellular adhesion molecule 3-grabbing nonintegrin mediates binding and internalization of Aspergillus fumigatus conidia by dendritic cells and macrophages.

J. Immunol. 173: 5635-5643

Shacter, E., Beecham, E.J., Covey, J.M., Kohn, K.W., Potter, M. (1988) Activated neutrophils induce prolonged DNA damage in neighboring cells Carcinogenesis 9(12), 2297-2304

Shaikhali, J., Heiber, I., Seidel, T., Ströher, E., Hiltscher, H., Birkmann, S., Dietz, K.J., Baier, M. (2008) The redox-sensitive transcription factor Rap2.4a controls nuclear expression of 2-Cys peroxiredoxin $A$ and other chloroplast antioxidant enzymes

BMC Plant Biol. 8, 48-62

Sheppard, F.R., Kelher, M.R., Moore, E.E., McLaughlin, N.J., Banerjee, A., Silliman, C.C. (2005) Structural organization of the neutrophil NADPH oxidase: phosphorylation and translocation during priming and activation J. Leukoc. Biol. 78(5), 1025-1042

Sibuya, K., Paris, S., Ando, T., Nakayama, H., Hatori, T., Latgé, J.-P. (2006) Catalases of Aspergillus fumigatus and Inflammation in Aspergillosis Jpn. J. Med. Mycol. 47, 249-255

Smith, J.M., Tang, C.M., Van Noorden, S., and Holden, D.W. (1994) Virulence of Aspergillus fumigatus double mutants lacking restriction and an alkaline protease in a low-dose model of invasive pulmonary aspergillosis

Infect. Immun. 62, 5247-5254

Stevens, D.A. (2004) Vaccinate against aspergillosis! A call to arms of the immune system

Clin. Inf. Dis. 38, 1131-1136

Sturtevant, J.E., Latgé, J.P. (1992) Participation of complement in the phagocytosis of the conidia of Aspergillus fumigatus by human polymorphonuclear cells J. Infect. Dis. 166, 580-586 
Sugareva, V., Hartl, A., Brock, M., Hubner, K., Rohde, M., Heinekamp, T., Brakhage, A.A. (2006) Characterisation of the laccase-encoding gene abr2 of the dihydroxynaphthalene-like melanin gene cluster of Aspergillus fumigatus Arch. Microbiol. 186: 345-355

Sugiyama, J. (1998) Relatedness, phylogeny, and evolution of the fungi Mycoscience. 39(4), 487-511

Suh, Y.A., Arnold, R.S., Lassegue, B., Shi, J., Xu, X., Sorescu, D., Chung, A.B., Griendling, K.K., Lambeth, J.D. (1999) Cell transformation by the superoxidegenerating oxidase Mox1 Nature 401(6748), 79-82

Tang, C.M., Cohen, J., Krausz, T., Van Noorden, S., Holden, D.W. (1993) The alkaline protease of Aspergillus fumigatus is not a virulence determinant in two murine models of invasive pulmonary aspergillosis Infect. Immun. 61(5), 1650-1656

Tekaia, F. \& Latgé, J.-P. (2005) Aspergillus fumigatus: saprophyte or pathogen? Curr. Opin. Microbiol. 8, 385-392

Thau, N., Monod, M., Crestani, B., Rolland, C., Tronchin, G., Latgé, J.P., Paris, S. (1994) Rodletless mutants of Aspergillus fumigatus Infect. Immun. 62, 4380-4388

Torosantucci, A., Bromuro, C., Chiani, P., de Bernardis, F., Berti, F., Galli, C., Norelli, F., Bellucci, C., Polonelli, L., Costantino, P., Rappuoli, R., Cassone, A. (2005) A novel glyco-conjugate vaccine against fungal pathogens J. Exp. Med. 202(5), 597-606

Tronchin, G., Esnault, K., Renier, G., Filmon, R., Chabasse, D., Bouchara, J.P. (1997) Expression and identification of laminin-binding protein in Aspergillus fumigatus conidia Infect. Immun. 65, 9-15

Tsai, H.F., Washburn, R.G., Chang, Y.C., Kwon-Chung, K.J. (1997) Aspergillus fumigatus arp1 modulates conidial pigmentation and complement deposition Mol. Microbiol. 26: 175-183

Urban, C., Sohn, K., Lottspeich, F., Brunner, H., Rupp, S. (2003) Identification of cell surface determinants in Candida albicans reveals Tsa1p, a protein differentially localized in the cell

FEBS Lett. 544(1-3), 228-235 
Verweij, P.E., Oakley, K.L., Morrissey, J., Morrissey, G., and Denning, D.W. (1998) Efficacy of LY303366 against amphotericin B-susceptible and -resistant Aspergillus fumigatus in a murine model of invasive aspergillosis Antimicrob. Agents Chemother. 42: 873-878

Wald, A., Leisenring, W., van Burik, J.A., Bowden, R.A. (1997) Epidemiology of Aspergillus infections in a large cohort of patients undergoing bone marrow transplantation

J. Infect. Dis. 175, 1459-1466

Wilson, T., de Lisle, G.W., Marcinkeviciene, J.A., Blanchard, J.S., Collins, D.M. (1998) Antisense RNA to ahpC, an oxidative stress defence gene involved in isoniazid resistance, indicates that AhpC of Mycobacterium bovis has virulence properties

Microbiology 144 (Pt 10), 2687-2695

Wilson, D. M., Mubatanhema, W. \& Jurjevic, Z. (2002) Biology and ecology of mycotoxigenic Aspergillus species as related to economic and health concerns Adv. Exp. Med. Biol. 504, 3-17.

Wolfsberg, T.G., Primakoff, P., Myles, D.G., White, J.M. (1995) ADAM, a novel family of membrane proteins containing A Disintegrin And Metalloprotease domain: multipotential functions in cell-cell and cell-matrix interactions J. Cell Biol. 131(2), 275-278

Wood, Z.A., Schröder, E., Robin Harris, J., Poole, L.B. (2003) Structure, mechanism and regulation of peroxiredoxins

Trends Biochem. Sci. 28(1), 32-40

Wyman, T.H., Bjornsen, A.J., Elzi, D.J., Smith, C.W., England, K.M., Kelher, M., Silliman, C.C. (2002) A two-insult in vitro model of PMN-mediated pulmonary endothelial damage: requirements for adherence and chemokine release Am. J. Physiol. Cell Physiol. 283(6), C1592-1603

Yoshida, S., Setoguchi, M., Higuchi, Y., Akizuki, S., Yamamoto, S. (1990) Molecular cloning of cDNA encoding MS2 antigen, a novel cell surface antigen strongly expressed in murine monocytic lineage Int. Immunol. 2(6), 585-591 


\section{Anhang}

\subsection{Gerätenachweis}

Tabelle 22: Verwendete Geräte

\begin{tabular}{|c|c|}
\hline Blockthermostat, Thermomixer 5436 & Fa. Eppendorf, Hamburg \\
\hline $\begin{array}{l}\text { Blotkammer TE SERIES TRANSPHOR } \\
\text { ELECTROPHORESIS UNIT }\end{array}$ & Hoefer, San Francisco, USA \\
\hline Brutschrank BB16 & Fa. Heraeus, Hanau \\
\hline Compact-Kältethermostat MGW RM6 & Fa. Lauda, Königshofen \\
\hline $\begin{array}{l}\text { DALT-Gelelektrophorese-Tank mit } \\
\text { Multitemp III-Kühlung und Hoefer } \\
\text { EPSSpannungsgeber }\end{array}$ & Fa. Hoefer, San Francisco, USA \\
\hline \multicolumn{2}{|l|}{ Digitalkamera } \\
\hline Durchlichttisch TFP-L/WL & $\begin{array}{r}\text { Fa. Vilber Lourmat, Marne-La-Vallee } \\
\text { Cedex } 1, \text { Frankreich }\end{array}$ \\
\hline ElectroCell Manipulator 600 & Fa. BTX Electroporation System \\
\hline $\begin{array}{l}\text { Elektrophoresegerät Electrophoresis } \\
\text { Power Supply ECPS } 3000 / 150\end{array}$ & $\begin{array}{r}\text { Fa. Pharmacia Biotech, Uppsala, } \\
\text { Schweden }\end{array}$ \\
\hline Elektrophoresekammer Horizon58 & Fa. Biometra, Göttingen \\
\hline Elektrophoresekammer Maxi & $\begin{array}{r}\text { Fa. von Keutz Labortechnik, } \\
\text { Reiskirchen }\end{array}$ \\
\hline Fastprep F120 & Thermo Scientific, Braunschweig \\
\hline Feinwaage SBC33 & Fa. Scaltec Instruments, Heiligenstadt \\
\hline Hybridisierungs-Ofen OV5 & Fa. Biometra, Göttingen \\
\hline Inkubationshaube TH30 + SM30-control & Fa. Edmund Bühler, Hechingen \\
\hline Mikroskop Axioskop 50+HB50 & Fa. Zeiss, Jena \\
\hline Mikrowele Micromat & Fa. AEG, Nürnberg \\
\hline Orbitalschüttler KS260 basic & Fa. IKA, Staufen \\
\hline PCR-cycler T3 Thermocycler & Fa. Biometra, Göttingen \\
\hline pH-Meter MP225 & Fa. Mettler Toledo, Gießen \\
\hline Photometer Ultrospec 1000 & $\begin{array}{r}\text { Fa. Pharmacia Biotech, Uppsala, } \\
\text { Schweden }\end{array}$ \\
\hline Sicherheitswerkbank HeraSafe & Fa. Heraeus, Hanau \\
\hline Tischzentrifuge Eppendorf 5415 D & Fa. Eppendorf, Hamburg \\
\hline Tischzentrifuge Z233MK-2 & Fa. Hermle, Wehingen \\
\hline Transilluminator BioDocll & Fa. Biometra, Göttingen \\
\hline Überkopfschüttler, test-tube-rotator 34528 & Fa. Snijders Scientific, Tilburg, Holland \\
\hline \multicolumn{2}{|l|}{ Ultraschallbad } \\
\hline Ultrazentrifuge Optima LE-80K & Fa. Beckman Coulter, Krefeld \\
\hline Vortexer & Fa. Heidolph, Schwabach \\
\hline Waage SBC52 & Fa. Scaltec Instruments, Heiligenstadt \\
\hline Wasserbad & Fa. GFL, Hannover \\
\hline
\end{tabular}




\begin{tabular}{|l|r|}
\hline Wippschüttler Duomax 1030 & Fa. Heidolph, Schwabach \\
\hline Zentrifuge Rotixa/RP & Fa. Hettich, Tuttlingen \\
\hline Zentrifuge Sorvall RC26Plus & Fa. DuPont, Bad Homburg \\
\hline Zentrifuge Universal 30 F & Fa. Hettich, Tuttlingen \\
\hline
\end{tabular}

\subsection{Verbrauchsmaterialien}

Tabelle 23: Verwendete Verbrauchsmaterialien

\begin{tabular}{|c|c|}
\hline $\begin{array}{l}\text { Bottle-Top-Filter (Porengröße 0,22 } \mu \mathrm{m}+ \\
0,45 \mu \mathrm{m} \text { ) }\end{array}$ & Corning, New York, USA \\
\hline Deckgläschen & AL, Karlsruhe \\
\hline Elektroporationsküvetten $1 \mathrm{~mm}$ & peqlab, Erlangen \\
\hline Eppendorfreagenzgefäße $(0,5-2,0 \mathrm{ml})$ & Eppendorf, Hamburg \\
\hline Filterpapier Typ 713 58x58cm & Macherey-Nagel GmbH, Düren \\
\hline Glasperlen $(0,45-5 \mathrm{~mm})$ & Braun, Melsungen \\
\hline Impfschlingen $(1 \mu \mathrm{l}, 10 \mu \mathrm{l})$ & Sarstedt AG, Nümbrecht \\
\hline $\begin{array}{l}\text { (Einmal-)Injektionskanülen Sterican } \\
0,45 \times 12 \mathrm{~mm} 26 \mathrm{G} \times 1 / 2^{\prime \prime}\end{array}$ & Braun, Melsungen \\
\hline Kodak Biomax Light Film & Sigma Aldrich, Seelze \\
\hline Laboratory film Parafilm & $\begin{array}{r}\text { Pechiney Plastic Packaging, } \\
\text { Menesha, USA }\end{array}$ \\
\hline Magermilchpulver Sucofin & REAL, Göttingen \\
\hline Mikro-Schraubröhre 1,5ml PP & Sarstedt AG, Nümbrecht \\
\hline $\begin{array}{l}\text { Nitrozellulose-Membran Optitran BA-S85 } \\
0,45 \mu \mathrm{m}\end{array}$ & Schleicher\&Schuell, Dassel \\
\hline Nitrozellulose-Membran Protan BA83 0,2 $\mu \mathrm{m}$ & Schleicher\&Schuell, Dassel \\
\hline Objektträger & Knittel Gläser, Braunschweig \\
\hline Pasteurpipetten & WU-Mainz, Mainz \\
\hline PCR-Softtubes $0,2 \mathrm{ml}$ & Biozym, Hessisch Oldendorf \\
\hline \multicolumn{2}{|l|}{ PD10-Säulchen } \\
\hline Petrischalen $60 \times 15 \mathrm{~mm} \& 94 \times 16 \mathrm{~mm}$ & Greiner bio-one, Frickenhausen \\
\hline Pipettenspitzen $10-1000 \mu \mathrm{l}$ & Sarstedt AG, Nümbrecht \\
\hline Plastikküvetten & MBT, Gießen \\
\hline Polystyrolgefäß cellstar 15ml & Greiner bio-one, Solingen \\
\hline Polystyrolgefäß Röhre $13 \mathrm{ml} 101 \times 16,5 \mathrm{~mm}$ PP & Sarstedt AG, Nümbrecht \\
\hline Polystyrolgefäß Röhre 50ml 114x28mm PP & Sarstedt AG, Nümbrecht \\
\hline \multicolumn{2}{|l|}{ Röntgenfilm Kodak BioMax Light } \\
\hline Skalpell cutfix 10 & Braun, Tuttlingen \\
\hline (Einmal-)Spritze monoject $1 \mathrm{ml}$ & Tyco healthcare, Gosport, UK \\
\hline (Einmal-)Spritze 10ml & Terumo corporation, Tokyo, Japan \\
\hline Sterilfilter für Spritzen $(0,2 \mu \mathrm{m})$ & Corning, New York, USA \\
\hline Wägepapier 9x11,5cm MX226 & Macherey-Nagel, Düren \\
\hline Whatman Gel Blotting Papier 58x58cm & Whatman $\mathrm{GmbH}$, Dassel \\
\hline
\end{tabular}


Zentrifugaleinheiten Vivaspin20 (10kDa)

Zellstoffpapierhandtücher

\subsection{Vektoren und Molekularstandards}

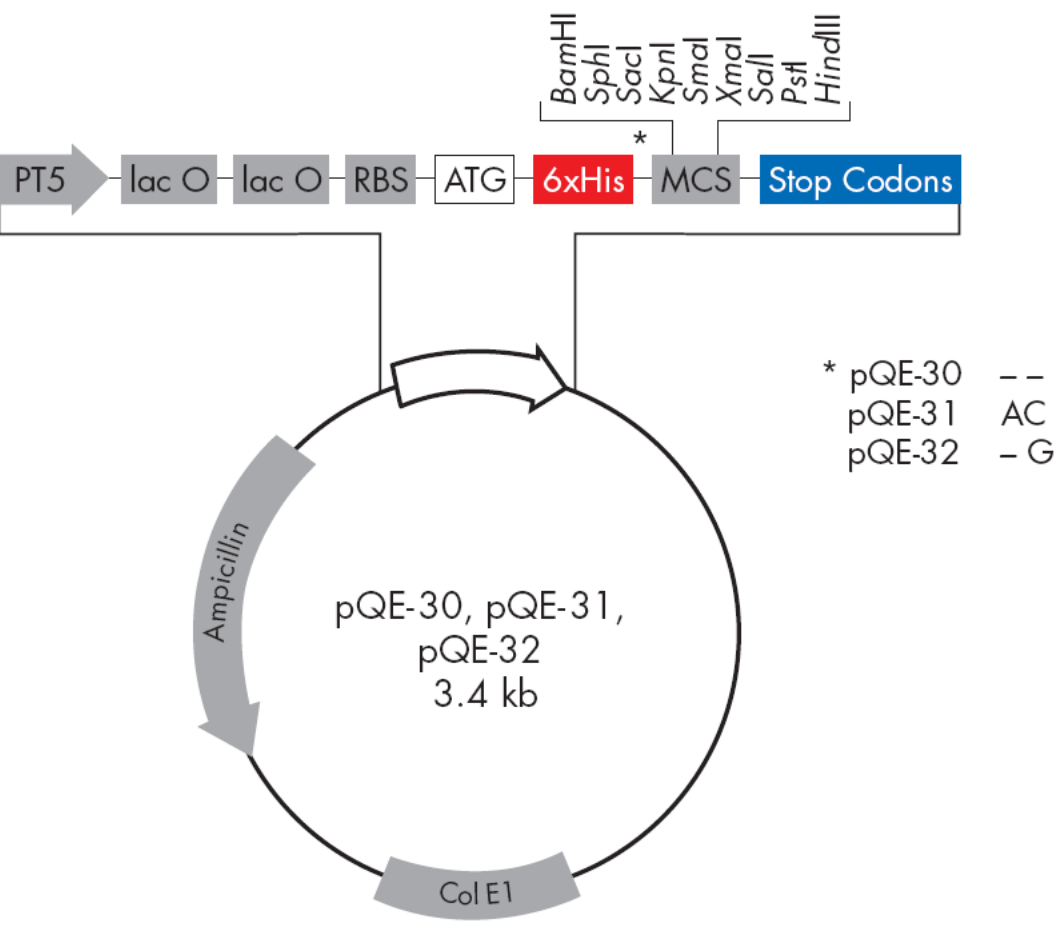

Abbildung 55: Expressionsplasmid pQE30

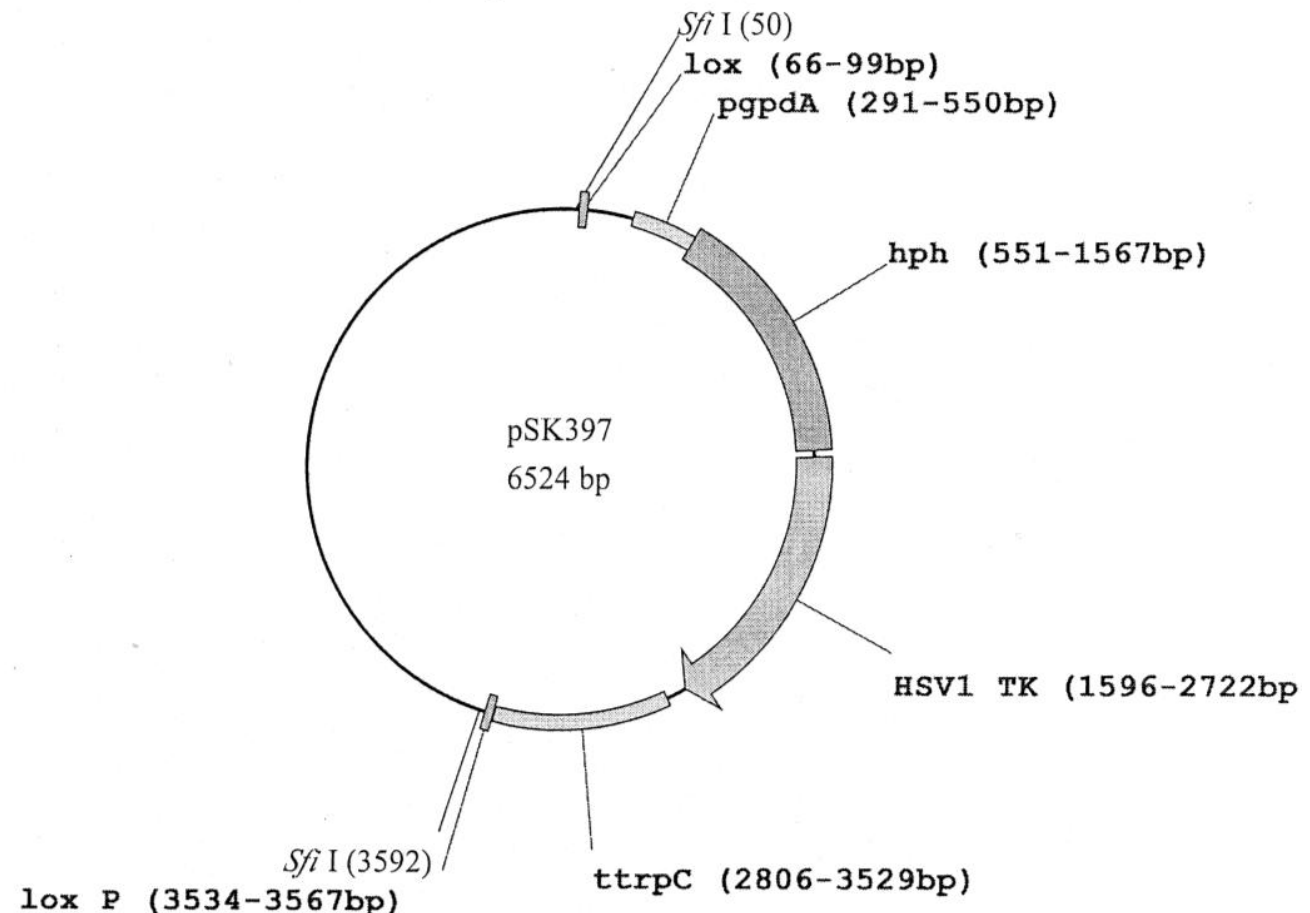

Abbildung 56: Plasmid pSK397; Resistenz-lieferndes Insert der Deletionsplasmide 


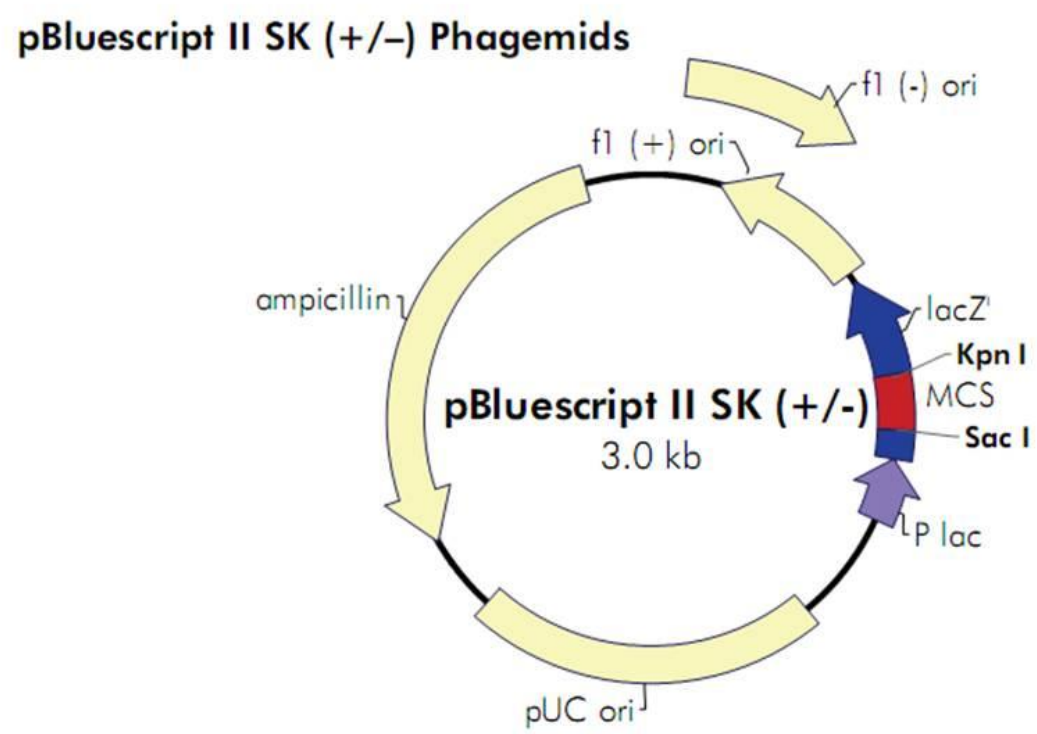

pBluescript II SK (+/-) Multiple Cloning Site Region (sequence shown 598-826)

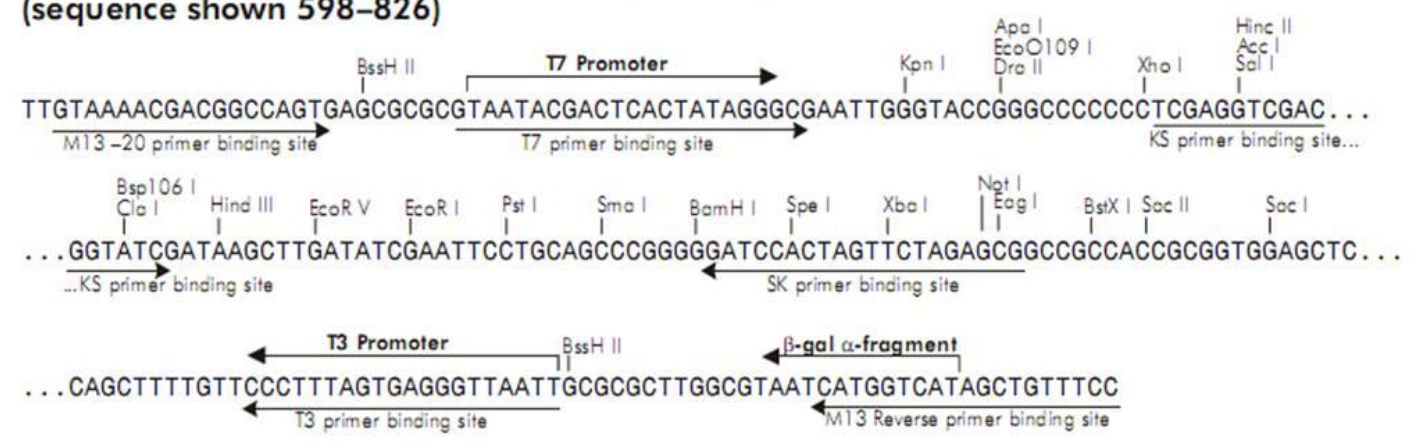

Abbildung 57: Plasmid pBlueskript II SK +

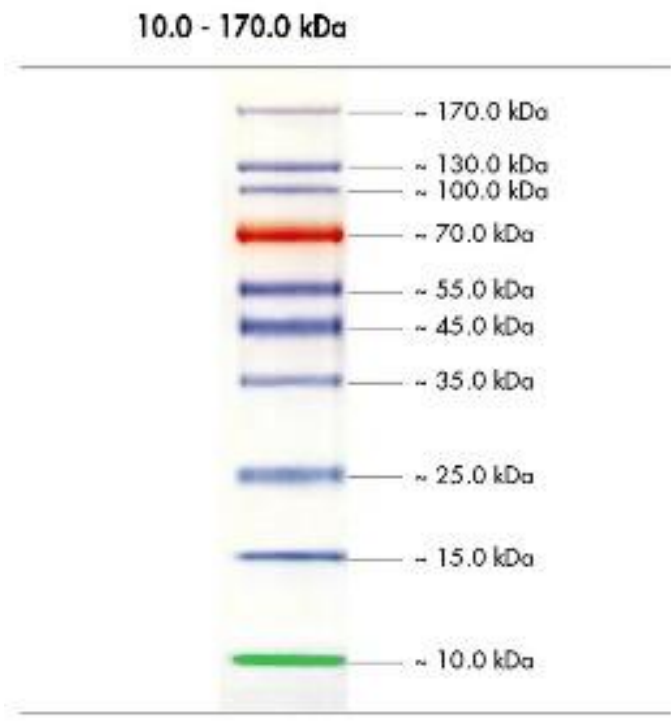

$8-16 \%$ SDSPAGE

Banden können von Lot zu Lot variieren.

Abbildung 58: peqGOLD protein marker IV 


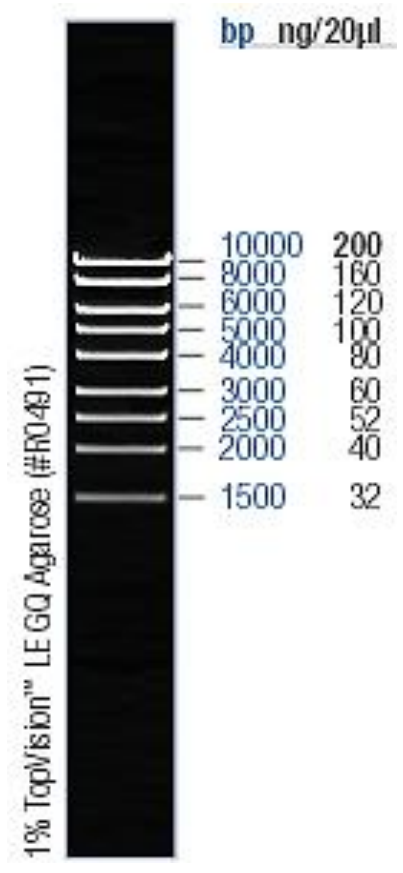

Abbildung 59: MassRuler High Range DNA Ladder

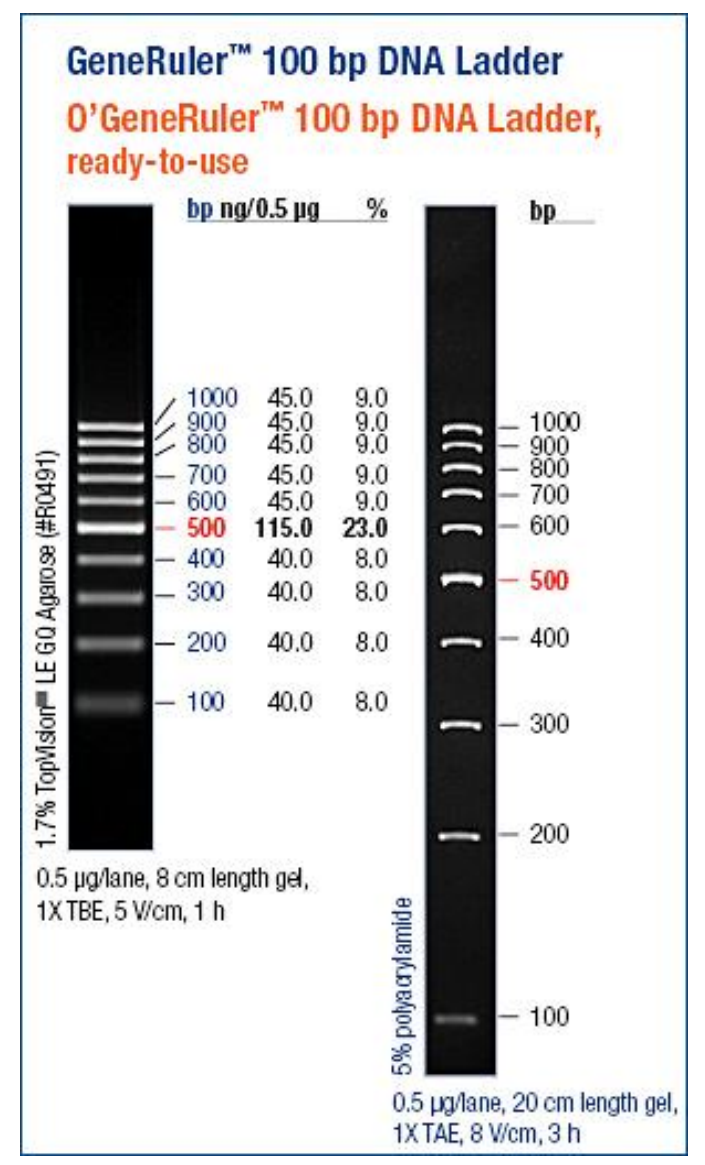

Abbildung 60: GeneRuler 100bp ladder 


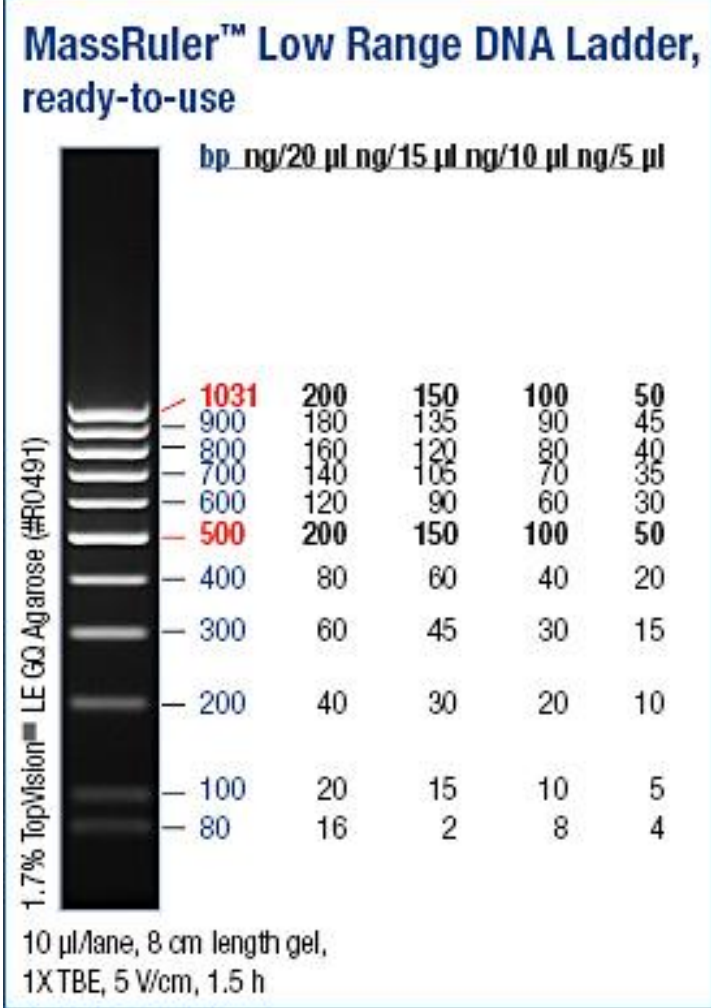

Abbildung 61: MassRuler Low Range DNA ladder

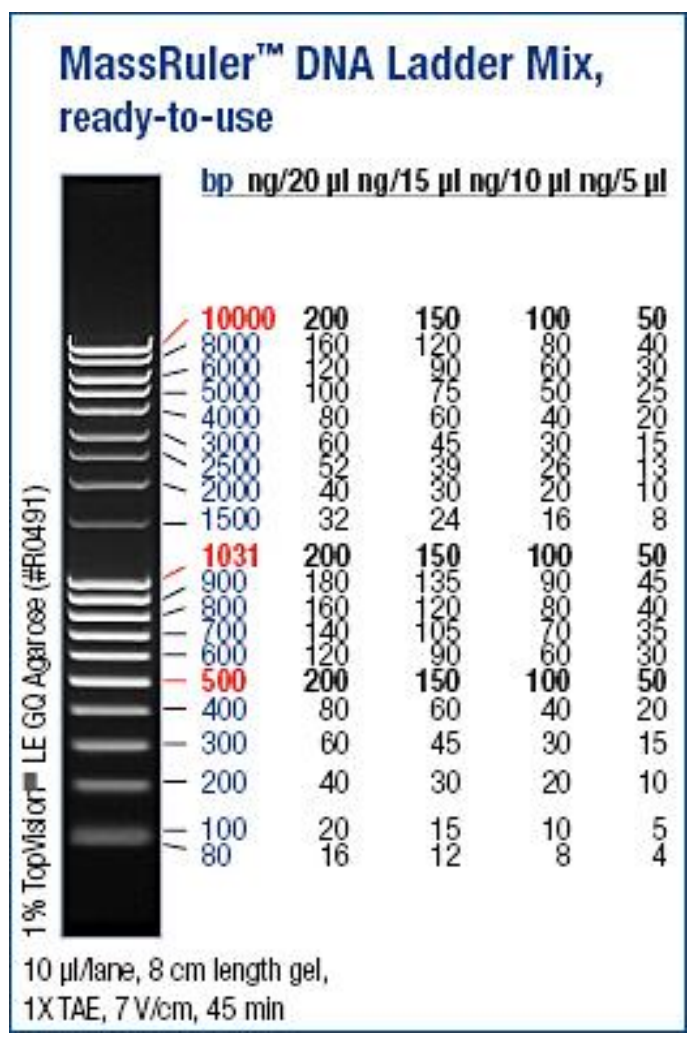

Abbildung 62: MassRuler DNA ladder mix 


\section{Danksagungen}

Ich möchte mich bei Herrn Prof. Groß bedanken, dass ich unter seiner Betreuung im Institut für medizinische Mikrobiologie im Rahmen meiner Promotion arbeiten durfte, und dass er mit Ratschlägen und Anregungen neue Ideen lieferte.

Ebenso danke ich Herrn Prof. Braus für die Übernahme der Koreferenz dieser Arbeit sowie ebenfalls für Tipps und Ideen zu der Thematik dieser Arbeit.

Bei Herrn Prof. Reichard bedanke ich mich für die Anleitung im Labor und für die Überlassung der interessanten Thematik.

Für die Finanzierung möchte ich mich bei der José-Carreras-Stiftung für Leukämie e. V. bedanken.

Herrn PD Dr. Krappmann möchte ich für die Bereitstellung einiger Plasmide sowie der Anfertigung der A.-fumigatus- $\Delta$ Aspf3-Revertante danken.

Ebenso gilt mein Dank Herrn Prof. Brakhage für die Überlassung weiterer Deletionsmutanten aus Aspergillus fumigatus.

Birgit Riemenschneider gilt mein besonderer Dank für die großartige Einführung ins Laborleben und die hervorragende Zusammenarbeit, auch wenn diese nicht bis zum Ende meiner Arbeit dauerte.

Für weitere Gesellschaft im Labor und allgemeiner Bereicherung des Alltags danke ich Christoph Paasch.

An Christiane Scholz geht mein Dank für die Hilfe bei der Durchführung der Tierversuche.

Meiner Familie danke ich für die konstant aufmunternden Worte und die Unterstützung während der gesamten Promotion und besonders gegen Ende der Arbeit.

Ingo Smutny danke ich vielmals für die großartige und konstruktive Korrektur des Manuskriptes sowie ebenfalls der andauernden Aufmunterungen. 


\section{Lebenslauf}

\begin{tabular}{|l|l|}
\hline Persönliche Daten \\
\hline Name & Rosenow \\
\hline Vorname & Martin \\
\hline Geburtsdatum & 10.09 .1979 \\
\hline Geburtsort & Hannover \\
\hline Familienstand & ledig \\
\hline Staatsangehörigkeit & deutsch \\
\hline
\end{tabular}

\begin{tabular}{|l|l|}
\hline \multicolumn{2}{|l|}{ Schulische Ausbildung } \\
\hline 1986 bis 1990 & Grundschule „Ernst-Reuter-Schule“ in Barsinghausen \\
\hline 1990 bis 1992 & $\begin{array}{l}\text { Orientierungsstufe am Schulzentrum am Spalterhals } \\
\text { Barsinghausen }\end{array}$ \\
\hline 1992 bis 1996 & $\begin{array}{l}\text { Sekundarstufe I des „Ganztagsgymnasiums am Spalterhals“ } \\
\text { Barsinghausen }\end{array}$ \\
\hline 1996 bis 1999 & $\begin{array}{l}\text { Sekundarstufe II des „Ganztagsgymnasiums am Spalterhals“ } \\
\text { Barsinghausen; Abschluss: Abitur 3.0 }\end{array}$ \\
\hline
\end{tabular}

\begin{tabular}{|l|l|}
\hline Zivildienst & \multicolumn{2}{|c|}{ Juli 1999 bis Juni 2000} & $\begin{array}{l}\text { auf der Infektionsstation der medizinischen Hochschule } \\
\text { Hannover }\end{array}$ \\
\hline
\end{tabular}

\begin{tabular}{|l|l|}
\hline Studium & \\
\hline Oktober 2000 bis September & $\begin{array}{l}\text { Grundstudium der Biologie an der Universität } \\
\text { Marburg }\end{array}$ \\
\hline Oktober 2002 bis April 2006 & $\begin{array}{l}\text { Hauptstudium der Biologie an der Universität } \\
\text { Marburg; } \\
\text { Abschluss: Diplom 2.0 }\end{array}$ \\
\hline Oktober 2007 bis Juli 2010 & Promotionsstudium an der Universität Göttingen \\
\hline
\end{tabular}

\begin{tabular}{|l|l|}
\hline \multicolumn{2}{|l|}{ Arbeitsverhältnisse/Promotion } \\
\hline Oktober 2007 \\
bis März 2010 & $\begin{array}{l}\text { Wissenschaftlicher Mitarbeiter am Institut für medizinische } \\
\text { Mikrobiologie am Klinikum der Georg-August-Universität } \\
\text { Göttingen / Promotionsstudium zu dem Thema: „Identifizierung } \\
\text { infektionsrelevanter Antigene des Schimmelpilzes Aspergillus } \\
\text { fumigatus sowie deren rekombinante Herstellung mit dem Ziel der } \\
\text { Entwicklung eines Impfstoffes gegen die invasive Aspergillose“ }\end{array}$ \\
\hline
\end{tabular}

